\title{
Bocetado de interacciones enactivas
}

\author{
Andrés Rodríguez
}

Tesis presentada ante la Facultad de Informática

de la Universidad Nacional de La Plata

como parte de los requerimientos

para acceder al título de Doctor en Ciencias Informáticas

\author{
Director \\ Dr. Gustavo Rossi \\ LIFIA - Facultad de Informática \\ Universidad Nacional de La Plata \\ Codirector \\ Dr. Pascual González López \\ LoUISE - Escuela Superior de Ingeniería Informática \\ Universidad Castilla-La Mancha
}

14 de julio de 2019 


\section{Andrés Rodríguez}

Bocetado de interacciones enactivas

14 de julio de 2019

Director: Dr. Gustavo Rossi Codirector: Dr. Pascual Gonzalez Lopez

\section{Universidad Nacional de La Plata}

Facultad de Informática

50 y 120

1900 La Plata 
A la memoria de mis viejos 



\section{Resumen}

El continuo desarrollo de tecnologías interactivas y la mayor comprensión de la participación del cuerpo en los procesos cognitivos ha impulsado al diseño de interacciones en el marco de las investigaciones HCI a la necesidad de resolver la relación del usuario con una multitud de dispositivos que se extienden más allá de los escritorios. Estos ámbitos de diseño abren nuevos desafíos a la hora de disponer de procesos, métodos y herramientas para alcanzar experiencias de uso adecuadas. En la medida que nuevos dispositivos y sistemas involucran los aspectos corporales y sociales del ser humano, se hace más relevante la consideración de paradigmas, teorías y modelos de soporte que excedan la selección de nodos de navegación y organización visual apropiada de widgets y pantallas. El diseño de interacción debe ocuparse no sólo de conseguir que se construya el producto de manera adecuada, sino además que se construya el producto correcto. Esta tesis se constituye en el cruce de tres temas: el diseño de sistemas interactivos que combinan un pie en lo digital y uno en lo físico, las teorías de la cognición corporizada y enactiva y las prácticas creativas soportadas por el bocetado, en particular los procesos de generación, evaluación y comunicación de ideas o propuestas de diseño. Este trabajo incluye contribuciones de diferente carácter. Se realiza un estudio profundo de las teorías sobre cognición corporizada y enactiva, del diseño de interacción con dispositivos digitales y del bocetado como herramienta básica del diseño creativo. Sobre la base de este análisis de la bibliografía existente y con una caracterización de la práctica de bocetado de interacciones enactivas basada en estudios etnometodológicos se plantea un framework para organizar conceptualmente esa práctica y una herramienta de soporte a esa actividad concebida como una composición creativa. Se discuten las contribuciones y se plantean posibles líneas de trabajo futuro. 



\section{Abstract}

The continuous development of interactive technologies and the greater understanding of body importance in cognitive processes has driven HCI research, specifically on interaction design, to solve the user's relationship with a multitude of beyond desktop devices. This has opened new challenges for having processes, methods and tools to achieve appropriate user experiences. Insofar as new devices and systems involve the body and social aspects of the human being, the consideration of paradigms, theories and support models that exceed the selection of navigation nodes and the appropriate visual organization of widgets and screens becomes more relevant. The interaction design must take care not only to get the product built properly, but also to build the right product. This thesis is at the crossroads of three themes: the design of interactive systems that combine a foot in the digital and one in the physical, the theories of embodied and enactive cognition and the creative practices supported by sketching, in particular the processes of generation, evaluation and communication of interaction design ideas. This work includes contributions of different character. An in-depth study of the theories on embodied and enactive cognition, the design of interaction with digital devices and the sketching as a basic tool of creative design is carried out. On the basis of this analysis of the existing literature and with a characterization of the enactive practice of enactive interactions based on ethnomethodological studies, a framework is proposed to conceptually organize this practice and a support tool for that activity conceived as a creative composition. The contributions are discussed and possible lines of future work are considered. 



\section{Agradecimientos}

Elaborar un listado exhaustivo de las personas a quienes debo reconocer su contribución al desarrollo de este trabajo sólo revelaría olvidos imperdonables. Muchas gracias a todos los que han participado conmigo de esta aventura.

Haré aquí sólo dos menciones particulares.

Por una parte, para tres personas que contribuyeron de una manera especial para que pudiera completar este trabajo. Gracias a Gustavo, que confió en mi hace mucho tiempo y a pesar de todo lo sigue haciendo, a Pascual, que me abrió de manera generosa las puertas en Albacete y me ayudó a focalizar cuando el trabajo se desviaba más de la cuenta y a Mariela por darme la oportunidad de acceder a un mundo fascinante en la MAE-UNTREF.

Para cerrar, pero no menos importante, un agradecimiento enorme todos los que estuvieron siempre muy cerca aguantando esta locura de hacer un doctorado a mis cincuentas. A Gaby, que se bancó más de lo esperable. A Nico, Fede y Mateo, imprescindibles para que no me quedara sin combustible antes de llegar acá. Y a Juan, cuyo sostén en momentos muy difíciles fue la mejor definición de hermano que haya podido encontrar. 



\section{Índice general}

1 Introducción 1

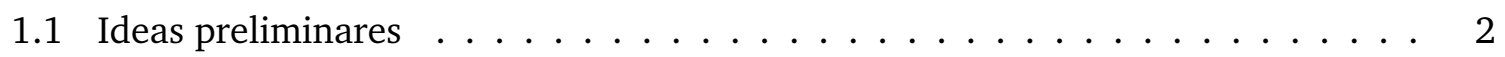

1.2 Contexto de la investigación y audiencia $\ldots \ldots \ldots \ldots$

1.3 Preguntas de investigación . . . . . . . . . . . . . . . . . . 7

1.4 Método de investigación $\ldots \ldots \ldots \ldots \ldots \ldots$

1.4.1 La triangulación de métodos como marco . . . . . . . . . . . . 8

1.4.2 Triangulando entre los campos de interés . . . . . . . . . . . . . 9

1.5 Digresión sobre sketchnoting . . . . . . . . . . . . . . . . . . . . . 12

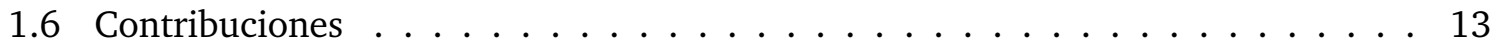

1.7 Publicaciones . . . . . . . . . . . . . . . . . . 13

1.8 Organización de la tesis $\ldots \ldots \ldots \ldots \ldots \ldots \ldots$

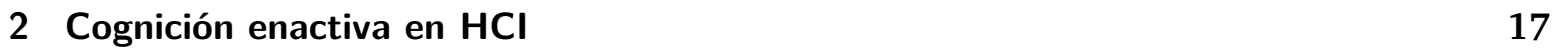

2.1 La cognición corporizada para el diseño de sistemas interactivos . . . . . . . . . 18

2.1 .1 Una reacción al cognitivismo . . . . . . . . . . . . . . . . 18

2.1.2 Computación y representación distribuidas (CRD) . . . . . . . . . . . 20

2.1 .3 Práctica socialmente situada (PSS) . . . . . . . . . . . . . . . 22

2.1.4 Acoplamiento sensorio-motor o enacción (ASM) . . . . . . . . . . . 23

2.2 Implicancias para el diseño de interacciones enactivas $\ldots \ldots \ldots$. . . . . . . 28

2.3 Conclusiones del capítulo . . . . . . . . . . . . . . . . . 37

3 Una revisión sobre el diseño, bocetado y herramientas disponibles 41

3.1 Diseño de interacciones digitales y bocetado . . . . . . . . . . . . . . 41

3.1.1 ¿De qué hablamos cuando decimos diseño? . . . . . . . . . . . . . . . . 41

3.1 .2 La interacción . . . . . . . . . . . . . . . . . 47

3.1 .3 El bocetado . . . . . . . . . . . . . . . . . . . . . . 49

3.2 Soporte al diseño de interacciones enactivas . . . . . . . . . . . . 55

3.2.1 Herramientas para abstraer y organizar . . . . . . . . . . . 57

3.2.2 Herramientas para diseñar, idear, dibujar . . . . . . . . . . . . . 60

3.2.3 Herramientas para bocetar con hardware, maquetar, construir . . . . . . 67

3.3 Conclusiones del capítulo . . . . . . . . . . . . . . . . . 74

4 Una caracterización del bocetado de interacciones enactivas 79

4.1 Introducción . . . . . . . . . . . . . . . . . . . . . 79 
4.2 La sustitución sensorial . . . . . . . . . . . . . . . . . . . . 80

4.3 En búsqueda de una caracterización . . . . . . . . . . . . . . 81

4.3.1 Exploración en modo etnometodológico . . . . . . . . . . . 81

4.3 .2 Registro de los talleres . . . . . . . . . . . . . . . . . . . . 84

4.4 Lecciones aprendidas . . . . . . . . . . . . . . . . . . . 111

4.4.1 Sobre la cognición corporizada en la ideación . . . . . . . . . . . . . . 112

4.4.2 Sobre las herramientas para la ideación enactiva . . . . . . . . . . . 115

4.4 .3 A modo de requerimientos . . . . . . . . . . . . . . . . . . . . . . . 119

5 Herramientas para el bocetado de interacciones enactivas 123

5.1 Pluma $1.0 \ldots \ldots \ldots$. . . . . . . . . . . . . . . . . . . . . 124

5.1 .1 Idea y objetivos . . . . . . . . . . . . . . . . . . . 125

5.1 .2 Diseño conceptual e implementación . . . . . . . . . . . . . . . 126

5.1 .3 Estudio de caso . . . . . . . . . . . . . . . . . . . . . 130

5.2 Un marco para el bocetado de interacciones enactivas . . . . . . . . . . . . 137

5.2.1 ¿Para qué bocetar en la ideación? . . . . . . . . . . . . . . . . . . . 139

5.2.2 Una forma de pensar la organización del bocetado . . . . . . . . . . . 142

5.2 .3 Resumen . . . . . . . . . . . . . . . . . . . . 146

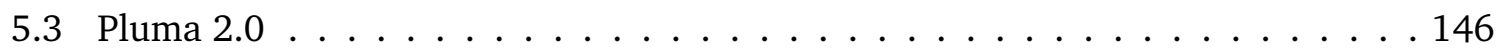

5.3 .1 Diseño . . . . . . . . . . . . . . . . . . . . . . 147

5.3 .2 Implementación . . . . . . . . . . . . . . . . . . . . . . . . . . . . . . . . . . . . . . . . . .

5.3 .3 Evaluación . . . . . . . . . . . . . . . . . . . . 157

5.3 .4 Discusión . . . . . . . . . . . . . . . . . . . 167

6 Conclusiones $\quad 171$

6.1 Preguntas, respuestas, contribuciones . . . . . . . . . . . 171

6.2 Trabajos futuros . . . . . . . . . . . . . . . . . . 176

$\begin{array}{ll}\text { Bibliografía } & 179\end{array}$

$\begin{array}{ll}\text { A Talleres de observación } & 203\end{array}$ 


\section{Prefacio}

Considerado en retrospectiva este proyecto puede leerse como un mojón en la búsqueda de una síntesis entre mi formación inicial como diseñador industrial y el devenir de una carrera que me ha llevado hacia el diseño de interacciones digitales tangibles a través de la ingeniería de software y la usabilidad.

A principios de los 90, mientras introducía algunas ideas de diseño para estudiantes de ingeniería mecánica en Neuquén y hacía algo que pretendía ser investigación sobre el uso de bocetos en el Centro de Investigaciones en Diseño Industrial de la FADU UBA descubrí los escritos de Donald Norman. La versión española de Diseño de los objetos cotidianos me produjo un efecto doble. Por un lado cierto alborozo en la formulación organizada de algunas ideas sobre la relación de la gente con las cosas artificiales que el diseño industrial solía considerar obvias, pero que se trasmitían casi por ósmosis en la facultad y hacían que el diseño fuese visto muchas veces como magia o arte inescrutable. Por otro la perplejidad de ver que le hablaba a la comunidad del software contándole como novedad las ideas que desde el diseño se habían practicado por décadas: conviene involucrar en el desarrollo a la persona de carne y hueso que va a usar el sistema; hay que preguntarle qué quiere (o mejor, hay que ver qué hace), es mejor si en el proceso se incluyen soluciones provisorias que puedan ser rápidamente evaluadas ¿Por qué habría de ser eso una novedad?

Lo descubrí unos años más tarde durante la cursada de la Maestría en Ingeniería de Software en la UNLP, cuando comencé a integrarme a los equipos de transferencia tecnológica en Lifia. Todos los desarrolladores eran sumamente capaces para modelar y programar el software. Todos conocían muy bien cómo especificar las necesidades a satisfacer (en un formato que sólo ellos mismos podían comprender). Pocos entendían para qué podía ser útil tener un modelo intermedio y descartable como una maqueta, que fuese comprensible por los futuros usuarios. Fue entonces cuando asumí una especie de cruzada evangelizadora en el querido proyecto de Medifé sobre la importancia, conveniencia y facilidad del uso de prototipos. Luego vino la posibilidad de cambiar en el eSidif del Ministerio de Hacienda los viejos formularios que RUP llamaba prototipos por maquetas visuales y más tarde varios proyectos se vieron de golpe llenos de algunos dibujos de pantallas a mano alzada, sobre hojas cuadriculadas. En cada intervención, los efectos aparecieron casi de inmediato. Ya no era necesario volver a hacer una y otra vez una funcionalidad porque al implementarla se descubría que no era lo que el usuario necesitaba o lo que un área del proyecto le había dicho a la otra. Nada nuevo. Ninguna 
innovación real. Sólo era adoptar en el diseño de software lo que otras disciplinas ya habían comprobado que funcionaba.

Sin embargo, me seguía produciendo inquietud eso de que la usabilidad estaba entre los "requerimientos no funcionales". ¿Que algo fuera fácil de usar no formaba parte de su función? ¿Cómo es que diseñar para qué sirve el sistema es un proceso separado de diseñar cómo se usa? Si no se puede usar, en realidad no sirve para (casi) nada. En el diseño industrial no hay nada que sugiera esa separación. En el análisis de un martillo y cómo funciona en manos de un carpintero, nada nos pide que distingamos conceptualmente entre la parte que martilla (su funcionalidad) y su mango (su interfaz). En el martillo la parte funcional es parte del control y el martillo es una totalidad. Cuando las personas manejan objetos y herramientas en la práctica cotidiana, estos niveles de descripción están mezclados en una única experiencia, sin embargo los sistemas interactivos con base de software son diseñados con una separación explícita de esos niveles.

Junto con esta transición desde el diseño de productos hacia el diseño centrado en usuario y usabilidad en la ingeniería de software, llegó la convocatoria a participar de la Maestría en Arte Electrónico en la UNTREF. Y apareció otro mundo sorprendente, ligado al diseño de interacciones desde un lugar muy diferente, con procesos centrados en el aprender haciendo y las interacciones tangibles. Organicé dos cursos de programación en entornos interactivos centrados en la actividad de diseñar para una vinculación con el entorno utilizando todo el cuerpo y siguiendo un proceso en paralelo de tres tareas: diseñar de forma iterativa la forma concreta de la interacción (la forma física y el comportamiento interactivo del sistema), diseñar y obtener de manera iterativa la función principal del sistema en su conjunto e investigar el contexto físico y social dentro del cual se usa el sistema.

La vinculación con las nociones de computación ubicua, sensible al contexto y de interacción corporizada fue casi automática y transparente. Fue cuando empecé a descubrir la necesidad de operacionalizar el uso de las teorías cognitivas que entraban en juego e investigar cómo desarrollar mejores herramientas para dar soporte a ese proceso creativo.

El resultado de este largo camino es esta investigación para el doctorado, que en algún punto es una manera de indagar en las herramientas que me hubiera gustado tener durante mi transición desde el diseño industrial "tradicional" hacia su transformación en el actual diseño de interacciones digitales.

La Plata, 14 de julio de 2019 


\section{Introducción}

The major difficulty for HCI is that the object of study is not an independent natural phenomenon, as in all of the sciences. Nor is it solely the creation of new artifacts, as in the design and engineering disciplines. HCI studies the interaction between people and artificially-created artifacts

\section{— Wendy E. Mackay and Anne-Laure Fayard}

HCI, Natural Science and Design: a framework for triangulation accross disciplines[156]

El continuo desarrollo de tecnologías interactivas y la mayor comprensión de la participación del cuerpo en los procesos cognitivos ha empujado al diseño de interacciones (y al campo HCI en general) a la necesidad de resolver la relación del usuario con una multitud de dispositivos que se extienden más allá de los escritorios[56]. Artefactos y sistemas que disponen de capacidades tan variadas como detectar gestos y posicionamientos, interpretar expresiones faciales, comunicarse utilizando diferentes modalidades de manera simultánea, etc. Estos ámbitos de diseño abren nuevos desafíos a la hora de disponer de procesos, métodos y herramientas para alcanzar experiencias de uso adecuadas. Lo mismo ocurre con el impulso y restricciones que plantea el apoyo en las teorías sobre la cognición corporizada[128].

En la medida que nuevos dispositivos y sistemas involucran otras dimensiones del ser humano y "salen más allá del escritorio", se hace más relevante la consideración de paradigmas, teorías y modelos de soporte que excedan la selección de nodos de navegación y organización visual apropiada de pantallas y widgets. Las etapas previas al proceso de la ingeniería de producto, que son habituales en muchas industrias como la automotriz, de línea blanca, audio, etc, se tornan necesarias en todos los productos que involucren software con cada vez más hardware ad hoc. En esta etapa, el diseño de interacción se ocupa, como sostiene Buxton, de conseguir no sólo que se construya el producto de manera adecuada, sino además que se construya el producto correcto[32]

El bocetado es una de las prácticas privilegiadas por los diseñadores, especialmente a la hora de generar y representar las ideas y los productos intermedios de su actividad. Consiste en la producción de representaciones gráficas, generalmente a mano alzada, realizadas con rapidez y mínimos detalles y que produce unos gráficos que los propios diseñadores suelen llamar “dibujos para pensar" [82, 185, 230] (ver Figura 1.1). Sus productos son tan idiosincráticos y ambiguos que a menudo solo son comprensibles por su autor. Esta práctica es habitual en las etapas iniciales de todas las disciplinas de diseño[142]. 
IDEA

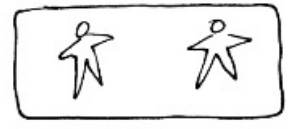

one-to one silent and personal.
METAPHOR

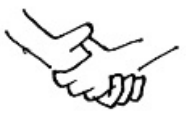

Holding hands give a squerze

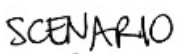

Q. ?

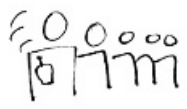
Cell phones ring
in public.

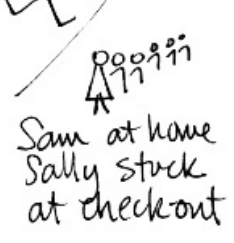

MODEL

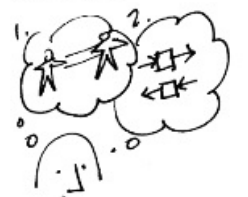

1. Single Channel

2. Packets

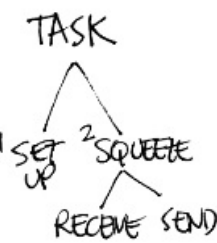

1. SETUP Sam/sally

2. SQUEEZE
DISPLAY

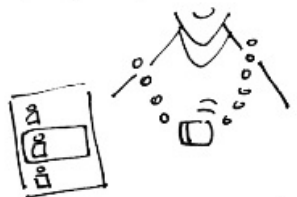

list vibration

pilot neclace

CONTROL

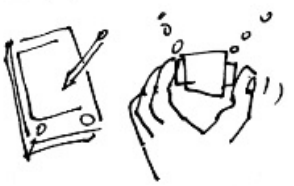

SELET SQLEEE

(tap)

Fig. 1.1.: Bocetos de Bill Verplank para un proyecto de "Haptic pager"[240]

El trabajo de esta tesis se constituye en el cruce de tres temas de interés actual para la Interacción entre Personas y Computadoras (HCI):

- la actividad del diseño de sistemas interactivos, con énfasis en la creación de los mecanismos de interacción que combinan un pie en lo digital y uno en lo físico. ¿Qué ocurre con el desafío de integrar la forma física con el software digital? ¿Las teorías de la corporización enactiva pueden ayudar a los diseñadores a encontrar una integración significativa de la forma física y los procesos digitales?

- las teorías de la cognición corporizada y enactiva: una teoría sobre la manera de dar sentido al mundo. ¿Cómo aproximar el diseño de sistemas interactivos tomando en cuenta de manera explícita que la cognición que los usuarios tienen de ellos es corporizada y enactiva? ¿Estas teorías pueden ayudar a los diseñadores a conseguir una integración significativa del sistema como un conjunto, de las interacciones que provee y del entorno físico y social en el que se utiliza?

- las prácticas creativas soportadas por el bocetado, en particular los procesos de generación, evaluación y comunicación de ideas o propuestas de diseño. ¿Cuáles son las similitudes y diferencias entre el bocetado a mano alzada y los bocetos de interacciones enactivas? ¿Cómo deberían ser las herramientas para soportarlos?

\subsection{Ideas preliminares}

El diseño de sistemas interactivos muestra una tendencia creciente a integrar la forma física y el proceso digital. Esto afecta a todas las disciplinas involucradas en el diseño de esos sistemas. Desde la perspectiva del diseño industrial o de producto, implica agregar comportamientos 
interactivos a los artefactos físicos, utilizando sensores, actuadores y software. Desde la perspectiva de la informática, significa crear interfaces tangibles, que utilizan diversos objetos físicos para controlar la información digital e interfaces contextuales que dependen fundamentalmente de las señales disponibles en el entorno y la situación. La computación ubicua, interacción tangible, computación portátil, realidad aumentada, etc. son algunas de las líneas de trabajo que crecieron en este enfoque. La popularidad actual de la interacción a través de dispositivos móviles, como el teléfono inteligente o la tableta, con aplicaciones que utilizan la ubicación GPS, el acelerómetro, etc., señala un desarrollo que se aleja de la clásica interfaz de escritorio. El programa de la computación ubicua de Weiser[244] contribuye a mover la interacción con los procesos digitales "de vuelta al mundo real”, mezclándolo perfectamente con los objetos físicos, los entornos y los contextos sociales.

En los últimos años ha habido un interés creciente en las teorías que entienden la cognición como un fenómeno corporizado, situado y enactivo (e.g. [223], [239], [112], [39], [57]). Las teorías de la Cognición Corporizada (CC en adelante) se expandieron sobre todo a mitad de los noventa, pero su origen tiene rastros que se extienden al pensamiento fenomenológico (Merleau-Ponty[170], [96]), al pragmatismo[48] y la cibernética ([16]), entre otros orígenes. La enacción, como veremos más adelante, es una forma de abordar la CC.

¿Por qué incluir temas de las ciencias cognitivas en una tesis de Interacción Hombre Computadora? El campo de investigación de HCI ha pasado por diversos giros en cuanto al foco principal de atención y vinculación con otras áreas a lo largo de su existencia. En lo que ella llama las "teorías contemporáneas" para el soporte en HCI, Yvonne Rogers[200] ha identificado un conjunto de giros o enfoques que son relevantes para mi trabajo. En particular la centralidad que el diseño, primero, y la corporización, más tarde, han adquirido en las investigaciones de HCI.

Desde principios de la década de 1990, el diseño se ha considerado central para HCI, comenzando con un enfoque en el diseño de software, el diseño centrado en el usuario y el diseño de la interfaz (por ejemplo, en los trabajos de Karat[126] y Winograd[249]). Los dos temas centrales en ese momento eran cómo mejorar la ingeniería de requerimientos y cómo desarrollar métodos que pudieran alimentar mejor el diseño centrado en el usuario. Más tarde, se comenzó a discutir de qué forma la teoría del diseño podría desempeñar un papel más central en HCI, donde pueden destacarse los trabajos de Donald Schön[209] o Löwgren y Stolterman[153]. Ya no se trataba sólo de cómo hacer un diseño de interacción sino cómo pensar en ello. Este cambio de la prescripción a la reflexión llamó la atención sobre la complejidad del diseño. Reducirlo a unas recetas de pasos a seguir o a las lecciones aprendidas se consideró una simplificación excesiva. Se hizo evidente la necesidad de más interpretación y comprensión sobre las elecciones que realiza un diseñador. Esta idea de que el diseño de interacción pueda estar basado en teorías de la estética, la ética, la política y la ideología fue (y sigue siendo para muchos aún hoy) un cambio radical en el diseño de software. Ya no había que pensar sólo en qué métodos usar per se, sino en cómo usarlos de manera sensible y hábil. Conceptos como el placer, la experiencia del usuario, el disfrute y el juego proporcionaron muchos elementos 
nuevos para pensar, permitiendo a los diseñadores contemplar lo que significa diseñar algo con lo que vivimos, no simplemente algo que usamos[92]. Otros efectos de este giro al diseño han sido los estudios filosóficos en el marco de la Tecnología como Experiencia de McCarthy y Wright[165] (cómo aplicar la fenomenología de la experiencia a la práctica del diseño) y los aspectos lúdicos que promueven la curiosidad, la exploración y el disfrute estético entre las personas cuando se encuentran con nuevas tecnologías. El fundamento teórico de estas incursiones en un HCI "más creativo" es que no hay una interpretación preferida de un sistema sino múltiples, como inspiran los Estudios de Ciencia y Tecnología (por ejemplo, Bijker[25]).

El segundo giro de interés es el viraje hacia la corporización ${ }^{1}$, especialmente a partir del éxito del libro de Paul Dourish Where the action is[56]. Se trata de comprender la interacción en términos prácticos con el entorno social y físico. Se inspira en trabajos como la discusión de fenomenología de Winograd y Flores[250], la noción de acciones situadas de Suchman[224], la concepción de affordances de Gibson[78], las ideas filosóficas de Heidegger[96]. El objetivo es cómo comprender las connotaciones de lo que significa una postura corporizada y cómo tornarla operativa. Klemmer et al en How bodies matter[131] sugieren una serie de temas concretos destinados a ayudar a los diseñadores, cinco temas destinados a inspirar nuevos enfoques de diseño que combinan lo físico con lo computacional y sirven también como entrada para evaluar sistemas en contexto. Otro enfoque es el Framework de Interacción Tangible de Hornecker y Buur[105] que conceptualiza las tecnologías en términos de interacción corporizada, manipulación tangible, representación física de datos e integración en el espacio real. De manera similar a Klemmer trata de resumir los problemas principales como preguntas que puedan impulsar e inspirar el diseño creativo.

Retomando la idea de la CC, ¿̇por qué es interesante incluir este enfoque cognitivo sobre la corporización? En primer lugar porque muestra de diversas maneras cómo se las arregla la gente para lidiar con el mundo "en la acción". Es decir, explica cómo la gente improvisa y comprende la forma en que el mundo es significativo, en el mismo acto de involucrarse con él. Esto es muy diferente al modelo clásico ofrecido por la ciencia cognitiva en el cual la cognición es alguna cosa que ocurre en la cabeza, separada del mundo, planeada con anticipación, algo sobre lo que se razona internamente y después se actúa en el mundo real[34].

La CC concibe la cognición como un proceso dinámico donde el significado surge dentro de la acción en curso, en lugar de suponerlo como fijo, pre-configurado, innato, etc.[232]. Para la CC no hay distinción esencial entre "detectar" y "actuar", entre "entrada" o "salida". Cada persona siempre está ocupada interactuando con el mundo, y el flujo de "sensación" siempre corre paralelo al de "acción". Incluso "solo mirar", implica que uno ya está actuando (con movimientos sacádicos de los ojos). Según CC, entonces, la acción y la percepción están inherentemente acopladas[78, 30]. Finalmente, la CC concibe la cognición no como un asunto aislado sino como situado en un contexto, que puede ser tanto el entorno físico como el entorno social. La situación influye fuertemente en cómo las personas dan sentido en la acción, y

\footnotetext{
${ }^{1}$ El término inglés embodiment ha recibido diferentes traducciones al español, como encarnación, materialización,
} corporeidad, corporización. En el resto de la tesis utilizaremos este último 
nuestra comprensión de la cognición no se puede abstraer de ese entorno local sin perder significado[223].

Estos cuatro aspectos (orientación a la acción, dinámica, acoplamiento y situación) muestran por qué la CC es relevante en el contexto actual del diseño de sistemas interactivos inmerso en un viraje a la corporización.

Los bocetos son una herramienta esencial del diseñador para capturar observaciones e ideas preliminares. Si son fluidos y flexibles, apoyan la creatividad. Los bocetos pueden ser concretos o abstractos, representativos o simbólicos, sueltos o ajustados, improvisados o ensayados. Robert McKim en Experiences in Visual Thinking[166] enseña cómo dibujar aprendiendo a ver y a imaginar. El ver alimenta al dibujar y el dibujo mejora con la visión. Lo que vemos está influenciado por lo que imaginamos; lo que imaginamos depende de lo que vemos. El ideal creativo de McKim de visualización rápida o bocetos de ideas es el oficio de hacer las tres cosas al mismo tiempo. Esto es similar a la experiencia de cualquier artesano en contacto directo con sus materiales: imaginar, moldear, ver todo al mismo tiempo.

McKim también describe la búsqueda rápida de alternativas como un modo de pensamiento no crítico que debe separarse de la crítica. La lluvia de ideas es un modo en el que los objetivos son la fluidez y la flexibilidad, la cantidad y la variedad. Si una idea es criticada antes de expresarse, muere prematuramente. El diseño, a diferencia de la artesanía, tiene esta calidad de fases o modos separados. Por ejemplo, el modo de expresión, que produce muchas opciones, puede ir seguido de una fase de prueba, seguida de una fase de ciclo donde se elige la siguiente estrategia. El proceso de diseño básico es visto como cíclico o iterativo (ver Figura 1.2).

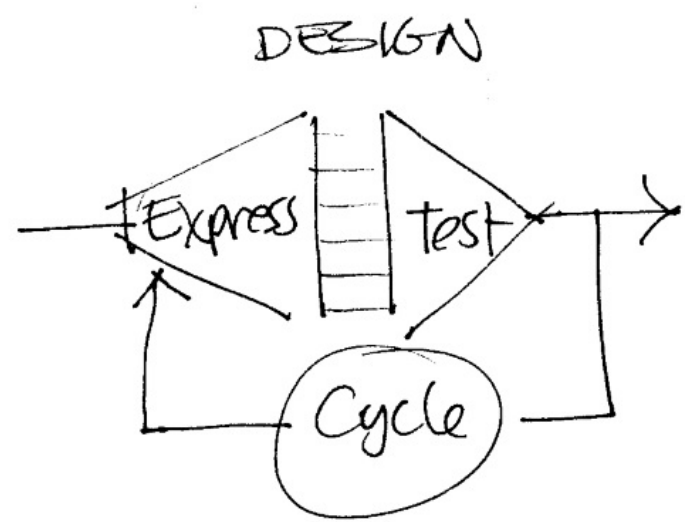

Fig. 1.2.: Iteración básica de diseño según McKim, tomado de [166]

Una de las razones para enfatizar en la fluidez y bajo costo de los bocetos es la necesidad del diseño de explorar varias alternativas de manera simultánea. Existe un peligro en la iteración si no se consideran las alternativas, si solo está trabajando en un diseño a la vez, nunca se hacen comparaciones, los criterios nunca se cuestionan. En el núcleo de la invención puede haber una corazonada seguida de un truco seguido de otra corazonada (arte), pero se necesita una idea o generalización para generar alternativas, prototipos y pruebas (diseño). El objetivo 
son los principios, que organizan el valor de un producto que crea un mercado que crea un paradigma y volvemos a una órbita fija. El diseño es la "órbita de transferencia" que nos lleva de una órbita pequeña a una más grande. Se puede encontrar evidencia en la literatura sobre las ventajas para la acción creativa que tiene el hecho de bocetar o prototipar varias ideas en paralelo[60, 93].

\subsection{Contexto de la investigación y audiencia}

El contexto general de esta investigación es el campo de la Interacción Hombre Computadora (HCI, por su sigla en inglés), "una disciplina relacionada con el diseño, la evaluación e implementación de sistemas de computación interactivos para uso humano y con el estudio de los principales fenómenos humanos relacionados con ellos"[98].

Para precisar un poco más el contexto utilizo el Sistema de Clasificación de Computación de la $\mathrm{ACM}^{2}$, que permite ubicar el trabajo de esta tesis en el Área de Computación Centrada en las Personas, específicamente en la relación de tres subcampos del Diseño de Interacciones: los procesos y métodos; las teorías, conceptos y paradigmas; los sistemas y herramientas para el diseño de interacciones (ver la Figura 1.3).
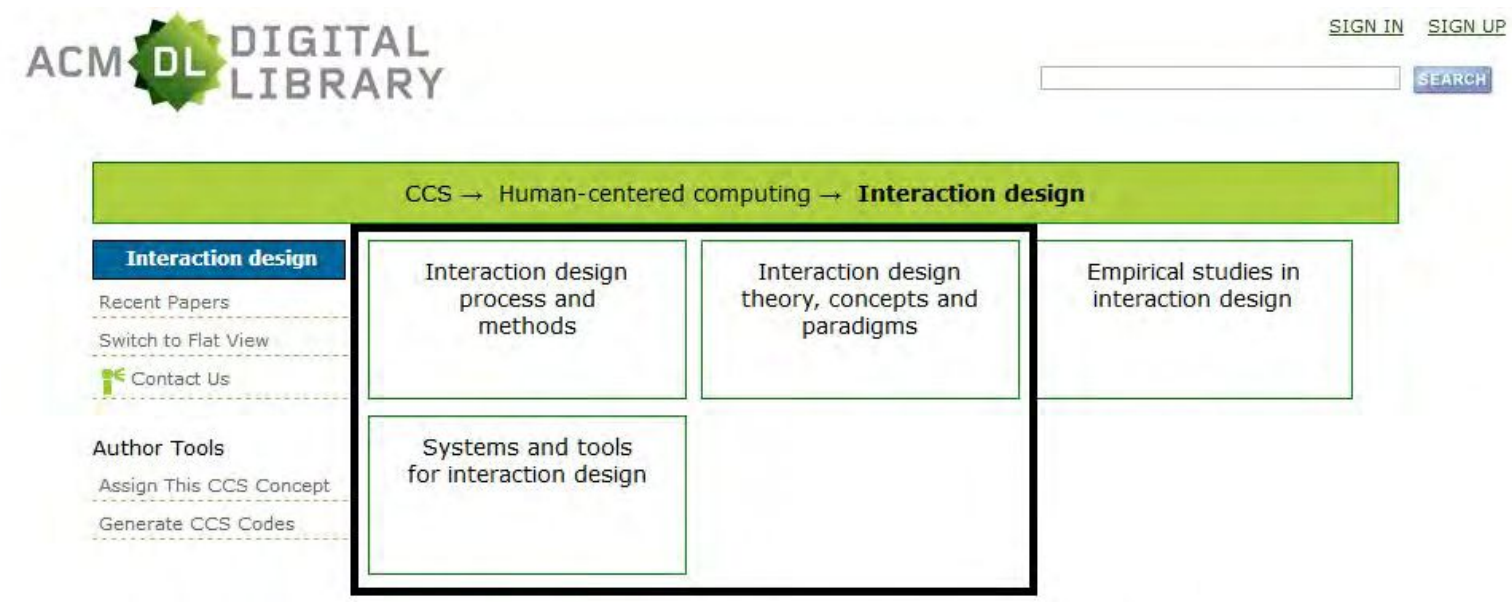

Fig. 1.3.: Contexto de la investigación de acuerdo con el Computing Coding System de ACM

En el libro de texto Interaction Design. Beyond Human Computer Interaction de Preece, Sharp y Roggers se define el Diseño de Interacciones como: "la actividad de diseñar productos interactivos que soporten el modo que la gente se comunica e interactúa en su vida diaria y ambiente de trabajo(...) crear experiencias de usuario que mejoren y aumenten el modo en que la gente trabaja, se comunica e interactúa"[190]. La visión inicial de HCI como una ciencia aplicada que podría usar las teorías y métodos de la ciencia cognitiva para dar sustento al diseño de software[35], que buscaba comprender cómo utilizaba la gente los sistemas y dispositivos computacionales para hacerlos usables y útiles, ha quedado en parte superada por el desarrollo de nuevos campos y aproximaciones relacionadas con la gente, el diseño y

\footnotetext{
${ }^{2}$ https://dl.acm.org/ccs/ccs.cfm?id $=0 \&$ lid $=0$
} 
la tecnología que emergieron[200]. Como dice Winograd, se trata ahora de "diseñar espacios para la comunicación e interacción humana"[248].

Desde la década de 1980 la HCI ha importado numerosos tipos de teorías. Uno de los principales beneficios de aplicar teorías específicas de otros campos sobre el comportamiento humano es que ayudan a identificar factores (por ejemplo, cognitivos, sociales y organizacionales) relevantes para el diseño y evaluación de productos interactivos. En particular, pueden ayudar a reducir un área en preocupaciones e investigar preguntas que luego pueden operacionalizarse en términos de un problema o espacio de diseño. Bederson y Shneiderman[17] sugieren que existen al menos cinco roles para las teorías en HCI:

- descriptivas: proporcionan conceptos, aclaran la terminología y orientan la investigación adicional;

- explicativas: explican relaciones y procesos;

- predictivas: permiten hacer predicciones sobre el rendimiento del usuario;

- prescriptivas: proporcionan orientación para el diseño;

- generativas: permiten a los profesionales crear, inventar o descubrir algo nuevo.

En esta tesis las teorías de la Cognición Corporizada y Enactiva servirán el rol de describir (proporcionar conceptos, aclarar la terminología y orientar la investigación adicional), explicar (relaciones y procesos) y contribuir a generar ideas de diseño para la interacción enactiva.

Para mantener manejable el alcance de la disertación, he restringido la investigación al diseño de interacciones enactivas con dispositivos digitales que se organizan en torno a una combinación de manipulación y gestos aéreos con feedback háptico, visual y sonoro. Esto excluye las interacciones distribuidas entre diversos dispositivos, instalaciones o artefactos colaborativos y otras tecnologías de sensado y actuación diferentes de las mencionadas.

La audiencia primaria del trabajo presentado en esta disertación son diseñadores de interacción e investigadores. La operacionalización de la cognición corporizada y enactiva para el diseño de interacciones como una base (Capítulo 2), los hallazgos de los talleres (Capítulo 4) y el Marco de Trabajo (Capítulo 5) abordan la audiencia más amplia de los investigadores del diseño de interacciones, donde la meta es inspirar e informar al proceso de construcción de sistemas que soporten la cognición corporizada y enactiva. El diseño del toolkit Pluma (Capítulo 5) está orientado a los diseñadores de interacciones enactivas y a desarrolladores de herramientas para soportar la práctica.

\subsection{Preguntas de investigación}

El objetivo central de esta investigación es operacionalizar la Cognición Corporizada Enactiva para el bocetado y la generación de ideas en el diseño de interacciones y caracterizar y soportar esta práctica con herramientas computacionales. Para ello, se plantean las siguientes preguntas que la tesis intenta responder: 
- PI 1.1 ¿De qué manera la Cognición Corporizada y Enactiva provee información al diseño sobre la forma en que los sistemas interactivos se conectan con las prácticas corporizadas de la gente y situadas en el mundo real?

- PI 1.2 ¿Cuáles son las características de los sistemas interactivos digitales que facilitan una interacción Corporizada y Enactiva entre las personas y esos sistemas?

PI 2. ¿Cómo podemos diseñar sistemas interactivos que se apoyen en la Cognición Corporizada y Enactiva?

- PI 2.1. ¿Qué características de la Cognición Corporizada y Enactiva son relevantes en el proceso de diseño de los sistemas interactivos?

- PI 2.2. ¿Qué características debe poseer el bocetado para dar soporte a la generación y evaluación de ideas para interacciones enactivas?

\subsection{Método de investigación}

\subsubsection{La triangulación de métodos como marco}

Los tres campos involucrados en este trabajo (Cognición Corporizada Enactiva, Diseño de Interacciones, Bocetado) tienen tradiciones, métodos y principios diferentes. Siguiendo la cita de cabecera que inicia el capítulo, sabemos que esta situación no es inusual en las investigaciones de HCI. Los miembros de esta comunidad suelen abordar sus objetivos con un enfoque multidisciplinario, tomando herramientas, técnicas y paradigmas de una amplia variedad de disciplinas existentes, tanto desde la ciencia como desde el diseño.

Para este trabajo de investigación he seguido la aproximación triangular que describen Mackay y Fayard [156], con un abordaje de múltiples perspectivas para los problemas en HCI: a) una perspectiva teórica, en la cual las teorías, modelos y marcos de trabajo son estudiados y utilizados para entender o conceptualizar un dominio del problema, b) una perspectiva de observación en la cual los investigadores estudian y observan cómo los usuarios interactúan con el mundo y c) una perspectiva de diseño en la cual el análisis de los datos de las observaciones y las teorías son trasladados en artefactos de diseño, los que a su vez pueden ser fuente de estudios de observación o teorización. Esta triangulación de métodos es especialmente útil cuando se necesita explorar y conectar varios métodos en un contexto particular[24].

La Figura 1.4 ilustra cómo se pueden integrar el diseño y los modelos científicos para la gama de actividades que se encuentran en HCI. En el nivel teórico, podemos crear y revisar modelos de interacción. A nivel empírico o del mundo real, podemos observar cómo las personas interactúan con diversas tecnologías y desarrollan modelos de uso. En ambos casos, podemos basarnos en la teoría y la observación para crear una instancia de nuevos artefactos, desde simulaciones iniciales hasta prototipos funcionales o productos. Estos artefactos evolucionan 


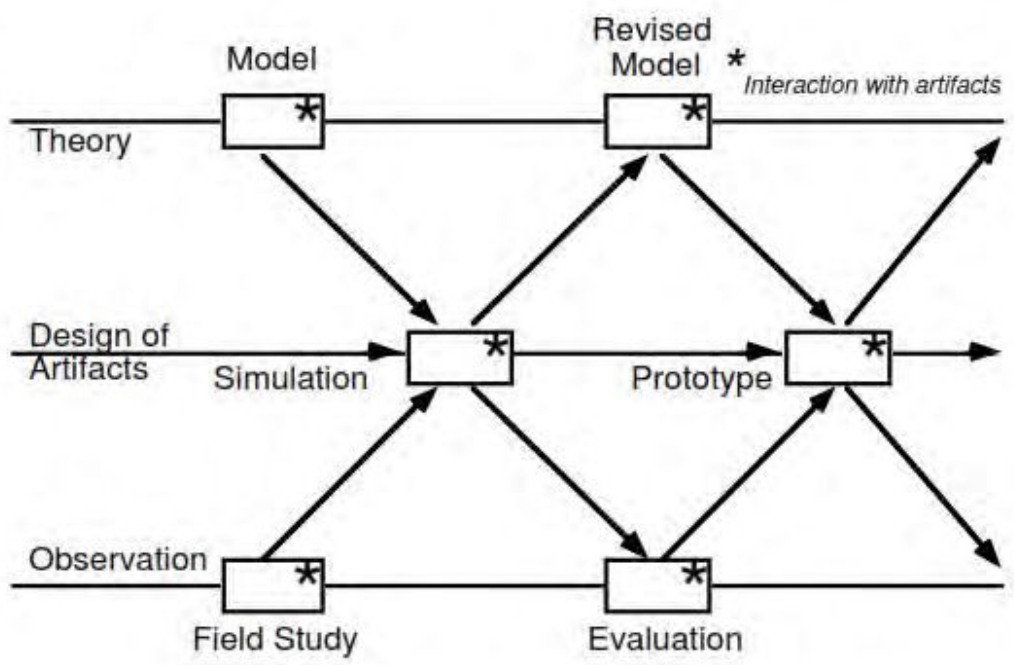

Fig. 1.4.: HCI crea y examina la interacción de la gente con artefactos creados artificialmente, moviéndose entre la teoría y la observación empírica. Las cajas representan la interacción con los artefactos creados artificialmente. Adaptada del trabajo de Mackay y Fayard[156]

constantemente e influyen o cambian los modelos a nivel teórico y las observaciones a nivel empírico. Se puede argumentar que los científicos se esfuerzan por comprender, mientras que los diseñadores se esfuerzan por crear. HCI es un campo interdisciplinario que debe hacer ambas cosas.

La solución es una triangulación: usar más de un enfoque de investigación para abordar la misma pregunta. Es la fortaleza para HCI: si logramos entender las relaciones entre ellos, podemos triangular a través de nuestras disciplinas y mejorar la validez y el valor de nuestra investigación.

\subsubsection{Triangulando entre los campos de interés}

En los próximos capítulos veremos la puesta en práctica de esta triangulación que se muestra en la Figura 1.5. Una línea de búsqueda teórica que busca determinar y comprender el marco de acción con las teorías de cognición corporizada y enactiva en el contexto de la creación y puesta en uso de dispositivos digitales interactivos, una línea de observación de la práctica concreta del bocetado de este tipo de interacciones y una línea de diseño, prototipado y análisis de herramientas para soportar la creación de interacciones enactivas. Establecí las diferentes actividades de manera que se alternaran a lo largo del tiempo, informándose mutuamente. La investigación general que se lleva a cabo se construye de manera iterativa en el sentido que sugieren estos ciclos de estudio, análisis, diseño y evaluación. Dentro de cada actividad de diseñar o estudiar seres humanos en acción, también hay reflexiones que pueden aportar una visión parcial: los resultados de los talleres se interpretan a la luz de la teoría, y también lo son los problemas de diseño particulares y la forma en que los abordamos. En conjunto, esto dio lugar a una comprensión cada vez más enfocada de las relaciones entre la cognición 
corporizada y enactiva, el diseño de sistemas interactivos y el contexto particular de la práctica del bocetado.

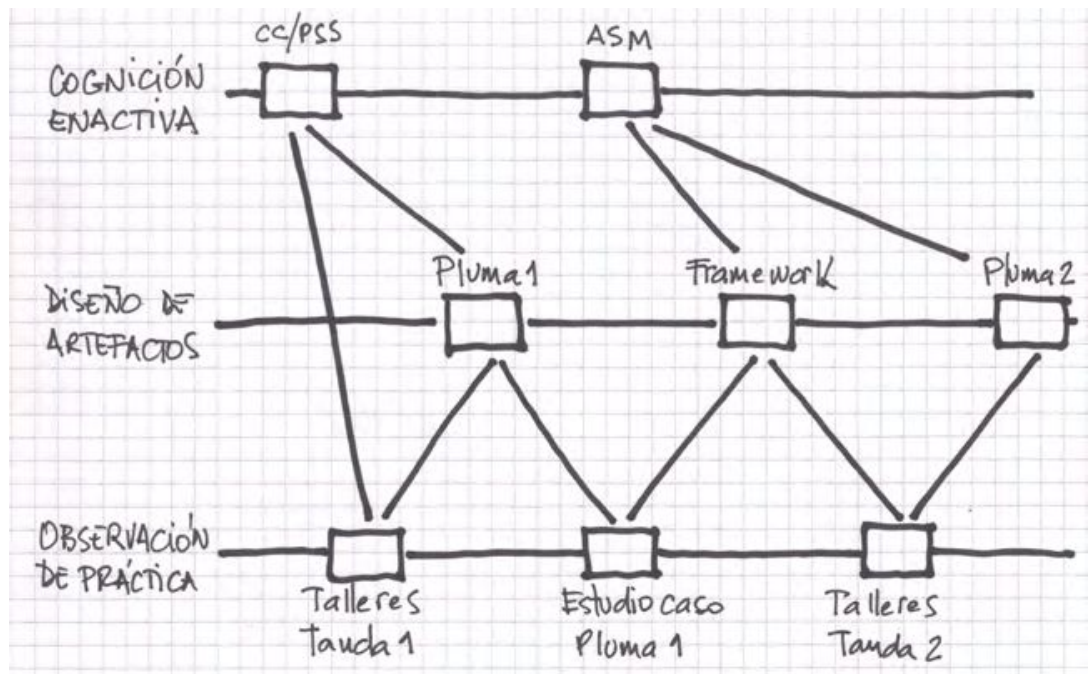

Fig. 1.5.: Implementación de la triangulación de métodos en este proyecto

\section{Línea teórica: Entender la Cognición Corporizada y Enactiva}

La teoría investigada es la "cognición corporizada y enactiva". Esto significa que se necesita una manera de decir cosas relevantes sobre cómo el cuerpo humano y la acción corporal concreta en el entorno físico se relaciona con la cognición humana. Algunos han abordado estos temas utilizando métodos etnográficos (por ejemplo, Goodwin[83]), pero otros, principalmente de la tradición de la psicología experimental, utilizan experimentos de laboratorio (por ejemplo, Van Rooij y sus colegas[204]). En línea con esa última tradición, agregamos en el desarrollo de las herramientas el uso del prototipo de toolkit como hipótesis física[246]. Esto permitió aprovechar la influencia del sistema diseñado sobre los patrones sensorio motores de comportamiento, resultados que pueden obtenerse con menos facilidad con las notas de los talleres[199]

\section{Línea de observación: Entender la práctica del bocetado}

Las prácticas humanas implican la forma cotidiana en que los seres humanos participan en todo tipo de actividades que conforman sus vidas. Hay prácticas profesionales, como en lo que hacen las personas en el trabajo, y prácticas en el entorno familiar, así como en el espacio público. Como se explicó más arriba, este trabajo se centra en apoyar la práctica de los diseñadores de sistemas digitales interactivos, en particular en la generación de ideas de interacción. Los enfoques tradicionales en las ciencias sociales son observar la práctica[76], entrevistar a las personas sobre su práctica o colaborar con profesionales[6]. En ese sentido, la observación en los talleres y las entrevistas situadas que se reportan en el Capítulo 4 forman parte importante de esta investigación con técnicas de etnometodología aplicada al estudio del diseño de interacciones[58]. 
La etnometodología es un marco analítico que se desarrolló originalmente como una reacción contra los enfoques tradicionales en sociología, que en gran parte eran teorías de arriba hacia abajo orientadas a identificar estructuras invariantes[74]. A modo de contraste, los etnometodólogos defienden un enfoque de abajo hacia arriba, según el cual las prácticas de trabajo se describen en términos de los logros prácticos de los miembros[4]. Para lograr esto, el enfoque se adhiere a un riguroso programa descriptivo que explica las prácticas laborales de los miembros.

Estos registros de prácticas de trabajo se presentan en gran parte como descripciones "espesas", es decir, relatos muy detallados que a menudo exponen las prácticas de trabajo que se dan por sentado y que resultan ser fundamentales para el rediseño de un sistema[76].

Button y Dourish proponen que los etnometodólogos y diseñadores podrían beneficiarse al tratar de ver el mundo a través de las perspectivas de los demás: “el diseño debe adoptar la mentalidad analítica de la etnometodología y la etnometodología debe llevar el manto práctico del diseño"[58]. Para mostrar cómo podría funcionar esta fusión de teorías, Button y Dourish dieron un ejemplo hipotético de dos preguntas diferentes que podrían plantearse al diseñar un nuevo sistema. En lugar de preguntar “¿cuáles son las implicancias de esta explicación etnometodológica del trabajo de los recepcionistas de hoteles para el diseño de un sistema de reservas?”, Sugirieron que una pregunta más perspicaz podría ser “¿cuáles son las implicancias de la operación y el uso de las categorías de miembros para cuestiones de individualidad y agrupación en sistemas de software?"[58]. Esto evita la propuesta de guías superficiales y con poca utilidad práctica como "implicancias para el diseño" en las conclusiones de registros etnometodológicos[55].

\section{Línea central: diseñar herramientas para diseñar sistemas interactivos}

El marco general dentro del cual se puede ubicar la aproximación en la línea central es el llamado Investigación a través del diseño (Research through Design, RtD por su sigla en inglés) $[6,254,43,136]$. Esta aproximación tiene un compromiso básico con el Diseño Centrado en Usuarios o Diseño Centrado en las Personas[179, 115], en la medida que el diseño tiene lugar en contacto directo con y completo respeto para la gente y el contexto para los cuales se diseña.

RtD es un marco de investigación relativamente joven en comparación con, por ejemplo, los métodos empíricos de prueba de hipótesis, el enfoque estándar en psicología experimental. RtD puede verse como una forma de Investigación de Acción (AR, Action Research) $[6,147]$ donde el investigador no observa y analiza el fenómeno de interés "desde atrás de la pared de vidrio", sino que interviene activamente en la situación en un Intento colaborativo de transformarlo para mejor.

La naturaleza iterativa y contextual de RtD se relaciona con el tipo de conocimiento en acción[208] que un diseñador aporta de manera natural en su trabajo, a fin de abordar de manera 
efectiva las complejidades involucradas: "La investigación es interactiva, un proceso coordinado que se desarrolla en nuestro comportamiento a lo largo del tiempo, como representamos, reformamos y reinterpretamos las formas materiales mediante las cuales modelamos el mundo y nuestras acciones"[38].

\subsection{Digresión sobre sketchnoting}

En una tesis dedicada al bocetado de interacciones no debe resultar extraño la utilización de dibujos a mano alzada para graficar los conceptos incluidos en el texto. En los años recientes se ha evidenciado un creciente redescubrimiento por parte de la comunidad de investigadores en HCI de las ventajas del bocetado a mano. La bibliografía sobre elsketchnoting o notas visuales es creciente (por ejemplo [196, 86, 203] e incluso algunas tesis en HCI han comenzado a incluirlas (por ejemplo la de Nicolai Marquard[158]).

Además de esas y otras obras sobre el tema que son citadas a lo largo del texto, también vale destacar el número de acontecimientos relacionados en las conferencias más importantes de HCI. En la versión 2015 de CHI, Nicolai Marquardt y Saul Greenberg dictaron un curso sobre "Sketching User Experiences"[160], en la edición 2017 de Designing Interactive Systems, se llevó a cabo un Workshop que reunió a diferentes investigadores sobre el tema "SkechingDIS: hand-drawn sketching in HCI"[225]. En su presentación se sostiene: los bocetos dibujados a mano pueden ser una forma fácil para que los investigadores de HCI se comuniquen y expresen ideas, así como para documentar, explorar y comunicar conceptos. Se pueden utilizar en todas las etapas del proceso de investigación y diseño de HCI.

Entre los objetivos que se planteó el taller, los siguientes fundamentan el uso de bocetos en esta tesis. Por un lado, discutir el futuro de los bocetos dibujados a mano, en particular ¿qué es lo que impide que los bocetos dibujados a mano en la investigación de HCI sean más visibles en la comunidad de HCI? ¿Qué investigación considera la comunidad de SketchingDIS que merece una investigación adicional?

Como consecuencia directa de ese taller, en la edición 2018 de CHI (además de repetir el taller[148]) se conformó el Grupo de Interés SketCHI[149]. Cursos y talleres similares se han impartido en NordiCHI 2016, TReSSPASS Summer School 2016 y CHI 2015. En el programa de la edición 2019 de CHI el taller Sketching in HCI: Hands-on Course of Sketching Techniques se ha vuelto a ofrecer ${ }^{3}$.

En esta tesis el lector encontrará varios ejemplos de notas visuales. Todas las figuras que no requieren fotografía han sido dibujadas a mano por el autor. Además, para cada capítulo se incluye un resumen visual de su contenido.

\footnotetext{
${ }^{3}$ http://chi2019.acm.org/accepted-courses/\#sketching-hci Accedido 12/03/2019
} 


\subsection{Contribuciones}

De acuerdo con la clasificación propuesta por Wobbrock para la investigación en HCI[251], este trabajo incluye los siguientes tipos de contribuciones:

1. Una contribución teórica: un framework conceptual para organizar las diferentes corporizaciones del bocetado en la generación de propuestas para interacciones enactivas, cómo se relacionan y cómo contribuyen al proceso de ideación.

2. Una contribución artefactual: dos versiones de una herramienta para utilizar la composición creativa con hardware y software en la ideación de interacciones enactivas.

3. Una contribución empírica: Estudios etnometodológicos sobre la práctica de ideación y bocetado en el diseño para la interacción enactiva

\subsection{Publicaciones}

En el marco de esta tesis se produjeron las siguientes publicaciones:

- Rodríguez, González, and Rossi. (2014). Sketching for Designing Enactive Interactions. XV International Conference on Human Computer Interaction, ACM, 39:1-39:2. http://doi.acm.org/10.1145/2662253.2662292

- Rodriguez, González and Rossi. (2015). Enactive Sketches for Designing Enactive Interactions. Proceedings of the Latin American Conference on Human Computer Interaction, ACM, 15:1-15:4.

http://dl.acm.org/citation.cfm?id=2824893.2824908

- Rodríguez, González, and Rossi. (2015). Marco de Trabajo para el Bocetado de Interacciones Enactivas. Revista Colombiana de Computación 16, 1: 48-74. https://doi.org/10.29375/25392115.2493

Otros trabajos relacionados con los temas que incluye esta tesis, desarrollados al mismo tiempo, generaron estas otras publicaciones:

- Rodríguez. (2014). Extending OpenUP to Conform with the ISO Usability Maturity Model. In Human-Centered Software Engineering. 5th IFIP WG 13.2 International Conference, Stefan Sauer, Cristian Bogdan, Peter Forbrig, Regina Bernhaupt and Marco Winckler (eds.). Springer, 90-107. https://doi.org/10.1007/978-3-662-44811-3_6.

- Rodríguez, Fernández, and Hormazábal. (2018). Beyond the GUI in agriculture: a bibliographic review, challenges and opportunities. Proceedings of the XIX International Conference on Human Computer Interaction, Interacción 2018, Palma, Spain, September 12-14, 2018, ACM, 35:1-35:8. https://doi.org/10.1145/3233824.3233844 
- Grigera, Gardey, Rodriguez, Garrido, and Rossi. (2019). One Metric for All: Calculating Interaction Effort of Individual Widgets. In Extended Abstracts of the 2019 CHI Conference on Human Factors in Computing Systems (CHI EA '19). ACM, New York, NY, USA, Paper LBW0278, 6 pages. https://doi.org/10.1145/3290607.3312902

\subsection{Organización de la tesis}

El resto de la tesis se organiza en cinco capítulos cuyo contenido se resume a continuación:

Capítulo 2 Presenta una introducción a los conceptos básicos de la Cognición Corporizada y Enactiva, los enfoques como Computación y Representación Distribuida, como Práctica Social Situada y como Acoplamiento Sensorio Motor, sus contribuciones y efectos en el diseño de sistemas interactivos.

Capítulo 3 Completa la línea de estudio teórico con la revisión bibliográfica de trabajos relacionados a esta tesis: en primer lugar, un abordaje detallado del rol que el bocetado cumple en el proceso de creación de ideas de diseño como herramienta central del pensamiento del diseñador; luego, una revisión de las herramientas que se han propuesto para dar soporte a este proceso de bocetado, en particular para el diseño de sistemas interactivos con interfaces tangibles.

Capítulo 4 Reporta una serie de Talleres para la generación de ideas de interacción enactiva sobre los que se efectuaron observaciones y análisis de tipo etnometodológico, con el objetivo de caracterizar la práctica del bocetado.

Capítulo 5 Se presentan las contribuciones propuestas por esta tesis para dar soporte al diseño de interacciones que se apoyen o den sustento a la perspectiva corporizada y enactiva de la cognición, que consisten en un framework para organizar conceptualmente el bocetado de interacciones enactivas y dos versiones de unas herramientas para incluir la composición de bocetos con software y hardware en ese proceso.

Capítulo 6 Se discuten los resultados obtenidos y se plantean las conclusiones de este trabajo. Finalmente se proponen líneas de acción futura. 


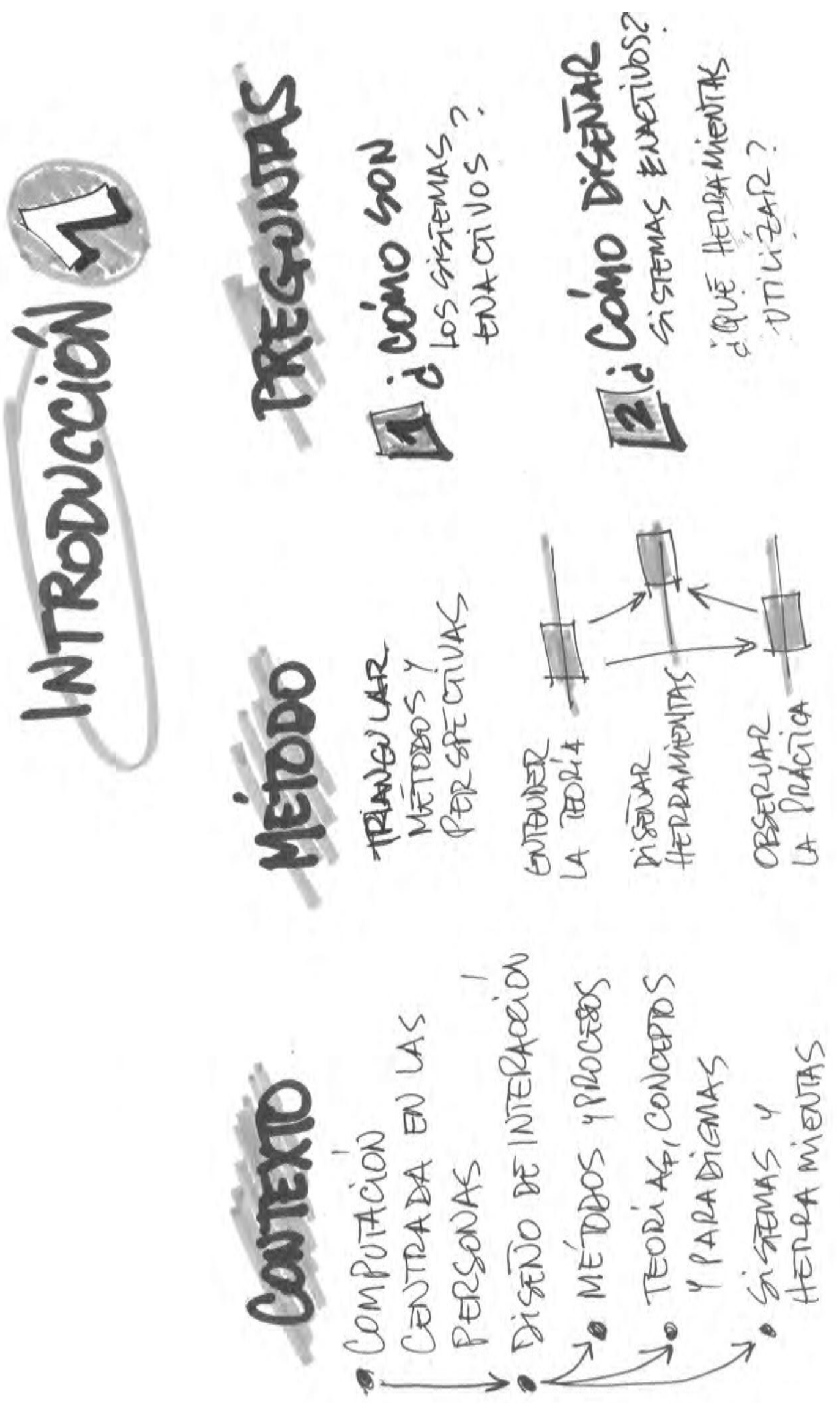





\section{Cognición enactiva en $\mathrm{HCl}$}

The theory of embodied cognition offers us new ways to think about bodies, mind and technology. Designing interactivity will never be the same

— David Kirsh

Embodied cognition and the magical future of interaction[128]

¿Por qué un capítulo sobre cognición en una tesis de Ciencias Informáticas? En primer lugar, vale decir que la ciencia cognitiva ha estado desde los comienzos conectada con los estudios en HCI de manera explícita. Como muestra, basta citar los textos fundacionales The psychology of human computer interaction por Stuart Card, Thomas Moran y Allen Newell[34] y HumanComputer Interaction: Psychology as a Science of Design por John Carroll[36], entre muchos otros. Esta tradición se basó inicialmente en la perspectiva clásica del procesamiento de la información, que mapea la psicología del usuario de manera bastante directa a los tipos de modelos de procesamiento de la información que utilizan las computadoras[174]. En la actualidad, tanto los avances teóricos en la ciencia cognitiva, como las tendencias recientes en el diseño de sistemas interactivos, están llegando mucho más allá de esa perspectiva clásica del procesamiento de la información.

El desarrollo de programas de investigación tales como la computación ubicua[244], sensible al contexto[49] y vestible[157] o la más reciente Internet de las Cosas[89] plantea nuevos requerimientos de interacción entre las personas y los dispositivos basados en software y hardware. En este sentido parece necesario disponer de mejores herramientas conceptuales para abordar la generación y el desarrollo de ideas para los nuevos sistemas interactivos.

En los estudios de HCI y la Ingeniería de software ya se ha consolidado la idea de que un proceso centrado en las personas es la mejor manera de abordar el diseño y desarrollo de sistemas interactivos[242], un proceso que tome en cuenta cómo son realmente quienes utilizarán el sistema, cómo actúan, cómo se relacionan con el mundo, etc.

Por estas razones es relevante presentar una introducción a los conceptos básicos de las nuevas teorías de cognición aplicados al diseño de sistemas digitales interactivos. 


\subsection{La cognición corporizada para el diseño de sistemas interactivos}

Con el surgimiento de nuevos ámbitos para el diseño de sistemas interactivos, como la realidad aumentada, la computación ubicua, la interacción tangible, la computación vestible y sensible al contexto, somos testigos de una tendencia sin precedentes dentro de la interacción entre el hombre y los sistemas hacia la integración de las formas físicas y los procesos digitales. Muchos aspectos teóricos que emergen de estos campos de diseño y como consecuencia los desafíos que los diseñadores enfrentan, están estrechamente relacionados con los temas discutidos en la Cognición Corporizada que puede proveer una base teórica relevante para el diseño de esta nueva clase de formas artificiales integradas[105, 56].

La idea central en la Cognición Corporizada (CC, en adelante) es que la corporalidad y el modo en que se captan las cosas y se interactúa con ellas influye en la cognición, incluso hasta formar parte de la misma. Por ejemplo, Thelen considera que "la cognición depende del tipo de experiencias que surgen de tener un cuerpo con capacidades perceptivas y motoras particulares que están inseparablemente vinculadas y que en conjunto forman una matriz dentro de la cual se combinan el razonamiento, la memoria, la emoción, el lenguaje y otros aspectos de la vida mental"[231].

Dentro de los múltiples estudios de la CC se pueden identificar variaciones que incluyen desde considerar la cognición como un fenómeno distribuido de representación y computación o una práctica socialmente situada hasta un acoplamiento sensorio-motor.

En relación con las ciencias informáticas y la ingeniería de software estas visiones cambian el foco desde las nociones de computación, representación, input, output, estado, memoria, problema, solución e información hacia un vocabulario menos familiar con nociones como práctica, situacionalidad, affordance, acoplamiento, habilidad, coordinación, enacción. Este vocabulario alternativo tiene raíces en la fenomenología, que es un modo diferente de ver el mundo respecto de la perspectiva científica "standard". Varios de los investigadores en CC adhieren a la perspectiva fenomenológica y rechazan explícitamente las teorías objetivistas[170, 62]. Otros en cambio definen la CC explícitamente dentro de la perspectiva objetivista, alejándose de posturas radicales [40]. La discusión entre fenomenología y objetivismo es compleja y excede el marco de esta tesis. Este trabajo asume que ambas visiones del mundo arrojan luz sobre la CC y sobre el tema de cómo diseñar sistemas interactivos para ella.

\subsubsection{Una reacción al cognitivismo}

La CC busca una mejor comprensión sobre la forma en que las personas dan sentido al mundo mientras interactúan con él y rechaza el paradigma dominante que la precede, conocido como Cognitivismo [217, 174, 70]. De acuerdo con esta posición previa, el conocimiento consiste esencialmente en representaciones almacenadas en el cerebro y todas las representaciones juntas forman un modelo mental del mundo exterior. El cerebro realiza computaciones sobre 
estas representaciones que permiten seleccionar una acción apropiada, dado el adecuado input perceptual. En otras palabras, la mente es esencialmente una computadora. En algunas ocasiones el cognitivismo se conoce como una aproximación de procesamiento de información. La representación gráfica por antonomasia de este modelo es el dibujo incluido en la obra de Card, Moran y Newell que se muestra en la Figura 2.1.

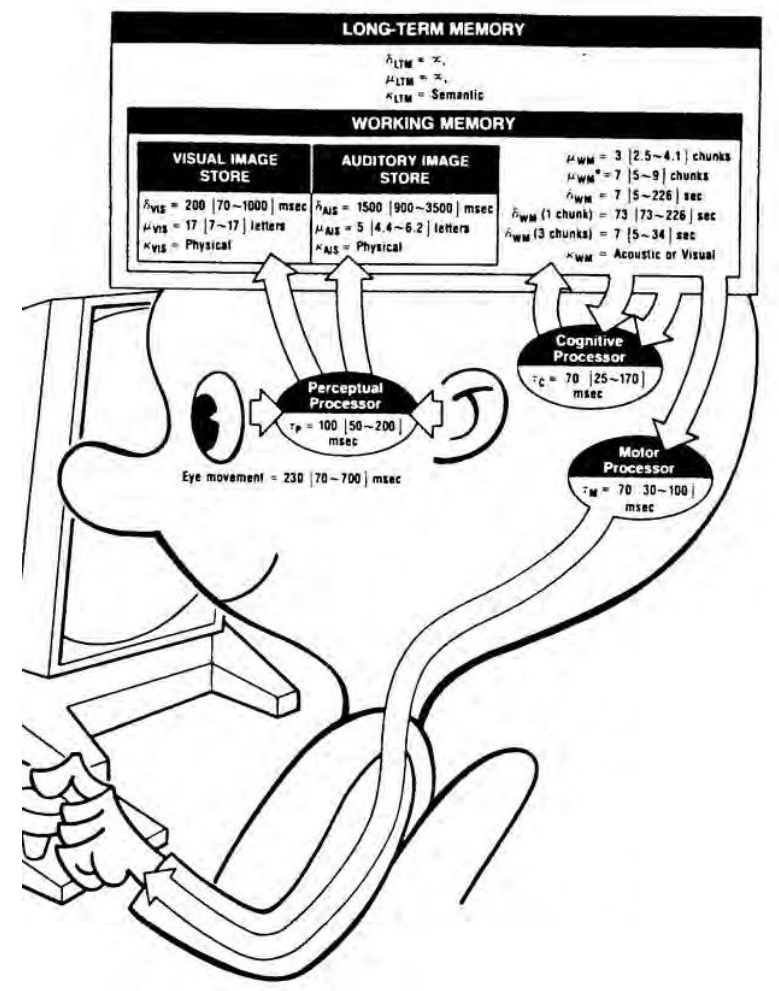

Fig. 2.1.: El modelo del Procesamiento Humano de Información de [34]

La CC rechaza esta división cartesiana entre la representación interna y el mundo externo, y le confiere un lugar especial al cuerpo (que de alguna manera no está ni "adentro", ni "afuera" en esa dualidad). Con el cuerpo como estructura de sustento, para la CC la cognición es una estabilidad temporal en un proceso auto-organizado, sostenido por una red de muchos elementos interactuantes que se extiende más allá del cerebro y alcanza las restricciones muculo-esqueléticas del cuerpo, los niveles homeostáticos (que vinculan con las emociones[46]), el acoplamiento sensorio-motriz, la emergencia en acciones y el acoplamiento entre las posibilidades de acciones del cuerpo por un lado y la estructura en el entorno físico y social por la otra $[78,39,112]$.

En resumen, el cerebro, el cuerpo y el entorno y en particular las relaciones entre ellos en conjunto forman parte del sistema cognitivo, del mecanismo que hace que la cognición ocurra. La cognición ocurre en la acción, es algo que se realiza en el mundo mismo, como un aspecto del comportamiento real en situaciones concretas y que no se puede entender como un razonamiento abstracto dentro de un modelo descriptivo [38], separado de circunstancias concretas[223]. Esto da al cerebro un rol diferente, de "facilitador de tráficos" en la interacción en curso, más que un planificador central[223]. 


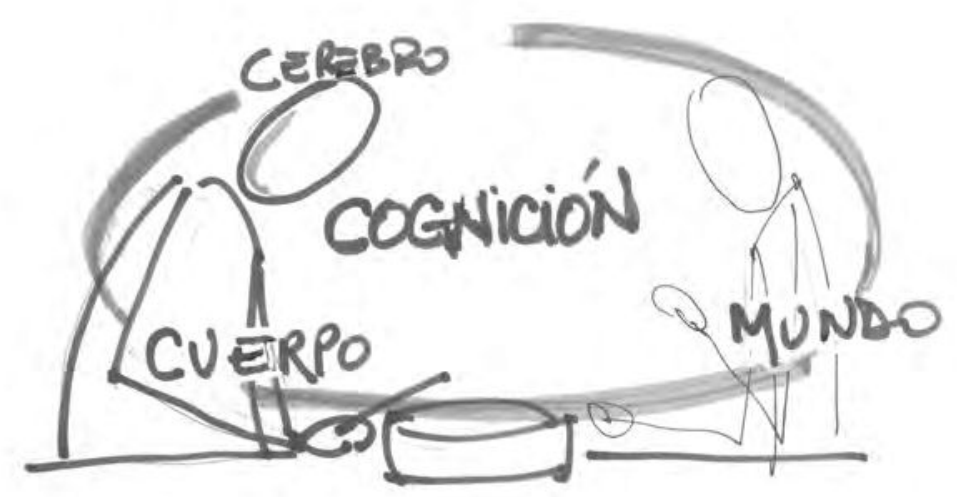

Fig. 2.2.: Esquema de Cognición Corporizada, adaptado de Hummels[109]

Existen en la literatura diferentes formas de abordar el estudio de la CC. En particular tomamos aquí la organización sugerida por van Dijk[52] en tres variantes con creciente énfasis en los aspectos corporizados de la cognición y consecuencias diferentes para el diseño de sistemas digitales interactivos: a) la Computación y Representación Distribuidas (CRD), b) la Práctica Socialmente Situada (PSS) y c) el Acoplamiento Sensorio Motor o Enacción (ASM).

\subsubsection{Computación y representación distribuidas (CRD)}

Donald Norman mostró que las personas a menudo confían en el conocimiento en el mundo en lugar del conocimiento en la cabeza[176]. Su trabajo se enfocó principalmente en la representación externa: la forma en que el entorno es una forma de "memoria" físicamente presente, de modo que uno no tiene que depender de la memoria interna. Por ejemplo, Norman describe su hábito de poner su bolso contra la puerta principal para no olvidarse de llevarlo al trabajo. Podemos ver esto como un primer paso para ir más allá de las teorías que asumen que todo el conocimiento se almacena internamente en el cerebro, reconociendo el valor de "tropezar con" un poco de información (por ejemplo, un bolso) en el lugar y momento correctos (en la puerta, saliendo a trabajar). Esto puede reducir la carga cognitiva ${ }^{1}$ y ayudar a centrarse en cosas relevantes para la tarea en cuestión.

Cognición distribuida El conocimiento en el mundo de Norman pertenece a un marco teórico denominado cognición distribuida. La idea básica es que tanto la representación de la información como su procesamiento (computación), se distribuye entre el cerebro y el entorno. Edwin Hutchins, uno de los principales defensores de este punto de vista, basó su teoría en análisis etnográficos de los comportamientos coordinados a bordo de un gran barco de la marina. Según Hutchins, el comportamiento inteligente a bordo de un barco (lo llamó "cognición en la naturaleza"2) hace que una ubicación se corrija en una carta de navegación como un logro

\footnotetext{
${ }^{1}$ Carga cognitiva: las demandas de recursos de memoria de trabajo para aprender y resolver una tarea o problema de aprendizaje[228]

${ }^{2}$ cognition in the wild
} 
cooperativo y coordinado de un sistema formado por cerebros y cuerpos de varias personas, así como de la estructura física de las diversas herramientas utilizadas[112]. Hollan y otros proponen un conjunto de principios básicos que describen cómo las personas "establecen y coordinan diferentes tipos de estructuras en su entorno", cómo las personas "descargan el esfuerzo cognitivo al medio ambiente cuando sea práctico" y cómo la organización social mejora aún más este proceso de balanceo de carga cognitiva[99].

La explosión de PostIts y el uso intensivo de pizarras con marcadores durante el desarrollo de software para auxiliar el pensamiento de diseño es una verificación concreta y consecuencia práctica de estas teorías.

Computación distribuida La noción de computación distribuida es un concepto más activo que complementa la representación distribuida de Norman. La computación distribuida significa no solo almacenar información y recuperarla del entorno físico; muestra lo que una persona puede hacer en el entorno para resolver problemas "en acción", es decir, cómo las personas utilizan la estructura en el entorno para realizar el cálculo. Por ejemplo, las personas admiten el razonamiento usando referencias deícticas (es decir, señalando objetos que son directamente visibles y usando frases como "este" y "allá"). Usando referencias deícticas, el conocimiento implícito no necesita ser explícito: en lugar de mostrar uno ve directamente[15, 39].

David Kirsh plantea la distinción entre acciones pragmáticas y epistémicas[130]. Las pragmáticas contribuyen directamente a lograr algún estado objetivo, mientras que las acciones epistémicas tienen como objetivo reorganizar el mundo de tal manera que las acciones subsiguientes se vuelvan más fáciles. Sacar un lápiz y papel sería una acción epistémica que hace que un cálculo difícil sea menos difícil, ya que el lápiz y el papel permiten al usuario hacer el cálculo en papel en lugar de hacerlo de memoria. En general, los objetos externos juegan un papel importante en tales acciones epistémicas. Según Hutchins[112], el pensamiento de la gente hace uso de la forma en que los recursos disponibles externamente, ya sea herramientas diseñadas específicamente para la tarea, u objetos de reclutamiento ad hoc, se encargarán de una parte del pensamiento para ellos. En otras palabras, no tiene que saber todo lo necesario para resolver un problema, lo que debe saber es cómo operar la herramienta que le resuelve el problema. Esto es precisamente lo que hace que muchas herramientas estén a la mano: uno puede descargar parte de la carga cognitiva sobre el medio ambiente.

Andamiaje cognitivo El filósofo Andy Clark califica de "andamios cognitivos" tales herramientas diseñadas y apoyos reclutados ad hoc en el entorno, en referencia a la teoría de Vygotsky sobre el uso de mecanismos de andamiaje en educación[243]. Vygotsky explicó cómo los maestros y los padres pueden proporcionar a los niños el tipo de retroalimentación justo en el momento adecuado durante sus actividades de aprendizaje exploratorio, de modo que puedan rendir mejor de lo que podrían al intentarlo solos[243]. En línea con la cognición distribuida, Clark muestra que también las manipulaciones de los objetos físicos pueden proporcionarnos esas señales y estructuras de apoyo externas, es decir, andamios cognitivos, que nos permiten 
resolver problemas de maneras que habrían sido mucho más difíciles utilizando métodos puramente cerebrales[39].

Entornos pre-estructurados Generalizando desde la función de andamiaje de objetos individuales, podemos decir que las personas en general tienden a vivir en "mundos diseñados y pre-estructurados para la vida"[1] dentro de los cuales las acciones relacionadas con la tarea consumen menos procesamiento cognitivo de lo que sería esperado si la misma tarea se realizaría aislada de su contexto regular. Por ejemplo, las tareas a menudo tienen una ubicación física dedicada (la cocción se realiza en una cocina), que está separada de otras ubicaciones de tareas, para que las tareas no se mezclen. Las herramientas y los materiales necesarios para una tarea se encuentran juntos en la ubicación de la tarea. Las actividades de mantenimiento de rutina en segundo plano (limpieza, organización física de las cosas en grupos) ayudan a hacer las tareas más fácilmente, y así sucesivamente[1]. En muchos de estos casos, las restricciones espaciales, por ejemplo, el hecho de que uno no puede estar en más de un lugar al mismo tiempo, se utiliza efectivamente como un medio para organizar sus acciones.

\subsubsection{Práctica socialmente situada (PSS)}

Un cuerpo de investigación que se originó en la antropología cultural y las ciencias sociales, con vínculos con el trabajo cooperativo apoyado por computadora (CSCW)y el Diseño participativo investigó la forma en que las herramientas y los aspectos del entorno en general se incorporan a las prácticas socialmente situadas de las personas[223, 56, 38]. La tendencia general de este trabajo es una que se aleja de la cognición como una solución de problemas racional y distante, y defiende, en cambio, el valor cognitivo de las circunstancias concretas y las diversas oportunidades de acción que pueden surgir "en la acción”[56].

Planes situados Como una de las principales defensoras de esta línea de investigación, Lucy Suchman sostiene que las personas no crean primero internamente un plan de acción que luego se ejecuta. En cambio, una persona actúa ante circunstancias concretas en el mundo y, al hacerlo, sus planes evolucionan de manera ad hoc e improvisada. Como parte de esta acción situada, las personas crean, adaptan, reorganizan y hacen uso de muchos tipos de artefactos disponibles en el ambiente[224].

Contextos de mundo real Al igual que en muchos estudios de cognición distribuida, el método principal es la observación etnográfica, reconociendo que la cognición "en la naturaleza" tiene su propia estructura particular impulsada por los detalles del contexto localmente disponible, que no se puede estudiar en experimentos de laboratorio. Como ejemplo, Ceci y Roazzi [37] muestran en su trabajo etnográfico cómo los niños vendedores ambulantes brasileños exhiben habilidad aritmética para hacer negocios de dinero en las calles, mientras que esos mismos niños no pudieron resolver (formalmente) los mismos problemas cuando se les presentó la tarea en un entorno de aula. Los vendedores ambulantes se basan fundamentalmente en ciertas señales locales disponibles en el contexto social y material particular. 
El uso de artefactos en contexto social Tanto el enfoque PSS como el CRD enfatizan cómo los artefactos físicos y las interacciones sociales entre las personas soportan la cognición. Ambos utilizan métodos etnográficos para investigar el comportamiento en contextos reales y cotidianos. Ambas líneas de investigación utilizan a veces el término "cognición situada". Sin embargo, donde CRD trata a las personas y los objetos físicos esencialmente como unidades computacionales en una red de procesamiento de información distribuida[112], la investigación de PSS enfatiza cómo los artefactos "se toman" como elementos significativos dentro de un proceso social entre personas. Como señala Paul Dourish: "El conocimiento se representa como algo que se puede extraer, transferir, intercambiar, almacenar, indexar, recuperar y gestionar (...) pero la verdadera piedra angular del conocimiento son las personas. (...) se debe hacer una distinción entre la idea de que el conocimiento puede representarse y almacenarse y la visión de que debe contextualizarse y hacerse relevante para la configuración en la que se encuentra para ser aplicado. El significado no es inherente a la información; la información se hace significativa"[56].

En otras palabras, la cognición distribuida ve las interacciones sociales y los andamios físicos como formas de procesamiento de la información, mientras que para la investigación de PSS, los andamios cognitivos solo pueden existir como parte de una situación social. Sin interrelaciones sociales, roles, normas, cultura, política y cosas por el estilo, no habría ningún significado en absoluto en el uso de artefactos físicos[223].

Artefactos representacionales En la cognición distribuida, los medios físicos como un texto en un pedazo de papel, una imagen o un mapa, se consideran medios disponibles localmente para almacenar el conocimiento "en el mundo", liberando al cerebro de la carga computacional. La PSS pone el énfasis en que dichos artefactos representativos (por ejemplo, las tiras de cartón utilizadas por los controladores de tráfico aéreo) no se usan simplemente como medios de almacenamiento, sino que funcionan como componentes activos en la forma en que el trabajo se organiza entre las personas[223, 38]. La función de las representaciones abstractas no es servir como especificaciones para las interacciones locales, sino orientarnos o posicionarnos de una manera que nos permita, a través de las interacciones locales, explotar algunas contingencias de nuestro entorno y evitar otras[223].

\subsubsection{Acoplamiento sensorio-motor o enacción (ASM)}

Con la construcción de robots físicos que aprenden a navegar en entornos reales se encontró que, como sostiene Suchman[223] la planificación y modelado interno del mundo en realidad no compite muy bien contra la creación interactiva de acoplamientos funcionales entre las capacidades sensorio motrices del robot y la estructura contingente del entorno. Es lo que sostuvo Rodney Brooks en su famosa frase: "Cuando examinamos un nivel de inteligencia muy simple encontramos que las representaciones y modelos explícitos del mundo simplemente se interponen. Parece ser mejor usar el propio mundo como su modelo".[30] 
Esta noción de acoplamiento que también aparece en la versión de Cognición situada socialmente de la CC se usa aquí fundamentalmente para denotar una relación entre la percepción y la acción, a través del mundo: durante la interacción del organismo con su entorno, se forma de manera gradual un acoplamiento estable entre la percepción y la acción con influencias en ambos sentidos, la acción influye sobre lo que se percibe a continuación mientras que lo percibido influye en la siguiente acción, de una forma cíclica[18].

Dinámicas del acoplamiento Es importante enfatizar la naturaleza dinámica del acoplamiento: ese acoplamiento sólo existe como un aspecto de acciones concretas que realiza el robot, no es información almacenada en el entorno ni en el robot. Estos acoplamientos sensorio-motores son estabilidades dinámicas creadas y sostenidas en el tiempo: existen puramente como patrones dentro de interacciones continuas con el entorno. Clark[39] da un buen ejemplo de la práctica humana cuando describe cómo atrapa la pelota un jardinero en baseball. En lugar de calcular primero la posición a alcanzar y la velocidad de carrera para atrapar la pelota, el jugador simplemente empieza a correr mientras se asegura que en su campo visual la pelota mantiene una línea horizontal recta. Haciendo ajustes continuos de la velocidad para mantener esa línea recta, el jugador se garantiza que estará justo en el punto y en el momento adecuado para atraparla[39]. Clark concluye que en ese acoplamiento sensorio motor la concepción de qué significa la tarea cognitiva debe ser cambiada. La tarea ya no es analizar, de manera separada y sobre la base del input perceptual "qué pasa afuera", más bien "la tarea (del sistema cognitivo) es mantener algún tipo de coordinación entre los mundos interno y externo"[39].

Acoplamientos hacia un control estable Los sistemas corporizados como los robots de Brooks son exitosos precisamente porque son capaces de crear por medio de un proceso iterativo de acciones exploratorias un control gradualmente estabilizado sobre el entorno. En ese sentido, el acoplamiento es siempre un proceso de aprendizaje evolutivo[232]. En otras palabras, el desarrollo de un acoplamiento sensorio motor se puede ver como el desarrollo de una "habilidad": un modo exitosos de hacer cosas lo suficientemente estable para emerger cada vez que se necesita. Este aspecto evolutivo es a menudo oscurecido en la ingeniería de robots ya que se lo consigue a fuerza de muchos intentos de ensayo y error y finalmente se cablea en las conexiones entre sensores y actuadores. Sin embargo, aún en estos casos podemos ver que los robots terminan desarrollando a través de su actividad interactiva acoplamientos que no fueron diseñados[39].

La práctica de la interacción enactiva implica un desarrollo de habilidades que emergen en el tiempo a través de una interacción continua entre el usuario y el artefacto. En la medida que las habilidades cognitivas se desarrollan, se produce una regularización creciente de los patrones de acción del cuerpo y de la dinámica de interacciones cuerpo-objeto. La Figura 2.3, tomada de del trabajo de Armstrong sobre instrumentos musicales enactivos [7] modela este proceso. Habilidad refiere a las cognitivas, motores y perceptuales. Además es indicador de la capacidad de desarrollo de coordinaciones entre las tres. Intención representa el mapeo entre la intencionalidad humana y el instrumento, mientras Reacción representa el mapeo de las reacciones del instrumento a la persona. 


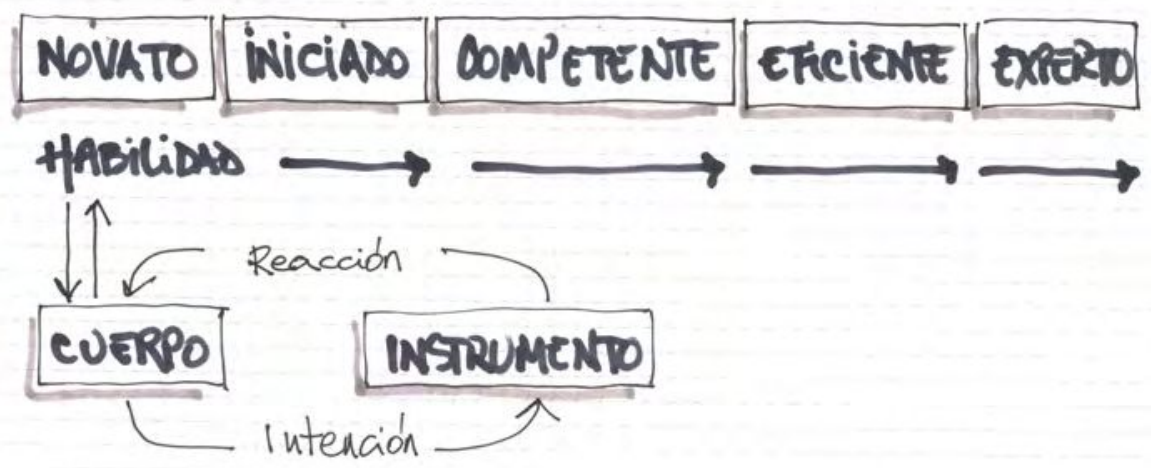

Fig. 2.3.: Evolución del flujo de interacciones enactivas

Awareness La actividad corporizada se puede definir como un estado del ser que consiste en mezclar la acción y la conciencia (awareness). Hay un flujo continuo entre percibir y actuar (en el sentido propuesto por Csikszentmihalyi[44]). En la figura 2.5 los bordes entre la percepción, el razonamiento y la acción (de la figura 2.4) se colapsan y la continuidad entre percibir y actuar se indica por la etiqueta "acción guiada por percepción". Corresponde con la noción de instrumento "ready-to-hand" de Heidegger[96]. La mezcla de acción y conciencia interrumpe la desconexión entre la persona y la computadora como factor de la experiencia. En este modelo de interacción no existe un foco explícito en los mecanismos conscientes, el aspecto que distingue al modo ready-to-hand es que es un modo de comportamiento inconsciente e irreflexivo.

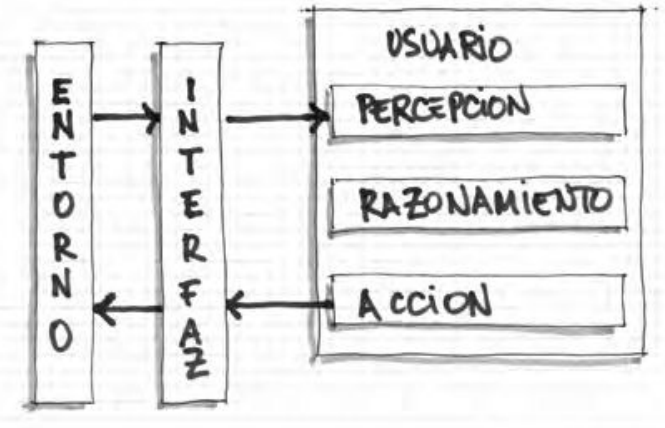

Fig. 2.4.: El modelo cognitivista de interacción

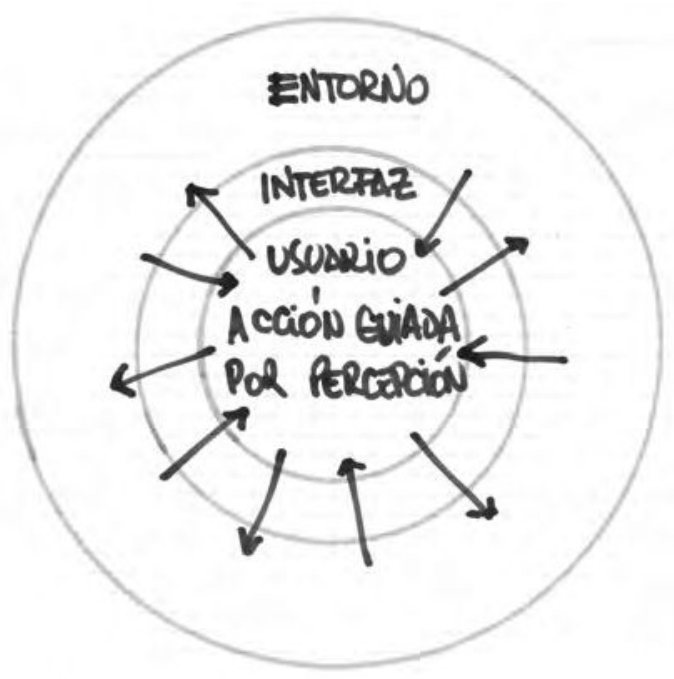

Fig. 2.5.: Modelo enactivo de interacción

El modelo enactivo de interacción representa una forma idealizada del modo de interactuar con las cosas, sin embargo no representa la suma total de la práctica de interacciones. De acuerdo con la teoría de Merleau-Ponty sobre la "doble corporización" la práctica de la interacción involucrará varios momentos de acción corporizada y de comprensión offline. Incluso estos modos pueden ser diferentes maneras de interactuar con el mismo objeto. En particular durante 

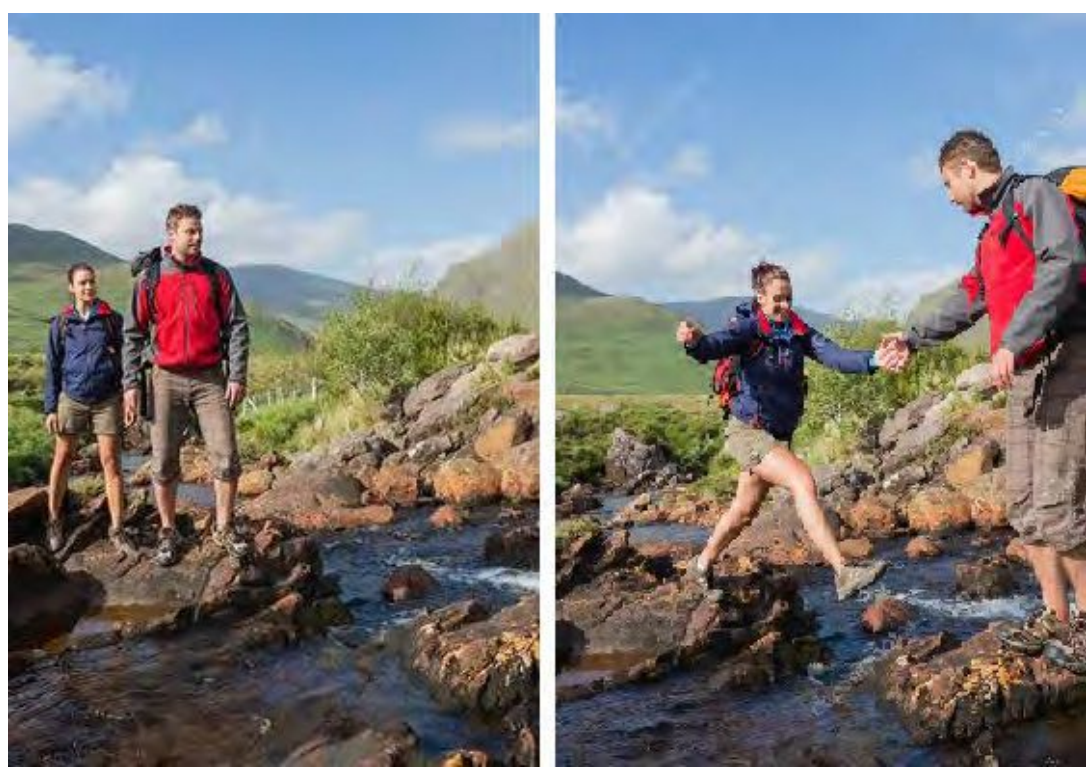

Fig. 2.6.: Las affordances no son propiedades del objeto, sino relaciones percibidas en el contexto. El mismo curso de agua puede parecer "cruzable" o no dependiendo del contexto y la situación

la etapa de aprendizaje del uso de un artefacto, el mismo estará "present-at-hand". Luego con el uso constante, el usuario internalizará la dinámica de interacción y el artefacto "desaparecerá" en el uso convirtiéndose en "ready-to-hand".

Affordances El concepto de affordance ${ }^{3}$ juega un papel importante en esta perspectiva. El psicólogo de la percepción James Gibson fue uno de los primeros en enfatizar que la cognición no es simplemente analizar un mundo pre-dado sino una forma de acoplar entre la percepción y la acción. Una affordance[77] se puede ver como la forma en que el mundo muestra al perceptor qué acciones puede prestar sobre la base de un acoplamiento sensorio motriz estable. Por ejemplo, mientras corremos a una cierta velocidad, un río puede parecer "cruzable" dependiendo tanto del ancho del río, como de las capacidades de salto del corredor y la velocidad actual de la carrera. El mismo río puede aparecer "no cruzable" si uno se para quieto en frente de él, en lugar de correr hacia el mismo a gran velocidad(ver Figura 2.6). Esto significa que la forma en que uno ve el mundo depende de cómo esté actuando en él y la acción y la percepción se acoplan en el tiempo como coordinaciones. La percepción deaffordances es enactiva[220]. Cada vez que el individuo se mueve físicamente a través del entorno esa acción cambia las características del entorno que están perceptualmente disponibles y puede revelar nuevas relaciones y oportunidades para interactuar.

El concepto de affordance ha sido sujeto a un debate intenso. Como un aspecto del acoplamiento sensorio motriz podemos verlo como la forma en la cual uno ve directamente qué hacer, lo que es un efecto directo de la forma en que la acción y la percepción se acoplan en el tiempo en las interacciones con el entorno. En cualquier caso, no es un mensaje codificado en la forma

\footnotetext{
${ }^{3}$ El término inglés affordance podría traducirse en el campo de diseño como "prestaciones". En la literatura en español de HCI y UX se utiliza sin traducir
} 
física de un artefacto que comunica al usuario "cómo se debería utilizar" (tal como lo presentó Norman a la comunidad de diseñadores al principio[176]).

Las herramientas cambian nuestro cuerpo y nuestra percepción Otro de las consecuencias de un abordaje de acoplamiento sensorio motor para el diseño de sistemas interactivos digitales es la incidencia que las herramientas tienen sobre nuestro cuerpo, nuestra percepción y nuestra concepción de lo que es posible. Cuando utilizamos una herramienta, sus dimensiones (o al menos su punto final) pasan a formar parte de nuestro cuerpo en funcionamiento. Esto implica además que las herramientas remodelan el espacio peripersonal y lo extienden al menos unos centímetros. ¿Podrán los sistemas interactivos digitales extenderlo a terrenos geográficos remotos? Cualquiera que diseña trabaja con un sentido de dónde termina el cuerpo y comienza el ambiente. Si las herramientas pueden ser absorbidas, este límite del cuerpo se convierte en un elemento a negociar en el diseño. La percepción se ve alterada por nuestra habilidad en el uso de herramientas. Una colina parece más empinada cuando uno lleva una mochila pesada. Cuando una herramienta se absorbe en nuestro esquema corporal, nuestra percepción de la altura, la distancia y las magnitudes relacionadas cambian. El esfuerzo adicional de cargar peso afecta la percepción. Ya vimos que en el enfoque de las affordances de Gibson, el mundo percibido se define en relación con el repertorio de acción de quien lo percibe. Cambie ese repertorio y cambiarán las posibilidades que un agente pueda encontrar. Con una herramienta, el repertorio de acciones se incrementa para incluir acciones habilitadas por herramientas, por lo que debería haber nuevos recursos para percibir. La habilidad también es un factor. La habilidad de una persona para usar una herramienta determina en parte las condiciones en las que se puede usar con éxito. Un carpintero experto puede usar un cincel de manera efectiva en más situaciones que un novato. En consecuencia, la habilidad afecta lo que un agente verá en una situación dada. Los usuarios expertos en herramientas detectan más características relevantes de la herramienta y las posibilidades relacionadas con ella que los usuarios menos expertos.

Un aspecto interesante relacionado con esto es la idea de paisaje enactivo propuesta por Kirsh[128], definido como la estructura que un agente co-crea con el mundo cuando actúa de una manera orientada hacia un objetivo. Es decir captura la naturaleza del mundo percibido que depende de la meta o actividad, los recursos que se activan en un entorno debido a las capacidades actuales del agente y sus intereses. La idea de un paisaje enactivo es un concepto útil en el diseño de nuevas herramientas o sistemas porque cuando una persona tiene una herramienta en sus manos, su paisaje activo se remodela: las personas perciben más cosas y propiedades cuando trabajan con una herramienta que cuando trabajaran sin ayuda. En cierto sentido, los diseñadores crean nuevos paisajes enactivos mediante el diseño de herramientas. Crean nuevas formas de involucrar al mundo.

Enacción El concepto de affordance está muy relacionado con el de enacción propuesto por Humberto Maturana y Francisco Varela ${ }^{4}$. En The embodied mind[239], Varela inicia su

\footnotetext{
${ }^{4}$ Enacción (enaction en inglés, es un término propuesto por los biólogos chilenos Humberto Maturana y Francisco Varela[163] a partir de la expresión española "en acción"
} 
registro de la cognición con una observación sobre la principal fuerza conductora de cualquier organismo vivo: mantenerse a sí mismo, en un loop continuo de interacciones con su entorno. Este proceso, llamado "autopoiesis"[163] es la base para la forma en que el organismo encuentra significado en el mundo. Varela llama a este uso "enacción": un proceso mediante el cual un ser vivo crea y mantiene su propio dominio de significación en generar y mantener su propia auto identificación como un organismo corporizado.[234]

La enacción subraya de qué forma dar sentido al mundo está asentado en el acoplamiento sensorio motor: la cognición concebida fundamentalmente como generación de contenido surge del acoplamiento sensorio motor entre el organismo y el entorno[234]. Es decir que percibimos el mundo siempre en términos de cómo ese mundo encaja en el proceso de nuestra auto sustentación. Como consecuencia, las cosas se muestran en términos de lo que podemos hacer con ellas, lo que básicamente es la idea de affordance.

En el curso del auto mantenimiento continuo, los organismos habitan los nichos ecológicos apropiados, es decir, los entornos adecuados, moldeados por la propia historia evolutiva y de comportamiento del organismo. En otras palabras, el "entorno" que habitamos no existe antes de que lo habitemos: cada criatura, en función de sus capacidades sensoriales y su repertorio de comportamiento, se manifiesta tanto en sí misma como en su entorno, a través de sus acciones: su Umwelt[236]. Para algunos teóricos, esto implica que "el mundo" que llegamos a entender no existe como una realidad objetiva fija: los acoplamientos sensoriomotores son generativos, el proceso que conduce al acoplamiento sensorimotor produce o enactúa (co-crea) el mundo: "los intercambios con el mundo son intrínsecamente significativos para el conocedor (...) el significado se encuentra en los compromisos en los que un organismo construye su mundo"[50]. Esta concepción relativista de "el mundo" es la versión más radicalizada de las teorías enactivas y algunos autores, como Andy Clark, rechazan explícitamente su adhesión[39]).

\subsection{Implicancias para el diseño de interacciones}

\section{enactivas}

En esta sección presento algunas de las implicancias para el diseño del análisis previo, dejando claro que acordamos con la crítica de Dourish sobre esta expresión: la idea es revelar "modos de pensamiento" que podrían "dar forma a la estrategia de investigación (y de diseño) más que presentar restricciones u oportunidades encontradas en un particular ejercicio de diseño" [55].

\section{Problemas de diseño desde una perspectiva CRD}

La interacción tangible $[69,237,105,113]$ es una tendencia reciente en el diseño de interacción que apunta a apoyar exactamente los tipos de estrategias de andamiaje que se describen en el marco de la CRD. La versión clásica de Hiroshi Ishii y sus colegas consiste en controles de interfaz físicos que se conectan a información almacenada digitalmente[113]. 
Consideremos dos de sus primeros ejemplos, transBOARD y metaDESK, ambos presentados en el clásico paper Tangible bits[114]. TransBOARD es una pizarra física mejorada digitalmente, que absorbe información del mundo físico, transforma estos datos en bits y los distribuye en el ciberespacio (Figura 2.7). MetaDESK es una "superficie interactiva bidireccional, que abarca espacios físicos y virtuales". MetaDESK contiene varios objetos tangibles, como activeLENS (Figura 2.9) y passiveLENS (Figura 2.8), que se pueden usar para navegar contenido digital de varias maneras.

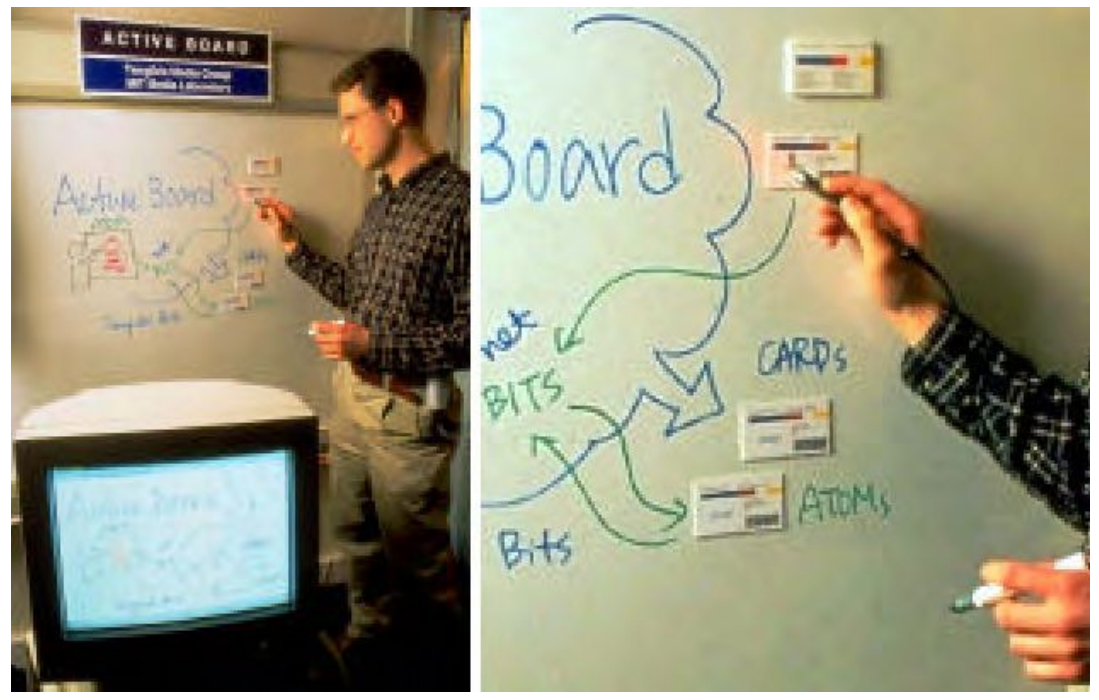

Fig. 2.7.: Sistema transBOARD con sus "hipertarjetas" de Ullmer y Ishii[238]

El modelo conceptual básico no ha cambiado mucho para los sistemas "tangibles" que se han propuesto desde entonces. Se asume primero que existe un cierto "mundo digital" (lo que Ishii y Ullmer llaman "ciberespacio"). La pregunta de diseño se centra en cómo el usuario puede acceder a este mundo. El objetivo es, por lo tanto, crear una interfaz a un mundo virtual, repleta de información digital. Enmarcados de esta manera, los principios de CRD apoyan la idea de que los accesorios tangibles adecuados reducirán la carga cognitiva y, por lo tanto, darán como resultado una interfaz más fácil de usar que la mayoría de las interfaces gráficas o de línea de comandos. En otras palabras, se espera que los phicons (íconos físicos) de Ishii y Ullmer superen

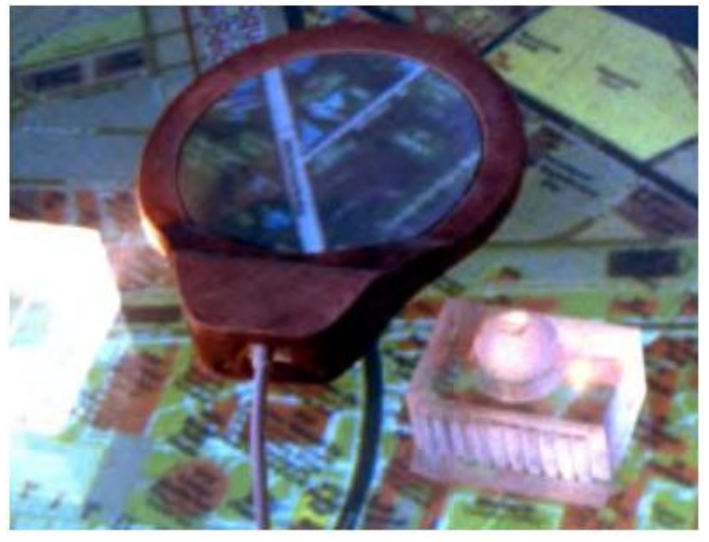

Fig. 2.8.: Passive Lens en MetaDesk

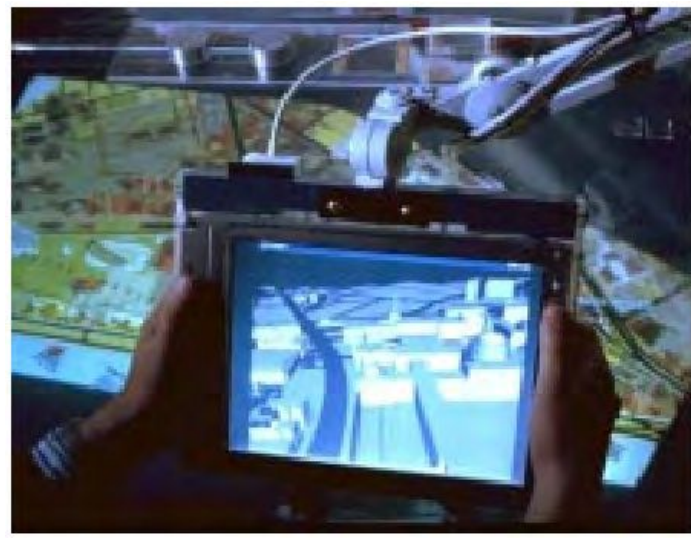

Fig. 2.9.: Active Lens en MetaDesk 
a los íconos gráficos en las medidas de usabilidad, ya que explotan las formas naturales en que las personas usan los objetos físicos (incluido nuestro propio cuerpo) para la representación y el cálculo. La idea clave de las TUI es dar formas físicas a la información digital. Las formas físicas sirven como representaciones y controles para sus contrapartes digitales. TUI hace que la información digital sea directamente manipulable con nuestras manos y perceptible a través de nuestros sentidos periféricos incorporándola físicamente[113]. De hecho, las interfaces tangibles, como transBOARD y metaDESK, pueden proporcionar interfaces fáciles de usar para la información digital. Esta es una de las formas en que la teoría de CC puede ayudar a mejorar el diseño de interacción.

Sin embargo, hay un problema persistente en el fondo. El uso de una representación implica que el significado de la interacción corporizada (es decir, qué significa un objeto tangible, o las manipulaciones que se pueden realizar con él) se basa en el significado de los objetos y procesos digitales a los que se conecta. Independientemente de lo que realmente sustente el significado de esta información digital, en cualquier caso no se basa en las interacciones corporizadas con la TUI, ya que se supone que la información digital ya tiene el significado que tiene, y la TUI funciona en un segundo paso para dar al usuario acceso a esos significados. Como el significado de los estados digitales está predefinido en principio podríamos crear otra interfaz tangible para estos mismos significados. Incluso podríamos crear una interfaz GUI para la misma "información digital" sin cambiar esencialmente los significados involucrados. Cada interfaz puede dar como resultado diferentes cantidades de carga cognitiva, pero a lo que se asigna la interfaz aún sería el mismo contenido. Si concebimos el desafío del diseño en términos de CRD, entonces, no es tanto la tangibilidad de la interfaz lo que importa, sino la cuestión más general de si la interfaz reduce la carga cognitiva.

La naturaleza problemática de la CRD como base para el diseño de sistemas digitales interactivos se refleja además en la interpretación que Norman dio a las affordances, que ha llevado a muchos diseñadores a creer, incorrectamente, que una affordance es un tipo de mensaje, inscrito en la forma física del objeto, que le dice al usuario qué acción puede o debe realizarse. Esa indicación de uso es de hecho una representación. El objetivo de Gibson, por el contrario, era precisamente eliminar la representación y el paso de mensajes, proponiendo en cambio un acoplamiento directo entre percepción y acción[78].

\section{El diseño desde una vista de Práctica Socialmente Situada}

La investigación de práctica socialmente situada hace hincapié en su aspecto social y está muy vinculada con áreas como CSCW. El objetivo es "diseñar sistemas que resuenen con (en lugar de restringir o, peor, refutar) la organización social de la acción"[56]. Se considera que la interacción corporizada con los artefactos físicos desempeña un papel crucial. En esta visión, a diferencia de lo sostenido por Ishii[114], los objetos tangibles interactivos pueden incorporarse en la práctica social y los usuarios mantienen con ellos interacciones significativas aunque no se establezcan conexiones con la información digital. De hecho, la interacción física 


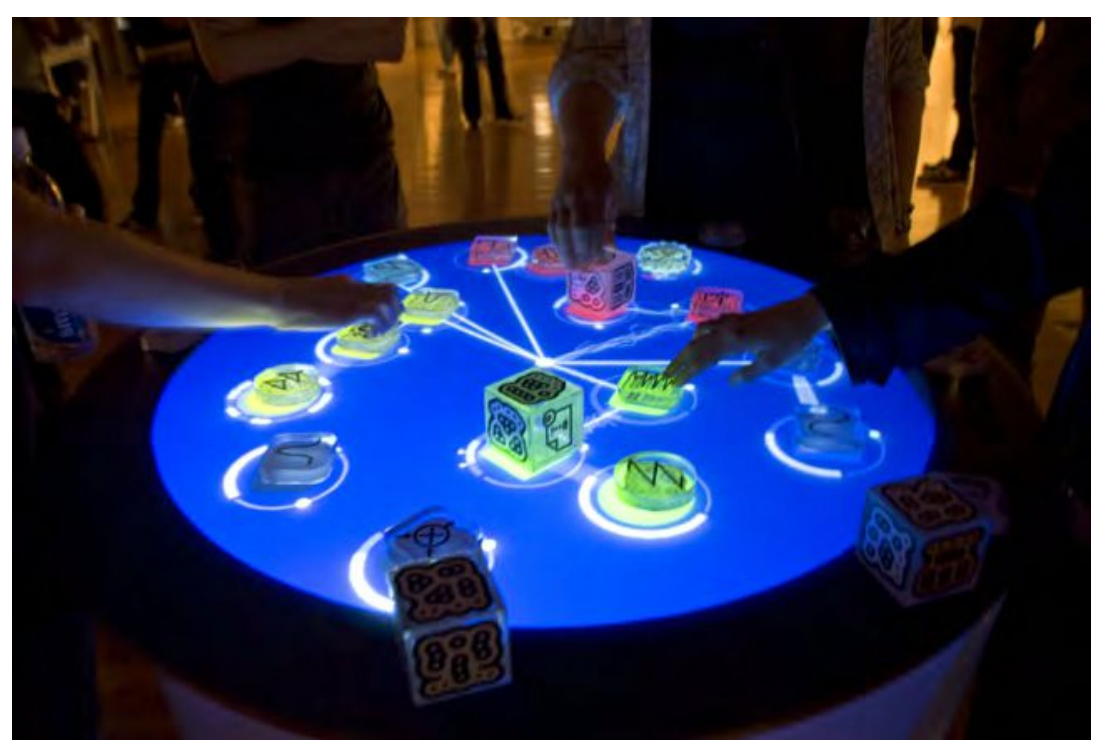

Fig. 2.10.: Reactable

significa que muchas de las acciones con la interfaz tendrán características "offline", dirigidas al entorno social más que al software en la computadora, lo cual invita a pensar que este tipo de actividades son tan relevantes para la interacción como las acciones con efectos inmediatos en el sistema computacional[67]

El objetivo principal del diseño no es que la interacción tangible se asigne "correctamente" a la información digital, sino que, en la otra dirección, la información digital se convierta de manera significativa en la práctica corporizada existente.

También se ha afirmado que las prácticas situadas se ven amenazadas cuando el trabajo se "automatiza" mediante software[211]. Los analistas tienden a ignorar el aspecto concreto y situado de los artefactos de representación tradicionales, como notas de papel o diagramas en una tabla. Al abstraer por primera vez el proceso de trabajo en una descripción formal y luego automatizar grandes partes de este proceso, los ingenieros ignoraron el hecho de que la experiencia real de trabajar en una situación social concreta de personas, involucrarse con diversos artefactos, es precisamente lo que fundamenta la comprensión de las personas para seleccionar acciones apropiadas. El problema subyacente puede ser que los conceptos utilizados para definir la tecnología informática también se utilicen para definir las prácticas humanas que se supone que la tecnología debe apoyar.

Como ejemplo concreto de las diferencias entre una vista PSS y una interpretación de CRD, consideremos Reactable[124]: una mesa interactiva en la que se pueden colocar objetos tangibles que generan o transforman sonido mediante el sistema digital, creando así un instrumento musical (Figura 2.10).

Aunque Reactable no fue diseñado en referencia explícita a la PSS, vemos que muchos de sus elementos resurgen. La importancia de la experiencia musical se crea "in situ" a medida que se 
desarrolla la acción continua de los participantes. Lo que hace el sistema depende fundamentalmente de las interacciones sociales entre los músicos (o entre el músico y la multitud), que coordinan continuamente sus acciones en tiempo real, aprovechando la visibilidad pública de las acciones de los demás. Uno podría describir a Reactable como una aplicación de la teoría de la CRD. Por ejemplo, objetos físicos particulares se asignan a sonidos digitales particulares o manipulaciones de sonido. Sin embargo, sería un error interpretar el diseño únicamente en ese sentido. Reactable no es solo un nuevo tipo de interfaz. Basado en la forma de esa interfaz, también es un nuevo instrumento musical. Su principal valor radica en la experiencia musical que las personas crean con ella. La interpretación musical se negocia socialmente por medio de actividades corporales continuas de los participantes. Y la función de andamiaje de los objetos tangibles solo tiene sentido dentro de la actividad general de coordinación social que el sistema apoya.

Se ha realizado mucha investigación para mostrar cómo los artefactos en su conjunto se combinan con las prácticas y cómo su uso significativo es, por lo tanto, un asunto situado. Sin embargo, la teoría no tiene consejos detallados sobre cómo diseñar para la interacción entre el cuerpo humano, la acción y la forma y el comportamiento de un sistema interactivo. Entonces, la pregunta es: ¿cómo diseñar formularios interactivos para apoyar las prácticas socialmente situadas? Un enfoque podría ser asegurarse de que la función general del sistema esté integrada de manera significativa en la práctica, y luego pensar en cómo diseñar una interfaz fácil de usar para esa funcionalidad. Esto último se puede hacer usando los principios de CRD. Hasta cierto punto, esto es lo que vemos que está sucediendo en Reactable: la funcionalidad en su conjunto se conecta de manera situada a la práctica musical, mientras que cualquier elemento de interfaz en particular es un objeto de control tangible en gran medida en el sentido de Ishii[113]. Otro enfoque relacionado sería copiar literalmente una habilidad práctica existente y su forma física asociada, y usar esto como elemento de interfaz para conectarse a un proceso digital. Por ejemplo, en el tocadiscos digital FinalScratch[131] donde se usa un aparato físico tradicional para controlar muestras de música digital. En ambos casos, se reconoce el valor de la práctica evolucionada y las prácticas existentes no son simplemente "reemplazadas" por procesos digitales.

A través de un proceso de formación de habilidades, uno desarrolla acoplamientos entre sus posibilidades de acción y la estructura físico-digital del sistema, lo que crea nuevos significados que no serían posibles en ninguna otra configuración física distinta de esta en particular. El diseño de las computadoras nunca ha enfatizado realmente esta participación de las habilidades corporizadas, ya que basado en un marco de procesamiento de información, tendía a ignorar completamente el aspecto físico de la computadora. Ahora que tenemos un sinfín de posibilidades para definir cómo se debe acoplar la informática digital a las habilidades corporizadas de las personas, de repente tenemos una pregunta de diseño: ¿cuál es la forma correcta de hacerlo? Curiosamente, Dourish parece reconocer la importancia de estos detalles sensoriomotores, por ejemplo, cuando analiza la teoría de las affordances de Gibson[56]. 


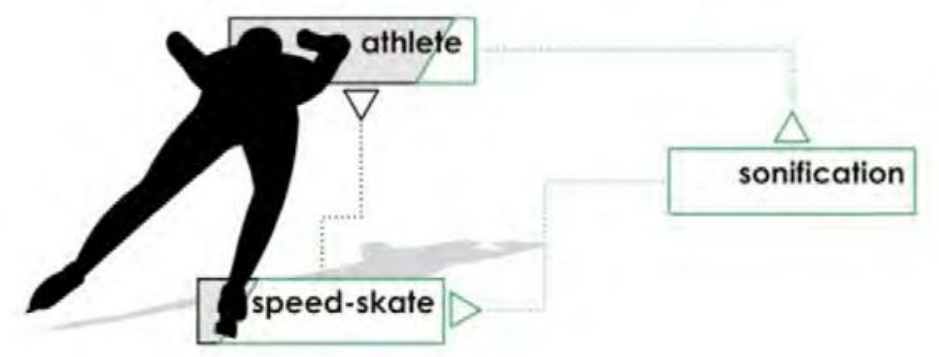

Fig. 2.11.: Esquema de ASE (Augmented Skating Experience) de Stienstra[219]

\section{El diseño de interacciones desde una perspectiva ASM}

Existen en la literatura varios reportes que exploran el diseño de sistemas interactivos con una visión de CC y específicamente del enfoque de enacción y acoplamiento sensorio motor. A continuación discutimos algunos de esos ejemplos.

Patín de carrera aumentado Un intento explícito de integrar la información digital con el acoplamiento sensoriomotor es ASE (Augmented Skating Experience) de Stienstra, un patín de carrera aumentado digitalmente que mapea de forma continua la acción del patinador hacia un feedback sonoro[219]. El requerimiento original del cliente fue desarrollar una plataforma de medición para aumentar la comprensión de la técnica del patinaje de carrera y mejorar los métodos de entrenamiento. La respuesta fue un sistema que entrega nuevos modos de percepción y vinculación con la acción al patinador. La cantidad de presión sensada en el patín es traducida a audio a través de un filtro de paso de banda (intensidad y volumen), con un rango desde la ausencia de sonido mientras no hay presión hasta un volumen intenso mientras se consigue una presión máxima (Figuras 2.11 y 2.12). Más aún, el balanceo sobre un patín se traduce en sonido bajo, mientras que el balanceo hacia adelante se traduce en uno alto[219]. En este concepto, la información digital no es el punto final del loop sensorio motor, sino que es fusionada en ese ciclo soportando la habilidad de patinar en velocidad.

En la evaluación, Stienstra encontró que la sonorización del movimiento permitió al patinador no sólo distinguir el ritmo de golpe, el equilibrio delantero y trasero de cada patín de velocidad, el equilibrio global y la cantidad de fuerza ejercida sobre el hielo durante el golpe, sino también controlarlo. El patinador encontró que la sonorización coincidía con el movimiento intuitivamente. Incluso pudo obtener patrones de sonorización para mejorar el entrenamiento que fueron rápidamente reconocidos por los atletas, lo que les permitió alcanzar una técnica más productiva en una situación dada.

Chaleco para escuchar con la piel Novich y Eagleman[180] presentaron hace unos años un chaleco basado en los principios de sustitución sensorial para facilitar entre otras funciones la posibilidad de que las personas con dificultades auditivas pudieran reconstruir la capacidad de escuchar utilizando la piel (ver Figura 2.13). El chaleco, que actualmente está desarrollado por 


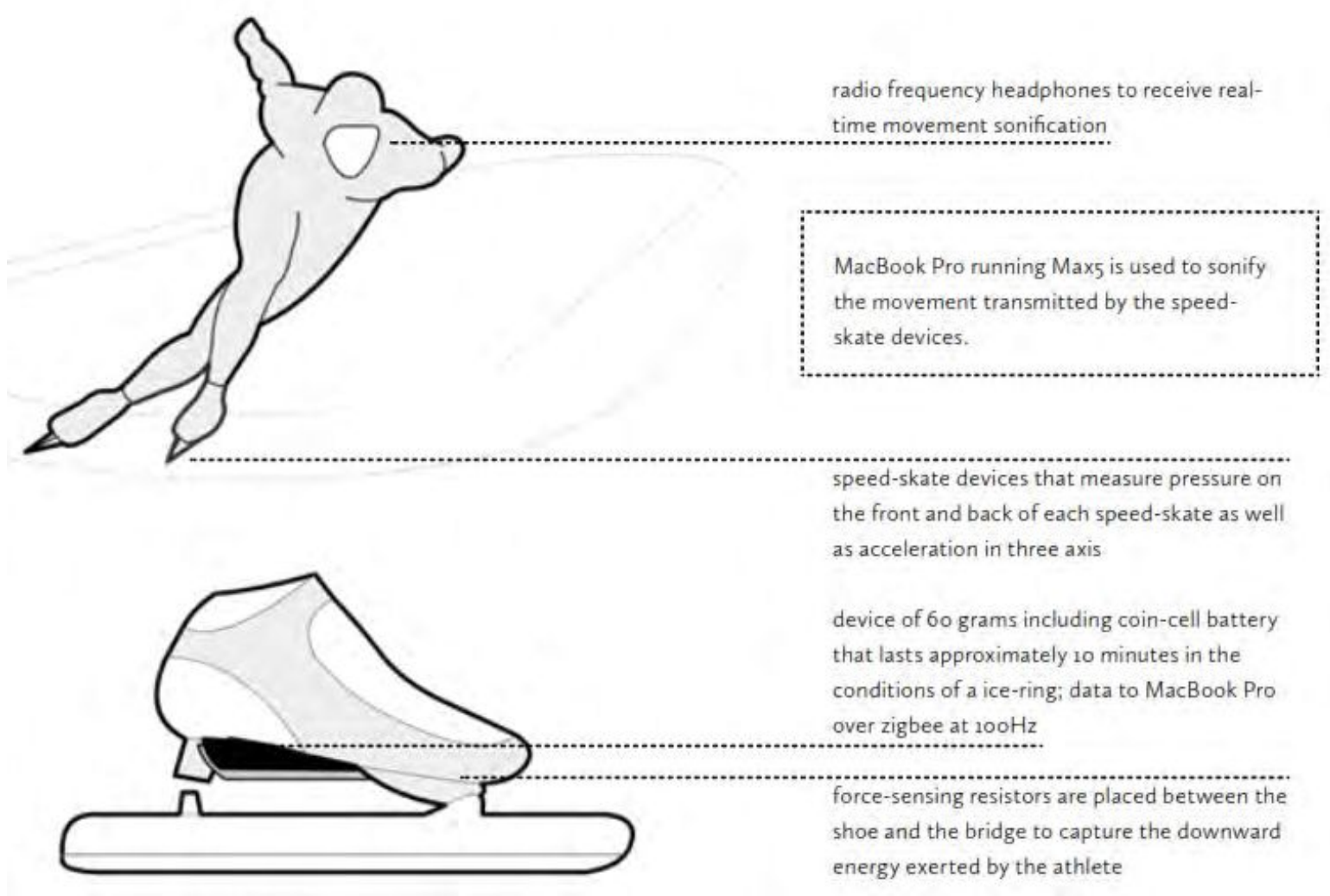

Fig. 2.12.: Componentes de ASE de Stienstra[219]

un spin off llamado Neosensory ${ }^{5}$ está basado 32 pequeños motores que transducen las ondas de sonidos en vibraciones sobre la espalda. Una computadora o un teléfono celular captura el sonido y lo samplea en una serie de frecuencias específicas. Cada banda de frecuencias dispara uno de los 32 motores. Con tiempo y práctica, el cerebro aprende de manera inconsciente a interpretar las series de vibraciones como sonidos y los sonidos individuales como palabras del lenguaje. Eagleman ha reportado experimentos con sordos así como ha mostrado las posibles implementaciones del dispositivo para comprender mejor los entornos complejos (por ejemplo, comprender "con el cuerpo" las tendencias de la bolsa de valores ${ }^{6}$ ).

Tanto el patín aumentado de Stienstra como el chaleco de Novich y Eagleman aplican un loop de feedback que conecta una salida de sistema con input sensorial de manera no habitual, enviando información por canales que sustituyen a los originales. De forma similar, el famoso ejemplo de sustitución sensorial de Paul Bach-Y-Rita[12] acoplando visión al tacto, visión al sonido, etc. Esas conexiones nuevas input-output, una especie de sinestesia artificial, no necesitan contener un significado predefinido para el usuario. En la medida de que se produce un mapeo confiable, este loop se convierte en una cognición significativa con el tiempo. Es decir, el loop de feedback pasará a tener algún sentido para el usuario, aún cuando de manera consciente el usuario no pueda reportarlo. Este efecto está en línea con la perspectiva de acoplamiento sensorio motor y enacción ya que esos acoplamientos se constituyen de una

\footnotetext{
${ }^{5}$ https://neosensory.com

${ }^{6}$ https://www.ted.com/talks/david_eagleman_can_we_create_new_senses_for_humans
} 


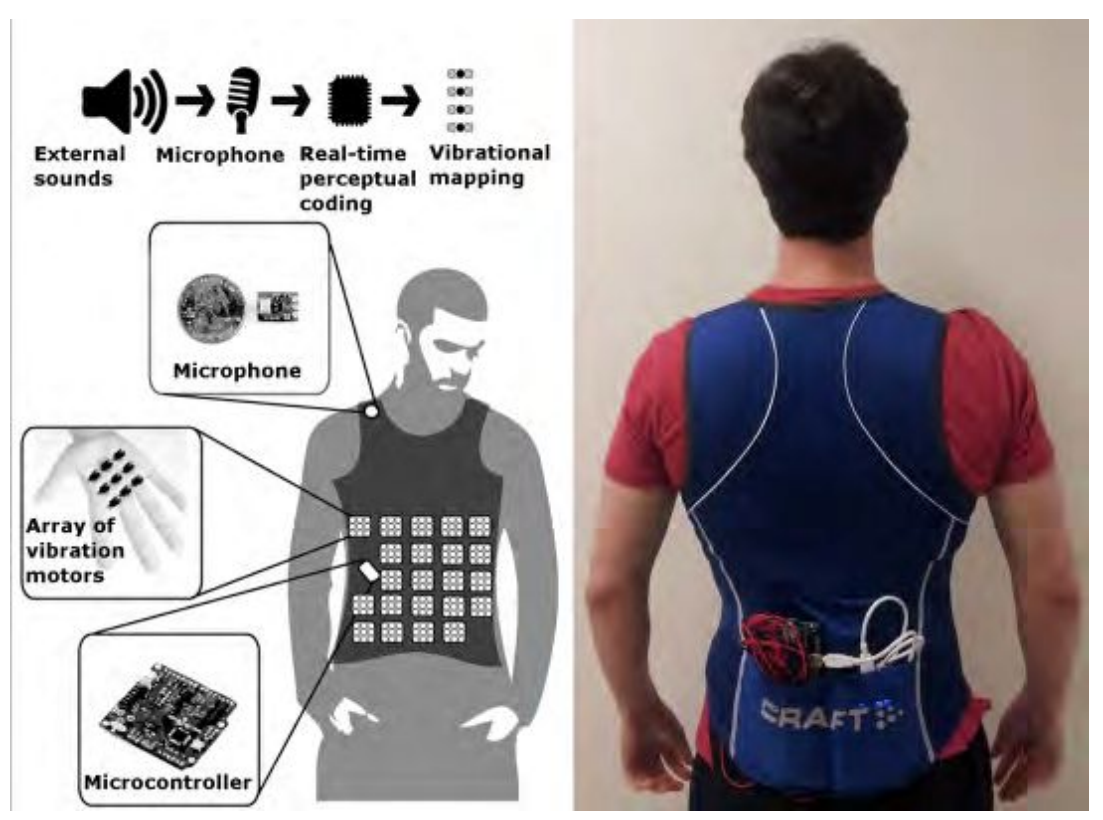

Fig. 2.13.: Chaleco para transducir sonido a feedback vibrotáctil de Novich y Eagleman

forma auto-organizada a través de la acción y no es necesaria una reflexión consciente para ello[111].

Los ejemplos mencionados permiten algunas conclusiones preliminares respecto del diseño apoyado en la perspectiva del acoplamiento sensorio motor. Por un lado no tiene mucho sentido describir estos sistemas como representaciones de algo más sin el riesgo de no comprender realmente de qué sistemas se trata. Además, estos ejemplos soportan la emergencia de acoplamientos no previstos por el diseñador y que habilitan realmente al usuario a relacionarse con ese entorno. El usuario no necesita tener una descripción consciente para poder utilizarlos e integrarlos en su mundo. Finalmente, la naturaleza dinámica de esa emergencia es central para la perspectiva enactiva que se manifiesta en una interacción y acoplamiento con el mundo a través del artefacto (más que una interacción con el artefacto).

Dos formas de abordar el diseño de sistemas interactivos digitales resultan por lo tanto particularmente relacionadas con el abordaje ASM: las interacciones transparentes yfaceless y la idea de interfaces versus experiencias de usuario.

Interacciones transparentes Gran parte del trabajo en HCI asume una idea de interfaz como superficie (siendo las pantallas las superficies preferidas). Existen pocos avances sobre la interacción sin superficies (surface-free, faceless). Una interacción faceless puede definirse como aquella desprovista de cualquier modalidad limitada por una superficie expresiva o impresiva (pero no de ambas). Escribir en un teclado es claramente una modalidad de superficie-límite expresiva y usar una pantalla de datos es una modalidad impresiva de superficie límite. Pero si el teclado se reemplaza por reconocimiento de voz tenemos una interación faceless en un sentido simple. En un sentido estricto, una interacción faceless puede definirse como aquella 
que no utiliza ninguna modalidad con superficie límite, es decir que emplea exclusivamente expresiones e impresiones libres de superficies[119].

La interacción faceless no es un fenómeno nuevo. Por ejemplo, las interfaces para ciegos o las aplicaciones que resuelven actividades en paralelo mientras manos u ojos están ocupados han existido por un buen tiempo. Janlert y Stolterman plantean tres direcciones conceptuales para el desarrollo de interaccionesfaceless[119]: una lleva a crear cosas, otra seres y la tercera, campos. Pensar en cosas significa que las interfaces tradicionales limitadas por superficies desaparecen y se puede interactuar con los artefactos resultantes en modos similares a las cosas analógicas: mover, apretar, tirar, sacudir, estirar, doblar, etc. como se puede interactuar con una silla sin que haya una superficie específica para la interacción. Diseñar seres significa pensar en artefactos digitales con mayor comportamiento e inteligencia, con los que se puede conversar. La interacción ya no es aprender cómo manipular la interfaz diseñada, sino comprender los objetivos, intenciones y planes del "ser" y tener un comportamiento que sea relevamente para él. El abordaje de campos significa que la interacción ya no está dirigida a un artefacto en particular, uno interactúa con el entorno, y la noción de usuario resulta menos apropiada que la de habitante o viajero a través de una especie de "campos de fuerzas interactivas"[119].

Diseño de interfaces o de sistemas En el trabajo de diseño que se relaciona con las nociones de acoplamiento sensorio motor y enacción, en realidad no siempre está claro si el objetivo es utilizar los principios sensoriomotores para crear una interfaz con la información digital dentro del sistema, o si el objetivo es crear un soporte tecnológico a través de cual crea acoplamientos sensoriomotores al mundo. Overbeeke y Wensveen sostienen: "El diseñador necesita crear un contexto para la experiencia, en lugar de simplemente un producto"[183].

En el skate de Stienstra, el loop continuo que involucra información digital es crucial para la formación de la habilidad corporizada de tratar con el mundo, lo que significa que la cuestión de qué aporta la información digital a este proceso de acoplamiento es inmediatamente relevante[219]. Sin embargo, en el ejemplo de patinaje, el dispositivo parece estar orientado hacia la optimización de estándares normativos que ya están definidos por la práctica existente (lo que es bueno y lo malo en relación con el "patinaje sobre hielo"). Aun así, en principio, los procesos digitales involucrados pueden transformar el significado generado por la creación de bucles sensorio-motores en el mundo mientras se utilizan estos dispositivos: el patinaje sobre hielo puede convertirse en algo completamente diferente con los audífonos encendidos.

En general, la pregunta de diseño desde una perspectiva sensorio-motora es cómo los artefactos interactivos pueden apoyar las formas básicas por las cuales las personas crean acoplamientos sensorio-motores a través del artefacto. El artefacto se convierte en parte del sistema que genera el acoplamiento al mundo, no un objeto en el mundo que debemos "acoplar a". La perspectiva de interacción corporizada comienza a iluminar no solo cómo actuamos sobre la tecnología, sino cómo actuamos a través de ella[56] 


\subsection{Conclusiones del capítulo}

Sobre la base de lo expuesto en las secciones anteriores podemos extraer algunas conclusiones preliminares para la consideración del enfoque de CC y en particular la corriente ASM en el diseño de sistemas digitales interactivos.

¿De qué manera la comprensión de la CCE puede aportar al diseño de la relación entre los procesos digitales y la forma física de los sistemas interactivos? ¿Puede contribuir a imaginar nuevas formas de construcción de sentido? ¿Estos sistemas interactivos corporizados pueden a su vez contribuir con la CCE de alguna manera particular? Si esto es así, ¿cómo se relacionan esos procesos digitales con los procesos cognitivos corporizados? En busca de respuestas a estas preguntas, repasé de manera crítica las teorías de computación y representación distribuidas (Hutchins[112], Kirsh[129], Clark[39]). Argumenté que al trabajar implícitamente desde esta visión, las interfaces de usuario tangibles como la de Ishii (2008) crean asignaciones metafóricas de forma física a significados digitales predefinidos. Esto es solo un paso menor en la dirección de lo que significa decir que la cognición está corporizada. Las nociones de andamiaje cognitivo, acción epistémica y memoria externa son relevantes y pueden guiar el diseño de interacción de manera fructífera (por ejemplo, Hollan et al[99]).

¿Cómo la cognición corporizada informa al diseño de la manera en que el sistema interactivo en general se conecta con las prácticas situadas en el mundo real de las personas? Ya no se trata de diseñar una interfaz amigable para la información digital. El objetivo es fundamentalmente el de crear artefactos tecnológicos que formen un elemento integrado en la actividad humana en el contexto físico y social. A través de esa actividad una persona enactúa un mundo significativo. La misma distinción entre "función" y la "interfaz" de un artefacto desaparece. No desaparece porque la forma de la interfaz esté metafóricamente mapeada a una función digital predefinida, sino porque los modos corporizados de hacer frente al mundo, a través del artefacto en una situación social, son lo que sostiene "la función" del sistema para el usuario[61].

¿Cuál es el papel de las "representaciones externas" en el proceso cognitivo corporizado? En la investigación de Prácticas Socialmente Situadas, se presta atención a la función de los artefactos representativos como actividad improvisada de sesgo al proporcionar un contexto de guía. En una sesión de bocetado de interacciones podríamos pensar en artefactos tales como notas adhesivas, rotafolios, modelos, diagramas, etc. Los "medios" digitales (por ejemplo, texto almacenado, imágenes, películas, audio) mediados por tecnología informática presentan variaciones modernas de tales representaciones externas. Una pregunta es qué sucede con el papel de este tipo de artefactos si comenzamos a diseñar versiones interactivas de ellos, con base en la noción de acoplamiento sensorio-motora y la idea de que las personas representan un significado a través del artefacto. ¿Funcionarán tales artefactos de manera diferente a los artefactos de representación más tradicionales, como texto en papel o una imagen en la pared? 



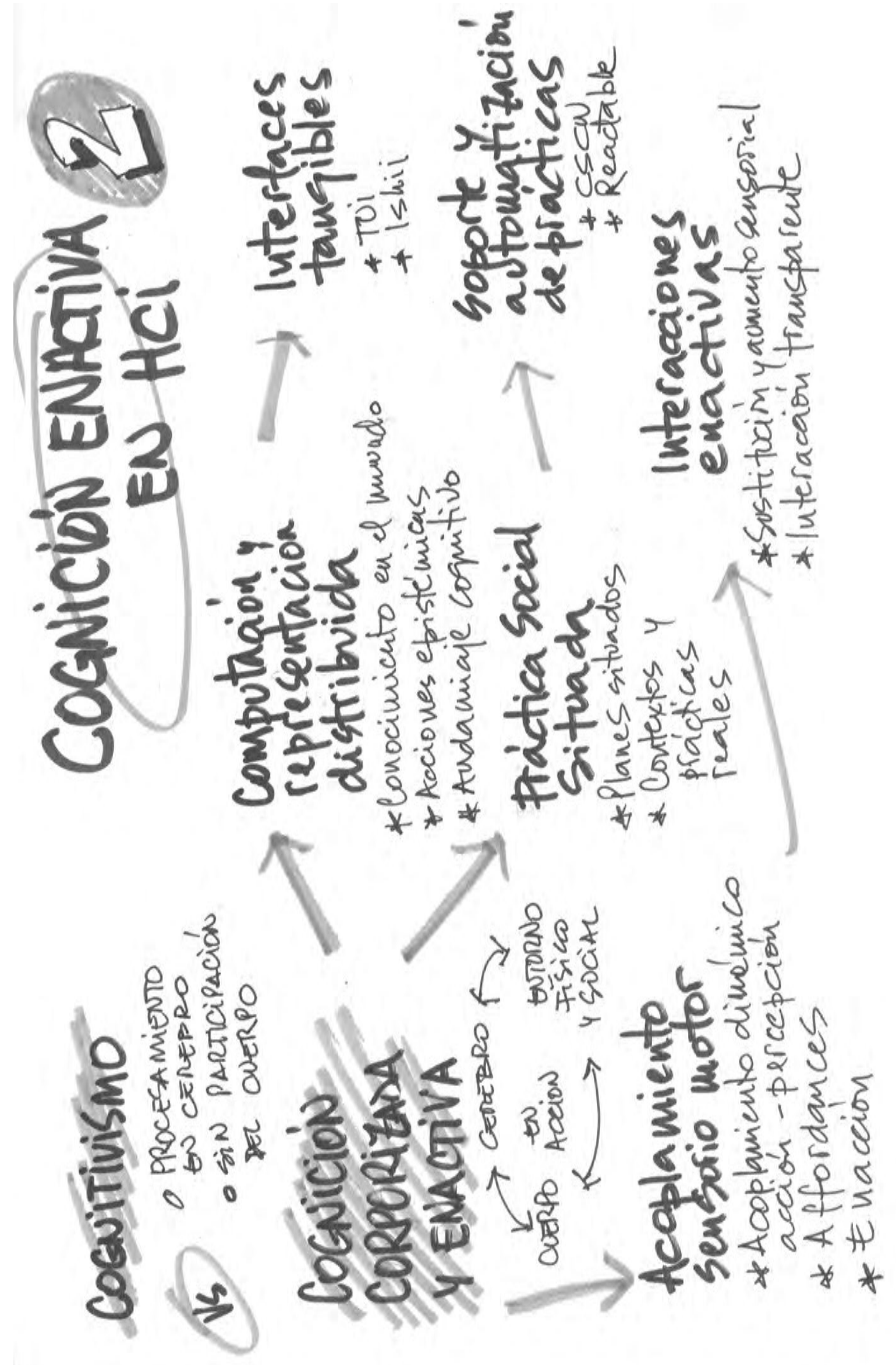





\title{
Una revisión sobre el diseño, bocetado y herramientas disponibles
}

\begin{abstract}
(the modern design process) is one in which an understanding of the problem and solution emerge together rather than one preceding the other. It is the drawing which is the focus of that activity of interwoven analysis and synthesis. (...) the kinds of problems designers find depend, to some extent, on the types of drawings they choose to construct.
\end{abstract}

\section{- Brian Lawson}

How designers think[141]

Presentada la teoría cognitiva que utilizo en la tesis como base del diseño de sistemas interactivos, en este Capítulo abordo el estado del arte en los otros temas que se relacionan con mi investigación.

El Capítulo se divide en dos partes. La primera contiene una revisión que permite dar contexto a la segunda, con algunas definiciones básicas: ¿qué tipo de diseño considero en esta tesis? ¿por qué requiere de algún tipo de soporte en particular? ¿qué se pone en juego al diseñar interacciones? ¿qué es y para qué se usa el bocetado? En la segunda, incluyo un relevamiento de los trabajos publicados con propuestas para brindar soporte a esa actividad de diseño, desde los frameworks conceptuales para organizar y encuadrar el diseño de interacciones basadas en sensores y actuadores hasta las toolkits creadas para soportar diferentes etapas o tareas de bocetado, maquetado, prototipado, etc. en la generación de ideas.

La conclusión del capítulo incluye una serie de orientaciones que se desprenden de estas revisiones y que sirven para guiar la búsqueda de respuestas a las preguntas de investigación planteadas en el Capítulo 1.

\subsection{Diseño de interacciones digitales y bocetado}

\subsection{1 ¿De qué hablamos cuando decimos diseño?}

La palabra diseño tiene múltiples significados y por eso requiere una definición inicial acerca de qué consideramos diseño en el contexto de esta tesis. 
El foco aquí está puesto en el conjunto de actividades que se realizan al comienzo de un proceso que tiene por objetivo producir un artefacto o sistema interactivo con componentes de software y hardware. Cuando simplemente está la idea de resolver algo con un sistema interactivo y ni siquiera es posible establecer si se utilizarán dispositivos móviles estándar, hardware ad hoc, interconexión entre dispositivos, etc. En efecto, mucho antes de pensar en los nodos de un mapa de navegaciones, de seleccionar y organizar visualmente unos widgets en un conjunto de pantallas, de establecer las dimensiones adecuadas para un puesto de trabajo o para los controles de una consola de juegos. Ni pensar en la mejor organización modular del software o los componentes de hardware óptimos.

Esta etapa, reconocida en industrias del mundo físico como la automotriz, de electrodomésticos o de construcción, aún no ha alcanzado un sitio de pleno derecho en la mesa de decisiones de la industria del software. Sin embargo, son numerosos los autores que abogan por un proceso explícito de diseño antes de comenzar las etapas de ingeniería. Como ejemplo, vale citar los trabajos de Winograd[249], Brooks[29], Buxton[32] o la serie de libros sobre la relación entre design thinking y la actividad de generación de software y hardware liderados por la Universidad de Stanford y el Hasso Plattner Institute[169, 188, 187, 168].

Quizá uno de los problemas para acelerar este proceso esté relacionado precisamente con la dificultad para encontrar una definición consensuada del diseño. En un clásico sobre metodologías en diseño, Design methods: seeds of human futures, John Christopher Jones había planteado ya en 1970 el problema de encontrar una buena definición con ejemplos que iban desde las visiones místicas del propio Jones ("Un complejo salto de fe, iniciar el cambio en las cosas hechas por el hombre") hasta las "constructivistas" de Christopher Alexander ("Encontrar los componentes físicos correctos para una estructura física") o de Bruce Archer ("Una actividad dirigida por metas para resolver problemas") [123].

Más cerca de las ciencias informáticas, Herbert Simon sostenía en Las ciencias de lo artificial que "diseña todo el que determina cursos de acción para cambiar una situación existente en otra preferida"[217].

Para cerrar este repaso, Terry Winograd señala en Bringing design to software que, aunque no podamos encontrar una definición para el sustantivo "diseño", lo importante es acordar que en realidad no se trata de una cosa sino de una actividad. El diseño es una actividad consciente, intencional que mantiene los aspectos humanos siempre en el centro. Diseñar involucra la incertidumbre y el riesgo. Es una conversación con los materiales que incluye simulaciones. Es creativo, es comunicación y tiene consecuencias sociales[249].

La actividad de diseñar contiene dos tareas complementarias: la resolución de problemas y la configuración de problemas[208]. La primera se podría caracterizar por la pregunta "¿Cómo se construye esto?”. La segunda implica la pregunta: “¿Qué es lo que corresponde construir?” Suponiendo que las especificaciones del producto o el brief de diseño definen el problema adecuadamente ¿Es suficiente para comenzar a construir el producto? Dicho de otra manera, 
es necesario adoptar un enfoque que aspire no sólo a diseñar correctamente, sino también a diseñar el producto correcto.

¿Cuál es la actividad arquetípica que le permite al diseñador organizar estas tareas complementarias? Para J.Ch. Jones, la respuesta es clara: dibujar es la única acción común de los diseñadores de todo tipo[123]. La respuesta de Fällman es similar, sólo un poco más específica. La actividad arquetípica del diseño es bocetar[64]. Muchos otros autores, por ejemplo Goel[80], Gedenryd[75], Suwa y Tversky[226] han llegado a la misma conclusión. Al decir esto, es importante enfatizar que no estoy afirmando que la actividad del boceto sea el diseño. Estoy señalando que cualquiera que diseña, en el sentido que estamos utilizando aquí, se acompaña de bocetos. Por lo tanto, incluso si no podemos (o no queremos) definir el diseño, quizás todavía podamos obtener algunos conocimientos sobre su naturaleza y práctica si nos tomamos un tiempo para profundizar en la naturaleza del boceto.

¿Por qué es necesario el boceto? Entre otras cosas, porque los problemas en el diseño no son sencillos, resultan difíciles de abordar, de captar y, como hemos visto en el capítulo anterior, para pensar el mundo es necesario hacerlo con y en el mundo, necesitamos externalizar las ideas para facilitar el proceso de movimientos entre solución y re-configuración del problema[53].

\section{¿Qué es lo difícil de idear en diseño?}

Casi todas las situaciones de diseño ofrecen fuentes de información, requisitos, demandas, deseos y necesidades, limitaciones y oportunidades potencialmente infinitas e ilimitadas. Estas "fuentes infinitas e ilimitadas" generalmente se presentan en forma de diversas posibilidades tecnológicas, numerosos factores contextuales y condiciones sociales en constante cambio, clientes sofisticados y/o no informados, demandas y deseos de los usuarios. Aunque todas estas fuentes pueden sugerir al diseñador sobre un diseño potencial, no es posible explorarlas exhaustivamente para obtener toda la información potencialmente útil. Enfrentar esas fuentes de información "infinitas" podría poner a un diseñador (incluso a uno experto) ante una complejidad abrumadora. El diseñador debe tomar decisiones y juicios: cómo encuadrar la situación, a quién escuchar, a qué prestar atención, qué descartar y cómo explorar, extraer, reconocer y elegir información útil de todas estas fuentes potenciales. Un diseñador sin experiencia puede sufrir de "parálisis de diseño" cuando se enfrenta a oportunidades infinitas. Estas situaciones de diseño a veces se caracterizan como problemas "menores", o en las palabras de Schön como una situación "desordenada"[209], o en las palabras de Rittel, un "problema perverso" (wicked problem)[195].

Por otra parte, la complejidad de diseño es una consecuencia de la naturaleza de la tarea en la situación específica, en relación con el propósito específico, y en relación con la habilidad profesional, la competencia y la experiencia del diseñador. Esto significa que un diseñador puede experimentar una situación de diseño particular como compleja, mientras que para otro podría no serlo[35, 153, 177, 201]. 
La mayoría de los enfoques y métodos están orientados a reducir la complejidad de alguna manera, pero reducir la complejidad del diseño no es una tarea fácil. Actuar sobre la complejidad del diseño a la manera del diseño ${ }^{1}$ exige enfoques, métodos, técnicas y habilidades apropiados. Con el tiempo, la ciencia ha desarrollado una comprensión detallada, rica y diversa de sus propósitos y enfoques. El rigor y la disciplina metodológica son la esencia de lo que hace la ciencia. Stolterman señala la necesidad de la investigación de HCI para lograr una comprensión filosófica y metodológica similar de lo que constituye el rigor y la disciplina de la práctica del diseño que permita apoyarla mejor[222].

Existen varios trabajos que pueden considerarse seminales en el escrutinio del diseño, como los de Nigel Cross[43], Brian Lawson[141], Jonas Löwgren[153] o Donald Schön[208]. Estos textos, en conjunto, delinean un camino desde una comprensión inicial del diseño basada en la ingeniería, fomentada por la tradición científica, hacia una comprensión de la práctica del diseño en los propios términos de los diseñadores. Estos trabajos proveen argumentos suficientes para sostener que existe algo que puede llamarse unamanera de diseñador y que el diseño es una actividad humana que merece un tratamiento intelectual propio. Estos autores sostienen que las herramientas y métodos que crean modos predefinidos de abordar la realidad no son de ayuda en el diseño. En cambio, todas las herramientas, técnicas y métodos que se suponen soportan la práctica del diseño tienen que ser incorporados intencionalmente como parte de un abordaje de diseño situado por el diseñador actuante. Como consecuencia de esto se convierte en importante para los que producen soporte para profesionales de diseño hacer posible esa incorporación en la propia forma de abordaje del diseñador. Los métodos y aproximaciones dirigidos a mejorar la práctica del diseño tienen que basarse en el respeto y la comprensión de la complejidad y riqueza del tema.

Esta idea fundamental se puede resumir en la noción de que al diseñador se lo puede preparar para la acción, pero no guiar en la acción con procedimientos prescriptivos. Cuando un diseñador se encuentra en una situación de diseño tiene que actuar con respeto por toda su riqueza y complejidad y de una manera que sea apropiada para los detalles de esa situación. Si alguien no está preparado para manejar tal complejidad, los métodos y técnicas no pueden ofrecer ninguna garantía para guiarlo a través de tales situaciones. Un ejemplo de un enfoque que logra cumplir este requisito se manifiesta en las nociones de reflexión-en la-acción, reflexión-sobre-la-acción y repertorio de diseño de Schön[208]. Con estos conceptos, Schön pretende proporcionar a los diseñadores herramientas conceptuales que puedan utilizar para desarrollar continuamente sus habilidades de diseño. A través de estos procesos de reflexión, un diseñador puede desarrollar un repertorio útil de ideas o conceptos de diseño que se utilizarán en futuras situaciones. En algún modo, esto es similar a la idea de un lenguaje patrones de Christopher Alexander[2] que tanta repercusión tuvo en la comunidad de ingeniería de software. Schön logró encontrar una manera de describir la práctica de diseño que puede ser reconocida por los diseñadores en ejercicio, además de proporcionar conceptos que pueden

\footnotetext{
${ }^{1}$ A falta de una mejor traducción, en el resto de la tesis reemplazo la expresión inglesa "designerly" propuesta por Nigel Cross [43] y Erik Stolterman[222] para indicar el modo de actuar propio de un diseñador, alternando entre las expresiones "a la manera de diseño", "a la manera de diseñador" y "diseñadamente"
} 

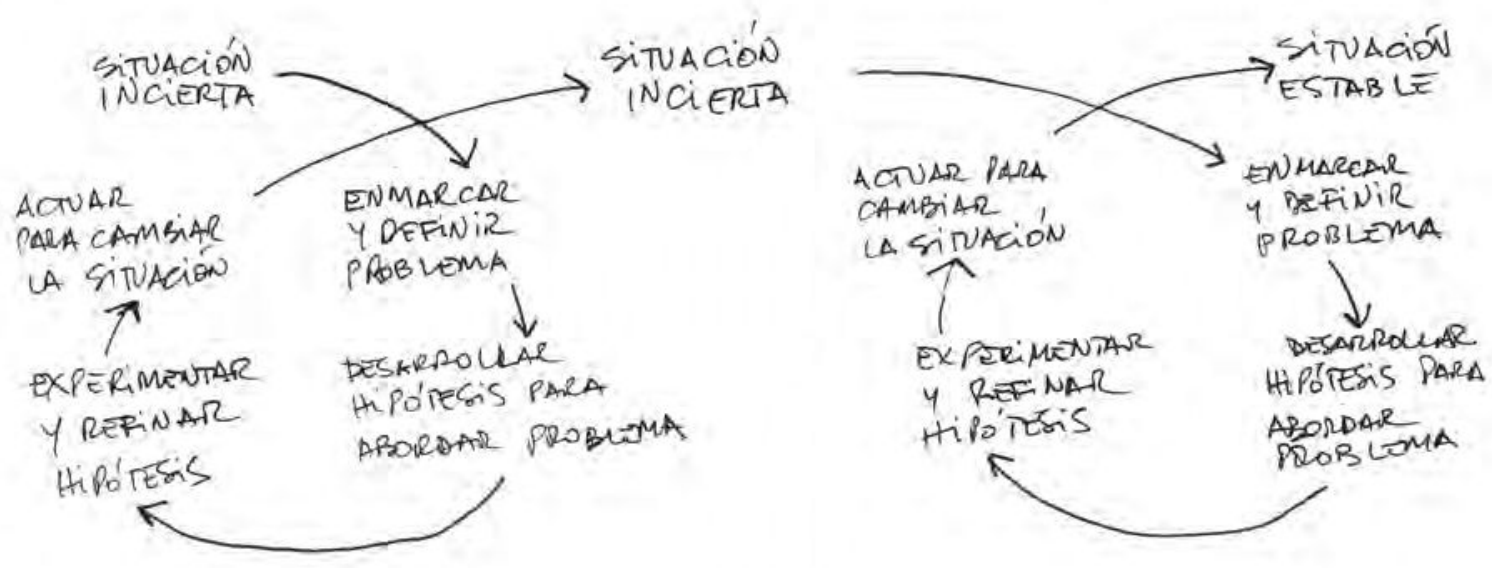

Fig. 3.1.: Modelo de investigación iterativa a la manera del diseño adaptada de Dalsgaard[45]

utilizarse como herramientas intelectuales en la planificación y el desarrollo del proceso de diseño. Y lo hizo sin prescribir el proceso en ningún nivel detallado. Su enfoque es, por lo tanto, un buen ejemplo de una estrategia basada en el entendimiento de que los diseñadores deben ser apoyados para estar "preparados para la acción" y no "orientados en la acción".

Es posible entender y describir la racionalidad subyacente del diseño etiquetada con conceptos como el diseñador pensativo de Lowgren[153] y el profesional reflexivo de Schön[208]. Estos autores, y otros como Buxton[32], Krippendorff[137], Moggridge[171], han descrito lo que consideran la racionalidad y actividad disciplinada del diseño. En estos trabajos se muestra que el boceto es el núcleo del diseño. Dibujar es una forma disciplinada de explorar las relaciones entre diversas ideas de diseño, entre un todo y detalles, entre forma y función, entre apariencia y materiales, etc. Estos autores también mencionan que un diseñador racional trabaja en muchos diseños alternativos en paralelo de manera iterativa, mientras va y viene entre el conjunto y los detalles. Esta forma de hacer diseño no es una opción. Es el núcleo de lo que significa actuar de una manera racional, disciplinada y de diseño.

Un aspecto final de ser riguroso y disciplinado está relacionado con la conciencia del proceso. Tanto el diseño como la ciencia requieren mucha atención al proceso, pero por diferentes razones. Mientras que los investigadores dedican tiempo a diseñar y planificar su proceso de investigación para coincidir con los estándares universales y establecidos de la ciencia, los diseñadores deben diseñar su proceso para adaptarse a las condiciones específicas y únicas de la tarea en cuestión (por ejemplo, la Figura 3.1 muestra el modelo de investigación iterativa a la manera de diseño de Dalsgaard[45]). Buxton escribe: "Para crear productos exitosos, es tan importante (si no más) invertir en el diseño del proceso de diseño, como en el diseño del producto en sí" ([32] p. 408). En términos similares, desde la ingeniería de software se ha manifestado Frederick Brooks en Design of design. Essays from a computer scientist [29]. Estos aspectos constituyen solo una pequeña fracción de lo que puede considerarse como el 
núcleo de la disciplina y el rigor de la práctica del diseño. El mensaje para esta tesis es que la investigación de HCI debe considerar las condiciones específicas del rigor y la disciplina en la práctica del diseño de interacción.

Yvonne Rogers realizó un estudio sobre los métodos utilizados en el diseño de interacciones[201] y encontró que casi todos los encuestados utilizaron una variedad de métodos de diseño, incluidos escenarios, storyboards, prototipos, etc. Pero casi nadie utilizó "métodos de modelado predictivo, como GOMS, y solo unos pocos usaron métodos de ingeniería de software ( $8 \%$ ), experimentos (10\%), diseño contextual (10\%) o directrices (5\%)" (p. 124). Muchos encuestados respondieron que estaban familiarizados con la mayoría de los principales enfoques teóricos en HCI, pero no los utilizaron. Rogers afirma que "el problema parece ser la brecha entre las exigencias del diseño real y la manera en que se conceptualiza la teoría". Ese estudio revela resultados positivos y problemáticos cuando se investiga cómo los profesionales usan y ven la investigación de HCI. Una interpretación es que el conjunto de herramientas básicas, utilizado por muchos, puede describirse como a la manera del diseño.

Este tipo de herramientas tienen cualidades que tradicionalmente se reconocen como útiles por los diseñadores. Eso significa que son herramientas claramente definidas con un propósito preciso que deben ser utilizadas de manera hábil por un diseñador competente para que sean útiles. Estas herramientas no eliminan ningún "poder" o libertad del diseñador. Estas herramientas no prescriben el proceso general ni exigen una secuencia de actividades paso a paso específica que pueda afectar la forma en que el diseñador hace las cosas. Estas herramientas no exigen ningún conocimiento teórico sofisticado. Esto está en línea con el hecho de que los modelos más complejos que requieren más del diseñador (como el diseño contextual, los experimentos, los métodos de ingeniería) fueron menos utilizados en el estudio de Rogers[201].

Ya hemos mencionado el interés creciente en el papel y la naturaleza del diseño en la investigación de HCI (por ejemplo, [249, 254, 153]). También hemos visto algunas contribuciones destinadas a la práctica del diseño que se basan en una comprensión firme de la misma. Estas contribuciones ya han tenido impacto y han aumentado el interés en una comprensión más profunda de la actividad, como los libros destacados de Buxton[32], Moggridge[171] y Kolko[133].

Stolterman[222] sostiene que esto sugiere una serie de actividades de investigación que son necesarias para establecer tal comprensión: la necesidad de hacer estudios detallados de las prácticas existentes del diseño de interacciones, que permitan obtener una resonancia de racionalidad[221] como suele denominarse la relación entre la práctica sugerida y la existente. Cualquier intento de introducir una nueva racionalidad en la práctica tiene que resonar con la que ya existe. Sin esa resonancia la introducción será extremadamente difícil. Es razonable asumir que las aproximaciones no utilizadas por los profesionales (como mostró el trabajo de Rogers[201]) no resuenan en la experiencia de los profesionales

Parece que los profesionales del diseño de interacción se inclinan a apreciar y utilizar: a) herramientas o técnicas simples (bocetos, prototipos, entrevistas, encuestas, observaciones, 
etc.), b) marcos que no prescriben sino que apoyan la reflexión y la toma de decisiones (patrones de diseño, formas de usar prototipos, estilos de interacción, etc.), c) conceptos individuales que son interesantes y abiertos para la interpretación y reflexión sobre cómo se pueden usar (asequibilidad, persona, sonda, etc.), d) ideas y enfoques teóricos y/o filosóficos de alto nivel que amplían el pensamiento del diseño pero no prescriben su acción (práctica reflexiva, diseño con diseño, experiencia en diseño, razón de diseño, etc.) [208, 137].

\subsubsection{La interacción}

La literatura en HCI presenta siete conceptos o formas de ver la interacción con dispositivos digitales: diálogo, transmisión, uso de herramientas, comportamiento óptimo, corporización, experiencia y control[103]. De estos, los más vinculados con mi trabajo son los que consideran la interacción como uso de herramientas, como acción corporizada y como experiencia.

- La interacción como uso de herramientas. Este concepto ve la interacción como uso de dispositivos para manipular y actuar en el mundo, sin diferenciar entre usar un martillo o una regla mental. Esta idea pervade el campo de HCI en diferentes formas y es central a la teoría de la acción[125]. La computadora es una herramienta, algo que los usuarios utilizamos para manipular y que nos extiende. La interacción es entonces el uso o manipulación de tecnología para objetivos que están más allá del uso en sí mismo de la herramienta. Se derivan tres implicancias de esta idea. En primer lugar sugiere que la interacción con las herramientas modela al usuario y cómo se comporta. La teoría de la acción captura esta idea en la noción de mediación y en la mutua influencia entre la gente y las herramientas en el ciclo tarea-artefacto. En segundo lugar, la interacción como uso de herramientas enfatiza el rol mediador de la herramienta, que apunta a "actuar a través de la interfaz". El grado en que la interfaz interfiere con el hacer es la clave, valorando positivamente las ideales de interfaces de usuario transparentes o invisibles[178]. Tercero, se enfatiza la idea de uso: estrictamente hablando nada es una herramienta excepto durante su uso. Por lo tanto, la interacción está atada al uso y las tareas con una especie de unidad entre el artefacto y su propósito[11].

- La interacción como acción corporizada. Interactuar es actuar y estar en situaciones del mundo real (material y social). Resulta difícil definir qué es una buena interacción en este marco salvo por la negativa: un artefacto bien diseñado no genera experiencias disruptivas en la intención del usuario y lo ayuda a ser "más humano", por ejemplo en las interacciones basadas en la realidad[117]. Para la evaluación y construcción de interacciones, este concepto cambia el foco desde los trabajos de laboratorio al trabajo en la realidad ("in the wild"), recolección de datos y descripciones densas de la interacción[42].

- La interacción como experiencia. La experiencia es considerada aquí como un flujo continuo de expectativas, sentimientos y recuerdos. Si bien la experiencia puede verse como un epifenómeno, un efecto lateral, la experiencia humana es un factor clave en la forma en que se despliega la interacción. Para Hassenzahl, la experiencia es un sentimien- 
to primario de evaluación mientras se interactúa con un producto o servicio[95]. Este sentimiento es parte de la interacción conformado por y conformante de la interacción. Esta idea además sostiene que la experiencia no se puede mapear a características de la interfaz o pasos en la interacción. De alguna manera la idea es que la experiencia de la interacción es el resultado de evaluaciones cognitivas de eventos. Esta idea de la interacción como experiencia contribuye a enfatizar las cualidades no instrumentales de la interacción y a destacar la influencia de las expectativas sobre la experiencia. Los patrones de asociación entre el diseño y las experiencias propuestos por Hassenzahl son una de las implicancias para el diseño de esta idea[95].

Una idea asociada a la interacción es la de interactividad. Janlert y Stolterman muestran que un único término no es suficiente para capturar y definir el significado completo de interactividad con precisión. Ellos proponen anclar "interactividad" como la actividad de interactuar, como un proceso en ejecución, y desarrollar otras dos ideas a su alrededor: interactabilidad e interactiveness[120].

La interactabilidad es la cualidad intrínseca de las cosas y los sistemas que refleja su capacidad de poder interactuar con ellos, el potencial que muestran para la interacción.

Interactiveness ${ }^{2}$ es la propensión o predisposición del sistema o artefacto a involucrar a los usuarios en las interacciones y mantener el ciclo. Podría haber un potencial alto de interactabilidad del sistema, pero los usuarios no involucrarse en una interacción real con él.

Un aspecto asociado con la interactibilidad es el de agencia, la idea que las acciones de ambas partes (humano y artefacto o sistema) están guiadas por algún diseño interno para alcanzar ciertas metas. En particular una agencia reconocible es importante, el artefacto tiene que mostrar alguna receptividad a las acciones del usuario, tiene que haber alguna conexión discernible entre lo que el usuario hace y lo que el sistema hace.

Para medir la interactabilidad es importante distinguir los espacios de acciones posibles y de operaciones. El espacio de acciones posibles es la totalidad de las acciones o reacciones que están disponibles para el usuario en relación con el sistema o artefacto, sea una respuesta al sistema o proactivamente de manera de conseguir que ocurra algo[120]. El espacio de operaciones, que es el conjunto de acciones del usuario que el sistema es capaz de "percibir". Las operaciones constituyen un estricto régimen de canales de entrada a través de los cuales las acciones humanas son sampleadas, filtradas, reducidas (o distorsionadas) y se les permite afectar el artefacto en el modo buscado y autorizado por el diseñador[120].

La actividad del diseño de la interacción consiste entonces en la determinación del tamaño, forma y estructura de estos espacios. Al diseñar el espacio de control de un artefacto o sistema, el diseñador tiene una gran libertad de elección sobre cuánto puede persuadir u obligar a los usuarios a involucrarse en ciertos puntos o regiones del espacio. O puede tratar de "mantenerse neutral" dejando que los usuarios encuentren y hagan sus propias elecciones respecto de

\footnotetext{
${ }^{2}$ En la tesis utilizo el término inglés ante la falta de un término en español apropiado para reflejar el mismo significado
} 
los patrones de operación. En esta tensión, una aproximación corporizada y más aún, con acoplamiento sensorio motor, estaría más cerca del segundo polo que del primero.

En la actividad de diseño es importante disponer de herramientas para conocer si se está más o menos cerca del objetivo. Siempre está el recurso de evaluar consultando a la gente si encuentran un artefacto más o menos interactuable, una situación más o menos interactiva, y obtener de manera empírica el grado de acuerdo y concordancia entre usuarios. Sin embargo, también es necesario disponer de algunos elementos, aunque sea rudimentarios, que permitan contrastar algunos atributos o características de esa interactividad para evaluar si sus valores están en el marco de lo deseado por el diseñador. Janlert y Stolterman proponen métricas como tamaño del espacio de control y de involucramiento, tiempo consumido por la interacción, número de interacciones en curso o threads simultáneos, presión para interactuar o el número de acciones u operaciones por unidad de tiempo, interactividad del entorno[120].

Las herramientas para soportar el diseño de interacciones deberían proveer alguna forma de utilizar estas métricas para comparar las ideas alternativas.

\subsubsection{El bocetado}

El bocetado básico utiliza elementos tan simples como lápiz y papel. Las herramientas pueden ser tan sencillas porque el énfasis no está puesto en el producto resultante (no hablamos de generar dibujos finales de presentación). El bocetado es un proceso por el cual el diseñador trabaja sobre el problema a mano con varios propósitos. El diseñador boceta para entender su problema de diseño y lo que le demanda, para explorar sus características particulares y problemas que deben ser enfrentados, para experimentar con diferentes aproximaciones a una solución y eventualmente para trabajar en la propuesta final, entre otros propósitos (ver Figura 3.2). Por lo tanto el énfasis está sobre el proceso de bocetar en sí mismo más que en su producto, y para ese proceso papel y lapiz son altamente adecuados (e incluso podrían verse como herramientas bastante sofisticadas según el trabajo de Gedenryd[75], pág. 101).

\section{¿Los bocetos son prototipos con otro nombre?}

Se puede argumentar que boceto es simplemente otra palabra para designar a los prototipos de baja-fidelidad. Sin embargo la diferencia básica es de propósito o intención, independientemente de formas y materiales. Existe una especie de continuum de intencionalidad entre el boceto y el prototipo: desde sugerir hasta describir, desde explorar hasta refinar, desde preguntar hasta responder, proponer a testear, etc. Es el propósito del diseñador situado en la acción del diseño quien da un sentido u otro a la producción gráfica a mano[32].

Los bocetos aparecen fundamentalmente en las primeras etapas de un proceso de diseño, mientras los prototipos se requieren a medida que avanza el proceso y se converge hacia la solución (ver Figura 3.3. Existe además una diferencia en cuanto a la inversión que es necesaria para bocetar o hacer un prototipo y esa es una diferencia fundamental a favor del 

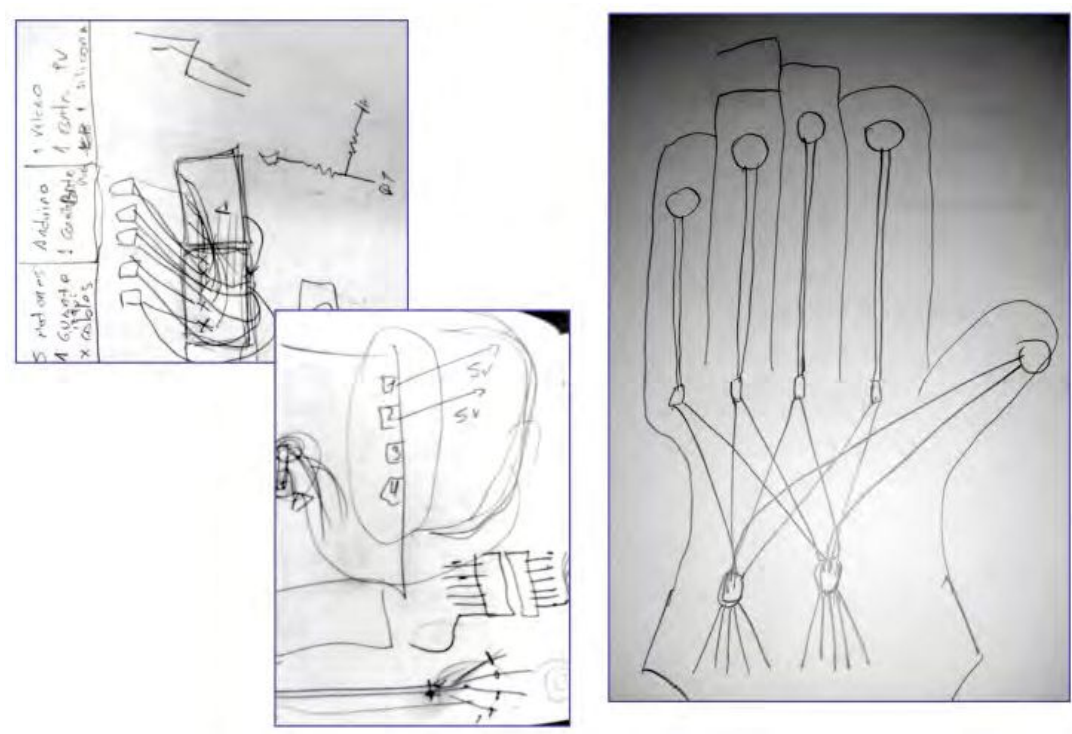

Fig. 3.2.: Ejemplos de bocetos durante el diseño de interacciones para un dispositivo con feedback vibrotáctil. A la izquierda y centro estudios sobre posibles circuitos y conexiones, a la derecha esbozo de guante con ubicación de sensores y actuadores (de los talleres reportados en el Capítulo 4)

boceto, lo que permite explorar rápidamente numerosas alternativas, recorriendo el espacio de diseño y convergiendo hacia una propuesta. La evidencia reportada en la literatura muestra las ventajas de explorar alternativas simultáneamente para converger a una mejor solución de diseño[59].

A la hora de intentar soportar el proceso de bocetado, la diferencia de intencionalidades es fundamental para que las herramientas realmente contribuyan al proceso cognitivo que el diseñador quiere (y necesita) utilizar para dar sentido al proceso de indagación que tiene por delante, que resuenen en su racionalidad.

\section{El bocetado como herramienta}

Uno de los objetivos de esta tesis es avanzar en la generación de herramientas para el bocetado de interacciones enactivas. Para ello es necesaria una comprensión, aunque sea mínima, de la naturaleza, rol y sentido que las herramientas tienen para un diseñador. La tecnología juega un rol crucial en la indagación del diseñador y los instrumentos pasan a ser centrales (instrumento de indagación es cualquier elemento que pueda dar soporte o andamiaje al proceso de búsqueda). Estos instrumentos no sólo permiten alcanzar un fin, algo que estaba pre-establecido, sino que pueden contribuir a afectar la percepción y comprensión del mundo, a explorarlo y darle un sentido. Dalsgaard[45] muestra que estos instrumentos deben colaborar con el diseñador en:

- La percepción revelando facetas de una situación de diseño que de otra manera se ocultaría, mientras que ocultan otras facetas. Al saber lo que un instrumento revela y 


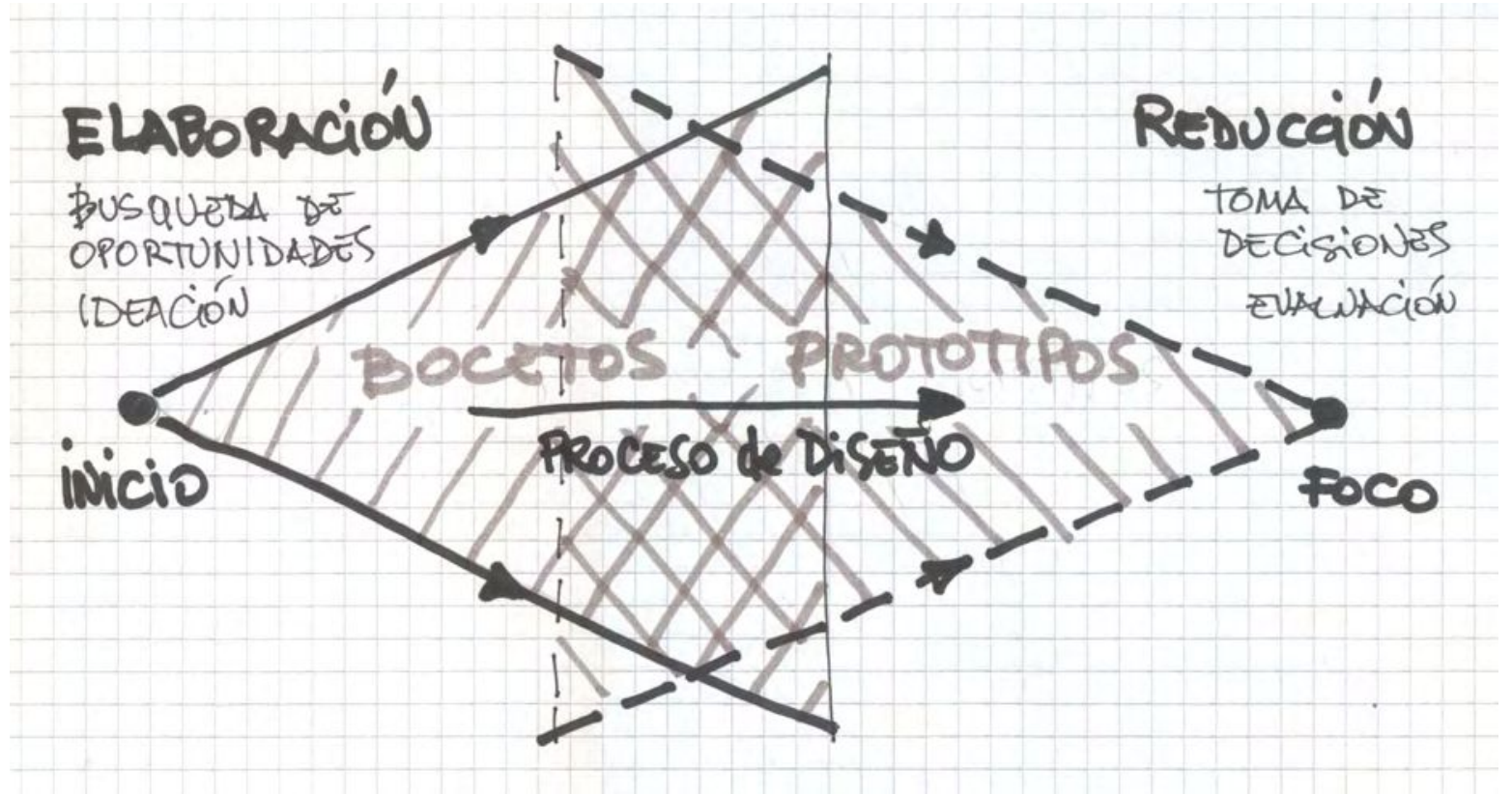

Fig. 3.3.: El doble embudo de diseño: elaboración (búsqueda de ideas y posibilidades, divergencia) y reducción (evaluación y toma de decisiones, convergencia). El primero es dominado fundamentalmente por el bocetado (barato y rápido) mientras los prototipos (más elaborados y caros) son la base para la toma de decisiones basada en pruebas. Adaptado de Buxton[32] y Laseau[140]

lo que esconde, un diseñador puede usar estas restricciones para establecer un mayor enfoque en los problemas de diseño designados

- La concepción ayudando a los diseñadores a entender y articular los problemas que enfrentan y desarrollar hipótesis sobre cómo podrían abordar estos problemas y examinan y revisan estas hipótesis. Algunos instrumentos hacen esto en formas abstractas, semióticas, otros en formas concretas y tangibles.

- La externalización, con los bocetos los diseñadores pueden hacer que las soluciones de diseño imaginado formen parte del mundo y permitirles manipularlas, evaluarlas y desarrollarlas con más detalle y complejidad. De esta manera, los instrumentos de investigación pueden ampliar nuestras capacidades descargando la cognición en representaciones y formas externas, y jugando a nuestras fortalezas y potenciales cognitivos.

- El conocimiento en la acción, ya que se generan nuevos conocimientos al actuar con un instrumento. Una variante particular de esto es la transinstrumentalidad, en la cual los diseñadores pueden comenzar a trabajar en un problema sin saber exactamente hacia dónde se dirigen, y confiar en su dominio y uso de instrumentos para ayudarlos a construir nuevos entendimientos en el camino.

- La mediación entre actores y artefactos para coordinar acciones, intercambiar y sintetizar perspectivas y puntos de vista y establecer referencias estables compartidas. 


\section{¿Para qué sirven los bocetos en la ideación?}

De acuerdo con el uso que les dan los diseñadores los bocetos para la ideación de diseño se pueden clasificar en tres tipos: bocetos para pensar (que apoyan los aspectos cognitivos, el pensamiento no verbal, durante la generación, exploración y evaluación de ideas), bocetos para conversar (el uso de la superficie compartida de dibujo para soportar discusiones grupales) y bocetos para archivar (el uso de la superficie de dibujo como forma de registrar y guardar las ideas de diseño para una futura referencia, como memoria externa)[66].

Los bocetos para pensar son importantes para la re-interpretación que proporciona nuevos conocimientos y este nuevo conocimiento lleva a más re-interpretación[191]. Varios investigadores proponen modelos cíclicos de re-interpretación, cada uno con una connotación ligeramente diferente. Por ejemplo el tipo de argumentación dialéctica entre ver-como y ver-eso de Goldschmidt [82] o las conversaciones interactivas con el boceto material de Schön[210]. Goldschmidt observa que los diseñadores producen bocetos ambiguos y poco claros. Ella sugiere que este es un componente sustancial de la creatividad en el proceso de diseño. Basándose en estudios de protocolo, Goldschmidt señala que, mientras hacen bocetos de ideas, los arquitectos utilizan de manera dialéctica dos tipos de razonamiento. Un tipo se basa en el pensamiento analógico o metafórico, que trata de extraer nuevo significado del croquis. Ella describe este tipo de razonamiento como ver-como. El otro tipo, ver-eso, se ocupa de las consecuencias de diseño de este significado recién adquirido del boceto[82]. Schon y Wiggins observan que los diseñadores desarrollan sus productos entablando una conversación interactiva con el papel en el que se basan. Describen el diseño como un proceso cíclico de bosquejar, interpretar y llevar los bocetos más allá. Según ellos: trabajando en algún medio visual de dibujo, en nuestros ejemplos el diseñador ve lo que está "allî" en alguna representación de un sitio, dibuja en relación con él, y ve lo que se ha dibujado, informando así al diseño adicional. En todo este "ver", el diseñador no solo registra visualmente la información, sino que también construye su significado e identifica los patrones y les da un significado más allá de ellos mismos[210]. Estas teorías proporcionan dos funciones generales de boceto dentro del proceso individual del diseñador. Primero, el boceto permite movimientos tentativos y no comprometidos de la descripción general a una específica. Segundo, el boceto implica un proceso cíclico de re-interpretación.

Sobre los bocetos para conversar, uno de los temas de interés es el rol del "contexto visual compartido" en la comunicación. En una discusión de diseño, el contexto visual compartido se puede usar para hacer referencias relativas, por ejemplo: "combinémoslo con eso", en lugar de describir toda la idea al referirse a ella. De esta manera, las referencias relativas proporcionan un proceso de comunicación más eficiente. En la comunicación de diseño, el uso de bocetos dibujados rápidamente en apoyo de las discusiones de grupo podría llevar a un proceso de diseño más eficiente al proporcionar un contexto visual compartido. . También se sugiere un segundo rol: el hecho de que los dibujos usualmente se acompañan de verbalizaciones apoya la idea de que los bocetos sólo parcialmente representan las ideas en mente. En general, un acto de dibujar en el bocetado no es un intento de representar una solución como tal, sino 
que es un dispositivo de notación que ayuda a su creador a razonar con estructuras mentales complejas. El proceso de creación y uso de dibujos transmite información que no se encuentra en los dibujos resultantes[212].

En la investigación sobre el pensamiento de diseño hay poca información relevante sobre los bocetos para archivar. Sin embargo a partir de investigaciones en cognición visual se han mostrado diferencias entre el reconocimiento de imágenes y palabras. Aparentemente es más fácil categorizar imágenes de objetos que las palabras que representan a los mismos objetos[189]. En la medida que los bocetos son más fáciles de reconocer entre otros bocetos, ellos facilitan el acceso de los diseñadores a ideas previas. Un acceso más fácil a esas ideas es probable que estimule su uso creciente. Por eso, los bocetos pueden impulsar el uso de información de ideas generadas antes si se facilita el acceso a esas ideas[154].

\section{Las enacciones del diseñador durante el bocetado}

Durante el bocetado los diseñadores no sólo realizan gráficos sobre un papel, sino que se acompañan usualmente de numerosos gestos y actuaciones. La actuación, en la que una persona representa el desempeño de otra persona o anima el comportamiento de un objeto, se ha considerado vital en el diseño. Al representar el rol de los usuarios y los componentes del sistema, un diseñador puede descubrir mejor cómo un sistema interactivo debe comportarse y aparecer ante el usuario[43, 229, 197].

En un ejemplo clásico de este comportamiento, se dice que Jeff Hawkins (el inventor de la PalmPilot) solía caminar con pequeños trozos de madera en su bolsillo a modo de prototipo de PDA para descubrir dónde y cuándo podría usar el producto[171]. Buchenau y Suri describen este tipo de prácticas como "prototipos de la experiencia de uso". La idea es que el diseñador experimente personalmente en lugar de ver una demostración o la actuación de otra persona para facilitar la comprensión de los problemas y la empatía con los interesados y sus experiencias[31].

Además de este tipo de técnicas planificadas y estructuradas, existen otras actuaciones que son imprevistas, situadas y se dan por sentadas. Estas expresiones de la dinámica de interacción y uso a menudo toman la forma de gestos.

Los diseñadores frecuentemente utilizan las manos para hacer referencias y gestos, para aclarar o enfatizar conceptos. Los gestos forman una parte importante del lenguaje de acción espacial de los diseñadores y hacer gestos es una forma conveniente de expresar el comportamiento tanto de los usuarios como de los objetos[108]. Estas actuaciones gestuales se hacen a veces en relación con el texto o un boceto. Sin embargo, los gestos y las acciones hipotéticas de los usuarios son efímeros y no dejan representaciones estables para un futuro escrutinio. Realizar secuencias de actuaciones de colaboración es una forma de explorar ideas y compartir conocimientos. Crean una experiencia vivida para el actor que también puede ser vista y 
evaluada por otros. Esto ayuda al equipo de diseño a centrarse el usuario en todas las etapas del diseño.

Schön afirma que "el diseñador diseña no solo con la mente, sino con el cuerpo y los sentidos, un hecho que plantea un desafío interesante para las computadoras"[209]. Sin embargo, los estudios sobre el comportamiento de los diseñadores se han centrado en gran medida en descubrir sus acciones cognitivas. Si bien hay algunos trabajos que también enfatizan el comportamiento físico de los diseñadores, el enfoque típico está en los métodos de diseño, y no en el soporte digital. La investigación sobre interacciones multimodales para el diseño ha resaltado la importancia de usar el habla y las acciones junto con los bocetos, pero normalmente se usa el video y el audio para capturar estas acciones. Los desarrollos recientes en las técnicas de interacción no tradicionales que incluyen interacciones tangibles, hápticas, verbales e incluso de todo el cuerpo, han creado una oportunidad para brindar apoyo computacional a los diseñadores al capturar su intención y razón de ser a través de sus acciones, habla y bocetos. La diferenciación entre acciones pragmáticas y epistémicas está relacionada con este comportamiento. En efecto, el desarrollo de acciones pragmáticas (las que llevan a un progreso directo en la tarea) mientras que las epistémicas (las que alteran el mundo para que los procesos cognitivos sean más rápidos, confiables y menos exigentes) son una consecuencia del uso de interacciones tangibles y corporizadas[130, 128].

El uso del propio cuerpo a través de acciones pragmáticas y epistémicas para la ideación de interacciones corporizadas está soportado además en la comprobación de que "observar no es tan bueno como actuar" ya que cada uno de nuestros sentidos recoge información diferente. La visión proporciona solo una fracción de la información necesaria para adaptarse interactivamente a las fuerzas que cambian rápidamente en nuestro entorno o cuerpos. Estos deben ser recogidos cinestésicamente[128]. Por ejemplo, cuando un alfarero trabaja en el volante y forma un cuenco, hay atributos sensoriales que se pueden sentir con las manos que no se pueden ver, como la sensación cuando la arcilla está a punto de rasgarse, o la sensación de la textura de la arcilla. El alfarero puede sentir el "espacio de continuación" de esta olla, el paisaje enactivo, de manera más efectiva y estar mejor posicionado para saber si él puede recuperarse de una situación que está a punto de arrancar. Las manos saben cosas que los ojos no saben.

El acto físico de dibujar un objeto familiar puede ayudarnos a comprender aspectos de él que nunca antes habíamos notado o pensado. Jugar con un modelo físico de algo que se vio por primera vez en las películas, un juguete transformador, por ejemplo, puede abrir nuestras mentes a algunas de sus propiedades más profundas. Sigue siendo el mismo objeto, y todavía tenemos el mismo concepto básico de él, pero sabemos más sobre él o lo vemos de una manera nueva. Participar físicamente nos ayudó a aprender mucho más que simplemente ver a alguien más jugar con él. Esto es de fundamental importancia a la hora de la ideación de interacciones enactivas[128]. El bocetado de interacciones enactivas tiene que soportar este proceso y facilitar la experimentación con objetos físicos durante la ideación. 


\subsection{Soporte al diseño de interacciones enactivas}

En esta sección reviso las diversas formas de soporte al proceso de ideación, bocetado y prototipado de interacciones corporizadas y enactivas que han sido publicadas. Comienzo por detallar el método de consulta, recolección y depuración. Finalmente, analizo los artículos seleccionados en relación con mi investigación.

El rango de contribuciones relevantes van desde frameworks conceptuales o teóricos hasta los toolkits de soporte a alguna de las actividades concretas del proceso de ideación, con un amplio espectro de trabajos que combinan ambos aspectos entre esos extremos. Dentro de HCI el término framework se utiliza para describir una forma de guía para el diseño y análisis[202]. Suelen derivarse de una teoría o un conjunto de asunciones sobre la estructura y la función de un fenómeno. Por ejemplo, el framework de Bellotti[19] para las interacciones basadas en sensores se inspira en ideas de las ciencias sociales. Otros emergen a partir del sentido común, la práctica del diseño y las generalizaciones derivadas de estudios de usuarios. Estos frameworks pueden tener propósitos diferentes como brindar registros explicativos de un fenómeno, presentar modelos predictivos, ofrecer guías prescriptivas o generativas para el diseñador. Las guías para utilizarlos van desde preguntas, desafíos, principios o heurísticas generales hasta etapas bien detalladas de los pasos a dar. En el otro polo, los toolkits pueden verse, según la definición básica de Greenberg, como una forma de encapsular los conceptos de interfaces de diseño para programadores, incluyendo conjuntos de widgets, constructores de interfaces y entornos de desarrollo[88]. Estos toolkits son empleados por los diseñadores y desarrolladores parar crear aplicaciones interactivas. Por lo tanto se trata de plataformas generativas diseñadas para crear nuevos artefactos, con la posibilidad de simplificar el proceso de autoría y habilitar exploraciones creativas. Ledo et al extienden esa definición agregando que "(los toolkits) proveen acceso fácil a algoritmos complejos, habilitan el prototipado rápido de interfaces de software y hardware y/o habilitan la exploración creativa del espacio de diseño"[144].

\section{Proceso de búsqueda y selección}

Para la búsqueda de trabajos pertinentes utilicé un proceso en etapas. Ejecuté la query que se indica a continuación sobre Scopus y obtuve 78 artículos publicados:

\footnotetext{
TITLE-ABS-KEY ( (framework OR tool OR toolkit) AND ( sketching OR prototyping ) AND ( "interaction design" OR design OR "user interface" ) AND (embodied OR tangible OR enactive) )
}

En la primera etapa, definí tres criterios de inclusión (está relacionado con el diseño de interacciones, incluye hardware para hacer prototipos interactivos o esquemas y guías conceptuales para comprender o facilitar el diseño corporizado) y de exclusión (no está relacionado con el diseño de interacciones, no está dirigido a diseñadores). Tras la lectura del resumen de los 


\begin{tabular}{lllll}
\hline & $\begin{array}{l}\text { Abstraer, organi- } \\
\text { zar }\end{array}$ & $\begin{array}{l}\text { Idear, dibujar, di- } \\
\text { señar }\end{array}$ & $\begin{array}{l}\text { Maquetar, cons- } \\
\text { truir }\end{array}$ \\
\hline Experiencia & {$[51,109]$} & {$[105,202,146]$} & {$[5]$} \\
\hline Interactividad & {$[152,151,237$,} & $\begin{array}{l}{[19,21,213,94,} \\
134,181,253,\end{array}$ \\
& $109]$ & $207]$ & $162,206,106,33$, \\
& & $\begin{array}{l}154,214,245, \\
186,63]\end{array}$ & {$[10,71,138,81$,} \\
& {$[68,101]$} & $205,161,135]$ \\
\hline
\end{tabular}

Tab. 3.1.: Mapa de organización de los trabajos revisados

78 artículos y su contraste contra los criterios de inclusión y exclusión el universo se redujo a 40 artículos. El listado completo de las referencias correspondientes está incluido en la Tabla 3.1.

La segunda etapa consistió en la lectura completa de los 40 artículos incluidos en la revisión, su organización en un esquema de dos dimensiones y su análisis. Utilicé dos dimensiones (ver Tabla 3.1) inspiradas en el trabajo de Mazalek y van den Hoven[164]) para organizar frameworks y toolkits para interacciones tangibles (cuando algún trabajo puede considerarse en más de una categoría se encuentra repetido en la celda correspondiente).

En el primer eje organizo los artículos según el propósito de asistencia que persiguen:

- Abstraer, sirven como herramientas de pensamiento, por ejemplo, al mapear el espacio de sistemas corporizados o al proporcionar taxonomías.

- Diseñar, sirven como herramientas en la ideación de diseño al plantear preguntas o desafíos o delinear los espacios problemáticos.

- Construir, proporcionan pasos concretos, heurísticas, pautas o herramientas para crear un sistema corporizado y, a veces, implementar rápidamente un boceto o prototipo del mismo.

En el segundo, selecciono tres tópicos importantes en los que el diseñador de interacciones corporizadas y enactivas hace foco: la corporización del diseño, la interactividad o la experiencia final del usuario.

- Corporización, intentan comprender el potencial y los recursos de diferentes formas físicas para sistemas interactivos

- Interactividad, abordan la interacción entre el usuario y el sistema, así como las asignaciones entre los espacios físicos y digitales, por ejemplo, diseñando enfoques de entrada de usuario o definiendo relaciones entre acciones físicas y efectos digitales

- Experiencias, enfocan en temas generales del paradigma de la experiencia del usuario como el disfrute, la estética y estimulación cognitiva

De los diferentes tipos de soporte según su propósito, el mayor número de ejemplos está repartido entre los grupos de diseñar y construir. Es lógico, considerando el explosivo crecimiento que en las últimas décadas se dio de plataformas de hardware y software libre con bajo 
umbral de acceso. Por su parte, la categoría de abstraer o conceptualizar está compuesta por frameworks, algunos de los cuales proveen guías específicas orientadas a la formulación de ideas de interactividad y corporización basadas en sensado, como Bellotti et al[19] y Benford et $\mathrm{al}[21]$.

Respecto a las facetas de diseño, la mayoría de los artículos abordan la interactividad y la corporización, lo cual es previsible en virtud de que se trata de los temas esenciales para el diseño de sistemas corporizados y que el origen de todas las propuestas yace en la ingeniería de software y en las líneas tradicionales de HCI. Muy pocos trabajos abordan de manera explícita la generación de ideas de diseño orientadas a las cualidades experienciales del sistema final. Las áreas vinculadas con las experiencias tiene un desarrollo más reciente (por ejemplo el trabajo de Rogers y Muller[202]). El trabajo de Hummels y van Dijk[109], que podemos ubicar entre los orientados al diseño con foco en las facetas de la experiencia y las interacciones, es el único framework que explícitamente hace uso de las teorías de cognición corporizada y fenomenología dejando de lado el enfoque basado en las ideas de representación para construir híbridos físico-digitales verdaderamente orientados al estar-en-el-mundo.

\subsubsection{Herramientas para abstraer y organizar}

Entre los trabajos publicados con frameworks y taxonomías para organizar la ideación de sistemas corporizados se destaca el trabajo pionero de Ishii y Ullmer con su framework y modelo de interacción para interfaces tangibles(TUI) [237]. Ese trabajo se centró principalmente en el tipo de asociaciones de representación física y digital con artefactos (ver Figura 3.4). Van den Hoven y Eggen[107] lo ampliaron subdividiéndolo en asociaciones fijas y flexibles, simbólicas e icónicas. Hoven y Eggen también agregaron una segunda dimensión con respecto a los tipos de objetos físicos (o artefactos), que pueden ser genéricos o personales. La última dimensión se refiere a la ausencia o presencia de un modelo mental ya existente de las asociaciones entre objetos físicos e información digital. Por ejemplo, cuando trae un recuerdo de unas vacaciones, puede usarlo en una interfaz de usuario tangible, ya que este artefacto físico ya está disponible y ha pasado una selección crítica por parte del propietario. Además, la reutilización de este artefacto puede reducir el tiempo de aprendizaje mediante el uso de modelos mentales existentes, como el conocimiento de qué fotos digitales y videos están vinculados al recuerdo. Este marco se centra en la corporización través de la abstracción. Aunque, como vimos en el Capítulo 2 no responde completamente a teorías de cognición corporizada, por su carácter pionero es una referencia ineludible en este campo.

Fishkin[68] presenta una taxonomía basada en el espectro para categorizar sistemas tangibles de acuerdo con el nivel de corporización. Sugiere que este enfoque proporciona una visión más amplia de los sistemas tangibles y, por lo tanto, puede unificar los marcos anteriores y también extenderlos para integrar sistemas que no se consideran estrictamente interfaces de usuario tangibles, como los de la computación ubicua. El documento es principalmente útil para examinar y comparar sistemas existentes, pero también puede servir para inspirar a los 


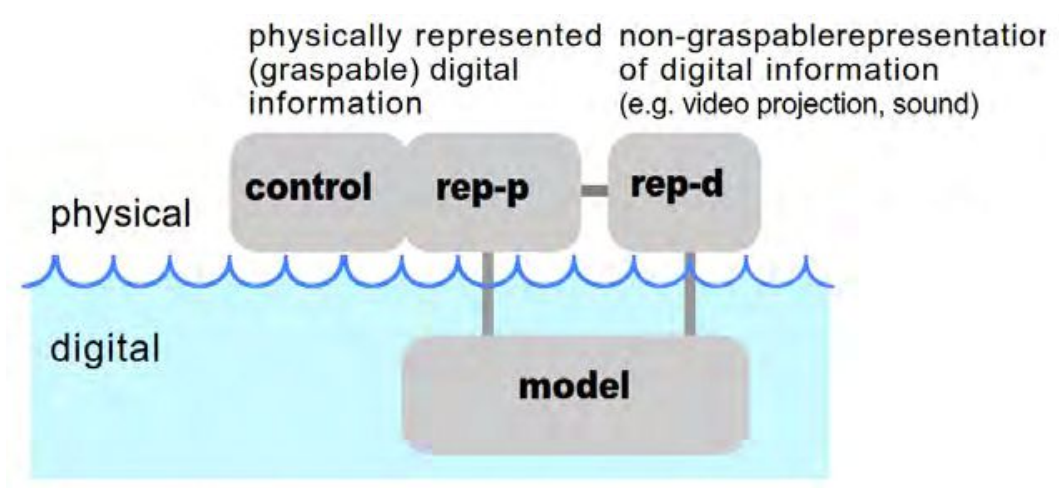

Fig. 3.4.: Modelo de interacción de interfaces tangibles MCRpd -Model Control Representation (physical and digital)- propuesto por Ullmer e Ishii y basado en el MVC de Smalltalk-80. Tomado de [237]

\begin{tabular}{ll}
\hline $\begin{array}{l}\text { Dimensiones de } \\
\text { filtrado }\end{array}$ & Variables de ejemplo \\
\hline Apariencia & tamaño, color, forma, peso, textura \\
\hline Datos & tamaño de dato, tipo de dato, uso de datos \\
\hline Funcionalidad & función de sistema, necesidad de usuarios \\
\hline Interactividad & $\begin{array}{l}\text { comportamiento de input, comportamiento de output, } \\
\text { feedback, información }\end{array}$ \\
\hline Estructura espacial & $\begin{array}{l}\text { disposición de interfaz, relación entre elementos de } \\
\text { interfaz (tangible, intangible, mezclado) }\end{array}$ \\
\hline
\end{tabular}

Tab. 3.2.: Dimensiones de filtrado de bocetos y prototipos, adaptado de Anatomía de Prototipos de $\operatorname{Lim}[152]$

diseñadores al proporcionarles una manera de pensar sobre el nivel de corporización y la metáfora a la que aspiran en sus diseños.

Un enfoque más reciente, vinculado también con la abstracción del dominio y con soporte en las teorías cognitivas mencionadas en el Capítulo 2 es el de Hummels y van Dijk[109]. Presentan un framework para pensar el diseño de tecnología para la construcción de sentido por acoplamiento sensorio motor que incluye siete principios de diseño: situacionalidad social, andamiaje cognitivo, trazabilidad, imaginería interactiva, sistema dialógico, perspectiva de primera persona, compromiso catalizador. Si bien este enfoque es el más próximo al abordaje de mi investigación, el trabajo de Hummels y van Dijk está orientado al diseño de tecnología para encuentros personales y los siete principios están basados en elicitar acoplamientos sensorio motores para soportar coordinaciones sociales entre los participantes.

Otros trabajos cuya intención es facilitar la abstracción y ubicación conceptual del trabajo del diseñador es la identificación y propuesta de dimensiones o vocabularios para la interacción, como los trabajos de Lim[152, 151], Holmquist[101] y Diefenbach[51].

Lim, Stolterman y Tenenberg[152] propusieron un framework para conceptualizar los prototipos (de acuerdo con su definición, un boceto sería una versión de baja fidelidad de prototipos). El framework, denominado Anatomía de prototipos, se estructura a partir de dos aspectos 


\begin{tabular}{lll}
\hline $\begin{array}{l}\text { Dimensiones de } \\
\text { manifestación }\end{array}$ & Definición & Ejemplos de variables \\
\hline Material & $\begin{array}{l}\text { Medio usado para dar forma } \\
\text { al boceto-prototipo }\end{array}$ & $\begin{array}{l}\text { Medio físico: materiales, } \\
\text { herramientas físicas o de } \\
\text { computación, objetos } \\
\text { reusados, etc. }\end{array}$ \\
\hline Resolución & $\begin{array}{l}\text { Nivel de detalle o sofisticación } \\
\text { de lo que se manifiesta }\end{array}$ & $\begin{array}{l}\text { Precisión de performance: } \\
\text { detalles de apariencia, } \\
\text { detalles de interacción, datos } \\
\text { reales vs simulados }\end{array}$ \\
\hline Alcance & $\begin{array}{l}\text { Rango de lo que se cubre con } \\
\text { lo manifestado }\end{array}$ & Nivel de contextualización \\
\hline
\end{tabular}

Tab. 3.3.: Dimensiones de manifestación de bocetos y prototipos, adaptado de Anatomía de Prototipos de $\operatorname{Lim}[152]$

fundamentales: los prototipos constituyen manifestaciones intencionadas de las ideas de diseño y están para atravesar el espacio de diseño, conduciendo a la creación de conocimiento significativo en cada paso del proceso. En ese trabajo, Lim y sus colegas identifican un conjunto de aspectos del diseño que el boceto-prototipo podría exhibir (lo que ellos llaman dimensiones de filtrado). El término filtro es utilizado para connotar la selección que el diseñador realiza de una parte del espacio de diseño, descartando de momento las facetas que no quiere o no necesita explorar. La decisión sobre qué filtrar responde siempre al propósito del prototipo. Cuando un diseñador crea un prototipo que manifiesta cierto aspecto de la idea de diseño, necesita elegir cuidadosamente el material, resolución y alcance del prototipo. Entre las dimensiones de filtrado vale mencionar la que será el centro de nuestro trabajo: la interactividad (descripta como el comportamiento entre entradas y salidas). Otras dimensiones de filtrado son la apariencia, los datos, la estructura espacial. En tanto manifestaciones de una idea de diseño, proponen tres dimensiones: el material (el medio elegido para darle forma al prototipo), la resolución (nivel de detalle o sofisticación de lo que se manifiesta, a veces conocido como "fidelidad") y alcance (el rango de lo que es manifestado de la idea). Las Tablas 3.2 y 3.3 adaptadas del artículo de Lim et al[152] detallan estas dimensiones y brindan algunos ejemplos.

La anatomía de los prototipos tiene una continuidad en la definición de atributos de interactividad presentada en Interactivity Attributes: A New Way of Thinking and Describing Interactivity[151]. En este trabajo proponen una forma de describir la dimensión de interactividad basada en una serie de 7 atributos con el propósito de usarlos como un lenguaje de diseño para pensar y describir la interactividad (concurrencia, continuidad, previsibilidad, rango de movimiento, velocidad de movimiento, proximidad,velocidad de respuesta). Los trabajos de campo mostraron que todos los atributos de interactividad fueron significativos. Parte de nuestro trabajo con las diferentes versiones de Pluma se basa en este vocabulario de interactividad.

Holmquist[101] propone un vocabulario para la interacción tangible a partir de abstraer su propia experiencia en diseño de sistemas corporizados. Introduce los conceptos de contenedores, 
herramientas y tokens, tres tipos de objetos físicos que pueden asociarse con información digital. Los contenedores y las herramientas no reflejan con su apariencia física una relación con la información digital asociada, mientras que los tokens sí lo hacen. Las fichas y los contenedores se utilizan para almacenar información digital. Las herramientas pueden manipular la información digital, y por lo tanto, típicamente representan funciones. Los grifos pueden presentar la información asociada con los tokens, y el concepto de sobrecarga se refiere al hecho de que los tokens pueden asociarse con más información simultáneamente. El marco también proporciona ejemplos de cómo se deben diseñar los tokens, considerando el uso de materiales, tamaños físicos y formas y el contexto de uso. Por ejemplo, los tokens que representan información a corto plazo podrían estar hechos de materiales que se desgastan. El foco está claramente en la corporización sobre cualquier otra dimensión.

El abordaje de Diefenbach, en cambio, está completamente orientado a los aspectos experienciales del uso. En An Interaction Vocabulary. Describing The How Of Interaction [51] sostienen que además de la estética visual del producto, el diseño debe abordar la estética de la interacción. En el trabajo presentan un enfoque propio del Cómo de la interacción. Sugieren un vocabulario de interacción compuesto por un conjunto de once rangos o dimensiones descriptivas de la interacción no relacionados con una tecnología específica (por ejemplo, lento-rápido, discreto-fluido, constante-inconstante, aproximado-preciso, etc.). El trabajo presenta ejemplos de aplicación del vocabulario con casos de diseño. Nuestro trabajo en Pluma utiliza este lenguaje junto con los atributos de interactividad de Lim[151].

\subsubsection{Herramientas para diseñar, idear, dibujar}

Ya hemos señalado que la ideación en diseño es un proceso que continuamente lleva al diseñador del foco sobre el problema al énfasis en la solución, con evaluaciones constantes para ajustar la orientación y hacer correcciones tempranas. El boceto, la herramienta por antonomasia de este proceso, difiere de otros dominios de diseño que lo emplean en que para el caso de las interacciones es imprescindible esbozar el aspecto dinámico, temporal de la relación entre el producto y el usuario. Sumado a ello, para el caso de las interacciones corporizadas y enactivas existe además la necesidad de expresar aspectos de la experiencia difíciles de graficar: lo kinestésico, háptico, sonoro, etc.[227, 64, 118].

Para apoyar estos requerimientos, encontramos algunos frameworks que plantean sugerencias o guías en formatos de preguntas y principios de trabajo y herramientas que soportan algunas tareas específicas como versiones digitales de la graficación y análisis de interacciones durante la ideación. Los trabajos de Bellotti (Making sense of sensing systems[19]) y Hartmann (Reflective physical prototyping through integrated design, test, and analysis[94]) además de su carácter pionero, reflejan el tipo de aporte al pensamiento y acción del diseñador que buscamos con la tesis: soportar la actividad del profesional en la acción, con su propia racionalidad de proceso sin guiarlo de manera prescriptiva, pero proveyéndole oportunas guías y ayudas para aumentar su capacidad de crear y evaluar propuestas en el proceso de ideación. 
Bellotti propuso un marco para abordar los desafíos de diseño de los sistemas de sensado que se basa en los aspectos comunicativos de la interacción, aprovechando lecciones de las ciencias sociales. El marco sugiere cinco preguntas que un usuario debe poder responder para saber cómo comunicarse con un sistema basado en sensores: cómo abordar el sistema, cómo captar su atención, cómo iniciar una acción, cómo monitorear la respuesta y cómo recuperarse de los errores. Con ese enfoque el framework sirve como una herramienta de pensamiento para diseñar y construir sistemas de detección ayudando a diseñar, refinar y depurar los aspectos comunicativos de la interacción usuario-sistema de los sistemas de detección.

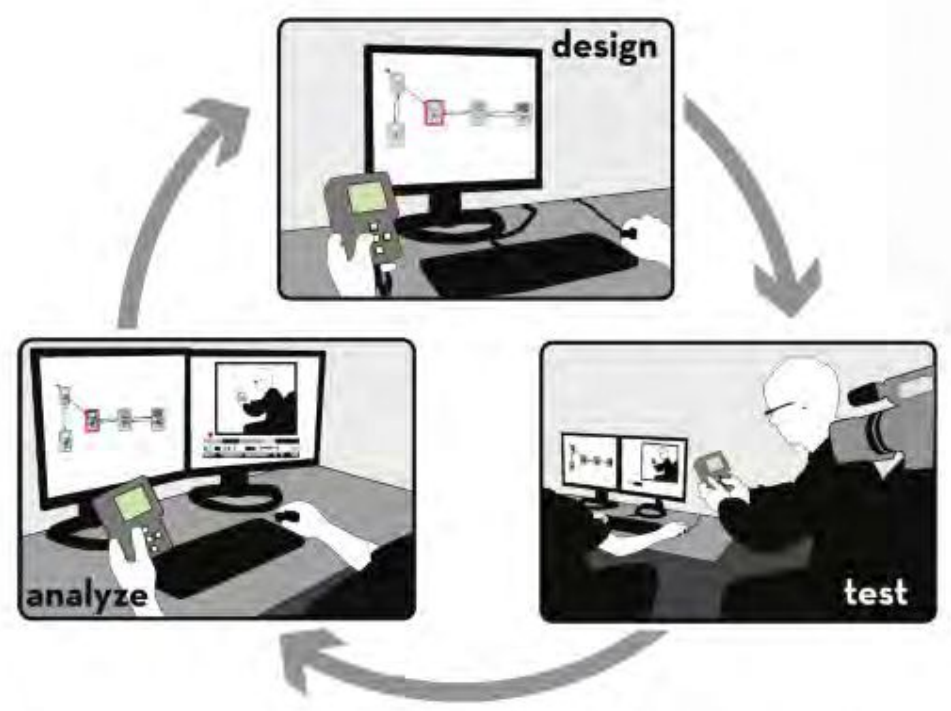

Fig. 3.5.: Soporte del pensamiento de diseño en d.tools[94]

Con d.tools Hartmann introduce la idea de herramientas que den soporte al ciclo iterativo de diseñar-probar-analizar basado en prototipos (ver Figura 3.5). El trabajo describe tres aportes: una herramienta de autoría visual basada en diagramas de transición de estado que proporciona un umbral bajo para la creación de prototipos; tres tipos de extensibilidad de hardware: en la interfaz de hardware a PC, el nivel de comunicación intra-hardware y el nivel de circuito; finalmente d.tools integra el diseño, prueba y análisis de los dispositivos de información. El trabajo provee soporte para que los diseñadores prueben los prototipos con usuarios y lo analicen mediante una anotación sincronizada entre la ejecución de los statecharts y el video (ver Figura 3.6).

Benford [21] utilizan un enfoque similar al de Bellotti con un marco para el diseño de la interacción basada en la comparación de los movimientos que un usuario normalmente haría (sensible), aquellos que pueden ser detectados por el sistema informático (sensable) y aquellos que son deseados por la aplicación (desirable). El marco intenta soportar tanto la generación de ideas en las etapas iniciales como analizar y refinar prototipos. Los autores sugieren que los diseñadores deberían utilizar las taxonomías de interfaz existentes para comprender los posibles movimientos esperados y detectados, y los métodos de diseño existentes (por ejemplo, participativos, inspiradores) para identificar el conjunto de movimientos deseados. De esa 


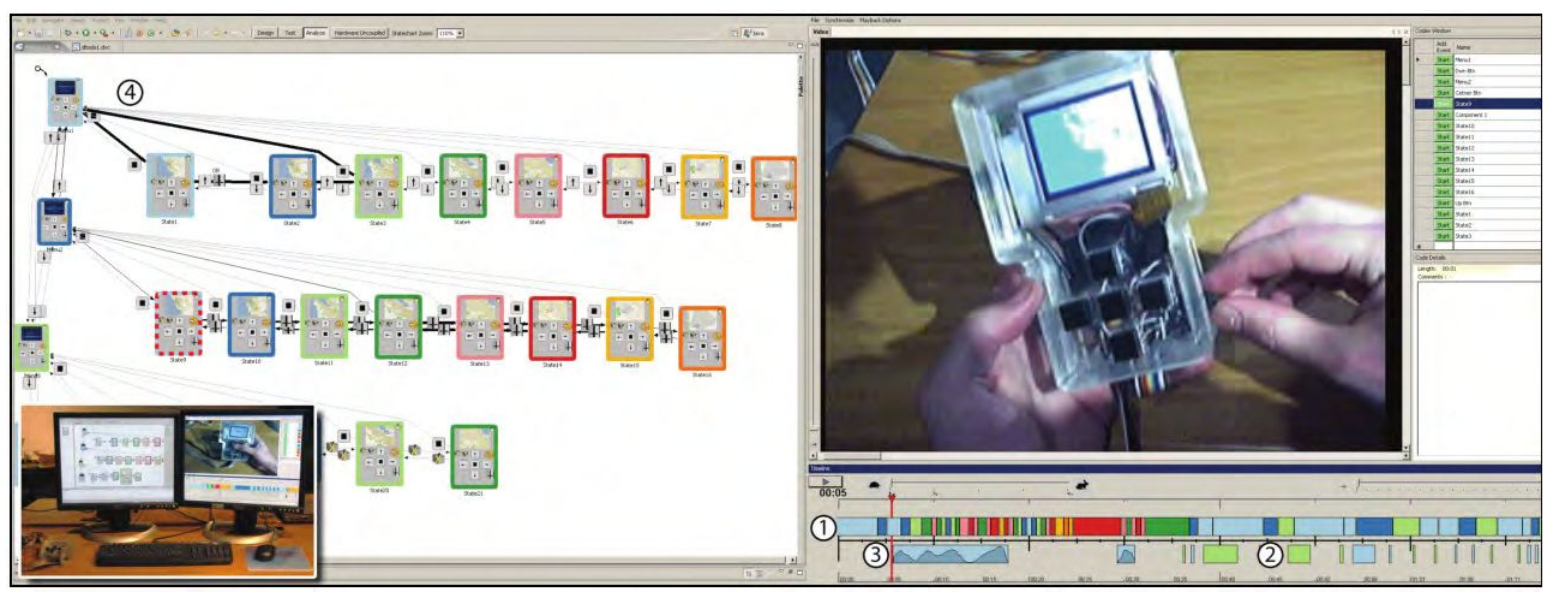

Fig. 3.6.: d.tools en modo análisis. La ejecución del statechart y el video se sincronizan y marcan para facilitar el análisis

manera, el framework ayuda a aclarar el pensamiento de diseño y generar ideas. Sin embargo, requiere que los diseñadores busquen en otra parte una guía detallada para seleccionar las tecnologías de detección, las interacciones y las formas físicas más adecuadas para su aplicación.

Otros trabajos han extendido y variado este tipo de ayudas para idear basadas con preguntas y guías conceptuales o versiones digitales del boceto analógico, enfocadas en alguna de las dimensiones que mencionamos antes: la interactividad, la corporización o fisicalidad del dispositivo o la experiencia del usuario final.

En la dimensión de la interactividad, creo relevante citar el Paradigma TAC de Shaer[213] y las herramientas Squidy[134], Sketchify[181] e Interactivity Sketcher[253].

Shaer et al[213] introducen el paradigma TAC (token and constraints), que proporciona construcciones para describir las Interfaces Tangibles como un conjunto de relaciones que mapean objetos físicos a información digital. De alguna manera es una extensión del framework de Ullmer e Ishii[237]. Parten de identificar como desafío clave en el diseño de aplicaciones corporizadas la naturaleza interconectada de los mundos físicos y virtuales y la falta de dispositivos de entrada y salida estandarizados y resaltan la necesidad de un kit de herramientas que pueda ayudar a los diseñadores a especificar, simular y construir esas interacciones. TAC aborda esta necesidad proporcionando un método de alto nivel para describir la estructura y funcionalidad de un sistemas, con cinco constructos básicos: pyfo, token, constraint, variable y TAC. Pyfo es un objeto físico que integra la interfaz tangible, token es un pyfo asible que representa información o función digital, constraint es un pyfo que limita el comportamiento del token con el que está asociado, una variable es información digital y un TAC es una relación entre un token, sus variables y uno o más constraints. Con estos elementos define un lenguaje de alto nivel para analizar ejemplos de interacciones tangibles así como diseñar otras nuevas.

Squidy[134] es una herramienta para diseño de interacciones multimodales, basada en una arquitectura de software que unifica una gran variedad de controladores y dispositivos. El 


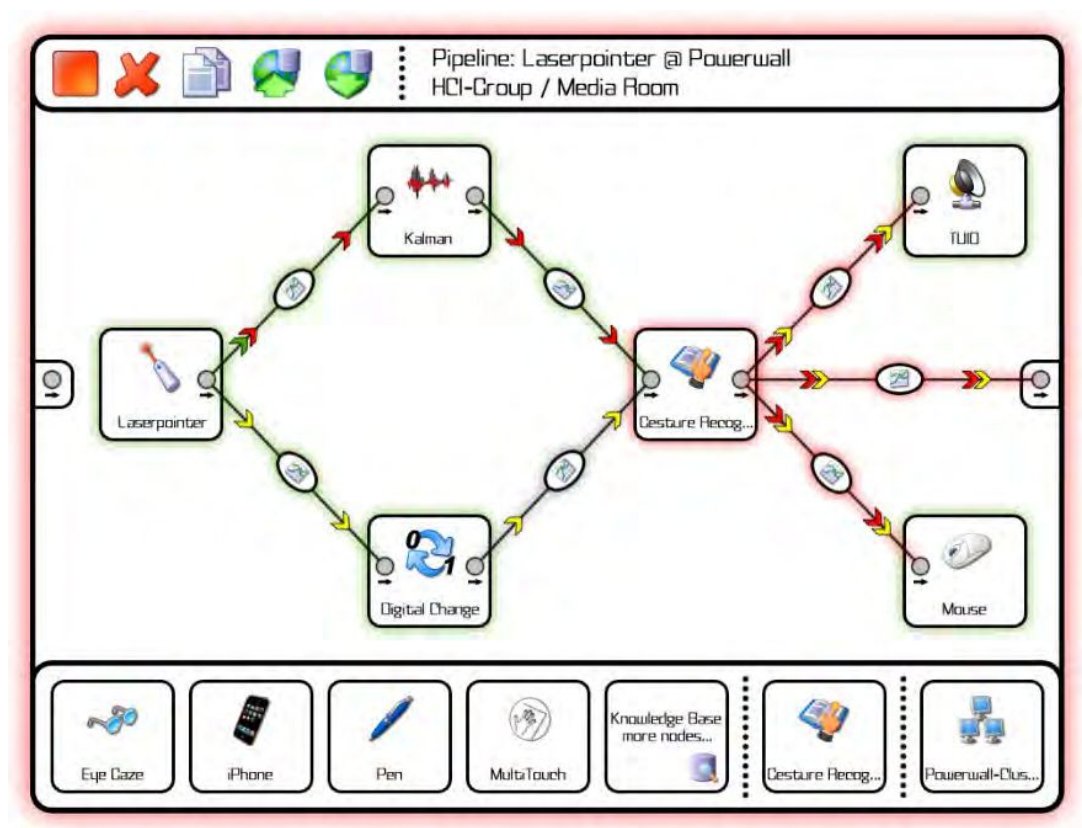

Fig. 3.7.: Pipeline en Squidy. El pipeline recibe datos de posición, botón e inercia del puntero laser, aplica un filtro Kalman, un filtro para reconocer cambio y otro para mejora de la selección y finalmente emula un mouse standar y envía datos via TUIO a las aplicaciones registradas. En la parte inferior de la pantalla presenta la base disponible de inputs, filtros y outputs. Tomado del trabajo de König[134]

entorno de diseño visual intenta mantener bajo el umbral (facilidad de uso), pero alto el techo (complejidad alcanzable). El sistema está basado en la construcción de diagramas de flujos de datos de entrada y salida con el concepto de pipe-and-filter (ver Figura 3.7). Squidy incluye una plataforma de prueba para estudios de evaluación comparativos controlados, así como técnicas estándar de registro y análisis para informar la iteración posterior del diseño.

Obrenovic presentó Sketchify[181] como una extensión de la idea de bosquejar con un lápiz sobre papel al concepto más genérico de la integración de materiales interactivos. Define material interactivo como cualquier pieza de software o hardware que representa o simula una parte de la experiencia interactiva del usuario (p.ej. la entrada de sensores, la salida en forma de sonido, video o imagen, o la interacción con servicios web o programas especializados). Sketchify es una herramienta para dibujar interfaces de usuario basada en esa idea. Combina dibujo a mano alzada (que incorpora como imágenes escaneadas) con widgets específicos de zonas interactivas. Por ejemplo, en la Figura 3.8 se muestra un dibujo a mano alzada de un iPod escaneado e insertado en Sketchify, al que se agregan algunas regiones activas para interactuar conformando un boceto interactivo. La arquitectura del sistema facilita la integración con otras aplicaciones y dispositivos que estén conectados a la computadora donde corre.

Como derivación de la anatomía de prototipos[152] y los atributos de interactividad[151], Woo presenta el Interactivity Sketcher[253]. Es una herramienta de diseño de interactividad que puede visualizar y experimentar las "cualidades invisibles de la interacción" de una manera tangible mediante el control de los atributos. El Interactivity Sketcher está compuesto por 


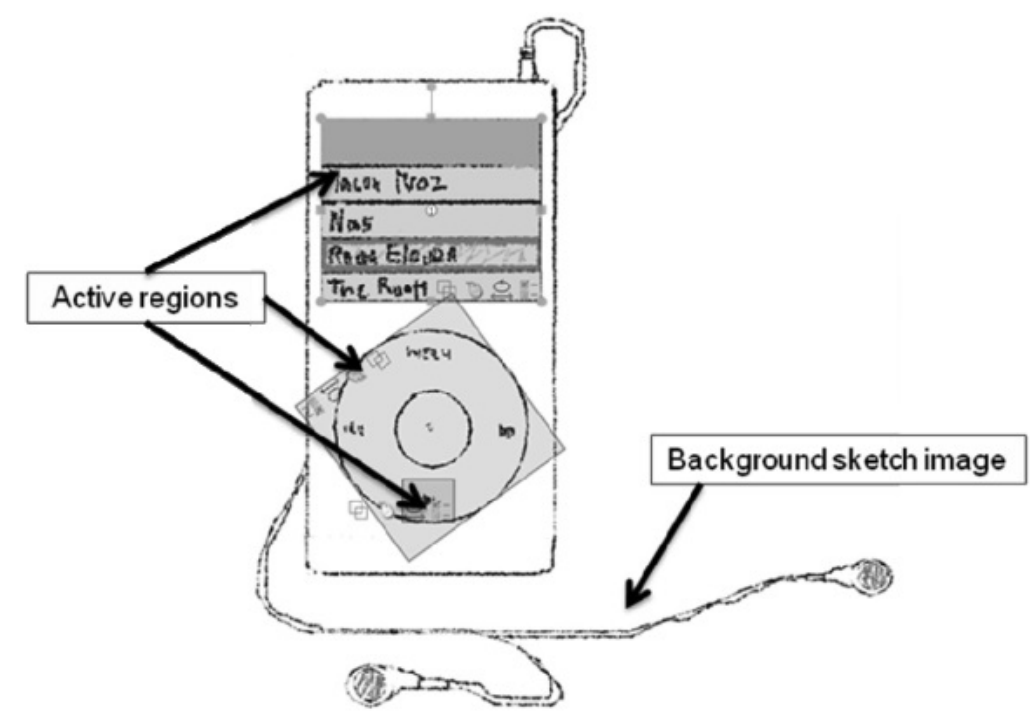

Fig. 3.8.: Boceto a mano alzada en Sketchify que contiene tres regiones activas para capturar los eventos del mouse y simular interacción. Tomado de [181]

una aplicación de software llamada IA y un conjunto de dispositivos de entrada y salida construidos sobre la base de sensores y actuadores controlados por Arduino (ver Figura 3.9). Esta herramienta intenta ayudar a explorar varias cualidades de interactividad al visualizar y manipular la relación entre una entrada y una salida a través de los controladores IA y la aplicación IA. El objetivo de los autores fue proveer una herramienta de bocetado de esos atributos de interactividad agnóstico a cualquier implementación concreta en términos de formas o tecnologías. En las versiones de Pluma (ver Capítulo 5) he tomado la idea de los atributos de interactividad, pero a partir del relevamiento de las teorías de la corporización (Capítulo 2) y de los estudios etnometodológicos de diseñadores (Capítulo 4) he descartado esta versión agnóstica del bocetado en favor de una que permita al diseñador enactuar sus bocetos con asiento en las formas físicas prefiguradas.

Otros trabajos en este tema se orientaron específicamente a soportar la dinámica de un sistema interactivo en funcionamiento. Como se ve en estudios realizados por Newman y Landay[175]) los diseñadores a menudo usan storyboards, además de los diagramas de transición que utilizó como sustento d.tools. Los storyboards son escenarios visuales que cuentan una historia. Desarrollado por primera vez por cineastas que intentan ilustrar sus manuscritos, están estrechamente relacionados con el lenguaje visual de los cómics y, con frecuencia, lo utilizan. Aquí los estados de la historia se expresan en marcos y los lectores tienen que inferir lo que sucede entre los marcos. Los bocetos en el diseño de interacción tienden a tomar la forma de storyboards, donde las flechas se usan para expresar movimientos y transiciones. Este hecho ha llevado a varios equipos de investigación a desarrollar herramientas informáticas para el storyboard (Silk[139], por ejemplo).

Entre los trabajos que se enfocan en los aspectos físicos o corporizados a la hora de generar ideas o dibujarlas vale mencionar las heurísticas de Sharlin[214], el Interaction frogger de 

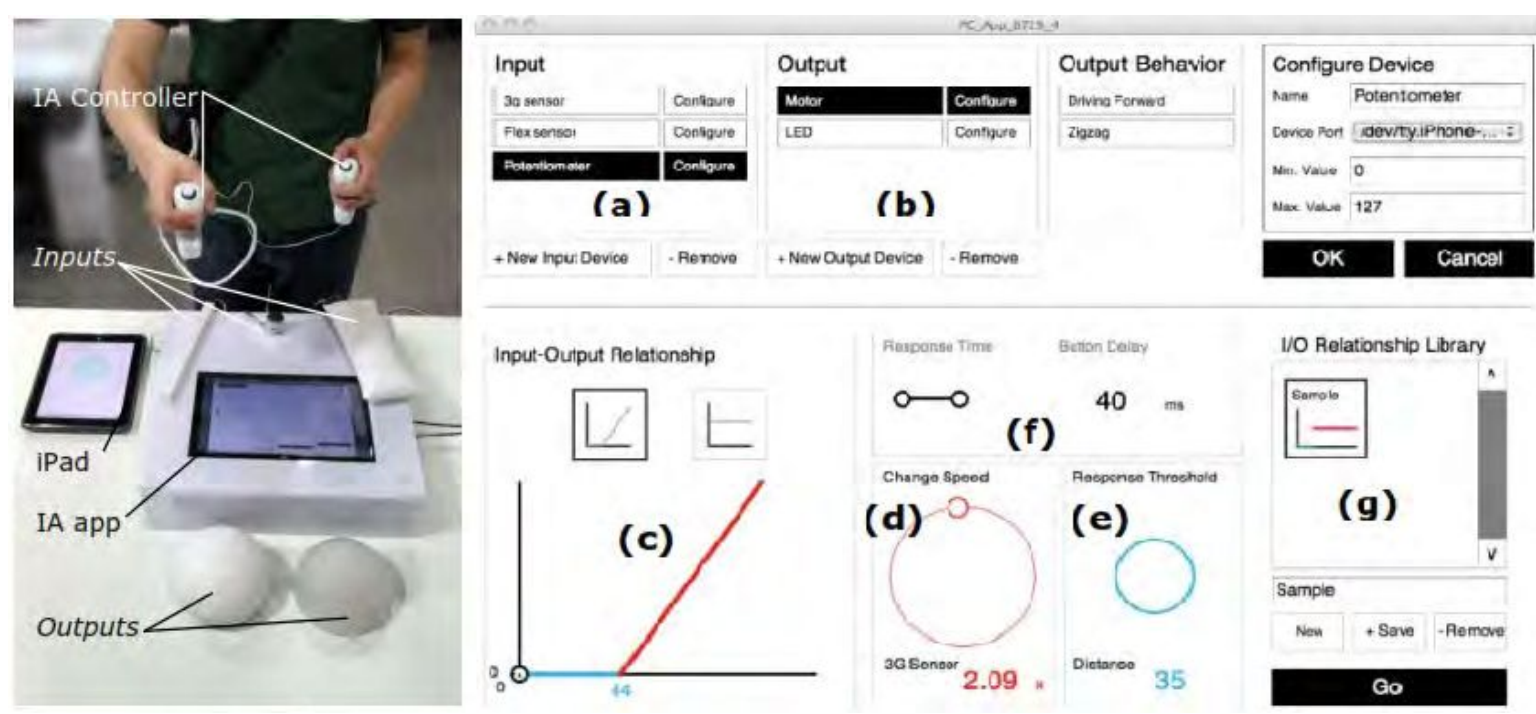

Fig. 3.9.: Interactivity sketcher. A la izquierda hardware que integra el toolkit, a la derecha layout de la aplicación IA para configurar la interactividad. Adaptado de [253]

Wensveen[245], las guías de Petrelli[186] y Djajadiningrat[54]. Como herramienta de soporte, el marco ATB de Esteves[63] para codificar acciones epistémicas en video.

Sharlin et al.[214] proponen tres heurísticas para incluir la corporización en el diseño de aplicaciones tangibles: primero, debe haber mapeos espaciales exitosos (relaciones físico digital), lo que equivale a una relación congruente entre las características espaciales de los objetos de la TUI; en segundo lugar, los mapeos entre lo físico y lo digital tienen que unificar el espacio de entrada y salida; finalmente, esos mapeos deben permitir una actividad exploratoria de prueba y error (probablemente eso requiere que los mapeos entre lo físico y lo digital sean uno a uno, en lugar de asignaciones transitorias de muchos a muchos o de uno a muchos).

Wensveen[245] presenta el Interaction Frogger, un marco que se centra en el acoplamiento entre la acción del usuario y la reacción del producto en tiempo, ubicación, dirección, dinámica, modalidad y expresión. Cuando este acoplamiento directo no es posible, se debe utilizar la retroalimentación para informar al usuario. Por lo tanto, el marco identifica tres categorías de retroalimentación: retroalimentación inherente, que es el resultado directo de una acción (por ejemplo, la apariencia, el sonido y la sensación de un botón que se presiona), retroalimentación funcional, que es el objetivo de una acción (por ejemplo, encender un dispositivo), y retroalimentación aumentada, que es retroalimentación no de la acción o el objetivo (por ejemplo, se enciende una luz para mostrar que el dispositivo está respondiendo cuando la retroalimentación funcional se retrasa). Estas tres categorías también se identifican para alimentación directa o para proporcionar información al usuario antes de que actúe (el esquema se presenta en la Figura 3.10).

El trabajo de Petrelli[186] se basa en la construcción de bocetos de hardware con el aprovechamiento de objetos existentes. Discuten los beneficios y desafíos que plantea el uso de dispositivos digitales disponibles (seleccionar un dispositivo, desguazarlo y reutilizar sus componentes) 


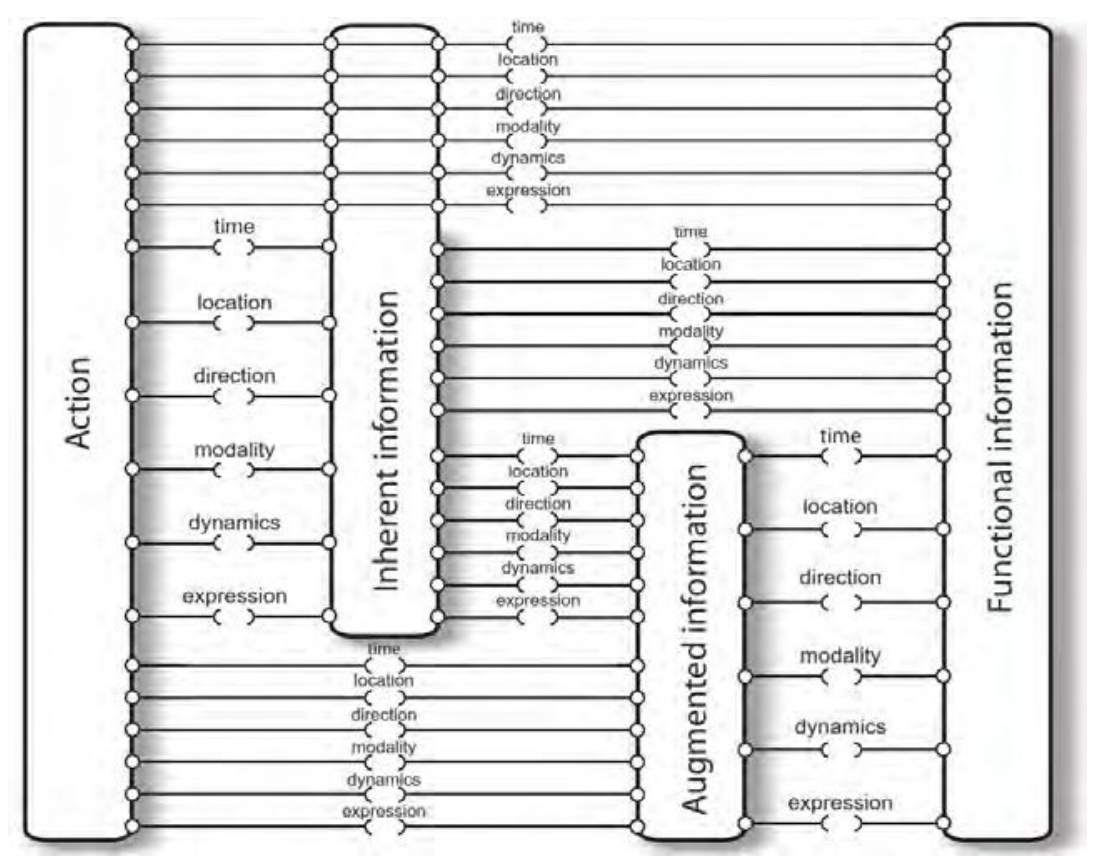

Fig. 3.10.: El marco Interaction Frogger de Wensveen. Esquema de las posibilidades de acoplamiento entre la información funcional y las acciones del usuario. En términos de los autores: la información inherente y aumentada se puede usar como "saltos de rana" cuando el acoplamiento directo no se puede usar. Tomada de [245]

a través de seis prototipos desarrollados en dos talleres. Sobre la base de esa experiencia, describen un proceso y ofrecen directrices concretas para la creación rápida de bocetos de interacciones tangibles. Por su parte, Djajadiningrat[54] presenta un enfoque basado en el diseño industrial y la generación de formas significativas. El documento no describe un conjunto estructurado de pautas o pasos sino que proporciona una perspectiva o forma de pensar diferente sobre el diseño de interacción tangible que contrasta con el enfoque dominante. El artículo puede ayudar a los diseñadores a pensar y conceptualizar la corporización de sus sistemas.

En el desempeño de tareas, las acciones pragmáticas se refieren a comportamientos que progresan directamente, mientras que las acciones epistémicas implican alterar el mundo para que los procesos cognitivos sean más rápidos, más confiables o menos exigentes. Las acciones epistémicas se presentan con frecuencia como una consecuencia beneficiosa de la interacción con sistemas tangibles. Esteves[63] aborda este problema presentando ATB, un framework para codificar video que permite identificar y medir diferentes acciones epistémicas durante las tareas de resolución de problemas.

En cuanto a las ayudas para idear, dibujar o diseñar con foco en la experiencia del usuario final, destacan los trabajos de Hornecker y Buur[105], Rogers y Muller[202] y Lenz y Diefenbach[146]. Los tres soportan de manera diferente el proceso concreto de la ideación.

Hornecker y Buur[105] crearon un framework que no ofrece una taxonomía, sino cuatro perspectivas para guiar la ideación y análisis en diseño de interacciones tangibles: la manipulación 
tangible, la interacción espacial, la facilitación corporizada y la representación expresiva. Para cada una de esos enfoques proponen sugerencias de trabajo y preguntas que el diseñador puede hacerse. Además, identifican tres formas de caracterizar la interacción tangible: una vista centrada en los datos (cercana al campo HCI), una vista expresiva centrada en el movimiento (próxima al diseño industrial) y una vista centrada en el espacio (adoptada en artes $\mathrm{y}$ arquitectura). Este es el primer framework que presenta esta visión integral y extendida de las interacciones tangibles, superando la barrera de lo meramente tridimensional o de la vinculación estricta entre datos y formas físicas.

El trabajo de Rogers y Muller[202] presenta un marco de experiencia basado en sensores y un caso de uso con el objetivo de proporcionar a los diseñadores e investigadores un conjunto de conceptos e inquietudes que pueden ayudar a explorar, enmarcar y evaluar el diseño de experiencias de usuario basadas en sensores. Su marco explica el concepto de "transformaciones", una característica de la percepción y cognición en curso durante la experiencia del usuario, en la que sus acciones y los efectos resultantes cambian el estado del sistema y del mundo. Las transformaciones proporcionan una manera de describir cómo un usuario experimenta y maneja los acoplamientos entre acciones y efectos en el mundo físico y digital. El marco proporciona consideraciones de diseño relacionadas con el concepto de transformaciones, y también en relación con las actividades y las propiedades de los sensores, la faceta de las tecnologías.

Finalmente, el trabajo de Lenz y Diefenbach[146] es una guía orientada a la práctica del trabajo que ya mencionamos entre las ayudas para abstraer y organizar ([51]). El artículo se plantea la cuestión de cómo conceptualizar la estética de la interacción emergente. Proponen que la diferenciación consciente entre los atributos de interacción (por ejemplo, lento, mediado, retrasado) y la experiencia emergente (por ejemplo, experimentar un momento positivo y significativo) es un paso conceptual crucial. Crear una experiencia particular (el Porqué) requiere conocimiento y la combinación intencionada de atributos en el nivel de interacción (el Cómo). Para apoyar esto desarrollaron un vocabulario de interacción, es decir, un conjunto de atributos derivados sistemáticamente para describir la interacción de una manera agnóstica de la tecnología. En el trabajo describen la utilización del vocabulario con varios casos de uso (la Figura 3.11 muestra el uso del vocabulario para definir perfiles de interacción de tres objetos). Si bien no se trata de un soporte específicamente orientado a sistemas digitales interactivos, su abordaje de la experiencia con base en la cognición corporizada lo ubica dentro de las herramientas de soporte que interesa a mi investigación. Como quedó indicado antes, las dos versiones de Pluma que presentamos en el Capítulo 5 incorporan una versión de este volcabulario.

\subsubsection{Herramientas para bocetar con hardware, maquetar, construir}

Numerosas plataformas integradas que facilitan la creación de objetos interactivos están disponibles en los últimos años. Arduino, Raspberry Pi, .NET Gadgeteer son ejemplos muy conocidos. Además de la disponibilidad cada vez mayor de sensores, actuadores y elementos 


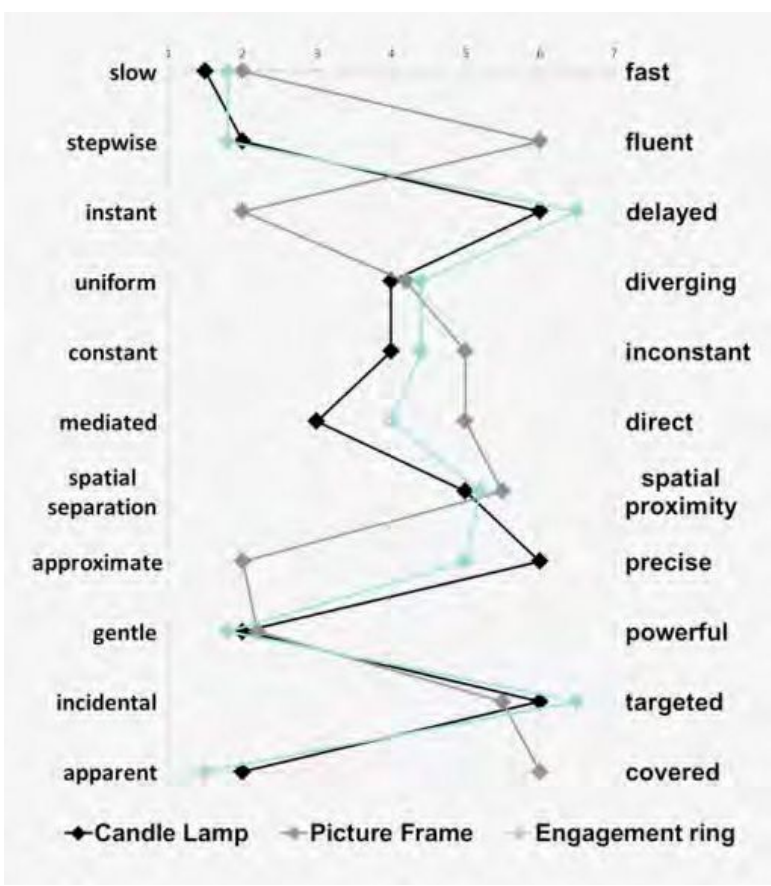

Fig. 3.11.: Comparación de perfiles de interacción de tres objetos (lámpara, marco de fotos y caja para un anillo de compromiso) con el vocabulario de Lenz, tomada de [146]

de red adicionales se han creado entornos de software y herramientas de desarrollo que bajan el umbral para crear aplicaciones, en muchos casos utilizando programación visual. Sin embargo, la mayoría de estas plataformas y entornos están pensadas en el ambiente maker o de hágalo-usted-mismo más que en el soporte de pensamiento y actividad de diseñadores[218]. Mi búsqueda se orientó a las herramientas (de software y/o hardware) que explícitamente tuvieron por objetivo soportar el bocetado en hardware de diseñadores.

El bocetado en o con hardware (sketching in hardware) consiste en la actividad de bocetar con elementos tecnológicos en una forma exploratoria y abierta. Es similar al bocetado con papel y lápiz o el bocetado con código, pero focaliza en los elementos electrónicos y tecnológicos, los componentes del hardware. Está muy relacionado con la idea de computación física ${ }^{3}$. El aspecto de bocetado de esta actividad es crucial, ya que la mayor parte del trabajo es intencionalmente algo imperfecto, un proceso de descubrimiento y aprendizaje, que conduce a proyectos que requieren más elaboración. Holmquist comparó esta actividad con el "bocetado en software" que realizan los programadores y diseñadores de interacción y la definió como la capacidad de construir una maqueta física y aumentarla con comportamientos interactivos[100],

Entre los trabajos pioneros y que son referencia ineludible en este área es necesario mencionar al trabajo de Greenberg con Phidgets[87] y de Ballagas con iStuff[14].

\footnotetext{
${ }^{3}$ La computación física consiste en construir sistemas físicos interactivos empleando software y hardware que puede captar información y responder al mundo analógico. Aunque esta definición podría incluir coches inteligentes con sistemas de control del tráfico, o procesos de automatización en fábricas, generalmente no se utiliza para este tipo de artefactos. En sentido amplio, la computación física incluye aparatos creativos enmarcados en el mundo digital, como arte hecho a mano, diseños caseros o DIY con sensores y microcontroladores, electro-dispositivos mecánicos controlados como motores, servos, iluminación u otro hardware (http://es.wikipedia.org/wiki/Informática_física)
} 
Greenberg presentó los phidgets o widgets físicos con la idea de que fueran lo que los widgets son para las GUIs. Al igual que los widgets, los dispositivos abstraen y empacan los dispositivos de input y output: ocultan los detalles de implementación y construcción, exponen la funcionalidad a través de una API bien definida y tienen una interfaz (opcional) interactiva en pantalla para mostrar y controlar el estado del dispositivo. A diferencia de los widgets, los phidgets también requieren: un administrador de conexión para rastrear cómo aparecen los dispositivos en línea; una forma de vincular un phidget de software con su contraparte física; y un modo de simulación para permitir al programador desarrollar, depurar y probar una interfaz física incluso cuando no hay un dispositivo físico presente. El kit luego fue ampliado con versiones para interfaces distribuidas, móviles, etc.

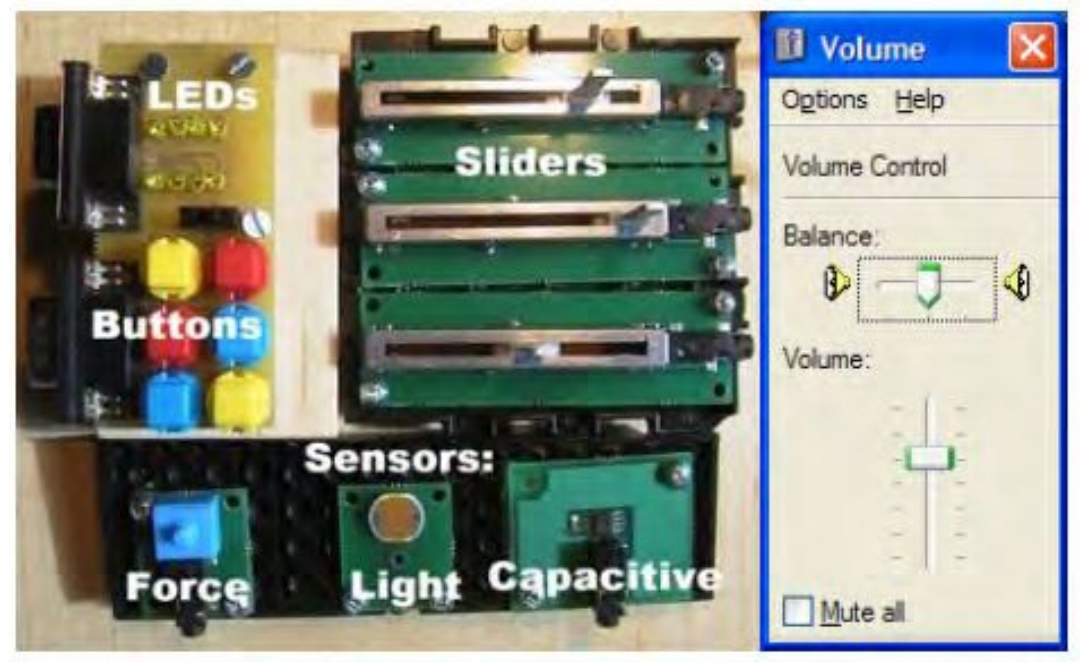

Fig. 3.12.: Una consola construida con varios inputs y outputs utilizados para ajustar el control del volumen utilizando Phidgets. Tomado de [85]

El foco de iStuff fue la exploración de interacciones beyond the desktop y de computación ubicua con un kit compuesto por elementos comunes reutilizados. Incluía un kit de herramientas inalámbricas comunicadas a traves de una arquitectura flexible basada en eventos. Algunos de los elementos para input y output se muestran en la Figura 3.13.

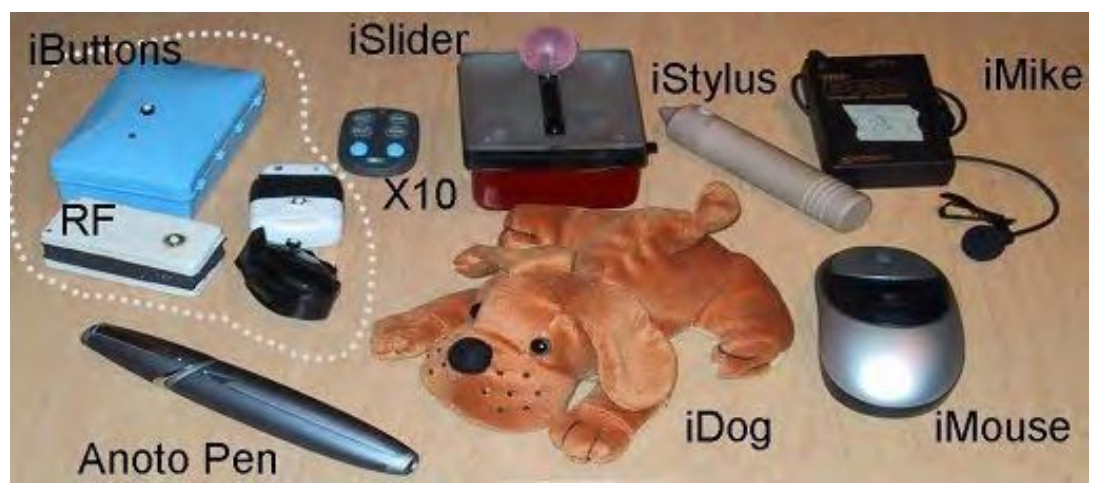

Fig. 3.13.: Componentes de input en iStuff, de https://hci.stanford.edu/research/istuff/

En relación con las exploraciones constructivas orientadas a la experiencia final del usuario, se puede mencionar el trabajo de Angelini, Internet of Tangible Things (IoTT) que propone un 
conjunto de 8 tarjetas con propiedades de interacción tangibles y 8 con atrituos de IoT, con el fin de explorar cómo se pueden explotar propiedades tangibles para mejorar la interacción con objetos de IoT. Incluyen un método para emplearlas en la exploración[5].

En la búsqueda de herramientas para soportar el bocetado de interactividad mediante la construcción con hardware, los siguientes trabajos se relacionan con mi investigación: ECCE[20], TESSA[206], WatchConnect[106], Vitaki[162] y Makerwear[127].

La plataforma ECCE (Entidades, Componentes, Acoplamientos y Ecosistemas) de Bellucci[20] es un conjunto de herramientas para no programadores que se plantea resolver tres desafíos: programar interacciones entre sensores, actuadores e interfaces digitales; implementar funcionalidad en diferentes plataformas con lenguajes de programación distintos y construir objetos personalizados electrónicos corporizados. Bellucci resuelve los desafíos con tres mecanismos: abstrae las implementaciones de bajo nivel, lo que reduce la complejidad de la creación de prototipos, utiliza una tarjeta con conexiones simplificadas (lo que evita la necesidad de circuitos ad hoc) y utiliza una plataforma web para programar y distribuir las versiones ejecutables con un formato de intercambio único. En Pluma retomamos la idea de placas que simplifiquen las conexiones utilizando, en nuestro caso, el sistema Grove.

\section{DEI片 ECCE TOOLKIT}

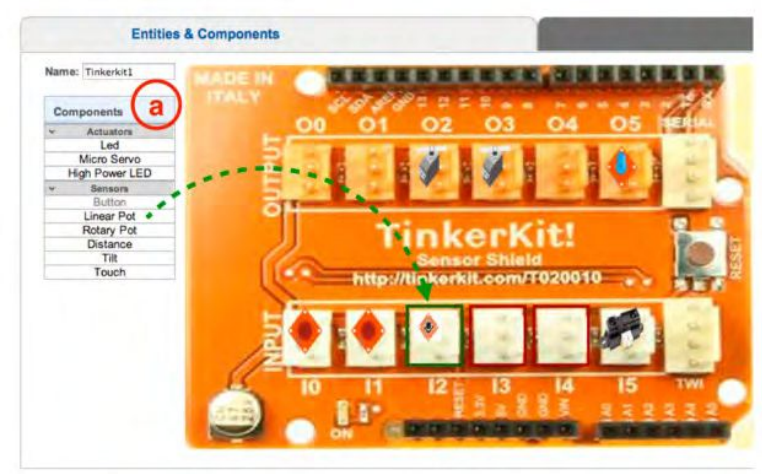

Fig. 3.14.: Captura de pantalla de la interfaz ECCE para defnir entidades interactivas conectadas a la placa Tinkerkit. El usuario hace drag\&drop del sensor o actuador desde la paleta al puerto deseado. Tomado de [20]
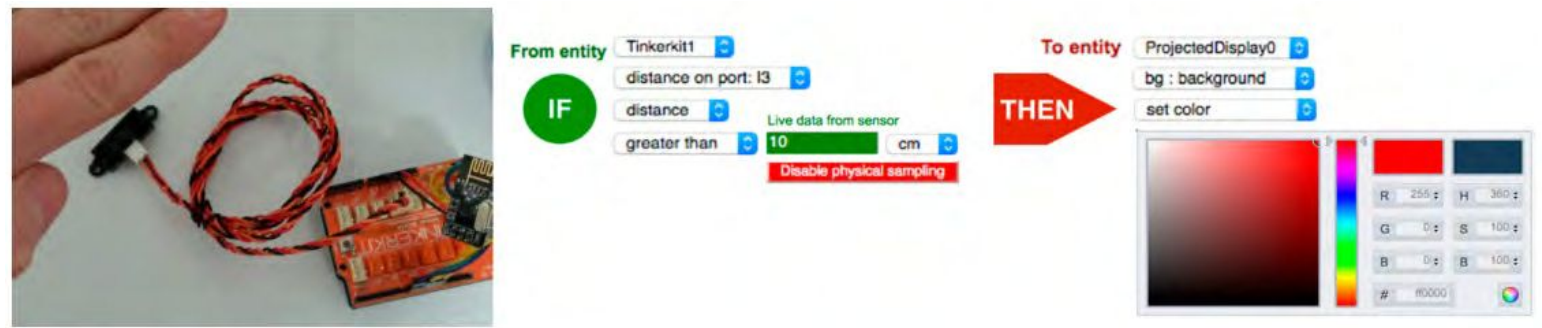

Fig. 3.15.: Programación por demostración en ECCE. El usuario interactúa con el sensor para completar las reglas de activación. Tomado de [20] 
TESSA es un conjunto de herramientas para experimentar interacciones con sustitución y aumento sensorial, que como explicamos más adelante es uno de los mecanismos privilegiados para el diseño de interacciones por acoplamiento sensorio motor (ver Capítulo 4). TESSA incluye hardware y software para facilitar la creación rápida de prototipos de interfaces que pueden mejorar un sentido utilizando información recopilada de otro sentido. El kit de herramientas contiene una gama de sensores (por ejemplo, ultrasonidos, sensores de temperatura) y actuadores (por ejemplo, tactores o sonido estéreo), diseñados modularmente para que las entradas y salidas se puedan intercambiar y personalizar fácilmente mediante la interfaz gráfica de usuario de TESSA, con retroalimentación en tiempo real. El sistema se ejecuta en una Raspberry Pi con una pantalla táctil incorporada, lo que proporciona una forma compacta y portátil que está disponible para pruebas de campo. La Figura 3.16 muestra ejemplos de bocetos de guante y cinturón construidos con TESSA y la GUI que provee el sistema para configurar[206].

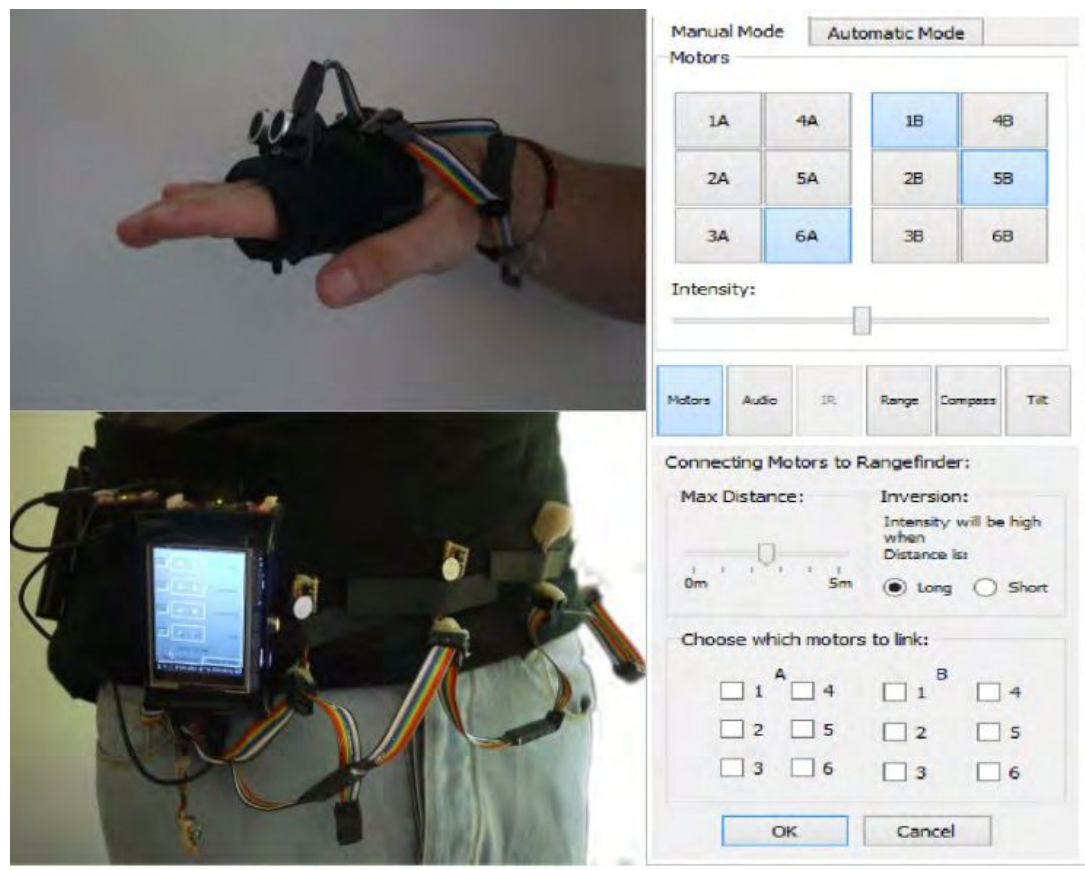

Fig. 3.16.: TESSA. Izquierda, configuración como guante y como cinturón. Derecha, GUI para configurar. Tomado de [206]

La utilización en conjunto de diversos dispositivos como relojes inteligentes, teléfonos y computadoras portátiles permite (y demanda) el diseño de nuevas interacciones cruzadas. Sin embargo, a pesar de la creciente disponibilidad de esos relojes, a veces la creación de bocetos y prototipos de las aplicaciones centradas en el reloj sigue siendo una tarea difícil. Para solucionar el problema, Houben presentó el toolkit WatchConnect. El kit de herramientas proporciona a los desarrolladores una plataforma de hardware extensible que emula un reloj inteligente, un framework que se integra con un constructor de IU existente y un conjunto de eventos de entrada y salida con diversos sensores. La Figura 3.17 muestra el concepto general y la arquitectura del software. Houben presenta la flexibilidad del toolkit con la demostración de varios casos que exploran todo el espacio de diseño[106]. En nuestras 
versiones de Pluma exploramos esta posibilidad de interacciones cruzadas entre dispositivos por ejemplo al incorporar widgets de una GUI en la pantalla de la computadora que interactúe con los bocetos en hardware soportados por Arduino además de la respuesta en tiempo real de los eventos de interacción.
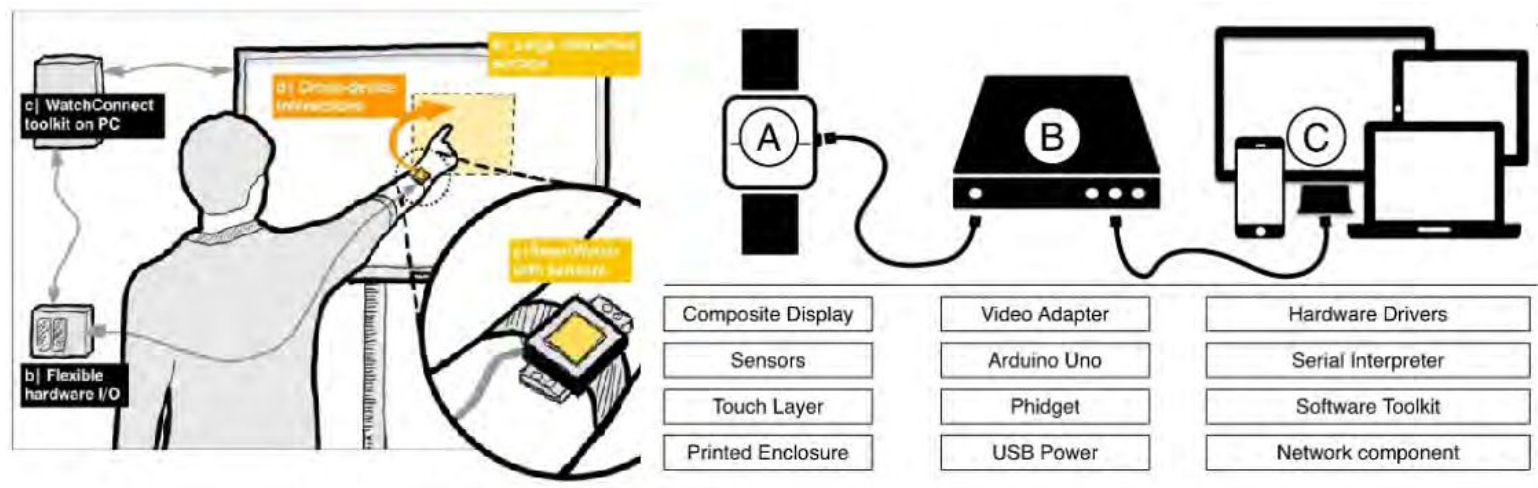

Fig. 3.17.: Izquierda: concepto de WatchConnect: a) prototipo de smartwatch con sensores, b) capa de hardware extensible, c) plataforma de desarrollo en PC, d) interacciones entre dispositivos con e) superficies interactivas. Derecha: arquitectura general del software

Martinez desarrolló un conjunto de herramientas de creación de prototipos vibrotáctiles para actuadores de masa giratoria excéntrica llamados VITAKI. El objetivo principal de esta plataforma es facilitar la creación de prototipos y los procedimientos de prueba de nuevas técnicas de interacción vibrotáctil para Realidad Virtual y videojuegos[162]. La plataforma incluye una herramienta con una especie de vocabulario de interacción háptica que facilita la customización de respuestas (ver Figura 3.18), algo similar a lo que utilizamos para la definición de gestos aéreos en Pluma.

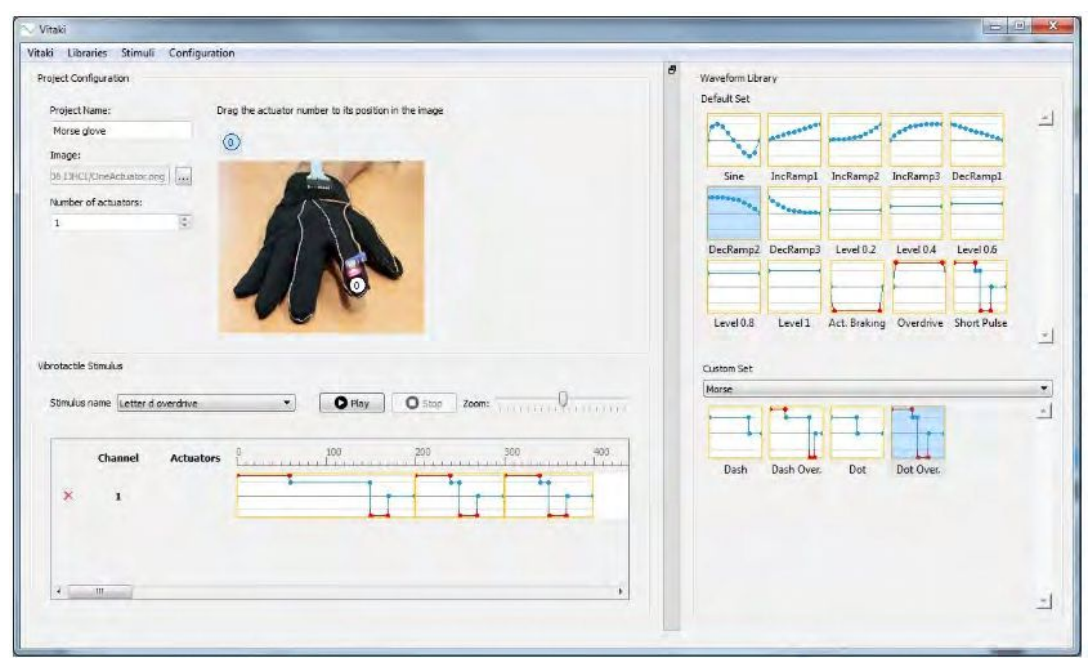

Fig. 3.18.: Codificación de la señal Morse de la letra d con la interfaz gráfica de Vitaki. Tomado de [162]

Finalmente, vale citar aquí MakerWear, un kit de construcción de ideas de interacción propuesto por Kazemitabaar. Aunque está orientado a niños es interesante la idea de composición creativa utilizando módulos tangibles autocontenidos y una estrategia de plug-and-play sobre una 
malla de zócalo con tejido integrado. Se pueden crear una amplia gama de diseños desde ropa reactiva con sonido hasta juegos sociales interactivos. Nuevamente aparece aquí la idea de bajar el umbral de construcción con hardware, en este caso con la estrategia de módulos enchufables que facilita además la rapidez de validación de una idea[127].

Cierro esta revisión con los trabajos que soportan específicamente la construcción corporizada, como Modkit, el Motor de interacciones y Bloctopus.

Modkit[10] ofrece bloques de comandos gráficos inspirados en el entorno de programación Scratch. Las herramientas Modkit funcionan con la biblioteca de código de la plataforma Arduino. El código puede tanto tener una representación visual (bajo umbral) como en formato de texto editable (techo alto) (ver Figura 3.19). Utiliza además la representación visual de componentes de hardware (ver Figura 3.20) para permitir la composición rápida de bocetos. En Pluma retomamos esta idea, aunque evitamos la compilación de nuevo código en el microcontrolador mediante la utilización del protocolo Firmata.

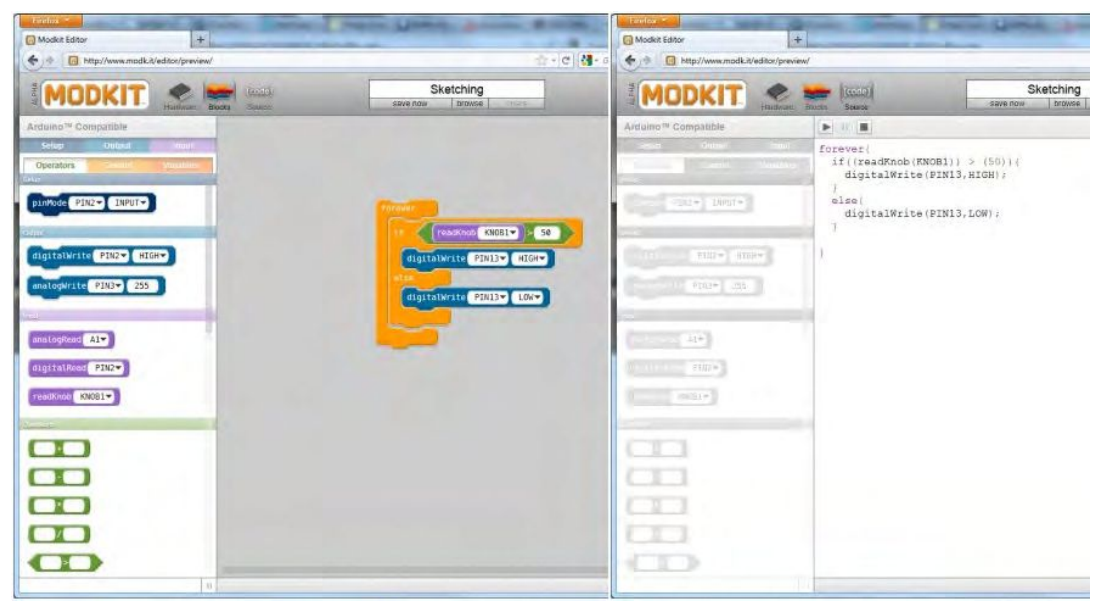

Fig. 3.19.: Representación visual o en formato texto del código. Tomado de [10]

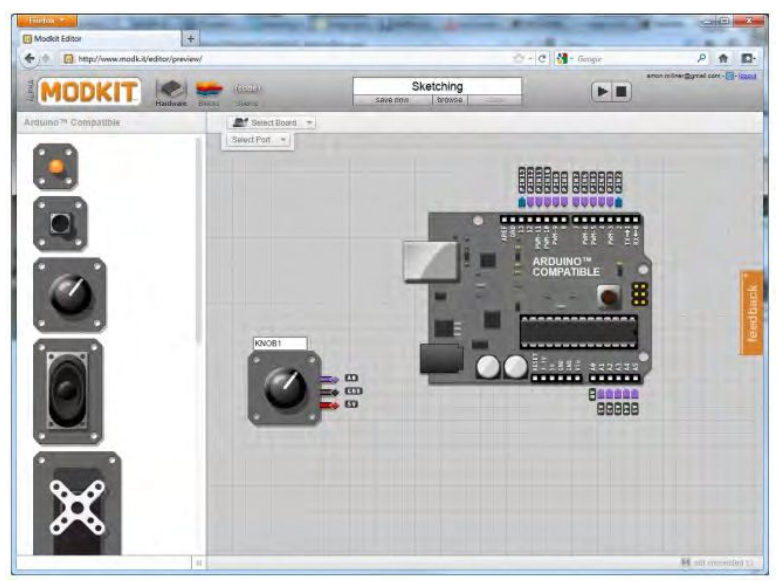

Fig. 3.20.: Base de Modkit para la composición visual de los bocetos con Arduino más sensores y actuadores. Tomado de [10]

El Motor de Interacción[161] es un sistema para la creación de prototipos conectados basado en un esquema de computadora Linux de tarjeta única (Raspberry Pi) y microcontroladores 
Arduino de bajo costo. Se trata de un framework genérico. Emplea herramientas disponibles y apoyadas por la comunidad que pueden habilitar hardware conectado a la web capaz de combinar interfaces tangibles con interfaces web audio / visual. Se basa en la idea de que las computadoras de una sola placa de bajo costo son una tecnología habilitadora que facilita la creación rápida de bocetos y prototipos complejos. La Figura 3.21 presenta la arquitectura del Motor de Interacciones.

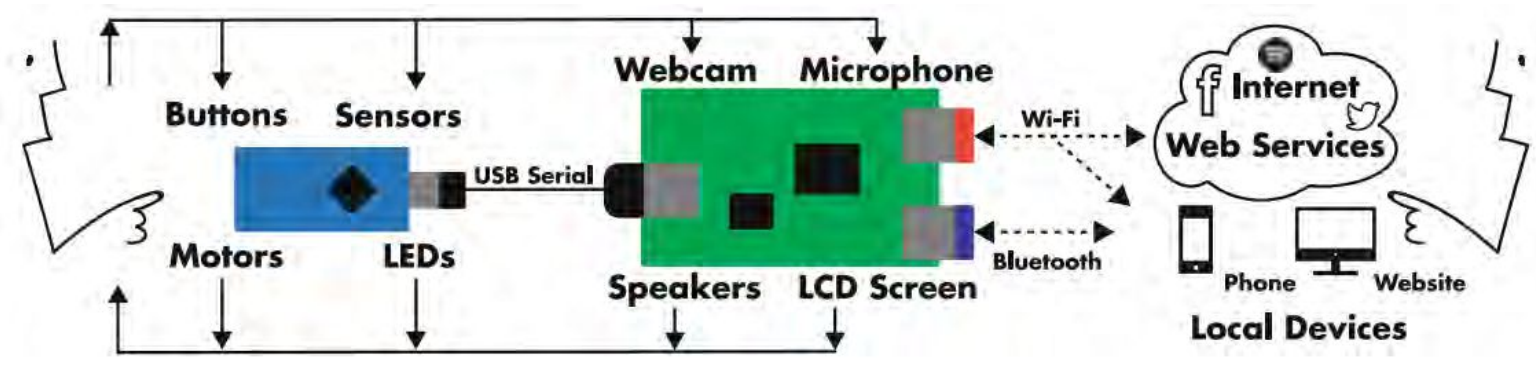

Fig. 3.21.: Arquitectura conceptual del Motor de interaccioens, que facilita las interacciones físicas y digitales entre personas, la nube y los dispositivos. Como se advierte en la figura está centrado en una computadora de tarjeta única, un microcontrolador, software abierto y conexión a servicios de la nube. Los autores lo han implementado utilizando Arduino como microcontrolador de sensroes y actuadores y desde Raspebrry Pi hasta ODROID XU-3 de ocho cores como computadora central. Tomado de [161]

Bloctopus[205] es un conjunto de herramientas de creación de prototipos electrónicos modulares que permite una interfaz eléctrica directa a través de USB y una interfaz física con bloques LEGO. Se basa sobre la idea de un modelo de sensor autónomo, donde cada módulo puede interactuar directamente con una computadora o con un microcontrolador, mediante el uso de mensajes musicales que pasan por MIDI. Los módulos se pueden programar con un modelo de flujo de datos simplificado mediante una interfaz de programación visual basada en web. La idea de utilizar módulos de conexión con fomato de componente Lego permite agregar interactividad a modelos Lego comunes. Para los sensores o actuadores utiliza al igual que Pluma los módulos Grove de Seeed Studio ${ }^{4}$ (ver Figura 3.22).

\subsection{Conclusiones del capítulo}

En la primera sección de este capítulo repasamos el conocimiento existente sobre el tipo de diseño que abordamos en esta tesis, las interacciones con dispositivos digitales y el uso de bocetos para idearlas.

Hemos visto que el diseño es esencialmente una actividad intencional y compleja, que involucra incertidumbre y riesgo y que merece entidad propia en el proceso de creación de sistemas interactivos. Su complejidad reside, entre otras cosas, en las numerosas fuentes de información, restricciones y deseos, muchas veces contradictorios, que es necesario compatibilizar hasta definir el problema a resolver (que puede ser muy diferente del que se consideró al comienzo).

\footnotetext{
${ }^{4}$ http://wiki.seeedstudio.com/Grove_System/
} 


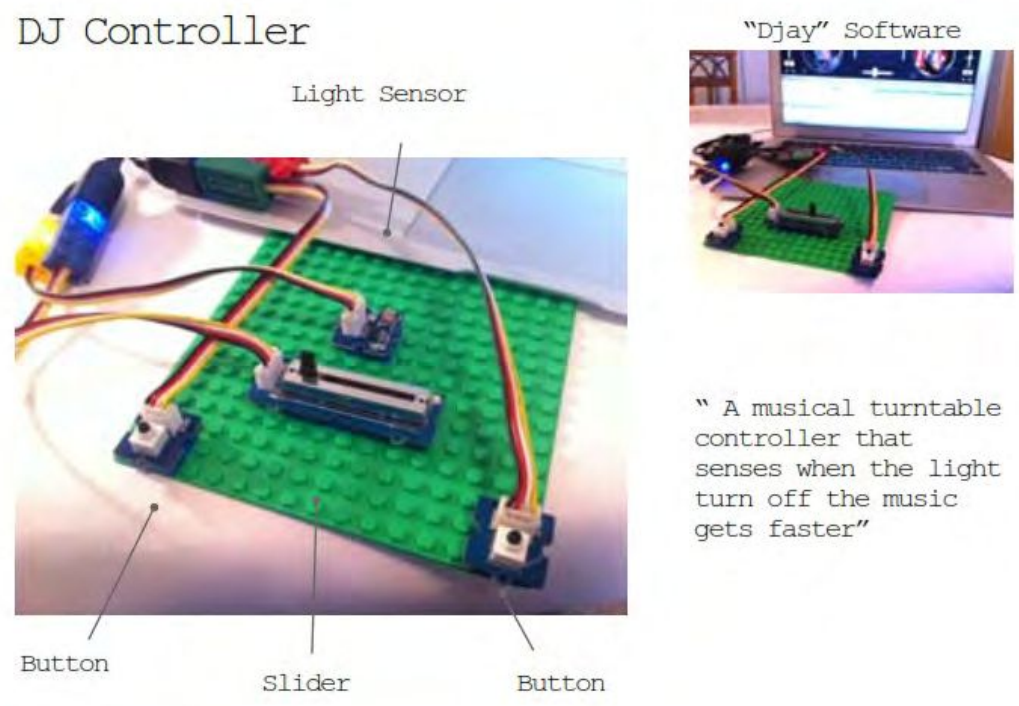

Fig. 3.22.: Ejemplo de un prototipo de controlador para un DJ construido con Bloctopus. Tomado de [205]

Sin embargo, la actividad de diseño no es un arte mágico e inescrutable sino que tiene su propia disciplina y rigor en la indagación, que involucra ciclos iterativos de enmarcado y re-definición de problemas, desarrollo de hipótesis, experimentación y actuación para cambiar progresivamente una situación incierta en una con mayor certidumbre. En esa práctica, el bocetado es esencial. Todas las externalizaciones, gráficas, tridimensionales o actuadas, que ayudan a pensar la situación, conversar sobre ella con otros o guardar ideas para más adelante, son centrales en el proceso de proponer una solución (hipótesis, ver-como) y analizar si se adapta al problema o lo redefine y abre un nuevo camino a explorar (testear, ver-eso).

En el caso de las relaciones entre personas y dispositivos digitales, donde lo temporal y dinámico es fundamental, el bocetado incorpora además la necesidad de experimentar la interactividad, la interacción-en-acción. Diseñar esa interacción es la actividad que intenta determinar los espacios de acciones (todo lo que la persona puede hacer) y operaciones (lo que el sistema es capaz de reconocer) en los que se vean involucrados el sistema o artefacto y sus usuarios.

Los trabajos recopilados y analizados en la segunda sección, permiten obtener un panorama del tipo de herramientas que han surgido de las investigaciones para soportar esa actividad de diseño. En ese sentido, hemos encontrado frameworks, guías, toolkits y aplicaciones que se ofrecen para (a) abstraer y conceptualizar la actividad, (b) generar ideas de diseño y (c) construir modelos para evaluar la interacción.

Además, de las distintas dimensiones en las que es posible considerar una idea de interacción, los trabajos se han centrado en la corporización o fisicalidad en sí misma, la interactividad como resultado de la interacción en la acción y las cualidades de la experiencia que exceden el mero uso de los dispositivos. Reportamos diversas herramientas para facilitar la creación, almacenamiento e intercambio de representaciones más o menos análogas a los bocetos en papel o las maquetas tridimensionales enriquecidas con capacidades interactivas, aunque son 
pocos los trabajos que se apoyan sobre las observaciones de la práctica tal como es llevada adelante efectivamente por los diseñadores de interacciones corporizadas.

Ya señalamos los estudios que habían revelado que los diseñadores demandan soportes que contribuyan a su propia lógica y racionalidad de diseño, sin enfrentarla o encorsetarla. Necesitan ser preparados para la acción, no guiados en ella. La carencia de caracterizaciones de esa práctica basadas en observaciones puede inducir a conjeturas erróneas. Hemos reportado trabajos que intentan proveer a los diseñadores una brújula para la exploración del nuevo mundo de interacción con sensores, actuadores y el software (prepararlos para la acción, sin guiarlos de manera prescriptiva en el camino a seguir). Sin embargo, en el caso de las herramientas para generar, bocetar y evaluar ideas el principal foco ha sido puesto sólo en la disminución del umbral de acceso a la elaboración de modelos (básicamente mediante la facilitación de conexiones y circuitos mediante componentes pre-ensamblados).

Creemos que existe espacio para ampliar el soporte al proceso de la generación de ideas, no sólo bajando el piso, sino expandiendo el techo y las paredes es el enfoque que intentamos abordar en la tesis para responder a las preguntas de investigación planteadas. 


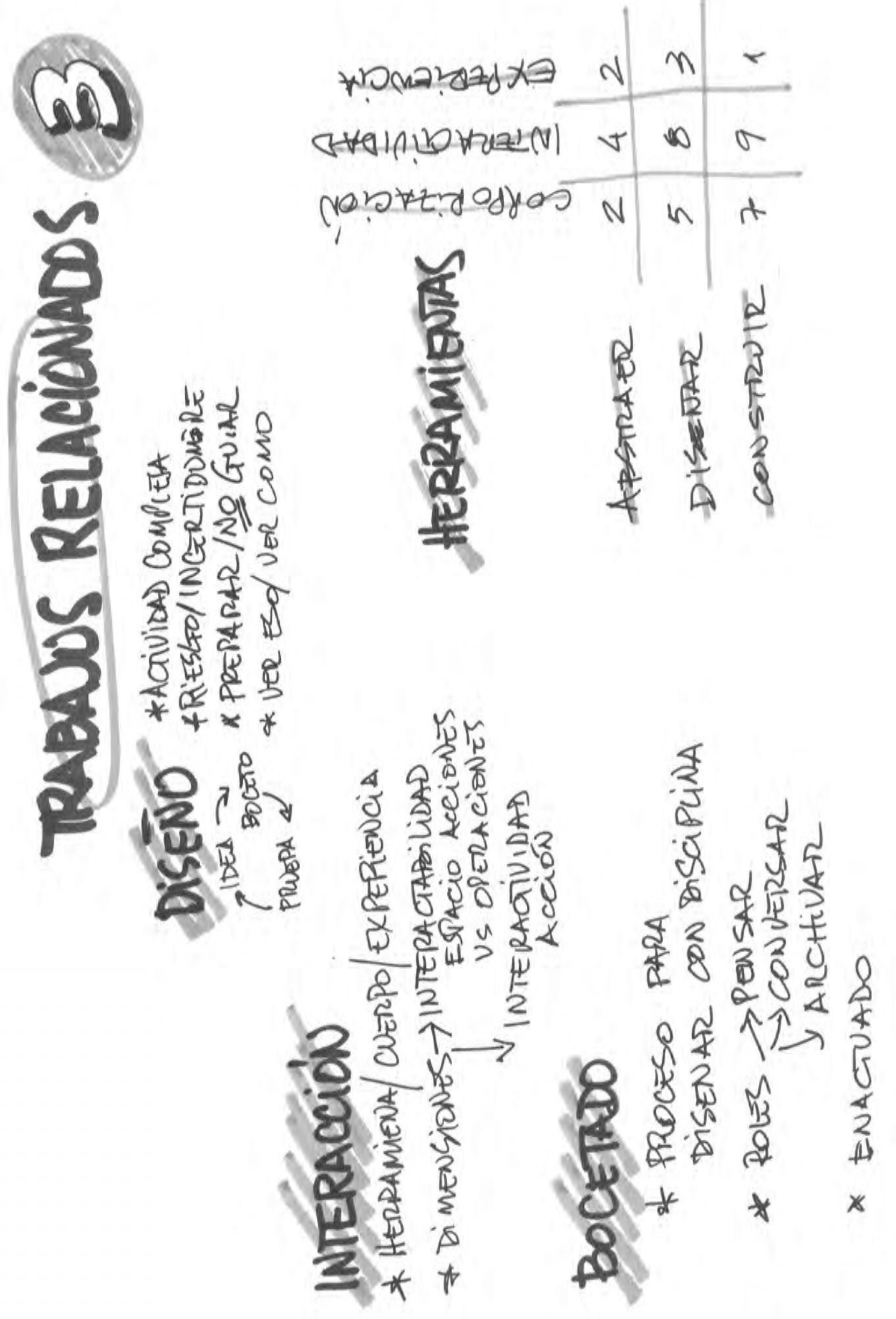





\title{
Una caracterización del bocetado de interacciones enactivas
}

You can observe a lot just by watching

\author{
- Yogi Berra \\ What I've learned about teamwork from Yankees and life[23]
}

\subsection{Introducción}

Como parte de la triangulación de métodos que definí en el Capítulo 1, llevé adelante estudios de observación con el objetivo de caracterizar la práctica de la ideación en el diseño de interacciones corporizadas y enactivas. Para ello realicé una serie de talleres con más de 60 profesionales que trabajan en la creación de experiencias digitales interactivas en diversos ámbitos. Estos profesionales realizan habitualmente prácticas con tecnologías interactivas diversas que incluyen la construcción de bocetos con software, hardware y un amplio conjunto de sensores y actuadores, además de los usuales bocetos a mano alzada en papel, maquetas, escenificaciones de experiencia de uso, etc.

En relación con las preguntas de investigación estos estudios buscaron echar luz sobre dos aspectos centrales. Por una parte, las concepciones que al momento de generar ideas de interacción los diseñadores ponen en juego sobre la cognición corporizada en general (y la versión de acoplamiento sensorio motor, en particular). Por otro lado, qué herramientas previas y ad hoc ponen en práctica a la hora de generar y evaluar esas ideas.

Con las consignas Ver con los oídos, Ver con la piel y Sentir en el cuerpo el entorno físico/digital se pidió a los diseñadores que generaran ideas de interfaces enactivas basadas en la sustitución sensorial, una de las estrategias de diseño que requiere una concepción de cognición corporizada[72] (los conceptos de sustitución sensorial son explicados en la sección siguiente). Los talleres se organizaron en dos tandas de un par de instancias cada una. En la primera tanda el énfasis se ubicó en obtener información sobre el uso de estrategias de bocetado adicionales al papel y lápiz o maquetado. La segunda, se orientó a la búsqueda de información sobre el uso del propio cuerpo por parte de los diseñadores en el bocetado y la ideación.

La configuración, observación y análisis de los talleres se sustentó en las técnicas de la etnometodología. Los registros de las cuatro instancias de talleres reflejan los resultados obtenidos y su implicancia para la caracterización del bocetado de interacciones enactivas y para el diseño de las herramientas propuestas. 


\subsection{La sustitución sensorial}

Sustitución sensorial es el nombre que recibe una estrategia por la cual se ofrece al usuario de dispositivos interactivos información por la vía de una modalidad sensorial diferente de aquella por la que esa información es habitualmente percibida, por ejemplo convierte datos visuales en estímulos hápticos[145, 241].

El ejemplo más famoso de sustitución sensorial es TVSS (Tactile Visual Substitution System) de Bach-y-Rita[12]. Se trata de una interfaz que provee feedback vibro-táctil a través de la estimulación de la zona lumbar a partir de la información recibida desde una cámara (ver Figura 4.1). Cuando una persona ciega o con los ojos vendados ha practicado suficiente con el dispositivo es capaz de percibir objetos a distancia y experimentar el mundo en frente de él más que sólo experimentar las vibraciones. De acuerdo con Bach-y-Rita lo que TVSS hace es sustituir una fuente de input sensorial (estimulación visual) con otra fuente (estimulación táctil) asegurándose que esta última provee la información apropiada que requiere el sistema visual del cerebro. De hecho la idea de que la experiencia de TVSS es como ver se soporta por la evidencia de similares efectos perceptuales como oclusión y paralaje manifestados en reportes verbales de algunos de los participantes[13].

En sentido estricto desde el punto de vista del enfoque de acoplamiento sensorio motor el nombre de sustitución sensorial no es el más adecuado. Se ha mostrado que después de la sustitución sensorial la experiencia es una transformación, extensión o aumento de las capacidades perceptuales más que algo equivalente o reducible a una modalidad ya existente[9]. Froese argumenta que en el caso general del uso de herramientas, existe una transformación de la relación del agente con el mundo (con cambios neuronales, conductuales, perceptivos y experienciales concomitantes). Por lo tanto, sería más apropiado hablar de "aumento sensorial" de las habilidades perceptivas existentes en lugar de "sustitución sensorial" per se. Además el uso de un sistema de este tipo no solo transforma los aspectos sensoriales de la realización del usuario, sino también el potencial de acción, sugiriendo el término "aumento sensoriomotor" o, en los términos de Froese la creación aumentada de sentido[73].

Tomando esta propuesta de Froese podemos definir de manera concisa una interfaz enactiva (IE) de la siguiente manera: es una interfaz tecnológica que está diseñada para conseguir una toma de sentido aumentada. Una IE es cualquier elemento de tecnología que está diseñado para permitir que su usuario participe en modos adicionales de creación de sentidos al permitir la regulación dirigida a objetivos de contingencias sensorio motoras previamente no disponibles. Existe, por lo tanto, una distinción entre las herramientas que mejoran el funcionamiento de las modalidades existentes, como el uso de anteojos por parte de una persona miope, y las herramientas que dan lugar a la presencia de nuevas modalidades, como el uso de TVSS por una persona ciega. En contraste con los dispositivos tecnológicos en general, el uso de una IE permite al participante generar y dar sentido a formas cualitativamente nuevas de regularidades sensorio motoras (por ejemplo, en el caso de TVSS, apreciando el significado de 

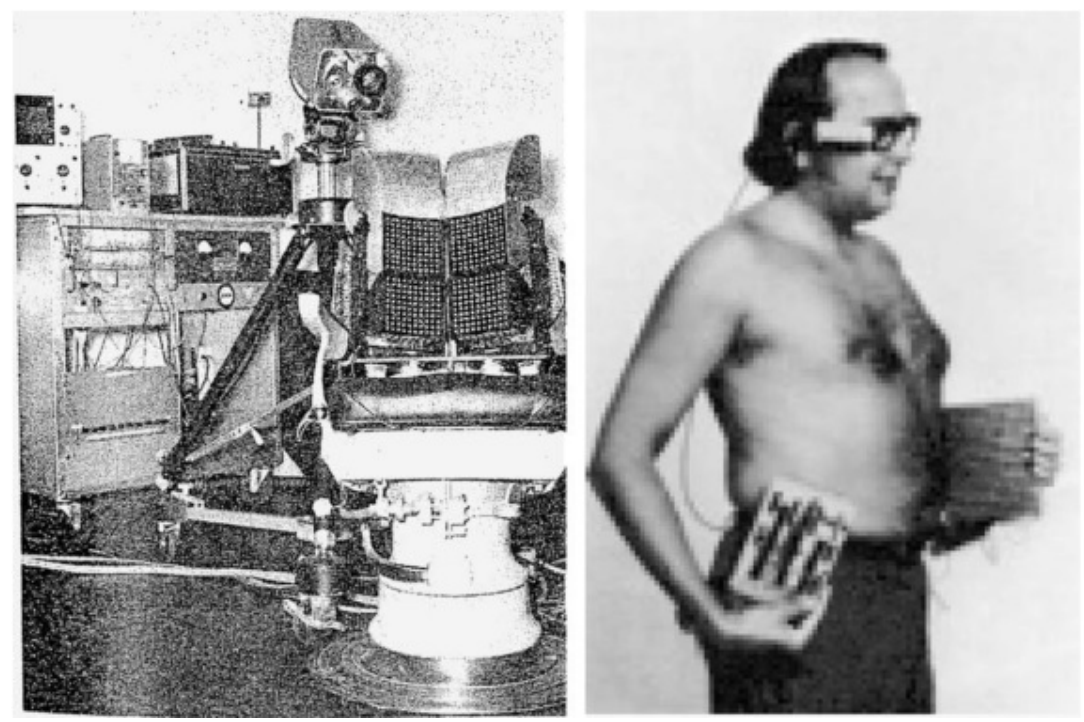

Fig. 4.1.: A la izquierda la versión original de TVSS por Bach-y-Rita con un array de 20x20 pines vibrotáctiles aplicados en la zona lumbar para representar la imagen capturada por la cámara. A derecha una versión posterior con un array de pines en el abdomen y la cámara montada en la cabeza, de [241]

los cambios en los patrones de estimulación táctil en relación con el movimiento de la cámara dentro del entorno), aunque en la práctica la diferencia no es absoluta.

Una descripción más detallada del concepto, mecanismos y experiencias de sustitución-aumento sensorial puede encontrarse en los trabajos de Lenay y Visell[145, 241]. Simplemente enfatizo aquí el punto general que, en contraste con algunos de estos ejemplos, cuando se utiliza una IE el dispositivo en sí, como el bastón de una persona ciega, debería volverse transparente en relación con la experiencia perceptiva aumentada del mundo. Por lo tanto, también se podría decir que el objetivo de diseñar una IE es crear un medio para facilitar nuevos modos de percepción, en lugar de crear un objeto que sea el objetivo de un modo de percepción existente.

\subsection{En búsqueda de una caracterización}

\subsubsection{Exploración en modo etnometodológico}

Para caracterizar la práctica de la ideación en el diseño de interacciones enactivas, organicé varias actividades de observación utilizando un enfoque etnometodológico basado en la Observación Participante, cuya pertinencia en HCI y específicamente como fuente de información para el diseño presentamos en el capítulo 1, tomando como base los trabajos de Dourish y Button[58].

Las actividades consistieron en talleres con la participación de profesionales que trabajan en la creación de experiencias digitales interactivas en diversos ámbitos. El contexto de los 
Talleres fue la Maestría en Tecnología y Estética de Artes Electrónicas (MAE) ${ }^{1}$ que brinda la Universidad Nacional de Tres de Febrero: "Las artes electrónicas ponen a la tecnología en el centro de su reflexión, no ya como una mera herramienta de creación, sino como un lenguaje que despliega mecanismos singulares desde el punto de vista estético, cognitivo y conceptual en lo que atañe al diálogo hombre-máquina. En tal sentido, las artes electrónicas suponen un enfoque que pone en relación diversas áreas del conocimiento -fundamentalmente, el arte, la ciencia y la tecnología-, proponiendo una labor que fomenta la dinámica transdisciplinaria" (de la presentación de la carrera).

En el contexto de la Maestría los estudiantes realizan numerosas prácticas con tecnologías interactivas diversas que incluyen la construcción de bocetos en software, fundamentalmente con la utilización de Processing ${ }^{2}$, y de bocetos con hardware basados en la plataforma Arduino ${ }^{3}$, Raspberry $\mathrm{Pi}^{4}$ o similares y en un amplio conjunto de sensores y actuadores, además de los usuales bocetos a mano alzada en papel, maquetas, escenificaciones de experiencia de uso con técnicas del estilo Mago de Oz, etc.

En esta Maestría el autor tiene a su cargo dos cursos semestrales de Programación de Entornos Sensoriales Interactivos en los cuales se hace foco en las tecnologías para la producción de ideas de interacción con ámbitos espaciales próximos y remotos. Utilizando como marcos conceptuales las ideas de Proxémica (ver el trabajo de Edward Hall[91]) y el enfoque de Acoplamiento sensorio motor en la Cognición Corporizada (ver Capítulo 2) los estudiantes desarrollan trabajos prácticos con las estrategias y mecanismos de sustitución-aumento sensorial esbozados más arriba.

Como introducción a los trabajos que configuran estos talleres, en cada curso se analizó en detalle el artículo Tactile sensory substitution models for enaction in HCI de Vissel[241], el caso de la Linterna enactiva desarrollada por Froese[73] (ver Figura 4.2) y el concepto de Mundos circundantes de von Uexkull[236] presentado en charla TED que David Eagleman dio en el año 2015 con el título "¿Podemos crear nuevos sentidos para los humanos?"5.

Cada Taller se extendió por cuatro sesiones semanales de 4 horas cada una a lo largo de las cuales los grupos trabajaron en la creación y desarrollo de sus ideas. La última sesión consistió en presentaciones de las ideas finales de cada grupo en modo demo utilizando la participación de otros estudiantes como usuarios y una reflexión final entre todo el grupo.

Cada grupo entregó todo el material producido durante el Taller, incluyendo un registro en video y todos los dibujos, modelos y anotaciones generadas. Tras la finalización de cada Taller el autor realizó entrevistas no estructuradas a cada grupo sobre el desarrollo del trabajo.

\footnotetext{
${ }^{1}$ https://maestriaae.net/ Accedido 14 de julio de 2019

${ }^{2}$ http://processing. org Accedido 14 de julio de 2019

${ }^{3}$ http: //www . arduino.cc Accedido 14 de julio de 2019

${ }^{4}$ https://www.raspberrypi.org/

${ }^{5}$ https://www.ted.com/talks/david_eagleman_can_we_create_new_senses_for_humans Accedido 14 de julio de 2019
} 


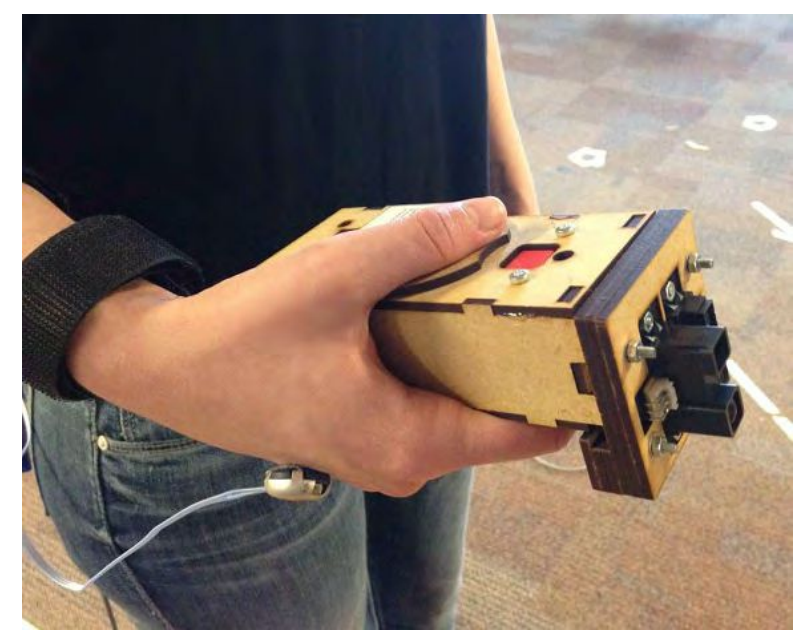

Fig. 4.2.: Enactive Torch de Froese[73]

\section{Acerca de la observación participante}

Una de las técnicas etnometodológicas, tomada de la etnografía, de mayor uso en la exploración de diseño de sistemas interactivos es la observación participante[90] (que incluso ha sido operacionalizada por Karen Holtzblatt como parte del método de diseño centrado en usuarios denominado Investigación en contexto[102]).

La aplicación de esta técnica para obtener información supone que la presencia (con percepción y experiencia directas) del investigador frente a los hechos que hacen a la práctica cotidiana de la población garantiza por sí sola la confiabilidad de los datos recogidos y el aprendizaje de los sentidos que subyacen a dichas actividades[76].

La observación participante consiste principalmente en dos actividades: observar sistemática y controladamente todo lo que acontece en torno del investigador y participar en una o varias actividades de la población. Participar, en el sentido de "desempeñarse como lo hacen los nativos" de aprender a realizar ciertas actividades y a comportarse como un miembro de la comunidad. Observación y participación pueden verse como dos polos: la primera implica ubicar al investigador afuera de la sociedad de forma tal que pudiera realizar su descripción con un registro detallado de lo que ve y escucha, como quien asiste a una obra de teatro. La participación pone énfasis en la experiencia vivida por el investigador en relación con su objetivo. Ambas suministran perspectivas diferentes sobre la misma realidad. La observación participante es entonces una tensión entre participar para observar y observar para participar[90].

Sobre el registro, Guber[90] señala que puede emplearse cualquier medio y forma, pero es importante considerar que siempre implicará alguna incidencia en la dinámica de lo real. Desde tomar notas abreviadas o registrar en audio y video para des-grabar y analizar más tarde hasta confiar en la memoria y no registrar nada en el momento. En nuestro caso, realizamos capturas de toda la actividad en audio y video durante los talleres e hicimos un análisis posterior para elaborar un registro con el modelo PATE: Personas-Actividades-Tiempo-Espacio, planteado por la misma Guber([90], pág. 105): 
Personas: desde el comienzo hasta el final de la observación todos los que mantienen diversos grados de relación con el investigador (participantes, testigos, otros presentes). Importa datos como sexo, edad, nacionalidad, grupo étnico, ocupación, vínculos entre sí, flujos sociales, vestimenta, actitudes generales, actividades desarrolladas en el lugar

Actividades: número de personas que las llevan a cabo, división de las tareas, cadenas de mando y poder, ritmo, tipo y duración, grado de habitualidad.

Espacio: información sobre las dimensiones del ámbito de observación, mobiliario, condiciones, objetos, decoración y el ámbito mayor en el que se inserta el espacio mayor de intercambio

Tiempo: el segmento temporal en que transcurren la observación, el encuentro y por otro la secuencia de hechos y vicisitudes de la interacción entre el investigador y los presentes.

El registro debe incluir además información sobre el encuentro (forma de concertación, canal de acceso al informante, número de encuentros previos, condiciones generales de apertura, desarrollo, interrupciones, cierre) y sobre el investigador (disposición durante el encuentro, expectativas que ha depositado, temas que se propone relevar, primeras impresiones, preguntas, comentarios, movimientos, silencios, dudas, inferencias y supuestos).

\subsubsection{Registro de los talleres}

\section{Objetivos de la exploración}

En relación con las preguntas de investigación (ver Capítulo 1) este estudio se planteó como objetivos contribuir a responder la PI2:

\section{PI 2. ¿Cómo podemos diseñar sistemas interactivos que se apoyen en la Cognición Corporiza- da y Enactiva?}

- PI 2.1. ¿Qué características de la Cognición Corporizada y Enactiva son relevantes en el proceso de diseño de los sistemas interactivos?

- PI 2.2. ¿Qué características debe poseer el bocetado para dar soporte a la generación y evaluación de ideas para interacciones enactivas?

Como andamios en el camino de encontrar las respuestas nos planteamos la búsqueda de información sobre:

- Las dimensiones del bocetado (en los términos de la anatomía de prototipos de Lim[152], ver Capítulo 3) que se priorizan en las diferentes etapas de la ideación

- Las formas en que los diseñadores utilizan la gestualidad y su propio cuerpo en el proceso de ideación y evaluación

- La existencia de algún tipo de aprovechamiento de la situación y el contexto

- Las vinculaciones en las ideas entre lo digital y lo físico

- Las maneras, tiempos, métodos utilizados para evaluar los bocetos y la existencia o no de emergencia de ideas a partir de las evaluaciones 
- Los errores que comenten los diseñadores en el proceso de bocetado de ideas y las soluciones a las que recurren

- Las herramientas que emplean para externalizar, comunicar y evaluar sus ideas

\section{Consignas utilizadas}

Se realizaron dos tandas de un par de talleres cada una. En la primera tanda (T1 y T2) la consigna de sustitución fue única para todos los grupos: T1: Ver con la piel y T2: Sentir en el cuerpo el entorno remoto o digital. En los dos talleres que conformaron la segunda tanda (T3 y T4), se dio la libertad a los grupos de elegir entre tres consignas: Ver con la piel, Sentir en el cuerpo el entorno remoto o digital y Oir con la piel.

Con el reemplazo de la consigna de acuerdo con lo indicado en el párrafo anterior, el brief de diseño fue el mismo en los cuatro talleres:

Generar ideas para una Interfaz Enactiva (IE) basada en la sustitución-aumento sensorial para proveer al usuario < percepción visual a través del oído $><$ percepción visual a través del tacto $><$ percepción corporal del entorno físico remoto o del entorno digital>.

La IE debe ser vestible. Se puede utilizar cualquier tecnología de software y hardware. Se pueden generar todas las ideas que se quiera, pero al final será entregada una sola idea por grupo. La idea a presentar deberá ser entregada en forma de bocetos o prototipos que puedan demostrar el funcionamiento buscado.

La presentación consistirá en una demo en la que intervendrán los otros participantes de la clase como usuarios.

El trabajo se desarrollará en forma colaborativa en grupos de 3 a 4 personas durante 4 clases en el ámbito del Aula Taller.

\section{Condiciones de espacio}

El contexto de desarrollo del trabajo fue el aula taller de la Maestría. En este aula, los estudiantes disponen de instalaciones y herramientas para realizar trabajos sobre software y hardware, mesas de trabajo y pizarrones para graficar. Habitualmente, además, los estudiantes llevan sus propias cajas de herramientas, materiales y notebooks.

Todos los bocetos y modelos intermedios que se generan deben ser retirados al finalizar la clase/sesión ya que el aula se utiliza para otros cursos en diferentes días de la semana. Para resolver estas interrupciones y la re-configuración del espacio de trabajo que esto implica, los participantes suelen registrar mediante fotografías el estado de sus anotaciones en pizarra y realizan una división del trabajo que facilite esa re-configuración: alguien se hace cargo de los modelos intermedios, otros de almacenar y compartir la programación, alguien más de las anotaciones en pizarra y papel, etc. 


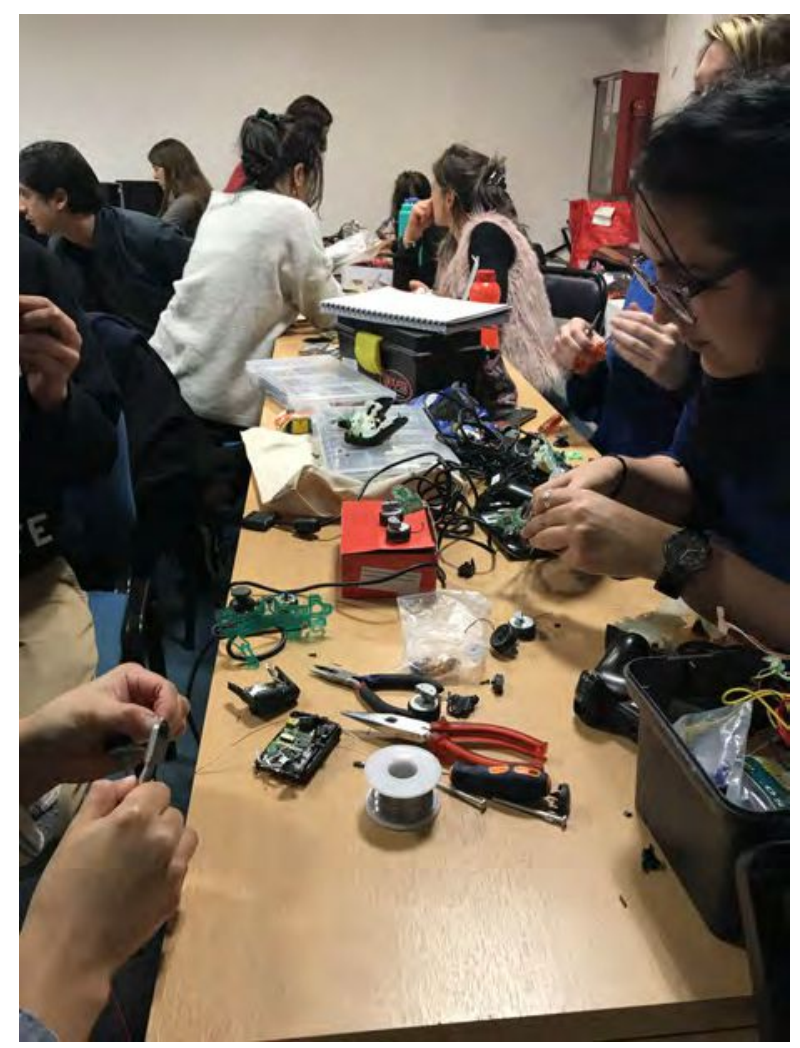

Fig. 4.3.: Un sector del aula taller utilizada

Al permitir el trabajo en grupos de hasta 5 personas, en cada instancia se organizaron un número de grupos que puedieron ubicarse en el taller sin problemas ni interrumpirse entre sí por el uso de alguna máquina o herramienta en particular.

Se ubicó una cámara fija para registrar en video la escena de todos los grupos trabajando y además, con el auxilio de un ayudante, el autor registró en audio y video los momentos de interacción con cada grupo en particular.

\section{El Observador Participante}

El autor eligió desempeñar el rol de Observador Participante en la condición de asesor o consultor de diseño externo al grupo. En cada sesión del Taller el autor recorrió cada uno de los grupos e interactuó con ellos en el rol señalado por espacio de al menos una hora con cada uno.

Estas observaciones se encuadran en el primero de los estilos etnometodológicos propuestos por Garfinkel que es el de estudios sobre las prácticas de trabajo. Para este tipo de intervención Garfinkel exige "la adecuación única, lo que quiere decir que el investigador ha de ser competente, ha de dominar las actividades que se están investigando. Sólo el haber tenido la experiencia de lo que se quiere describir garantiza el objetivo de la investigación que no es otro que el mayor nivel de precisión y especificidad posible de los detalles constitutivos de la 


\begin{tabular}{lccccc}
\hline Background & T-1 & T-2 & T-3 & T-4 & Total \\
\hline Arquitectura & & & 2 & 3 & 5 \\
Artes electrónicas & & 4 & 3 & 4 & 11 \\
Arte visual, imagen y sonido & 7 & 5 & 10 & 2 & 24 \\
Diseño & 5 & & 6 & 4 & 15 \\
Informática & 2 & 2 & 1 & 6 & 11 \\
Ingeniería & 2 & & & 1 & 3 \\
\hline Totales & 16 & 11 & 22 & 20 & 69
\end{tabular}

Tab. 4.1.: Distribución por background en cada instancia

actividad ocupacional en cuestión"[194]. Estos aspectos se ven satisfechos por la formación y experiencia de varios años del autor en práctica, docencia e investigación en diseño industrial, primero, y de sistemas interactivos corporizados, hasta la actualidad.

\section{Demografía de los participantes}

A lo largo de las instancias implementadas participaron un total de 69 profesionales $(\mathrm{F}=33$, $\mathrm{M}=36$ ) con diferentes formaciones previas (ver distribución en Tabla 4.1). Todos ellos trabajaban activamente en sus áreas de expertise al momento de cada instancia. Los participantes fueron de seis nacionalidades diferentes (ver Tabla 4.2) con una edad promedio de 32.3 años $(\mathrm{SD}=5.09)$.

\section{Ideas generadas}

A lo largo de las instancias del Taller se generaron las 15 ideas de interacción enactiva por sustitución y aumento sensorial que se presentan en la Tabla 4.3. A continuación se incluye el resumen del registro de trabajo de cada uno de los proyectos con las observaciones relevantes rescatadas en las sesiones de trabajo. Esta forma de presentar el registro es en aras de facilitar el flujo de lectura al tiempo que se garantiza la fundamentación de las conclusiones obtenidas. En el Anexo A se incluye la configuración completa de cada sesión y links al sitio web donde puede consultarte el registro completo.

\begin{tabular}{lccc}
\hline País & F & M & Total \\
\hline Argentina & 25 & 21 & 46 \\
Brasil & 2 & 2 & 4 \\
Colombia & & 11 & 11 \\
Italia & 1 & & 1 \\
México & 4 & 1 & 5 \\
Venezuela & 1 & 1 & 2 \\
\hline Totales & $\mathbf{3 3}$ & $\mathbf{3 6}$ & $\mathbf{6 9}$
\end{tabular}

Tab. 4.2.: Distribución por género y nacionalidad 


\begin{tabular}{lll}
\hline Instancia & Título & Descripción \\
\hline \multirow{2}{*}{ T-1 } & Abuelino & Títere basado en linterna enactiva \\
& Atrapa pesadillas & Atrapa sueños electrónico \\
& Mouse háptico & Mouse aumentado con háptica \\
\hline \multirow{2}{*}{ T-2 } & Zona de tránsito & Interacción con fronteras virtuales \\
& Aplausos corporales & Percepción corporal del aplauso recibido \\
& Tocar el alma & Percepción del ritmo cardíaco de un tercero \\
\hline \multirow{3}{*}{ T-3 } & Sphaira & Experiencia háptica dinámica \\
& Imagen háptica & De la vista al tacto \\
& Sonar para ciegos & Transducción háptica de obstáculos físicos \\
& Calor y color & La temperatura del color \\
\hline \multirow{3}{*}{ T-4 } & Zapatillas para ciegos & Orientación háptica \\
& Letras en los dedos & Guante para recepción háptica de la voz \\
& 4.7K Luz háptica & La luz que acaricia \\
& Empatheia vibratio & Vibraciones que ayudan a empatizar \\
& Caricias remotas & Acariciar a la distancia
\end{tabular}

Tab. 4.3.: Ideas de interacción enactivas generadas en los Talleres

Taller T-1 En la instancia inicial los participantes trabajaron con la consigna Ver con la piel y presentaron tres IEs basadas en aumento sensorial por feedback háptico.

Abuelino El títere Abuelino (ver Figura 4.5) es una adaptación lúdica de la Linterna Enactiva de Froese[73]. Este grupo trabajó desde el comienzo con la idea de realizar una especie de "prótesis de reemplazo sensorial" y propuso generar un títere que sirviera de guía para el desplazamiento de niños con dificultades visuales. Para detectar la distancia entre el dispositivo y un obstáculo utiliza sensores de ultrasonido (en lugar de infrarrojos de la linterna original) y un pequeño motor vibrador entrega un feedback háptico sobre la muñeca del usuario, con una intensidad inversamente proporcional a la distancia medida.

Estos diseñadores trabajaron directamente con la realización de modelos físicos, sin ninguna instancia previa de bocetado en papel. Luego de una breve discusión sobre las ideas a explorar, se organizaron en dos subgrupos y avanzaron en forma paralela en el desarrollo del títere y de la electrónica asociada. Una de las primeras decisiones fue utilizar sensores de ultrasonido por su familiaridad a partir de trabajos previos y su aspecto visual generó la idea que fueran los ojos del títere (ver Figura 4.4). Entonces el grupo encargado del cuerpo construyó rápidamente diferentes modelos cosiendo retazos de telas (ver Figura 4.5 izquierda arriba) y probándolos realizando pequeñas enacciones del uso del títere siendo ellos mismos los usuarios. En forma paralela, el resto del grupo trabajó sobre la electrónica y el software. Tomaron las tarjetas tipo protoboard como plataformas de bocetado y realizaron unos modelos simples probando la conexión y respuesta del sensor de ultrasonido y luego de un pequeño motor ERM. Programaron sobre la IDE de Arduino con un proceso iterativo de prueba y error (ver Figura 4.5 izquierda centro). Cuando estuvieron conformes con las respuestas brindadas por el motor a los datos entregados por el sensor de ultrasonido, pasaron a una etapa de refinamiento del boceto para combinarlo con el vestido del títere. 


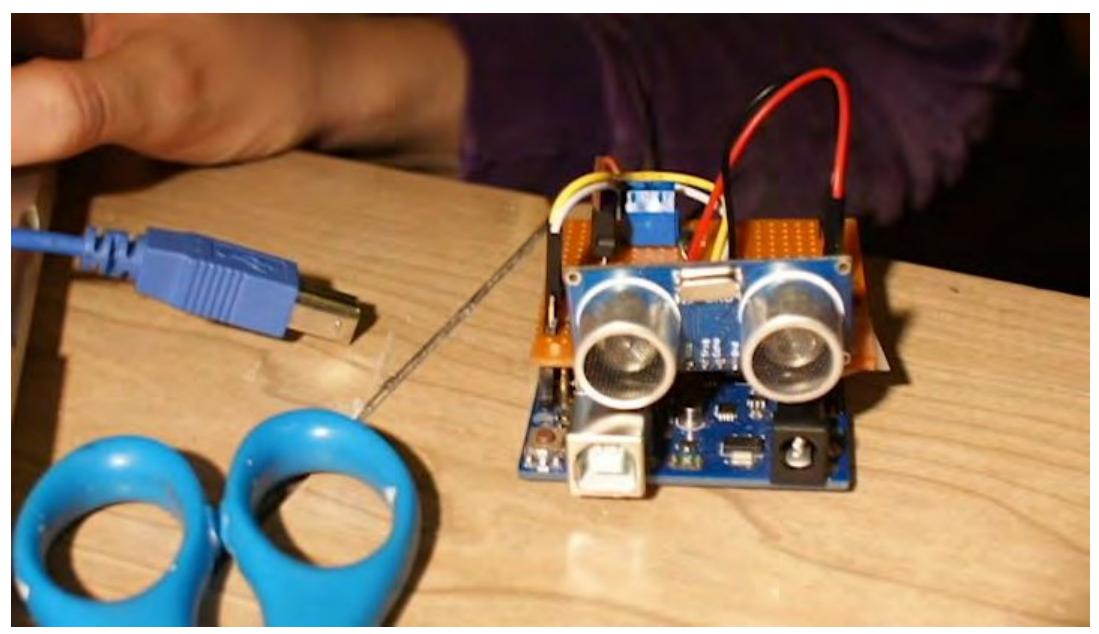

Fig. 4.4.: Abuelino: los aspectos visuales del títere se estructuraron de manera oportunista a partir de la forma del sensor de ultrasonido

El ajuste de la interactabilidad (que básicamente definieron como la curva de respuesta del motor a la distancia medida) fue realizado directamente sobre el programa de Arduino lo que los obligaba a salir del "flujo de pensamiento" para entrar en la rutina del cambio de código, compilación y descarga a la tarjeta. Sin embargo, cuando comenzaron a combinar la electrónica con el vestido del títere, concluyeron que necesitaban probar la interactividad en términos de feedback háptico con modelos que combinaran todas las partes de la idea. Para poder validar los atributos de las curvas de respuesta que habían analizado "en abstracto" sólo con la electrónica, necesitaban incluir el motor para experimentar las diferencias de colocarlo en una muñequera, sobre la palma o el dorso de la mano, etc.

La idea final, probada con estudiantes de otros grupos en la demo de cierre (ver Figura 4.5 izquierda abajo) satisfizo los dos objetivos que el grupo se había propuesto: adaptar la linterna de Froese con formato lúdico sin dejar de proporcionar la misma sustitución sensorial.

Atrapa pesadillas Los integrantes del segundo grupo trabajaron sobre la idea de un "atrapa sueños"6 (lo llamaron "Atrapa pesadillas"). Su idea fue disponer de un dispositivo que detecte la presencia de algo o alguien acercándose por la espalda y brinde un feedback háptico en el colgante frontal (ver Figura 4.6). Quizá el hecho que de los cuatro integrantes del grupo, dos fueran venezolanos y una mexicana haya sido determinante al elegir el Atrapa sueños como inspiración.

A diferencia del primer grupo, estos participantes comenzaron con unos bocetos en papel donde representaron en estilo storyboard el tipo de experiencia de usuario que buscaban con anotaciones textuales. Rápidamente pasaron a la construcción de modelos físicos con el

\footnotetext{
${ }^{6}$ Un atrapa sueños es un adminículo hecho a mano, cuya base es un aro (...) con una red en su interior y decorado con (...) plumas. Según la creencia popular, su función consiste en filtrar los sueños de las personas, dejando pasar solo los sueños y visiones positivas; los sueños que no recuerdas son los que bajan lentamente por las plumas. Las pesadillas se quedan atrapadas en las plumas a la mañana siguiente se queman con la luz del día para que no se cumplan https://es.wikipedia.org/wiki/Atrapasueños
} 


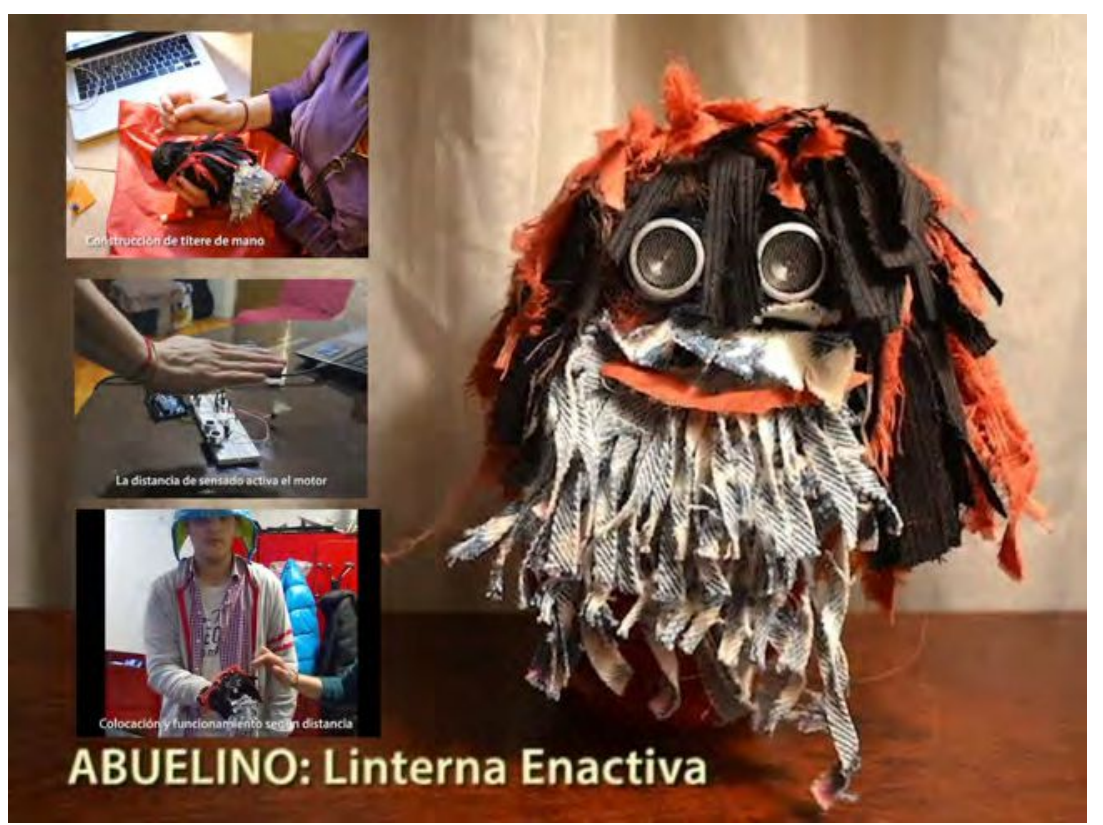

Fig. 4.5.: Algunos pasos en el bocetado de Abuelino: bocetado del cuerpo a partir de retazos disponibles de telas, construcción de la curva de interactividad mediante secuencias de programación, descarga a placa, ejecución y corrección, pruebas con usuarios y boceto final

agregado de interactabilidad mediante el uso de Leds, un motor vibrador y un sensor infrarrojo pasivo (PIR) ${ }^{7}$. Para el control del sensor y la respuesta lumínica y háptica utilizaron la versión Lilypad de Arduino ${ }^{8}$, porque "estéticamente se adapta mejor para algo que debe llevarse colgado" (descripción de uno de los miembros del grupo).

Todas las pruebas y modificaciones de la interactabilidad que buscaban las realizaron directamente con bocetos interactivos que disponían sobre algún miembro del grupo como usuario. También utilizaron el ciclo iterativo de prueba y error para modificar la interactividad entregada por la relación entre inputs y outputs. Se quejaron varias veces de que esto los obligaba a abandonar el flujo de pensamiento y focalizarse en los programas de Arduino.

Mouse háptico El tercer grupo de este taller, integrado por dos programadores y dos artistas visuales, planteó un mouse háptico sobre la base de las ideas presentadas por Brayda[28]. La idea es que el mouse permita a un usuario con dificultades visuales reconocer la "textura" de una imagen mostrada en pantalla mediante su recorrida con el cursor. El mouse ofrece diferente feedback vibrotáctil y auditivo cuando el cursor atraviesa diferentes zonas de textura. Su idea inicial fue permitir a un usuario sin posibilidades de visión recorrer con el mouse una imagen pictórica.

Tomaron como base un mouse tradicional y a modo de bricolaje bocetaron sobre él las modificaciones que necesitaban. De forma paralela trabajaron sobre unos programas con Processing para mostrar en pantalla las imágenes a recorrer y simular el comportamiento

\footnotetext{
${ }^{7}$ https://es.wikipedia.org/wiki/Sensor_infrarrojo_pasivo

${ }^{8}$ https://www.arduino.cc/en/Main/ArduinoBoardLilyPad/
} 


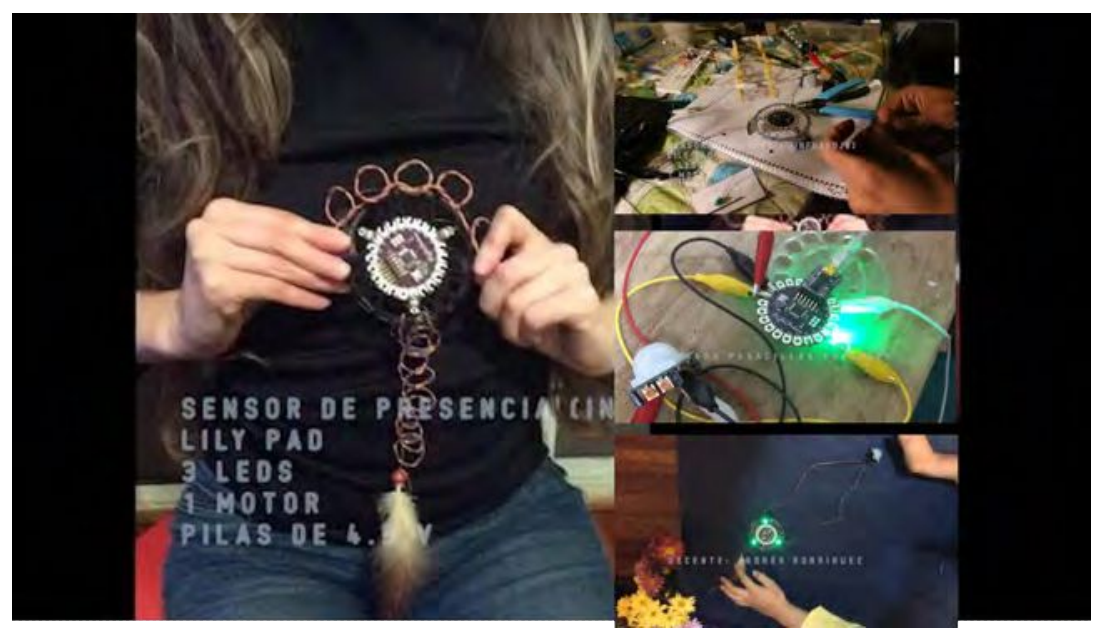

Fig. 4.6.: Atrapa pesadillas: maqueta inicial, bocetos en papel, pruebas funcionales, boceto final

del mouse modificado. Realizaron algunas pruebas colocando la placa Arduino adosada al mouse, pero la experiencia obtenida distaba demasiado del uso habitual del dispositivo. Por ello optaron por generar un complemento de conexión intermedia entre el mouse y la computadora, donde colocaron la placa controladora y el resto del hardware necesario (ver Figura 4.7).

La etapa más extensa de este grupo consistió en el ajuste de la experiencia buscada mediante reiteradas pruebas con usuarios (utilizaron a los miembros de los otros grupos) con cada uno de los bocetos intermedios que generaron. Al igual que los otros dos grupos, casi no trabajaron con bocetos en papel. Con una aproximación de tipo bricolaje, fueron construyendo su idea como una corporización de la interactividad que estaban buscando.
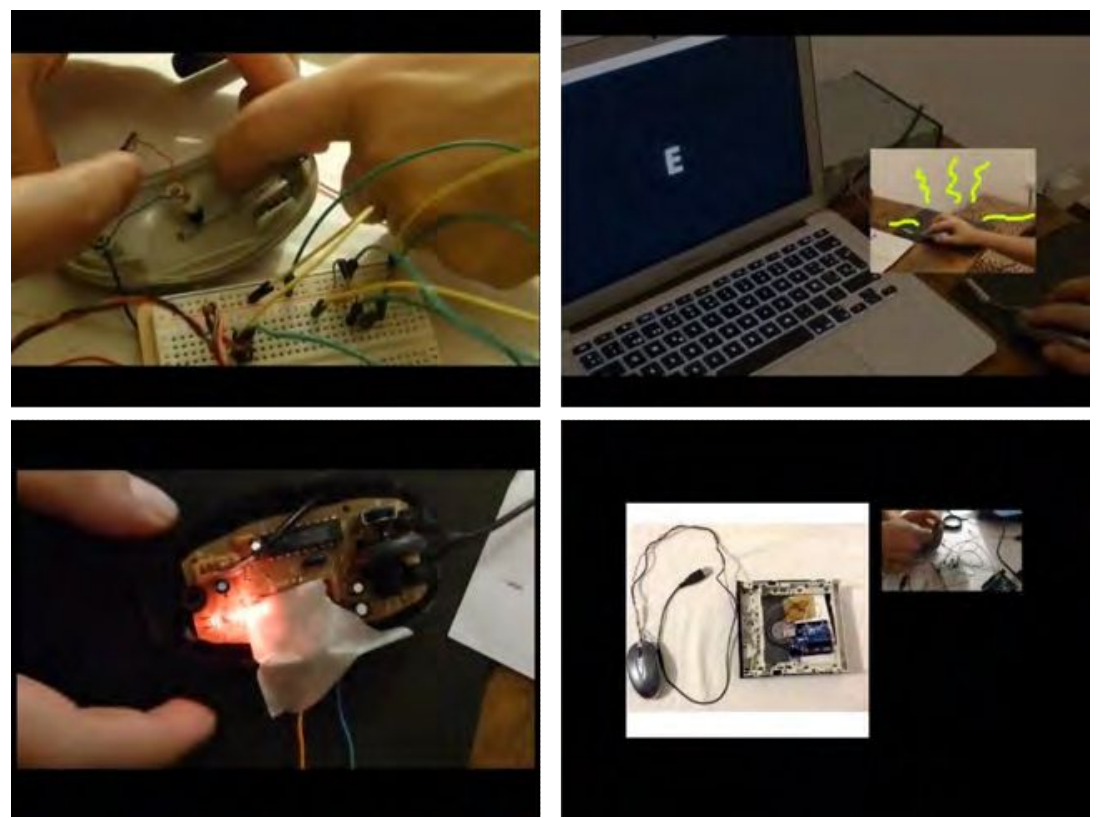

Fig. 4.7.: Mouse háptico: primeros bocetos interactivos, pruebas funcionales con usuario y boceto final

Taller T-2 Esta instancia del taller se realizó con la consigna de Sentir en el cuerpo el espacio físico o digital y generó las actividades y propuestas que se describen a continuación. 
Zona de tránsito Este grupo utilizó la consigna para generar un aumento sensorial a través de percibir en el cuerpo la aproximación a una frontera por parte de un migrante. Conformado por dos realizadores cinematográficos, una artista visual y un programador de juegos, este grupo se propuso de entrada brindar al usuario una sensación corporal de una situación espacial y social traumática como es la inminencia del acercamiento a una frontera por parte de un migrante. La elección del tema tiene además un componente de contexto. Contemporáneo con el taller los medios masivos difundían noticias sobre tandas de migrantes subsaharianos muertos al intentar alcanzar las costas europeas por el Mediterráneo. Las noticias incluían reportes sobre diferentes estrategias encaradas por la Agencia Europea de Guardia de Fronteras y Costas para detectar las masas migratorias en el mar utilizando dispositivos de detección de signos vitales, como radiaciones de temperatura corporal o ritmos cardíacos. En las discusiones iniciales del grupo hicieron énfasis en el estado emocional que sufre el migrante y se concentraron en la aceleración de sus pulsaciones como el emergente corporal de esa angustia. El objetivo del grupo fue generar un dispositivo que permitiera a otras personas vivenciar en su cuerpo esa sensación. Todas estas ideas les llevaron casi la clase inicial entera y sólo dejaron como rastro algunas anotaciones en cuadernos.

Probablemente basados en la experiencia con el manejo de espacios escénicos se plantearon incluir la IE en un entorno diseñado. Por una parte idearon una interfaz basada en un dispositivo con sensores de ultrasonido y actuadores lineales de resonancia que ubicarían en un cinturón colocado en el pecho del usuario. La frontera la constituye una especie de local semicerrado proyectado como rectángulos de acrílico en los que se leen las leyes migratorias. La primera idea fue que al acercarse a "la frontera", el dispositivo fuera capaz de trasducir la distancia detectada a estímulos vibrotáctiles que intentan reproducir pulsaciones cardíacas que se aceleran a medida que la distancia se acorta.

En la primera aproximación trabajaron directamente sobre hardware con protoboard y la IDE de Arduino. Conectaron un motor DC y un sensor de Ultrasonido directamente a la placa (ver Figura 4.8) y probaron algunas curvas de respuesta. Uno de los integrantes sostenía con sus manos el boceto sobre su pecho y otro hacía las correcciones y descargas del programa. En la siguiente clase probaron con un pequeño motor ERM y encontraron que debían aumentar la intensidad de respuesta para hacerla perceptible. Ahí descubrieron la necesidad de armar un circuito específico para el manejo del motor, lo que derivó en el armado de una nueva placa (ver Figura 4.9). En este punto, sólo el programador de juegos tenía los conocimientos necesarios para armar el driver del motor, lo que ralentizó el trabajo de todo el grupo.

Finalmente, cuando probaron el nuevo boceto con la placa extra en el cinturón (Figura 4.10), y simularon en los pizarrones la idea de frontera encontraron que debían reforzar la experiencia corporal de la aproximación y "encierro" en una zona de tránsito 9 . Para ello

\footnotetext{
9"'La zona de tránsito es un espacio generalmente ubicado en torno a las instalaciones aeroportuarias y que funciona como un límite fronterizo donde no existe frontera alguna, es decir donde no necesariamente coinciden los límites territoriales físicos del Estado, y en el cual, sin embargo, se exhibe un fuerte control aduanero y fronterizo organizado en torno a la presencia y desarrollo de tecnologías avanzadas de registro y sensado (scanners, detección de metales, cámaras de seguridad, documentos con chips embebidos, hologramas, etc.). La
} 


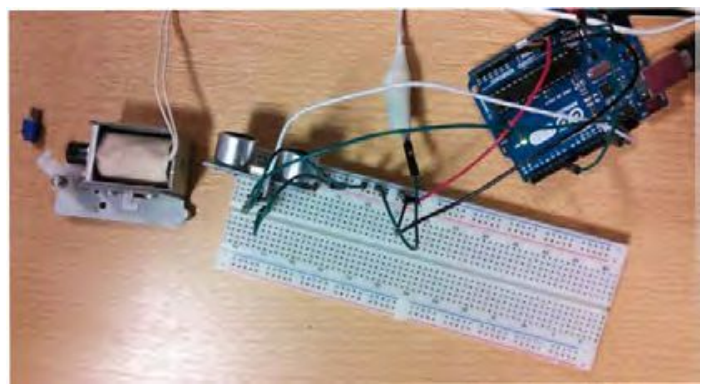

Fig. 4.8.: Zona de tránsito. Boceto inicial

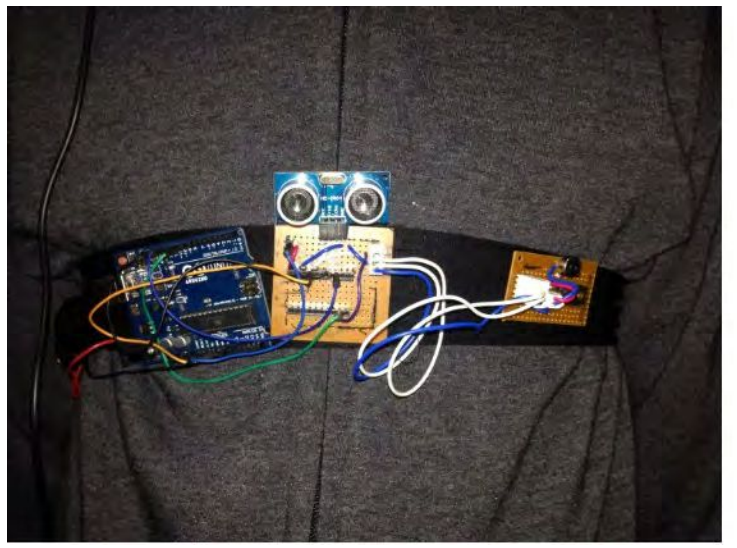

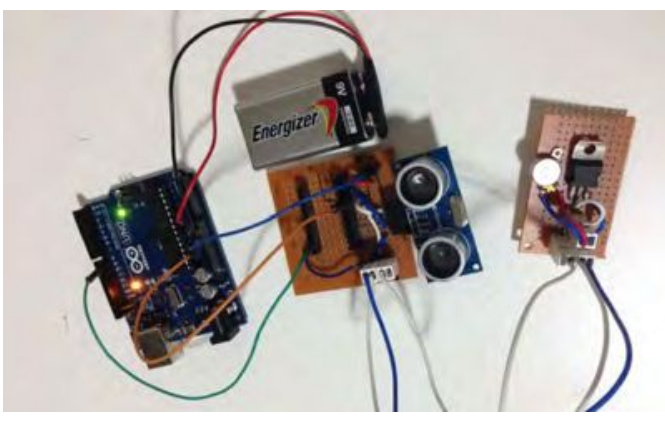

Fig. 4.9.: Zona de tránsito. Ultimo boceto de dispositivo vestible

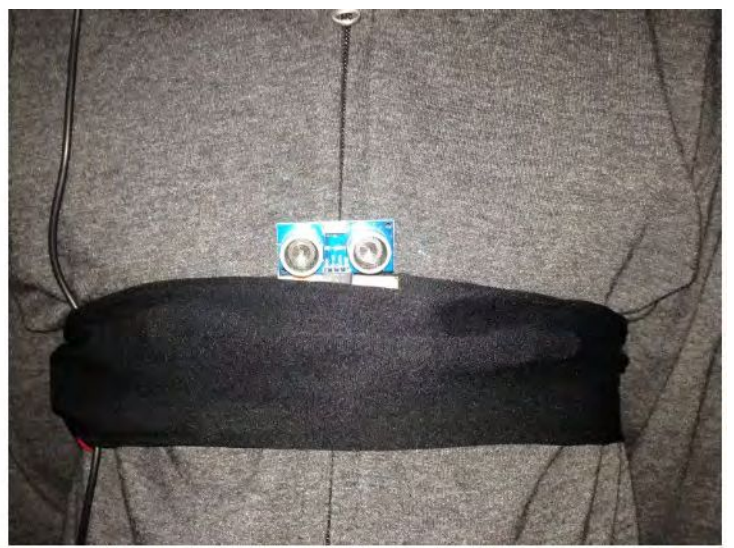

Fig. 4.10.: Zona de tránsito. Elaboración de cinturón en pecho

agregaron una modalidad más a la experiencia: el sonido. Con el uso de auriculares, a medida que el usuario se acerca a la frontera escucha un audio en sonido estéreo reproduce en un canal discursos gubernamentales asociados al problema de la migración, mientras que en otro canal se reproducen testimonios de migrantes en diferentes idiomas tomados de la web. La necesidad de esta modalidad agregada la descubrieron en el momento de bocetar la experiencia de la IE que habían creado.

Todos los miembros del grupo estuvieron de acuerdo en que sólo con la sensación vibrotáctil la experiencia corporal era insuficiente para recrear la angustia de un migrante. Una muestra más de la necesidad del bocetado rápido con software y hardware como parte del proceso de indagación propio del diseño en etapas tempranas.

Aplausos corporales Este grupo exploró una forma de aumento sensorial mediante la percepción de aplausos recibidos a través de sentirlos en el cuerpo (sin importar si se escuchan o no). Para ello imaginaron la necesidad de capturar alguna de las dimensiones del aplauso y discutieron sobre sensores piezoeléctricos ${ }^{10}$ para generar una sustitución sensorial del aplauso escuchado por la percepción de una vibración corporal.

\footnotetext{
"zona de tránsito" es la frontera en su estado más puro de artificialidad y eficiencia en términos de control"(de la memoria descriptiva de Zona de Tránsito)

${ }^{10}$ https://es .wikipedia.org/wiki/Sensor_piezoeléctrico
} 


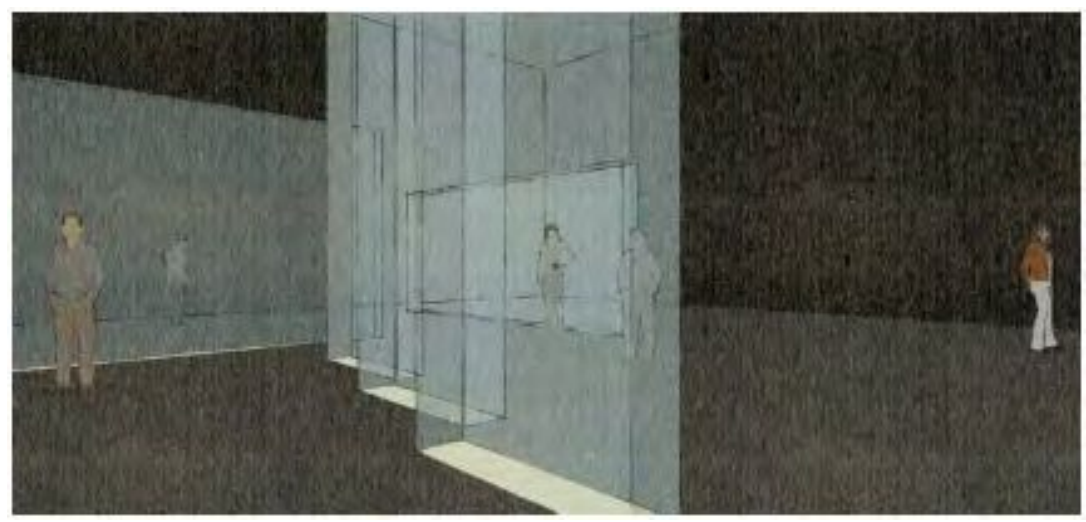

Fig. 4.11.: Zona de tránsito, propuesta de instalación

Al principio hicieron algunos bocetos simples en papel (ver Figura 4.12) que sólo trasmitían la posible estructura de la IE sin indicar la posible interactabilidad, aunque mientras los comentaban entre ellos gesticulaban y enactuaban la interactividad imaginada. Luego hicieron algunas pruebas simples para comprobar que era posible capturar el aplauso de la manera que lo imaginaron. Y el primer paso consistió en construir un boceto rápido con hardware conectando un par de piezoeléctricos directamente a un Arduino y explorar la captura de información utilizando la salida de pantalla del puerto serie. Necesitaron explorar diferentes tamaños de los piezoeléctricos (actuando el aplauso, ver Figura 4.13) y modificar el programa hasta que se sintieron conforme con la captura. En este punto vale señalar que sufrieron la misma interrupción del flujo de acción mencionado en grupos anteriores (por la necesidad de modificar, recompilar y subir los programas).

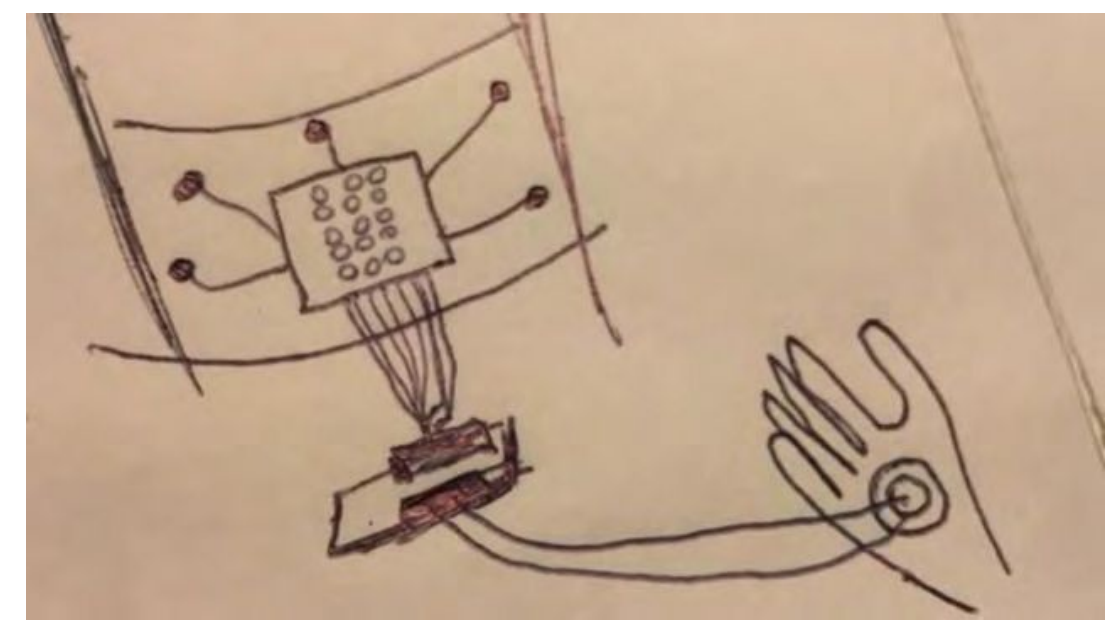

Fig. 4.12.: Aplausos corporales, boceto papel

Al mismo tiempo, las conversaciones entre ellos marcaban que la transición de lo imaginado a lo experimentado al aplaudir sobre el piezo sufría una pérdida de riqueza. Al mismo tiempo otra parte del grupo exploraba la sensación vibratoria provista por pequeños ERM ${ }^{11}$. En la exploración de esto decidieron agregar alguna información que permitiera a quien aplaudía

\footnotetext{
${ }^{11} \mathrm{https}$ //www.precisionmicrodrives.com/vibration-motors/eccentric-rotating-mass-vibration-motors-erms/
} 


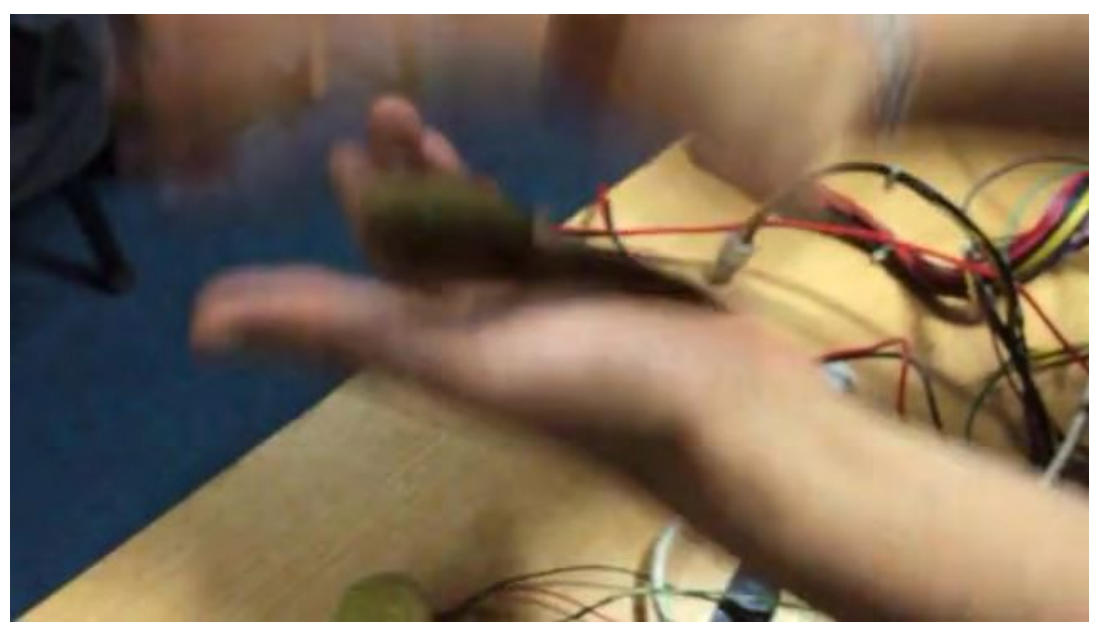

Fig. 4.13.: Aplausos corporales, prueba de boceto de actuador

saber si su tarea era capturada por el sistema adecuadamente y decidieron sumar feedback visual al cinturón de percepción háptica. Nuevamente vemos un caso de diseño oportunista y de proceso conducido por la corporización. Sólo al ejercitar el aplauso y la vibración comprendieron que quien aplaudía no tenía la misma corporización del significado del aplauso que en el caso normal (ver Figura 4.14). Cuando uno aplaude, sabe que el otro lo recibe porque la dimensión principal es el sonido, su intensidad y frecuencia, además del gesto corporal. En el experimento realizado la riqueza del sonido se diluye para quien realiza el gesto y sólo es percibida la intensidad de parte de quien posee el cinturón. Como se trataba de producir bocetos decidieron no explorar opciones de una comunicación inalámbrica, aunque era parte del objetivo inicial del proyecto.

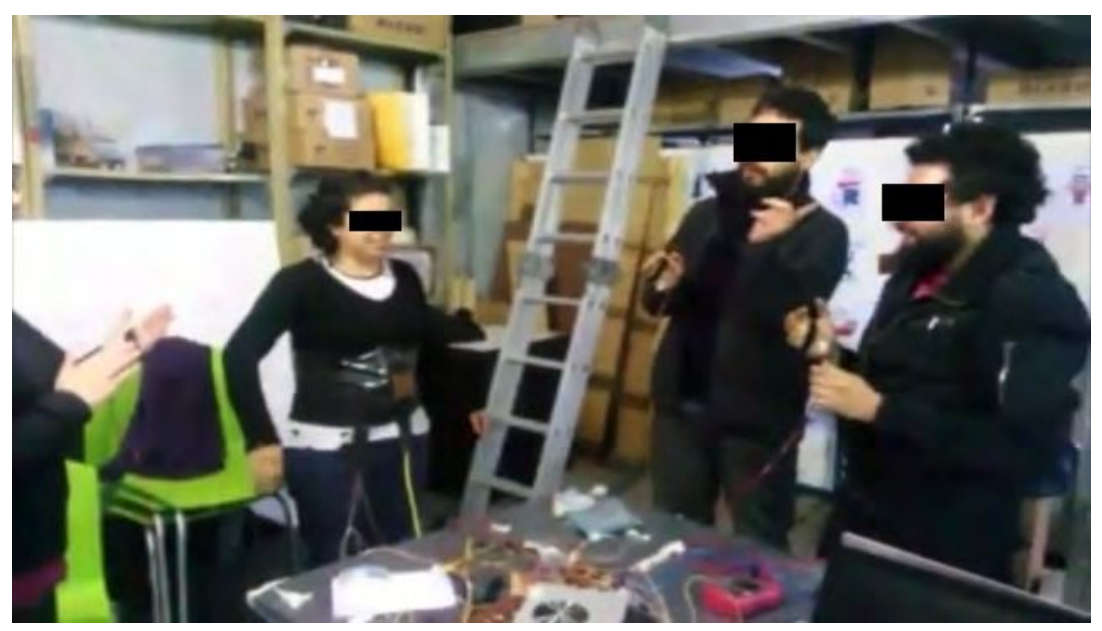

Fig. 4.14.: Aplausos corporales, prueba en boceto de experiencia

Tocar el alma Este grupo se alejó un poco de la consigna al comienzo, ya que se enfocaron sólo en un aumento de la percepción háptica, pero sobre el final agregaron una exploración de entorno al transformar la IE en un dispositivo colaborativo. Generaron lo que llamaron "máquina de latidos electrónicos", con el objetivo de explorar un aumento sensorial con 
percepción háptica del impulso eléctrico del latido del corazón. La IE utiliza un sensor de pulso procesado con un Arduino que después lo traduce en una descarga eléctrica casi imperceptible. La sutileza de la descarga obliga al que la experimenta a concentrarse en sentir el ritmo cardíaco del otro (o de si mismo).

Una de las reflexiones de su registro muestra la clara idea de acoplamiento sensoriomotor que los guió: "el objetivo es lograr percibir nuestro impulso más vital a través de nuestro sentido más importante: el tacto. Generar reflexión entorno a este ciclo de sístoles y diástoles presente siempre en nuestras vidas, en nuestro propio cuerpo. Tocarlo para materializarlo en nosotros mismos y en el otro, para aprender a verlo y escucharlo".

Al principio tenían la idea de sensar de alguna manera la frecuencia cardíaca y utilizarla para la interacción. Sin embargo, no tenían clara la existencia de los sensores adecuados ni si estos sensores podían conectarse fácilmente en un entorno de Arduino. Entonces utilizaron la web como fuente de información y encontraron la posibilidad de construir un circuito que emulara al sensor de pulsos con un emisor y detector de luz infrarroja ${ }^{12}$. Utilizaron gran parte del tiempo en la construcción del circuito y debido a una falla en una de las pruebas terminaron quemando el programador USB de la placa Arduino, con lo cual la última versión subida al procesador ATMEGA es la que emplearon en las pruebas.

Dedicaron el resto del tiempo del taller a idear la forma de ubicar la electrónica en una IE que permitiera a los usuarios estar cara a cara, con un LED rojo en medio titilando los valores obtenidos del pulso. Finalmente bocetaron un contenedor simple con un par de Leds indicando el estado encendido/apagado y la frecuencia de pulso sensado (ver Figuras 4.15 y 4.16).

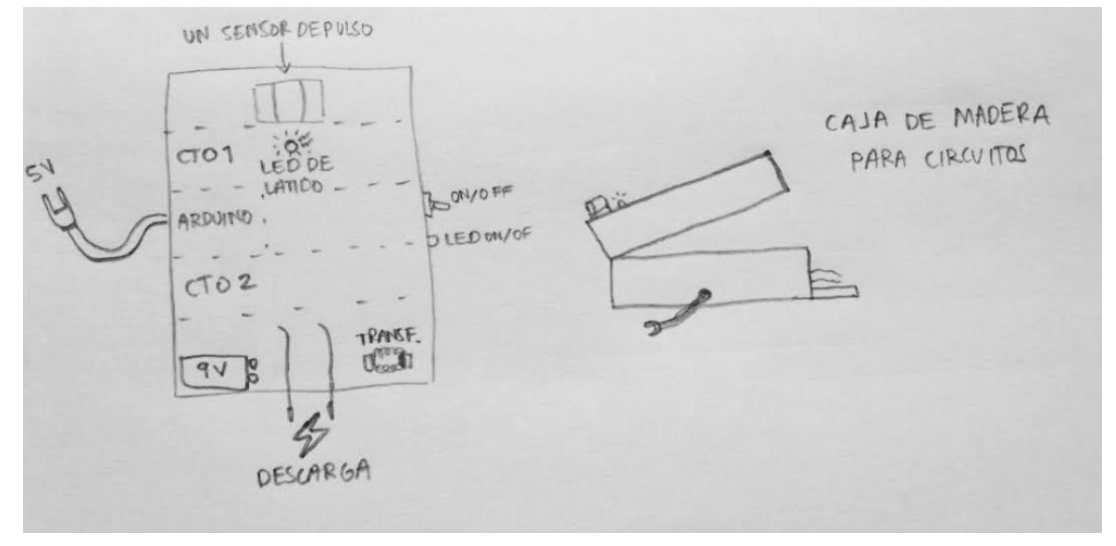

Fig. 4.15.: Tocar el alma. Boceto a mano alzada de la posible estructura de interfaz

En la demo final, este grupo fue el único que requirió para la experiencia la utilización de un ambiente a oscuras, con la única iluminación de los Leds (Figura 4.17). La concentración en la frecuencia exhibida por esta pequeña fuente de luz fue parte del diseño de experiencia enactiva.

\footnotetext{
${ }^{12}$ https://makezine.com/projects/ir-pulse-sensor/
} 


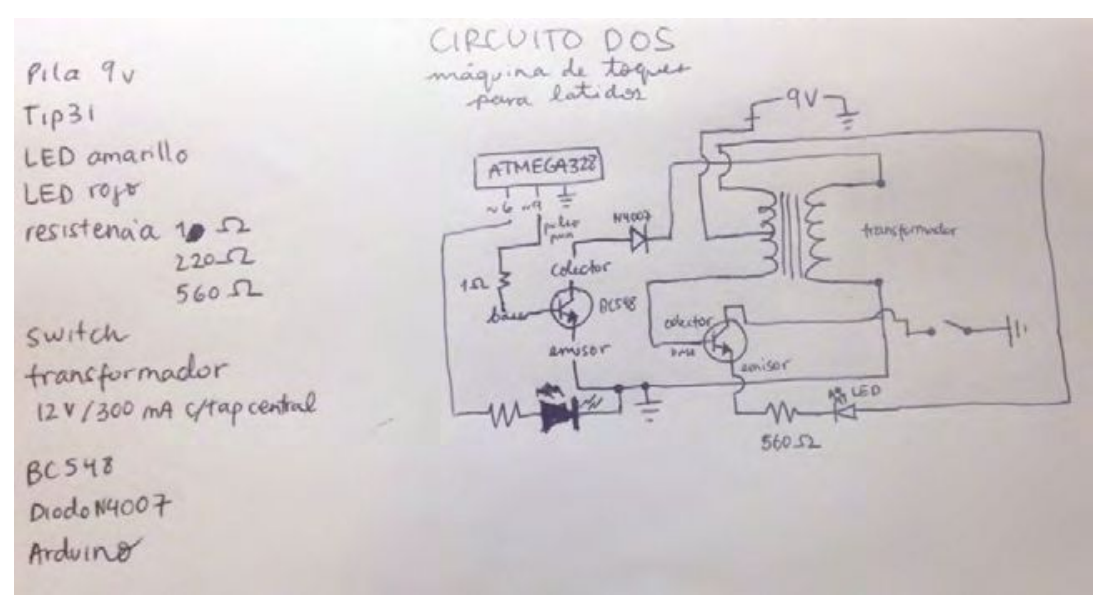

Fig. 4.16.: Tocar el alma. Boceto de circuito utilizando lenguaje de esquemas electrónicos y anotaciones de materiales

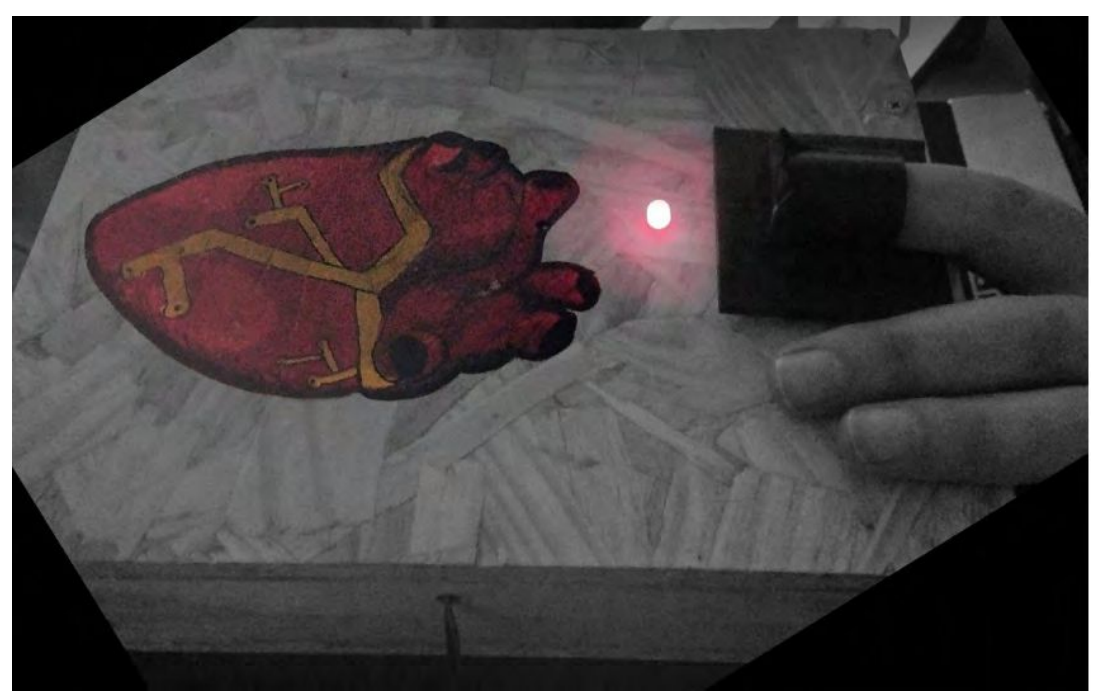

Fig. 4.17.: Tocar el alma. Boceto en prueba de usuario durante la demo final

Taller T-3 Este Taller fue el primero de la segunda tanda, en la que se dio más libertad a los grupos ya que se plantearon tres consignas que podían utilizarse indistintamente para la generación de ideas: Ver con la piel, Sentir en el cuerpo el entorno, Oir con la piel.

Sphaira Este grupo fue el único de todos los talleres que se planteó la idea del uso del movimiento para la interacción enactiva. Se propusieron generar una especie de objeto lúdico, una esfera que al ser lanzada de un jugador a otro entregara una respuesta háptica diferente dependiendo sólo de los ejes de su movimiento. En las ideas que discutieron al comienzo imaginaron un juego en el que el receptor ganaba cuando era capaz de reproducir el mismo movimiento que el que había recibido y que la única indicación para esto era la acción del propio movimiento, ya que la esfera no debía poseer signos visibles que permitieran reconocer fácilmente el eje en el cual estaba girando. 
En este caso es interesante observar nuevamente cómo las ideas surgen de manera oportunista. Por un lado, la idea de utilizar el eje del movimiento como disparador del feedback háptico surgió cuando detectaron entre el material disponible un componente electrónico inercial, fácilmente conectable con Arduino, que combina acelerómetro y giróscopo e informa la velocidad, orientación y fuerzas gravitacionales que operan sobre él ${ }^{13}$. Por otro, las experiencias previas de los integrantes del grupo parecen determinantes: entre ellos había una experimentada diseñadora de juegos electrónicos con interfaces tangibles y un diseñador industrial. Después de jugar un poco arrojándose unas pelotas improvisadas que hicieron con ropa enrollada e imaginarse cómo podrían transmitir/percibir sensaciones hápticas diferentes, pasaron a la instancia de verificar que eran capaces de conectar y utilizar el componente inercial. En la segunda sesión, dedicaron la primera mitad a pensar alternativas de uso de una esfera de telgopor de unos $20 \mathrm{~cm}$ que habían llevado. Después de discutir durante un buen rato y seguir jugando a arrojarse la esfera, concluyeron en la posibilidad de utilizar una especie de plano ecuatorial interno donde ubicar toda la electrónica necesaria. Cortaron un cartón con las medidas apropiadas y entonces todo el grupo se dedicó a analizar cómo conectar la unidad inercial a Arduino y programar la interactabilidad que habían pensado. Avanzaron con la idea de reconocer el giro sólo en dos ejes ortogonales y entregar una respuesta háptica reciclando los pequeños motores disponibles en los gamepads de consolas (ver Figura 4.18 derecha).

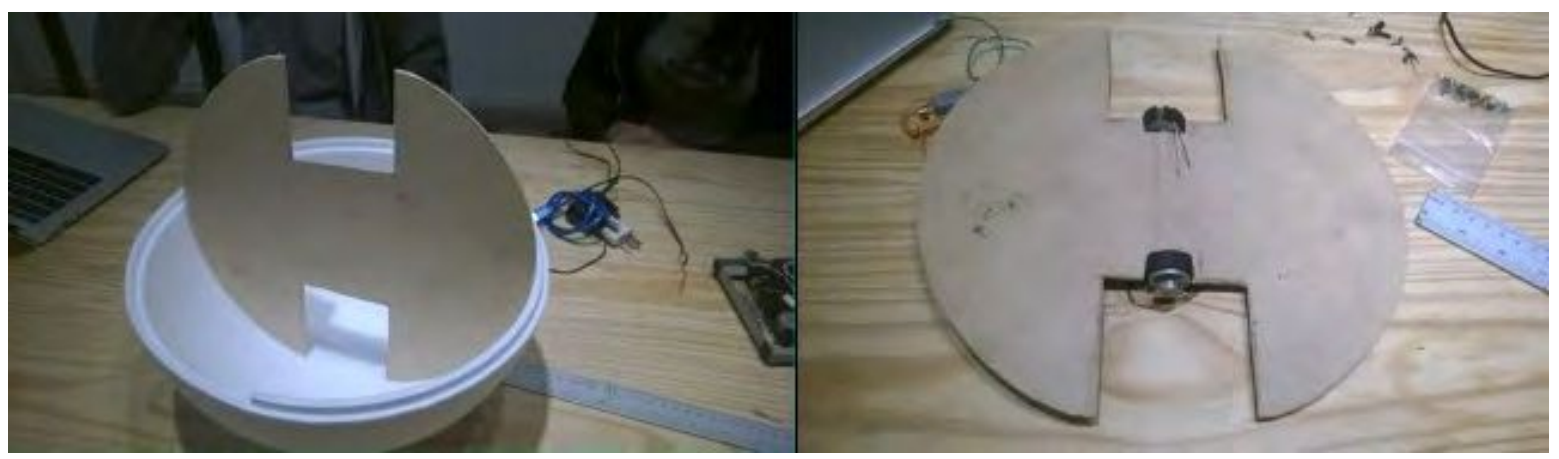

Fig. 4.18.: Sphaira. Boceto inicial de plano ecuatorial con posible fijación de motores vibradores

Para generar la interactabilidad buscada experimentaron de manera extensiva con salida numérica por la consola del puerto serie de Arduino. Pero no pudieron determinar en ningún momento el tipo de expresividad lograda, además de requerir continuamente cambios en la programación, compilación y descarga a la placa, antes de poder validar el resultado. Por otra parte, es obvio que el movimiento del componente siempre fue una composición en los tres ejes ortogonales, por lo que tuvieron que decidir las proporciones mínimas para "aislar" el giro en uno de los ejes seleccionados. Este proceso también les demandó una larga secuencia de ensayos y correcciones al programa.

Tras un largo proceso de manipular el MPU6050 montado sobre un trozo de cartón junto con dos motores, decidieron integrar el boceto completo y probar sobre la semiesfera. Fijaron rápidamente toda la electrónica y motores con precintos plásticos al cartón del plano ecuatorial

\footnotetext{
${ }^{13}$ Sensor IMU Modelo MPU6050 https ://playground.arduino.cc/Main/MPU-6050
} 
(ver Figura 4.19) y experimentaron con nuevas curvas de respuesta hasta que estuvieron satisfechos. Finalmente agregaron una batería interna y cerraron la esfera durante la última sesión de demo, ya que al no disponer de un interruptor la vida útil del boceto se redujo a la duración de una batería de $9 \mathrm{~V}$ sometida además de la entrega a la placa a la alimentación de los motores mediante un doble puente $\mathrm{H}$. En la demo, todos los otros participantes experimentaron el juego. Aunque todos dijeron que percibían claramente las diferencias en la respuesta háptica al recibir la esfera, pocos pudieron reproducir el movimiento recibido cuando la volvían a arrojar. El boceto cumplió con la corporización de la idea buscada, pero se requerían mayores ajustes de interactabilidad para alcanzar la interactividad perseguida.

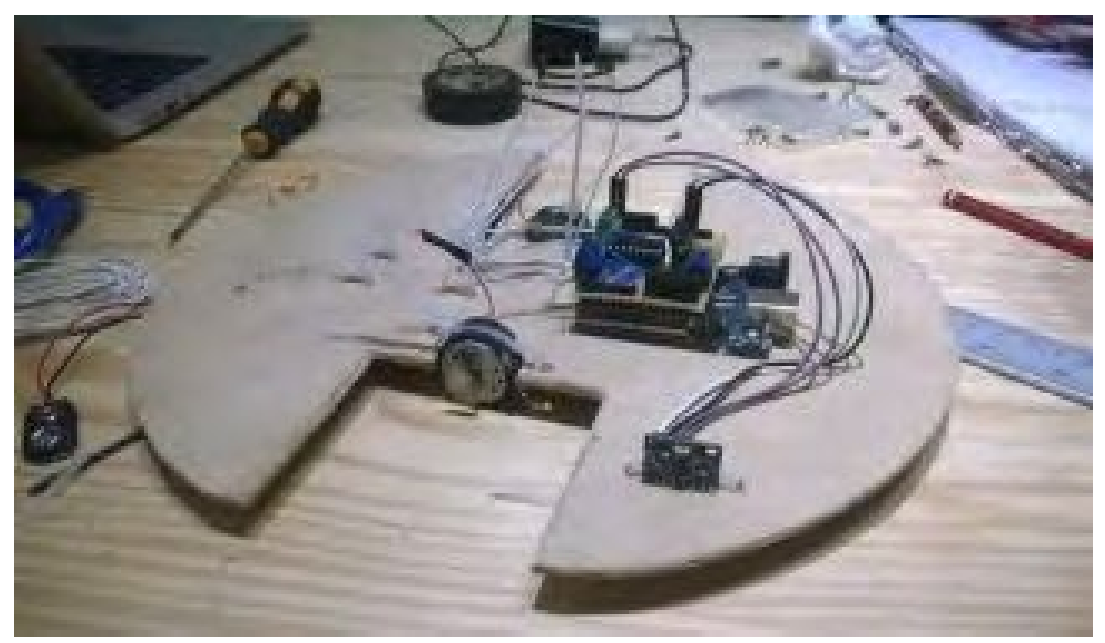

Fig. 4.19.: Sphaira. Versión de boceto con motores y electrónica fijada con precintos previa al cierre y demo.

Color por calor Este grupo se planteó percibir la temperatura cromática mediante un estímulo térmico sobre la piel. Imaginaron un guante con algún sensor cromático que pudiera activar un elemento térmico montado en un chaleco o algo similar.

Nuevamente las experiencias previas y el oportunismo juegan un papel fundamental a la hora de seleccionar el problema y la forma de abordarlo. Entre los miembros de este grupo, quien llevaba la voz cantante es una profesora de artes visuales con amplia experiencia en teoría del color. Al comienzo del trabajo insistió con generar alguna IE que pusiera en juego las categorizaciones del color diferenciados por su temperatura subjetiva (cálidos y fríos), que les atribuyen una serie de asociaciones psicológicas y efectos visuales antagónicos que contrastan y se complementan.

La IE que se imaginaron se compone de un guante con un sensor de color y un chaleco provisto de actuadores térmicos. Para la interacción imaginaron escanear distintos planos coloreados en una imagen impresa utilizando el guante y generar en el chaleco el feedback térmico por transducción de la luz a la temperatura (usando de placas de Peltier ubicadas en la cara interna del chaleco). 


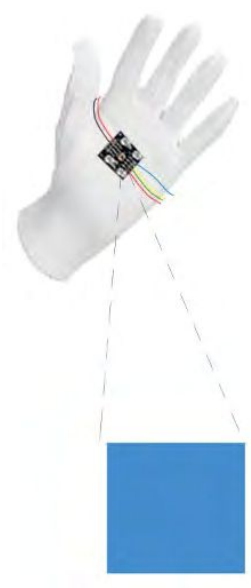

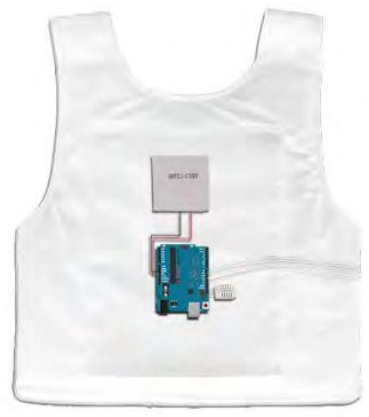

REVERSO

Celda de Peltier enfria (hasta -10 grados)

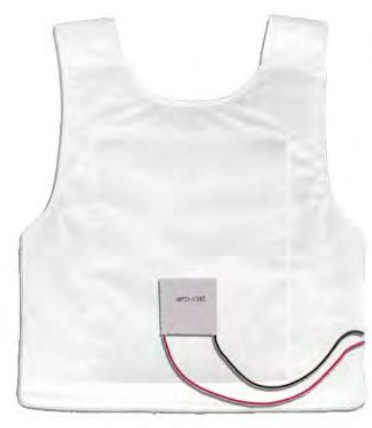

ANVERSO

Celda de Peltier calienta (hasta 50 grados)

Fig. 4.20.: Proyecto Color por Calor. Idea general de sensado en guante y actuado en chaleco

El aspecto de oportunidad estuvo vinculado con la disponibilidad de un Sensor de color TCS $3210^{14}$. Lo primero que hicieron fueron algunos esbozos con el software de Arduino para validar el sensado del guante. Lograron sensar planos opacos de color homogéneo en tiempo real, pero comprobaron que la máxima efectividad en la lectura del estímulo era en condiciones de "penumbra". Se plantearon entonces ajustar la programación para restar la luminancia y la temperatura de color presente en el ambiente al momento de la utilización del dispositivo.

Este grupo intentó un recorrido desde la idea general a la implementación por partes. Sin embargo, se topó con serios problemas como se reporta a continuación. Esas dificultades terminaron siendo lo suficientemente importantes para impedirles llegar a un boceto completo de la interacción.

Después de definir una aproximación válida al sensado se dedicaron a los actuadores térmicos. Utilizaron celdas de Peltier TEC1-12706 15 y probaron con una fuente de tensión graduable de 0 a 12 volt. Entregando gradualmente un máximo de 3 volt la placa, montada en un dispositivo (cooler y disipador), calienta y enfría mucho recorriendo el arco térmico en pocos segundos. El paso de enfriar a calentar lo logran por inversión de polaridad con dos reles pasando de -50 grados a +70 en pocos segundos.

La primera dificultad fue que cuando quisieron pasar a la construcción del circuito completo, encontraron que necesitaban algo similar al que bocetaron en la Figura 4.21, que implicaba resolver por ejemplo temas de entrega de amperaje que están limitados con Arduino, el cambio de polaridad, etc.

Las primeras pruebas para ajustar el circuito incluyeron el muestreo por experiencia directa de contacto corporal con la placa a traves de la palma de la mano con los valores maximo y mínimo de temperatura tolerable para luego establecer el rango en PWM (modulación del ancho de pulso) para la programación.

\footnotetext{
${ }^{14}$ http://pdf1.alldatasheet.com/datasheet-pdf/view/454463/TAOS/TCS3210.html

${ }^{15} \mathrm{https}$ ://pdf1.alldatasheet. com/datasheet-pdf/view/227422/ETC2/TEC1-12706.html
} 


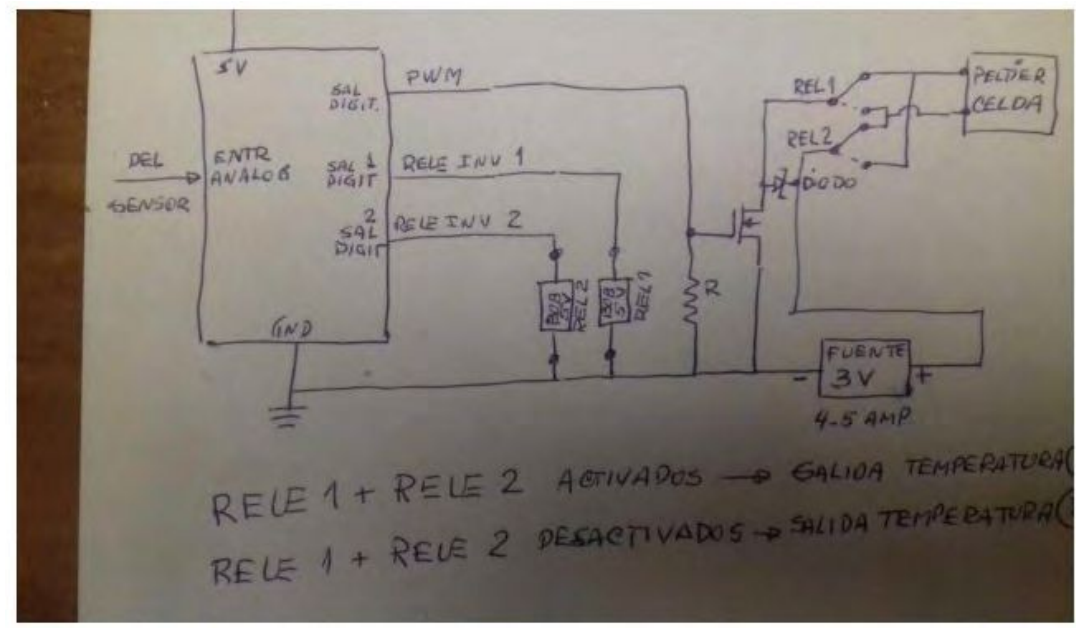

Fig. 4.21.: Proyecto Color por Calor. Ideas para el circuito de sensado y actuación dibujadas como esquemático

Frente a la dificultad de abordar un circuito completo, adoptaron un enfoque divide y conquistarás. Hicieron un circuito provisorio en placa de prototipado. Su función básica es entregar pulso variable, amplificar el amperaje requerido por la placa Peltier y, combinada con los módulos relés, permite invertir el signo de la tensión para lograr que la placa Peltier enfríe o caliente, según la señal que reciba de arduino. Las primeras pruebas con este módulo les permitieron obtener la siguiente verificación: los valores de tensión y corriente óptimos para entregar la temperatura extrema (positiva o negativa) son distintos si la celda de Peltier está conectada directamente a la fuente o al circuito (módulo de control de salida) En la fase inicial, conectando la celda a la fuente de tensión variable obtenían la temperatura extrema casi intolerable para la piel humana en los 4 volt a 1.2 A. Con el módulo de salida, obtuvieron la misma entrega con una tensión de $6 \mathrm{~V}$ y consumo de $0.8 \mathrm{~A}$. Estuvieron conformes con esta mejora, pero lamentablemente les llevó tanto tiempo que no pudieron completar el boceto de la idea general conectando todo. En la sesión final mostraron el funcionamiento de las partes de entrada y salida por separado.

Taller T-4 Al igual que el Taller anterior, en este se plantearon tres consignas que podían utilizarse indistintamente para la generación de ideas: Ver con la piel, Sentir en el cuerpo el entorno, Oír con la piel.

Zapatillas para ciegos Este grupo se propuso desarrollar un par de zapatillas que sean capaces de "reconocer y decodificar cierta información del suelo y transformarla en señales vibrotáctiles capaces de ser percibidas y decodificadas por el usuario". Aunque partieron de la idea de sustitución sensorial (vibrotáctil por visión), queda claro en su planteo inicial la visión representacional con la que abordaron el trabajo: "La emisión de una señal o de un conjunto de señales en diferentes frecuencias e intensidades, determinará al usuario diferentes acciones. Estas acciones pueden ser "acciones simples" como indicar al usuario cuándo debe caminar hacia adelante, cuando retroceder, cuando doblar a la derecha, así como información de el 
lapso de tiempo a realizar dicha acción. La acciones pueden adquirir mayor complejidad a medida que se se profundice en necesidades específicas generando nuevos patrones de lectura y decodificación a partir del mismo dispositivo" (del enunciado inicial que acordaron).

Se propusieron utilizar dos elementos complementarios. Una especie de senda peatonal con prioridad para ciegos que incluya una línea de circulación sobre la vereda con una codificación de color conforme a cierta información del entorno y una zapatilla con sensores de lectura, un procesador de datos que recibe la información del suelo, analiza los valores obtenidos y transforma a información vibro táctil según una base de datos codificado, y motores vibradores que emiten la información a la persona.

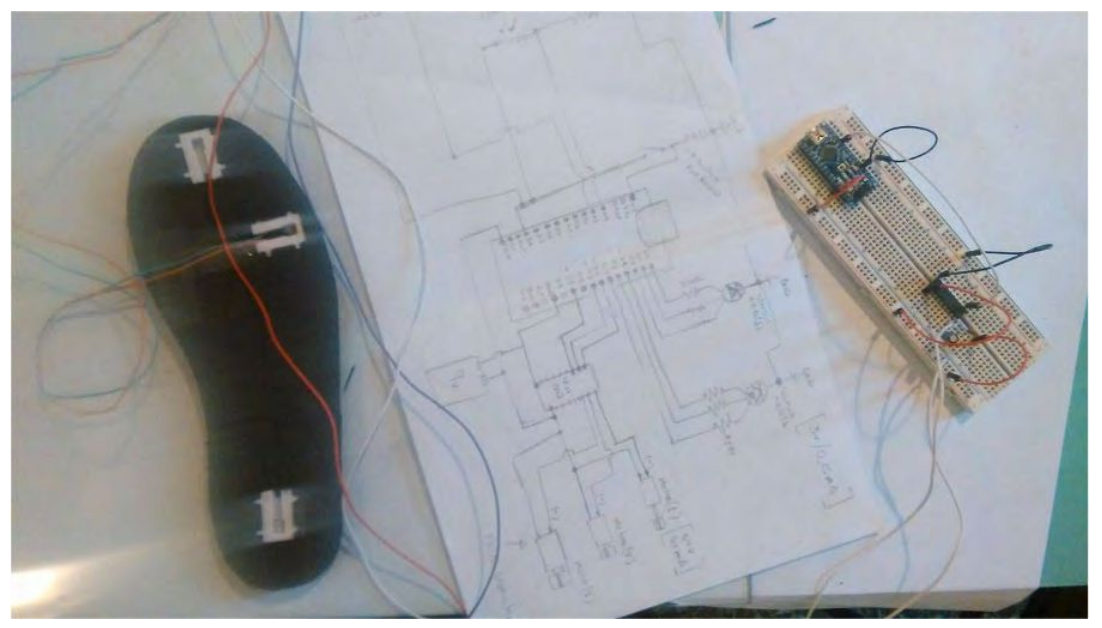

Fig. 4.22.: Proyecto zapatillas para ciegos. Boceto de ubicación de actuadores

El inicio del trabajo de exploración incluyó la experimentación con señales vibro-táctiles. Para determinar la cantidad y distribución de actuadores construyeron rápidamente unos bocetos con motores recuperados de celulares desguazados controlados por una placa Arduino Nano y un circuito para el control de motores que reutilizaron de un trabajo de otro curso de la Maestría. En este paso utilizaron sus conocimientos previos de electrónica para seleccionar motores con el mínimo consumo para facilitar la utilización de circuitos simples. Tuvieron una discusión en el grupo sobre el tipo de situaciones que el dispositivo debería utilizar para generar las señales. Finalmente acordaron el conjunto básico de las siguientes cinco: avanzar / retroceder, girar a derecha / izquierda, detenerse. Esta movida de enmarcado les generó la próxima de diseño: la distribución de los actuadores respondió directamente al tipo de señales que querían entregar y optaron por colocar los motores como muestra la Figura 4.22. Entonces, para la señal "Ir hacia adelante", la operación de la zapatilla implicaría encender motor "izquierdaFrente" y motor "derechaFrente", "doblar a la Izquierda", encender motor "izquierdaLateral".

Probaron con el boceto en sus propios pies numerosas ocasiones, ajustando vía PWM la intensidad de la señal. Como resultado obtuvieron los rangos de entrega necesarios para una señal reconocible. Para ello, armaron una zapatilla y la probaron todos los miembros del grupo 
varias veces. Luego probaron las variaciones para las frecuencias de encendido y apagado, obteniendo los mejores valores en el rango de 100-200ms.

Al mismo tiempo, una parte del grupo realizó bocetos y pruebas para los aspectos de sensado que habían ideado. Tomaron como elemento disparador de la idea los robots seguidores de líneas donde un sensor infrarrojo determina colores blancos y colores negros del suelo y posiciona el carro siguiendo uno de estos dos colores. Realizaron pruebas a partir de esta idea con sensores infrarrojos reflectivos (este trabajo es el que realizan como práctica en la materia Robótica que tuvieron inmediatamente antes que el taller que se reporta aquí). También trabajaron con sensores de color para tener un espectro más amplios de manejo de información y determinar para cada color una acción específica. Construyeron una versión propia de sensor de color integrando un Led RGB y una resistencia LDR. La construcción de este sensor ad hoc demandó mucho tiempo y los sacó del flujo de ideación, se concentraron sólo en la definición, construcción y ajuste del sensor. Tanto es así que incluso modificaron el contenedor inicial y diseñaron uno a medida que imprimieron en 3D (ver Figura 4.23). Cuando tuvieron optimizado su sensor, descubrieron que no habían definido dónde lo ubicarían y cómo harían la medición. Decidieron colocar dos sensores en cada zapatilla, uno en el frente y otro en la parte posterior de la zapatilla como se muestra en la imagen. Reproduzco aquí una cita de la entrevista con el grupo: "Una vez construido el sensor de color, notamos que era necesario realizar la lectura en el momento exacto en el que el pie estaba apoyado en el suelo, así como también poder saber cuando la persona está caminando o permanece quieta. Para poder tener esta información, incluimos a los sensores de un switch pull down en cada sensor. Cada vez que el pie está pisando el suelo el sensor hace la lectura. De esta manera podemos llegar a determinar según la cantidad de veces que el switch se enciende si la persona está caminando o permanece quieta, así como si está de pie o está sentada". Como puede verse involucraron una gran cantidad de conocimiento técnico en el desarrollo, descuidando por largos tramos del trabajo el proceso de ideación en pos de un refinamiento de la idea que inicialmente tuvieron, sin explorar otras posibilidades.

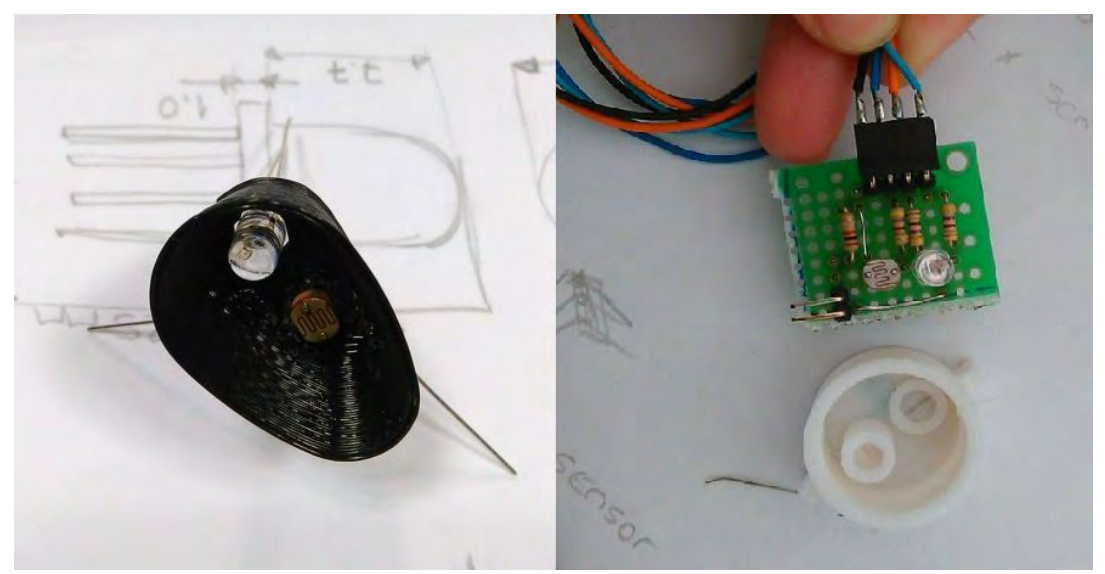

Fig. 4.23.: Proyecto zapatillas para ciegos. Sensor de color, primer boceto (izquierda) y refinamiento de prototipo con carcasa impresa en 3D y componentes soldados (derecha) 
Luego pasaron a experimentar la idea utilizando otros compañeros del taller como usuarios recorriendo un laberinto con una senda que pintaron en el piso del taller.

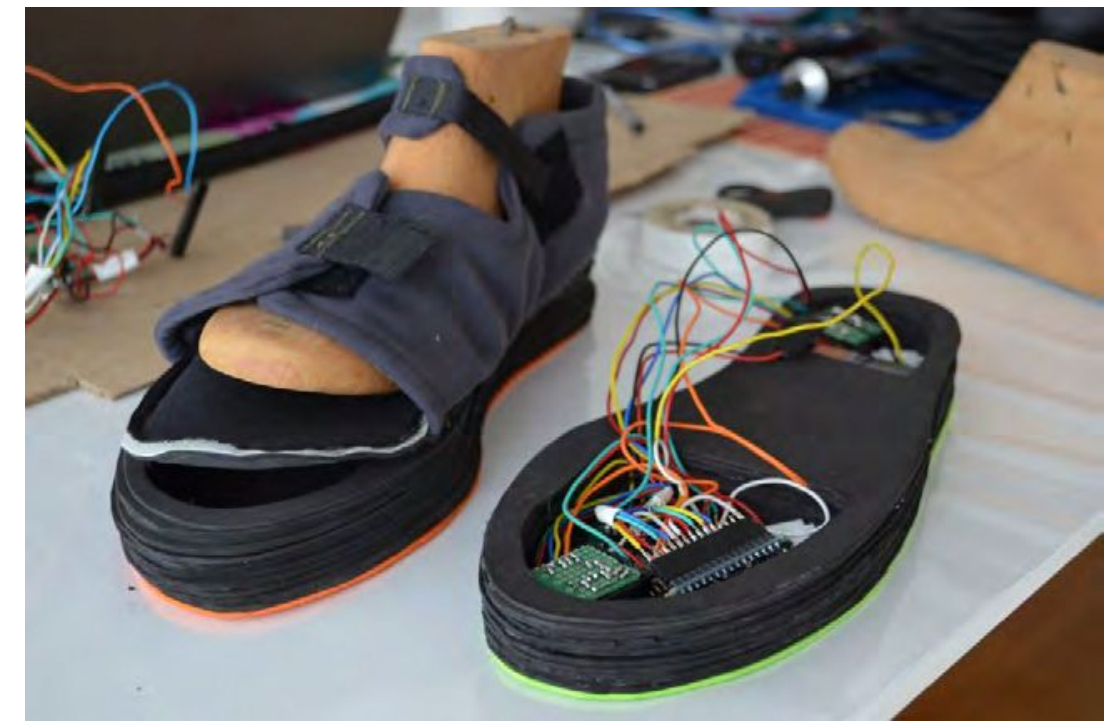

Fig. 4.24.: Proyecto zapatillas para ciegos. Boceto de zapatilla utilizado en la demo final

En las sesiones de trabajo con el grupo y las entrevistas posteriores reconocieron que el bocetado con el hardware les insumió demasiado tiempo y los distrajo del objetivo inicial de generar ideas de interacción: "Como resultado final logramos definir y construir la electrónica necesaria para las acciones que requerimos, con algunos desafíos más a resolver. Por cuestiones de espacio utilizamos solamente dos motores en cada pie y reducimos algunos componentes electrónicos. (Lo que nos llevó bastante tiempo de desarrollo poder ubicar todas las piezas dentro de la zapatilla). En cuanto al programa solamente alcanzamos a resolver un programa que detecte dos colores y responda a esos dos de diferente manera. De todas formas a partir de haber resuelto físicamente la zapatilla con la electrónica correspondiente, podemos a partir de eso experimentar diferentes cuestiones y probar otros códigos de Arduino de aquí en adelante" (cita de las des-grabaciones).

Letras en los dedos Este grupo se propuso generar una interfaz enactiva para ayudar a personas sordas o con disminución auditiva. Basados en la idea de sustitución sensorial y la consigna Oir con la piel, pensaron en un dispositivo que trasformara los estímulos auditivos en vibraciones táctiles para así poder sentirlas a través de los dedos de una mano. Discutieron un poco al comienzo sobre formas posibles de generar esa sustitución. La riqueza en las experiencias de los integrantes del grupo fue interesante en esa discusión: un músico, un artista electrónico, una artista visual y un programador lograron acordar el uso de una transformación de las palabras o frases cortas en vibraciones a ser percibidas en los dedos de una mano, con alguna forma de codificación.

La idea que finalmente primó en cuanto a la posbile estructura de la IE estuvo propuesta por el programador quien sostuvo insistentemente el uso de la API de Google Speech y 
alguna combinación entre un programa en Processing y un guante con los motores vibradores controlados por Arduino. Uno de los primeros bocetos en papel de esta idea se puede ver en la Figura 4.26 ). Las ideas iniciales del guante también las bocetaron en papel antes de pasar a una construcción de maquetas o hardware. En un momento del brainstorming inicial se dio una especie de escenificación de la posible interactividad a conseguir, con la artista plástica personificando al usuario que recibía en el guante las vibraciones y el programador dibujando en una pizarra las letras que se "decodificaban" de la voz hablada (Figura 4.25).

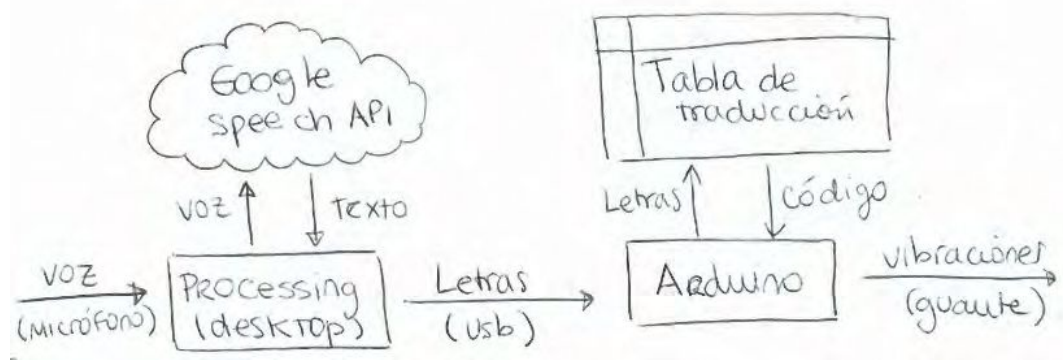

Fig. 4.25.: Letras en los dedos. Boceto en papel con los bloques de software y las conexiones requeridas

Después de otros bocetos en papel, cuando acordaron la estructura de lo que pensaban proponer pasaron a verificar la idea con un boceto en hardware, utilizando un guante de látex izquierdo, una placa Arduino Uno y un sólo motor vibrador de celular, con circuitos de cables y protoboard. Hicieron unos programas en Processing para capturar el audio, convertirlo a texto utilizando una clave pública de la API de Google Speech (que les permitía 50 traducciones diarias) y enviarlo por cable via USB a una placa Arduino Uno que controlaba la actuación de un par de motores ERM. (Figura 4.27).
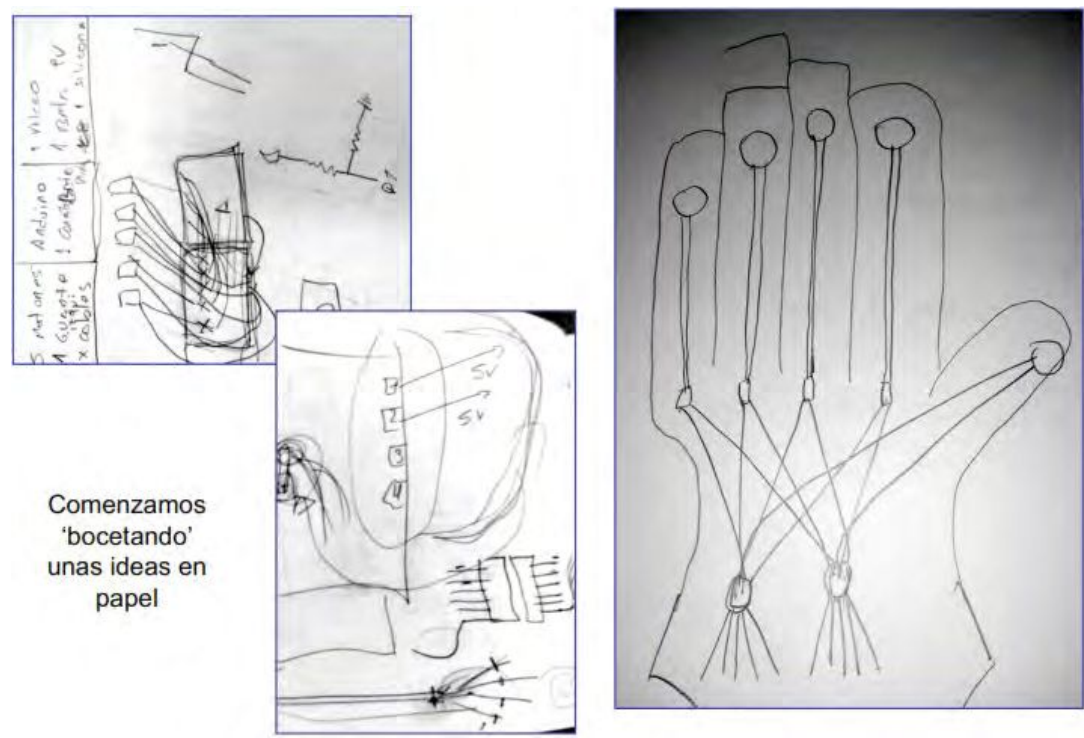

Fig. 4.26.: Letras en los dedos. Bocetos en papel con ideas del guante, componentes y cableado

Cuando estuvieron conformes con la interactividad conseguida en el primer boceto, decidieron experimentar con la libertad de una conexión inalámbrica. Para eso hicieron dos cambios 


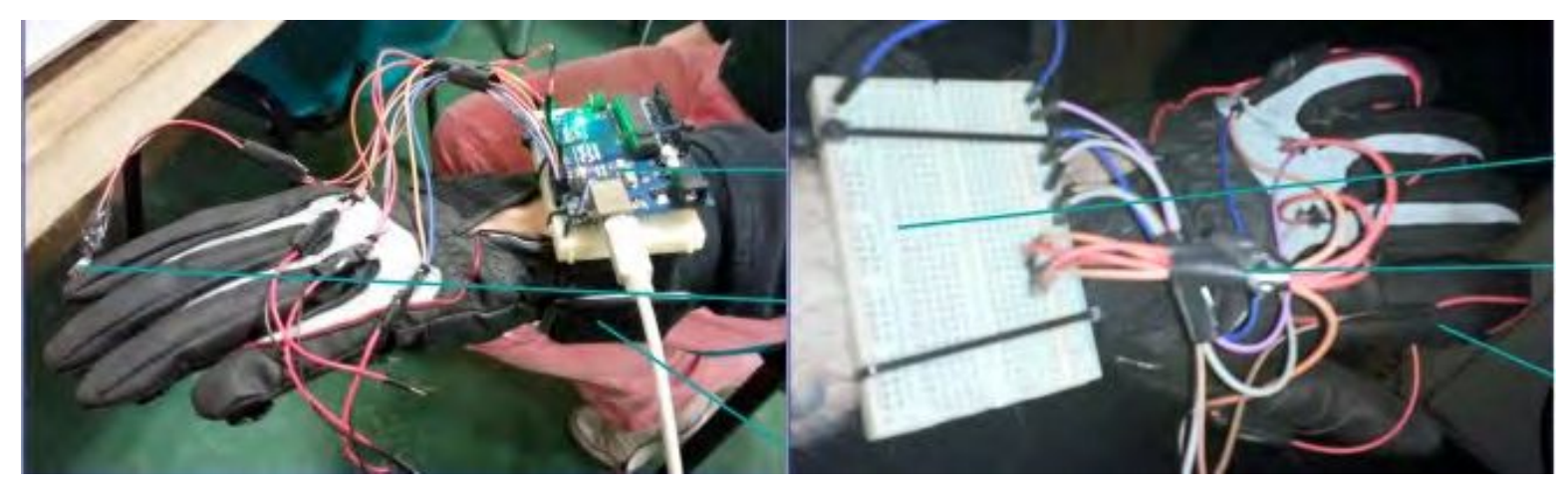

Fig. 4.27.: Letras en los dedos. Bocetos en hardware del guante. Nótese la aproximación rápidad de fijar una protoboard al guante con precintos y utilizar cableado con jumpers simples para las conexiones

importantes. Por un lado reemplazaron el Arduino Uno por una placa Nano ${ }^{16}$ y agregaron un módulo Bluetooth para comunicarlo con un smartphone basado en Android. Entonces el programador hizo una pequeña aplicación que utiliza la misma tabla de traducción con texto escrito como entrada. De manera inalámbrica, los código enviados por el smartphone son convertidos por Arduino en impulsos para controlar la vibración de los motores. El cambio del modo de input obedeció sólo a la búsqueda de poder hacer más pruebas y no estar restringidos por las 50 traducciones diarias de Google Speech. Sin embargo, dejaron claro que en este punto el texto sólo representaba una forma más asequible para bocetar el efecto que ellos buscaban de percibir una palabra codificada en feedback vibrotáctil en los dedos.

En la demo final uno de los miembros del grupo enviaba texto desde su smartphone y quien hacía de usuario (en el otro extremo del aula) intentaba descifrarlo a partir de las vibraciones percibidas. Luego de un entrenamiento muy breve, los usuarios pudieron elicitar algunas palabras simples, pero se complicaron con frases largas.

4.7k luz háptica Este grupo se propuso generar múltiples estímulos hápticos a partir del sensado de luz. Después de una discusión inicial entre todos encararon la idea de trabajar con módulos simples cada uno compuesto por un sensor de luz y un micromotor vibrador, que pudiera escalar en cantidades y ser ubicados en distintas partes del cuerpo. A partir de las clases previas sobre háptica quisieron explorar la asociación de captura de luz con las diferentes resoluciones de agudeza táctil y generar una especie de aumento sensorial.

Con una postura de tinkering ${ }^{17}$ desguazaron todos los celulares que pudieron para extraer los motores. El primer descubrimiento que hicieron de ese desguace fue que la mayoría de motores recuperados eran diferentes lo que puso en duda la idea modular del comienzo. Esa duda se incrementó cuando comenzaron a probarlos conectados con Arduino y experimentaron las diferencias en intensidad de vibración. Sin embargo, con una adecuación oportunista

\footnotetext{
${ }^{16}$ https://store.arduino.cc/usa/arduino-nano

${ }^{17}$ Decidí utilizar el término original en inglés a falta de una buena traducción en español del sentido con que el vocablo se utiliza en la literatura para referir a una mezcla de acciones y actitudes de exploración, bricolaje, combinación de elementos, etc.
} 


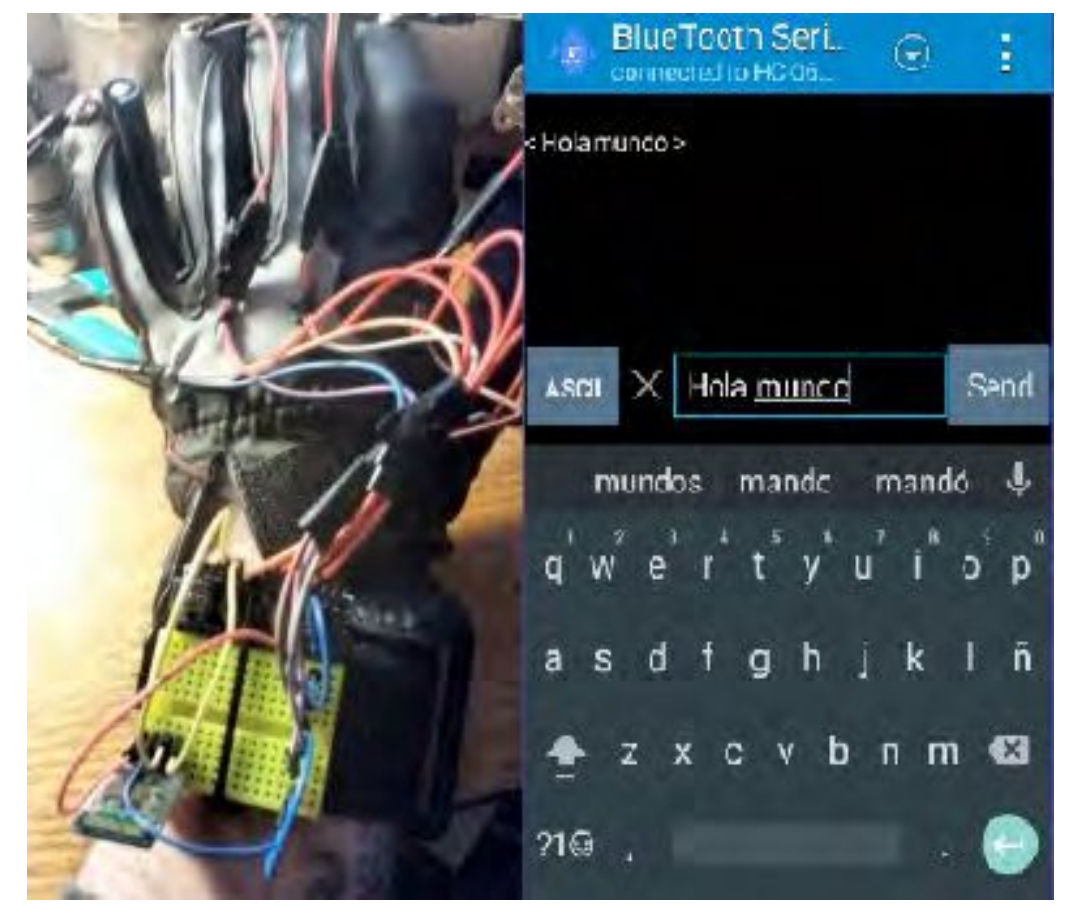

Fig. 4.28.: Letras en los dedos. Segundo boceto en hardware, incorporando el módulo Bluetooth y el Arduino Nano, con el boceto de aplicación Android para recibir el input mediante texto escrito

pasaron del filtrado de la interactividad al de la experiencia y asimilaron las diferencias de los motores a distintas "personalidades" (así las llamaron) en función de su intensidad de vibración. Sin embargo, una de las diseñadoras planteó que en caso de un avance hacia prototipos más funcionales todos los actuadores deberían ser del mismo modelo y otorgar personalidad mediante el software (en un claro giro representacional).

Armaron tantos módulos de sensor LDR más motor vibrador con el cableado de conexión correspondiente (sin otro circuito de administración de la potencia) y los conectaron con Arduino. Establecieron que el prototipo debía ser utilizado en un entorno de penumbras en donde la luz directa pueda ser captada por los sensores, "los cuales (sic) encenderán los motores correspondientes según el valor de luz captada" (de las des-grabaciones).

Elaboraron un boceto con 11 módulos sensor-actuador. Para el control utilizaron Arduino (disponían de las placas y ya habían experimentado con ellas en cursos anteriores). Como cada placa tiene 6 entradas analógicas y querían mantener los 11 módulos en funcionamiento se encontraron con la dificultad de vincular varias placas entre sí (quizá con I2C). Ninguno en el grupo tenía conocimientos para implementar alguna comunicación del tipo I2C o similar, por eso decidieron emplear un truco para el boceto: cargaron el programa que toma la información de sensores y los convierte en impulsos para los actuadores en una placa Arduino UNO y una placa Arduino Nano (ver Figura 4.29) y conectaron cada una de esas placas a una notebook diferente. A los efectos de probar el boceto, el recurso de estilo tinkerer resultó completamente eficiente. En las conversaciones durante la demo final, respecto de este punto comentaron que 


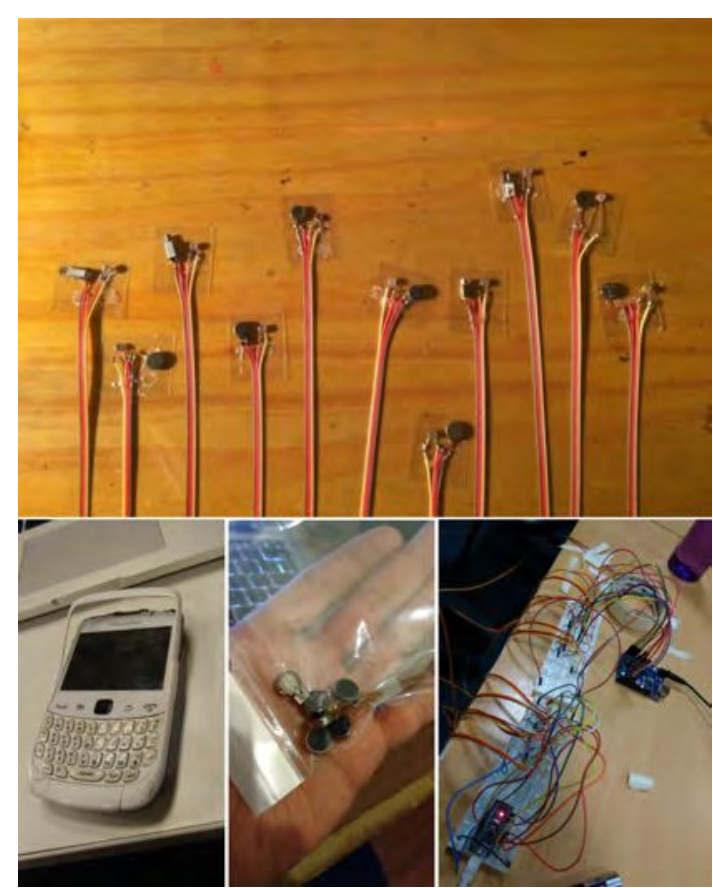

Fig. 4.29.: 4.7k Luz háptica. Bocetos en harware

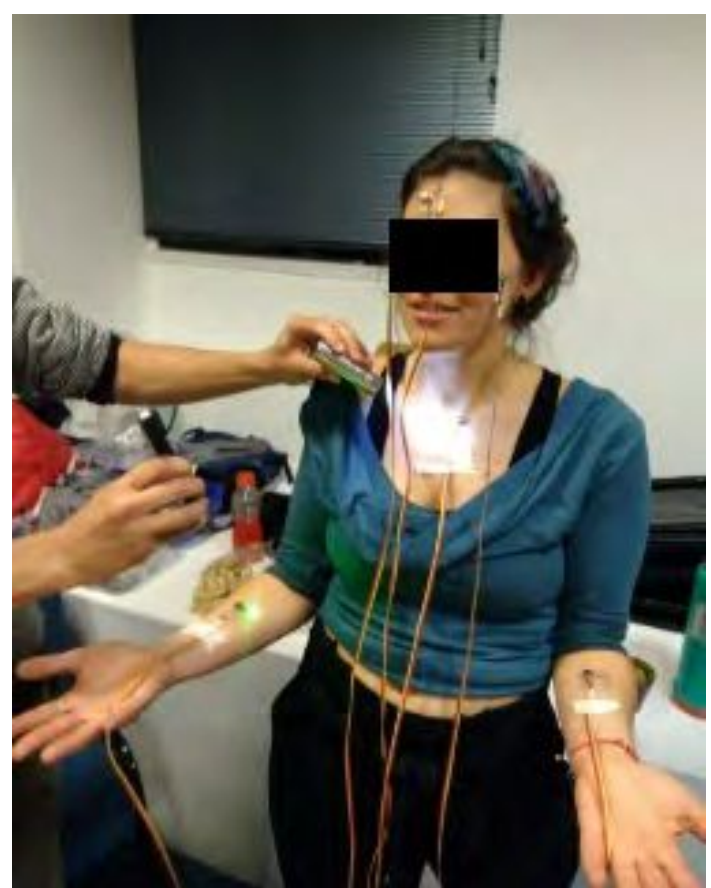

Fig. 4.30.: 4.7k Luz háptica. Prueba con usuario

para una evolución de la idea en prototipo funcional utilizarían "un sistema de multiplexado de pines o el uso de alguna shield que expanda las posibilidades del Arduino".

Empatheia vibratio De manera similar a lo ocurrido en el T-2 con el grupo que desarrolló Zona de tránsito, este grupo estuvo muy influido en sus ideas por un debate contemporáneo al Taller. En esos meses se produjo en el Congreso de la Nación el tratamiento de proyectos de ley para la legalización de la interrupción voluntaria de embarazo en Argentina. Entonces se platearon un dispositivo que pudiera participar en una "Interacción performante sobre campaña por el aborto" (de las des-grabaciones del primer encuentro). Tomaron inspiración de un texto sobre Tribus, grietas e identidad social presentado en el sitio web de divulgación científica El gato y la caja ${ }^{18}$ : "Una de las señales tribales que podemos encontrar en la calle hoy en Argentina, es el pañuelo verde que señala apoyo por la legalización de la interrupción voluntaria del embarazo. Para entender la forma en la que se relacionan tanto las personas que forman parte de la tribu que proyecta esa señal (en verde) como las que se encuentran en la tribu que se opone a la legalización (en rojo) e identifica esta señal como de una tribu opositora, se mapearon las interacciones de Twitter que incluyen las palabras 'pañuelo verde'. Se ve la alta endogamia en ambas estructuras de comunicación, así como los escasos mensajes puente entre ambas tribus." (se reproduce la visualización en la Figura 4.31).

Este grupo fue quizá el que más se orientó a corporizar la generación de significados en el usuario. Con la premisa de promover la necesidad de abrirse a otras posturas y dialogar ("salir de la tribu" lo llamaron) pensaron en un sistema que rescatara twits de cada una de las tribus

\footnotetext{
${ }^{18}$ https://elgatoylacaja.com.ar/pensar_con_otros/capitulo-7/
} 


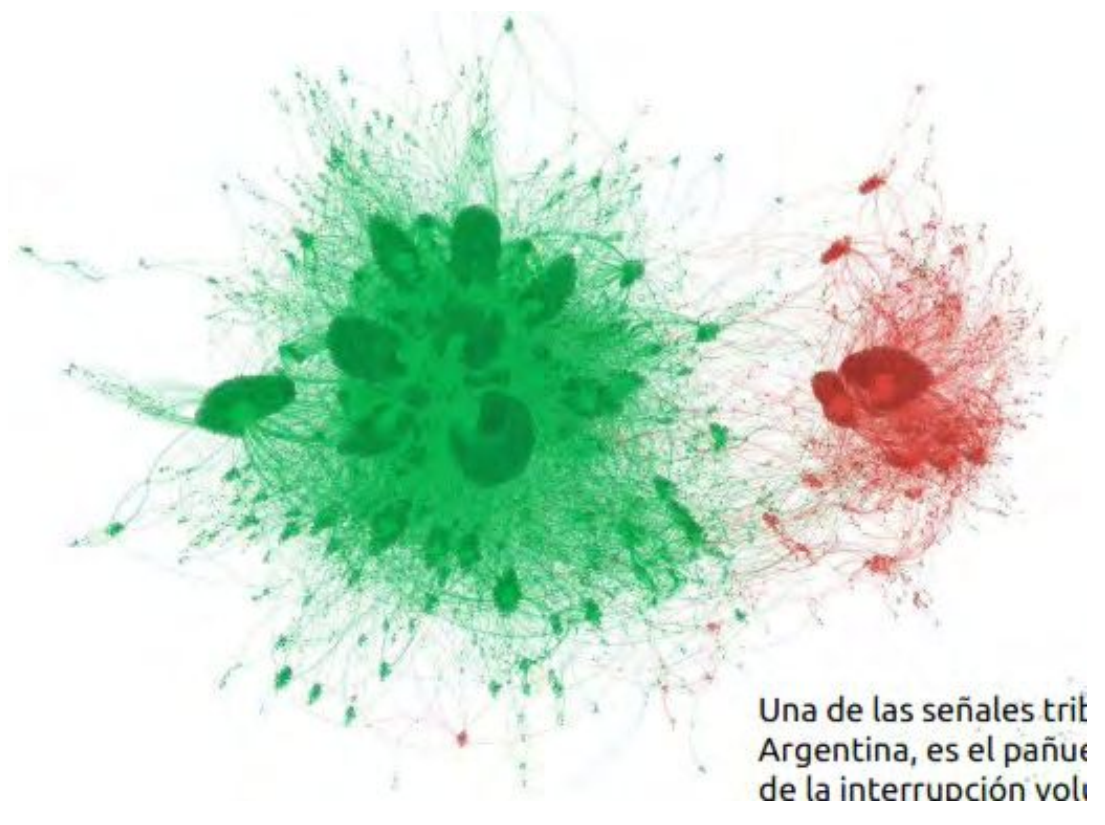

Fig. 4.31.: Empatheia vibratio. Visualización que inspiró al grupo sobre los twits de las tribus a favor (verde) y en contra (rojo) de la legalización del aborto. Tomado de https://elgatoylacaja.com.ar/pensar_con_otros/capitulo-7

en pugna y generara en el usuario estímulos provenientes de la tribu diferente a la suya. Bocetaron un sistema basado en una pequeña aplicación de Processing para extraer y procesar twits con los hashtags de la campaña referida (\#AbortoLegalYa o \#SalvemosLasDosVidas) y un dispositivo corporal con estímulo vibrotáctil. Después de discutir cómo presentar los mensajes, decidieron dividir la pantalla en dos mitades coloreadas según las identidades tribales (verde y celeste). El usuario tiene que elegir a qué tribu pertenece eligiendo con el mouse una de esas mitades.

El dispositivo vestible consistió en una vincha y un cinturón pectoral. En ambos casos tienen incorporados en su cara interna pequeños motores vibradores (obtenidos por desguace como otros grupos, en este caso de controladores de juegos, ver Figura 4.32). Estos motores están controlados por una placa Arduino. Utilizando una librería de Processing que permite acceder a la API de Twitter codificaron en la aplicación la posibilidad de detectar un nuevo twit asociado a cada hashtag. Entonces, como querían que los usuarios corporizaran el estímulo a abrirse a posturas de otra tribu, decidieron cruzar los impulsos a trasmitir. Vincularon la aplicación Processing con Arduino vía biblioteca Wire y puerto USB.

Cuando se plantearon cómo corporizar el estímulo de alguna forma, con el uso de metáforas, volvieron a una visión cuasi representacional. Establecieron que la persona con una posición de "tribu celeste" debería pensar mejor el tema y entonces enviaron señales a la vincha para "movilizar pensamientos". En cambio, quien estuviera a favor de la legalización (tribu verde) debería abrirse a dialogar y entonces recibiría un estímulo en el cinturón pectoral para “movilizar el corazón”. La Figura 4.33 muestra los bocetos con hardware de esos dispositivos vestibles. 


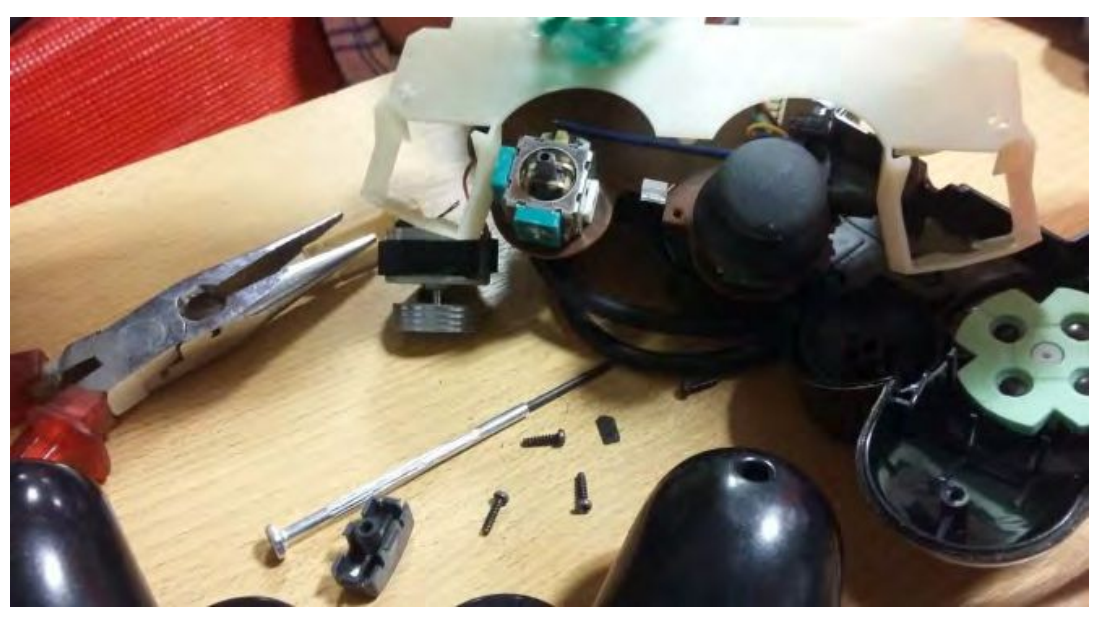

Fig. 4.32.: Empatheia. El proceso incluyó diversas actividades de tinkering y desguace, en este caso de un controlador de juegos para extraer los motores vibradores

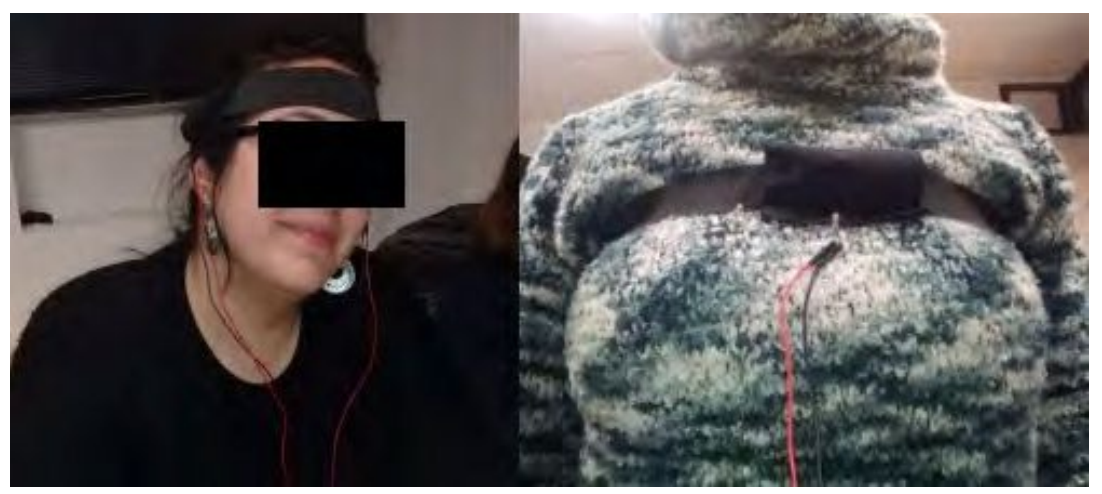

Fig. 4.33.: Empatheia. Bocetado de componentes vestibles. Izquierda: vincha para "movilizar pensamientos"; derecha: cinturón pectoral para "abrir el corazón al diálogo"

Caricias remotas Estímulos hápticos a distancia. Este grupo se enfocó en una forma de exploración sensorial "para acariciar de una manera diferente y de tener la posibilidad de "completar" el vacío que puede generarse por la distancia" (de las des-grabaciones). Se inspiraron en el Análisis transaccional de Eric Berne[22] que considera caricia como "cualquier acto que implique el reconocimiento de la presencia de otro, cualquier estímulo social dirigido de un ser vivo a otro y que reconoce la existencia de este" (de las notas del grupo).

Decidieron crear un dispositivo que fuese capaz de transmitir la sensación de una caricia entre dos personas a distancia. La idea que acordaron fue que un "acariciador" se realizaría a sí mismo una caricia, por ejemplo en la mejilla, y el "acariciado" recibiría un estímulo similar en el mismo lugar de su cuerpo y lo bocetaron en papel para confirmar el acuerdo (ver bocetos en Figura 4.34 .

Exploraron diferentes posibilidades en una especie de brainstorming frente a la pizarra. Finalmente crearon un mecanismo en el cual una persona acciona un sensor capacitivo cuya señal activa un mini motor vibratorio colocado en otra persona, generando una vibración suave que sugiere una caricia. De esta manera se estimulan los sensores hápticos con los que contamos 


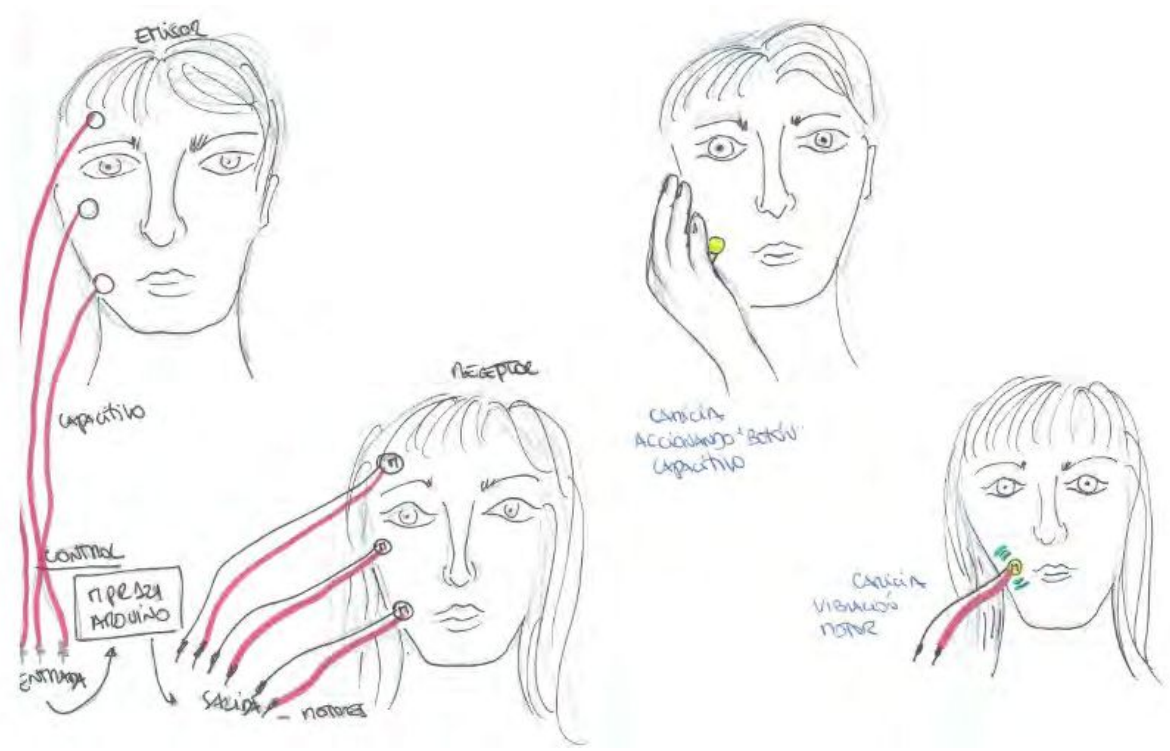

Fig. 4.34.: Caricias remotas. Bocetado de ideas para el dispositivo de actuación y sensado

por naturaleza en la piel. Tanto sensores naturales como artificiales intentan recomponer la sensación de tacto.

También este grupo utilizó en el armado de bocetos una combinación de tinkering y recuperación de componentes, en particular motores vibradores de celulares desguazados. Con bocetos del tipo experiencia de uso, simulando el entorno remoto mediante cableados de los sensores como de los actuadores validaron sus ideas antes de pasar a la construcción de modelos que efectivamente comunicaran por red (ver Figura 4.35 .

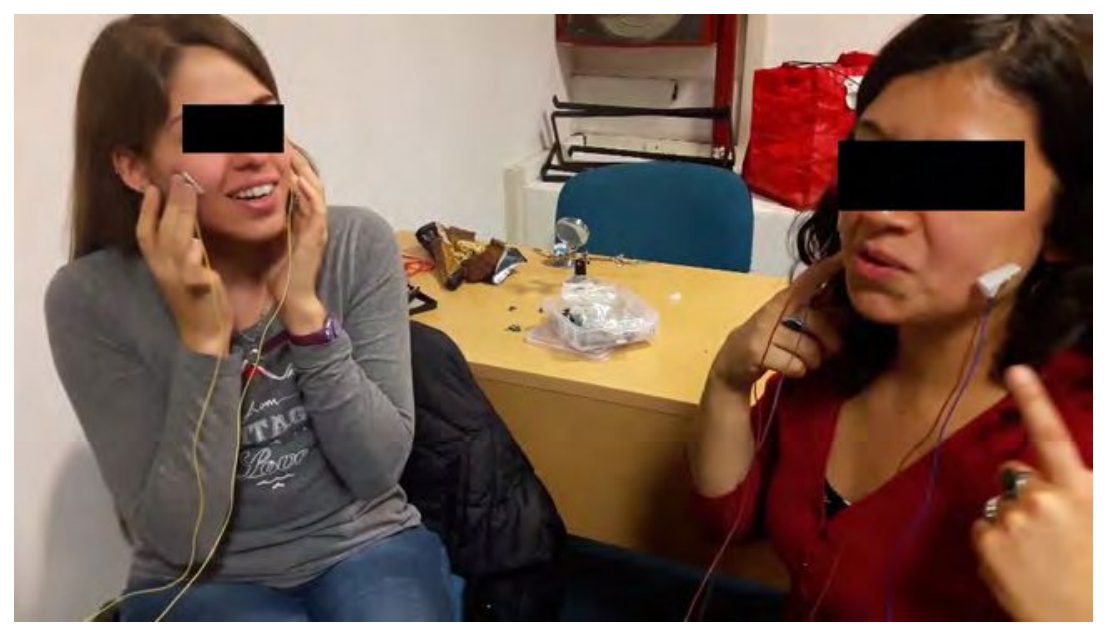

Fig. 4.35.: Caricias remotas. Prueba de experiencia

\subsection{Lecciones aprendidas}

El estudio observacional permitió encontrar información valiosa para comenzar a responder las preguntas que planteadas en el Capítulo 1: ¿Cómo podemos diseñar sistemas interactivos que 
den soporte a la Cognición Corporizada Enactiva? (ver página 8). Efectivamente, el análisis de todo el material provisto por los talleres arrojó luz tanto sobre la forma en que los diseñadores utilizaron las ideas de cognición corporizada y acoplamiento sensorio motor para fundamentar sus procesos de diseño como sobre los requerimientos a satisfacer por las herramientas que se propongan brindarles un soporte adecuado a esos procesos.

El análisis que se presenta a continuación trata de priorizar lo observado sobre la opinión del observador, lo que los profesionales hicieron en su proceso de ideación y bocetado, aunque lo observado pueda diferir de lo que explicaron en las entrevistas posteriores. Es decir, se intenta capturar qué es lo que se observa que hacen realmente los diseñadores, sus gestos, conversaciones, movimientos, en lugar de lo que "dicen" que están haciendo. Respuestas post hoc siempre se interpretan en el contexto de la interacción observada in situ.

\subsubsection{Sobre la cognición corporizada en la ideación}

Respecto de la pregunta 2.1. ¿De qué manera la teoría de Cognición Corporizada y Enactiva provee información al proceso de diseño de la relación entre los procesos digitales y las formas físicas de los sistemas interactivos? encontramos que en oportunidades los diseñadores mantienen sesgos hacia un enfoque representacional y luego vuelven al cuerpo, poniéndolo en el centro de la idea. Por otra parte en todos los procesos encontramos una especie de uso de huellas que permiten jalonar el camino creativo y volver rápidamente a la situación que envolvía a uno de esos mojones (lo que otorga una especie de trazabilidad al proceso).

El sesgo hacia la idea de una memoria externa y la vuelta al cuerpo En varios grupos hubo momentos del proceso de diseño que reflejaron un patrón en el que los bocetos parecían moverse hacia dispositivos de almacenamiento de información, con su función de registrar, almacenar y presentar los resultados. Por ejemplo en el caso del guante (Letras en los dedos), idearon la IE con una visión representativa que convertía las letras en impulsos vibrotáctiles, una forma de almacenamiento de las letras en otro formato. Esta dirección conduce a un problema a la hora de incluir la interfaz en la práctica: ¿Por qué digitalizar las letras? ¿Para qué?, una visión realmente corporizada implicaría la exploración de un nuevo idioma táctil como hace Novich[180]. El propio grupo detectó esta inconsistencia, pero resolvieron que necesitaban esa visión "representacional" sólo a los efectos de generar rápido un boceto. Lograron reconectar la acción corporal al reencuadrar las respuestas vibratorias como andamios ambientales, más vinculados con la existencia de una comunicación que con su contenido específico.

Otra evidencia de que el sesgo de representar está presente puede interpretarse en el abordaje divide y conquistarás del grupo Color por calor, ya que entienderon que podían separar inputs de outputs, trabajarlos por separado y simplemente luego establecer un circuito que los vinculara. El aspecto experiencial de esta idea no estuvo presente casi en ningún momento de su proceso. 
En los otros grupos los diseñadores aprendieron a través de las movidas de reencuadre en la ideación a no representar el cuerpo sino permitir que se represente a si mismo.

Aplausos en el cuerpo no tiene una representación prefijada del aplauso hacia una zona del cuerpo. El aplauso literalmente será experimentado en el propio cuerpo del receptor, sin importar su posición o relación espacial con quien emite el aplauso. Algo similar ocurre con Zapatillas, que resuelve la indicación de orientación sólo con la ubicación de los actuadores (similar a soluciones reportadas en la literatura para guiar el desplazamiento a pie, por ejemplo [167], y diferente de ideas habitualmente implementada por makers, por ejemplo Vision Shoe ${ }^{19}$, donde el aspecto representacional es evidente).

Otro contrapunto interesante en este aspecto es el contraste entre Zona de tránsito, que representan los latidos de corazón como aceleración predefinida del estímulo vibratorio versus Tocar el alma que "exhibe" directamente a través del tacto el latido detectado por el sensor.

En los diferentes grupos hay una recorrida permanente de un camino que va desde la posición representacional (casi cognitivista) al enfoque más radical del acoplamiento sensorio motor (con avances y retornos). Cualquier caracterización del proceso de ideación de interacciones enactivas debería considerar este recorrido como un camino normal y proveerle andamios para recorrer la vía hacia el acoplamiento sensorio motor sin forzar ni obligar un proceso que saque al diseñador de su propia racionalidad, tal como plantearon Stolterman[221] y Rogers[201].

Dejar huellas La estigmergia es el mecanismo de coordinación entre agentes a través del medio ambiente y las huellas dejadas en él. Cada acción genera una huella que estimula el desempeño de una acción siguiente (por el mismo agente o uno diferente). De esa manera, las acciones subsiguientes tienden a reforzarse y construirse unas sobre otras, lo que lleva a la aparición espontánea de una actividad coherente y aparentemente sistemática[150]. En el caso de las actividades humanas, esas huellas son residuos físicos concretos de la actividad. Una vez que se dejan como elementos en el espacio físico son cosas con las que uno puede tropezar, que pueden atraer la atención visual, invitar a acercarse, se pueden pasar por alto, etc. Son cosas que se pueden ocultar de otras personas (como las notas personales) o ser exhibidas (como las fotografías). Se pueden recopilar, organizar, mover, etc. como cualquier otro objeto físico. Todo esto influye de inmediato en los acoplamientos sensorio-motores de los que forman parte esos artefactos, de la misma manera que el rastro de hormigas tiene un impacto en el acoplamiento de una hormiga en particular a su entorno.

Entonces, tomando prestados estos conceptos, podemos decir que los artefactos persistentes producidos durante la ideación (bocetos, audios, maquetas, anotaciones, etc) pueden considerarse como huellas que ayudan a construir el camino hacia la producción de una idea. Podemos enfocarnos en el aspecto sensorio-motor de esos artefactos en lugar de su función representativa (externalizar una idea) o social (pensar con otros). Si surgiera algo de carácter representativo siempre sería un aspecto inherente de las interacciones corporizadas de las personas en el

\footnotetext{
${ }^{19}$ https://www.instructables.com/id/Vision-Shoe-Shoe-for-the-Blind/
} 
espacio físico, al igual que el rastro en el bosque es el primer resultado de la acción, y solo más tarde ayuda a guiarlo[233]. Sin embargo, en línea con lo propuesto por van Dijk[52], en el caso de la ideación de interacciones no se trata de simples huellas, sino de huellas creativas, ya que son expresiones intencionadas, actos que involucran objetos a través de los cuales una persona se expresa a si misma en un mundo social. La idea general no es nueva, en relación con el diseño es importante porque la gente a través de crear y luego utilizar las huellas creativas se pone a sí misma en relación con otras en una serie de actos expresivos. Desde el punto de vista de la Computación y Representación Distribuida esas huellas generadas son antes que nada representaciones externas o andamios para realizar computaciones en el entorno (por ejemplo en la actividad de relacionar y agrupar atributos). En las teorías de la Práctica Social Situada los artefactos que los diseñadores producen también se llaman representaciones externas, pero lo que se enfatiza es que son importantes como vehículos públicos por los cuales la gente muestra entre sí lo que están haciendo y pensando de forma que sus actividades se puedan coordinar socialmente en la acción [223]. Sin embargo, en el enfoque de acoplamiento sensorio motor lo que literalmente se deja como huella (es decir, el texto que se escribe o la imagen que se bosqueja) no representa en sí mismo completamente lo que la persona está exteriorizando al realizar ese acto de expresión: el significado de esa expresión solo se puede encontrar en el acto en sí[84], y el artefacto es un elemento de andamiaje en la realización del acto [47]. El boceto es para el diseñador un soporte necesario para enactuar esa expresión. En otras palabras, la conexión entre el acoplamiento sensorio motor y los andamios expresivos se realiza justo donde está la acción, como propone Dourish[56].

Durante la ideación los diseñadores gradualmente comienzan a construir un espacio compartido de huellas que perduran en los bocetos, las anotaciones en papel o pizarra, las configuraciones del espacio de trabajo, etc, con el objetivo de construir la idea de interacción que se expresa en la configuración final de los artefactos y los compromisos de cada participante. Ese camino de migas de pan no es lineal, como en cualquier exploración tiene curvas y contracurvas, pero puede ser recorrido en el sentido opuesto para abrir nuevas bifurcaciones. Hemos observado este proceder, por ejemplo en el caso del grupo de las Zapatillas para ciegos, que comenzaron con la idea de múltiples actuadores en el pie, bocetaron y probaron sus ideas, yendo y viniendo entre diferentes configuraciones, pero finalmente decidieron abrir un nuevo camino con menos actuadores y el agregado del sensor de colores. O el caso de Zona de tránsito que comenzaron con un camino "hacia una frontera como un "límite frontal" y fueron dejando pequeños hitos que jalonaron un recorrido hacia una zona de encierro. Cuando observaron en retrospectiva el camino reconocieron la necesidad de incorporar otras dimensiones a la interacción.

Todos los grupos hicieron este ida y vuelta en el camino de ideación. Avanzaron con una propuesta, la bocetaron y probaron. Sólo al repasar el rationale que los había llevado a esa idea (para lo cual fueron imprescindibles todas las huellas dejadas, tales como bocetos, anotaciones, videos, etc, que les permitieran re-visitar y re-vivir el momento previo de creación) se sintieron en la seguridad que la nueva idea que proponían realmente les abría un nuevo sendero de exploración. 


\subsubsection{Sobre las herramientas para la ideación enactiva}

Para poder soportar este proceso de ideación nos habíamos preguntado 2.2. ¿Qué características debe poseer el bocetado para facilitar la generación y evaluación de ideas de interacciones enactivas?. El análisis del material de los talleres nos ha permitido observar fundamentalmente cuatro aspectos relacionados directamente con las herramientas utilizadas por los diseñadores: la elección de la interactividad como dimensión del filtrado en cada uno de los bocetos (tanto dibujos y esquemas gráficos como elementos tridimensionales físicos e interactivos); la presentación de los atributos de interacción en todos los tipos de modelos y actuaciones empleadas; el uso de bocetos como interacciones "actuadas" muchas veces conducidas por gestos; el abordaje del estilo tinkering con la necesidad de mantener la creación de los bocetos alineada con el flujo cognitivo de los diseñadores.

La interactividad como la dimensión preferida del filtrado de los bocetos Todos los diseñadores trabajaron directamente sobre la forma de la interacción en la acción (la interactividad, en términos de Janlert y Stolterman[120]). Dejaron para las etapas finales las pruebas sobre otras dimensiones de filtrado, como la apariencia, la funcionalidad o estructura espacial[152]. Mantener el foco sobre la interacción en sí misma involucra una postura de exploración y descubrimiento que favorece la emergencia de la forma del producto como una corporización de la interactividad buscada, tal como postula el abordaje enactivo. Esta emergencia impulsa además la toma oportunista de decisiones. Es frecuente que la toma de decisiones de diseño se basen en descubrimientos inesperados o aspectos descubiertos de un boceto, tal como reveló Hartmann[93]. Por ejemplo, el grupo que realizó "Abuelino" comenzó trabajando con sensores infrarrojos de distancia, pero prefirió utilizar los de ultrasonido cuando descubrieron que podían convertirse en los ojos del títere por su aspecto visual sin perder su aporte funcional.

Colocar el foco en la interacción en sí misma implica además una postura de creación en la acción, porque es la propia interactividad la que genera el significado y ayuda a consolidar la idea de la interfaz. De alguna forma el producto surge como una encarnación o corporización de la interactividad que se busca, en un ida y vuelta constante de definiciones sobre la extensión de campos de acción y operación (en términos de Janlert y Stolterman[120]). Los diseñadores se abocaron a crear y evolucionar sus ideas con bocetos interactivos construidos rápidamente. Estos bocetos les permitieron testear sus ideas sobre la experiencia de usuario buscada con un adecuado balance entre velocidad en la prueba y calidad del resultado. En todos los casos realizaron exploración tridimensional desde el mismo comienzo del proceso.

La expresión de los atributos de interacción en cada tipo de boceto Los diseñadores registraron los atributos deseados de interacción en cada modelo que construyeron utilizando recursos diferentes en cada caso. Sobre los bocetos 2D o los storyboards lo hicieron con anotaciones textuales o un lenguaje de símbolos sólo comprendido por sus autores. Pero también en las maquetas o bocetos en hardware trataron de registrar cómo lograr la interactividad que imaginaron (post-Its en maquetas, comentarios en el código del software). 
En el contexto de acción del aquí y el ahora, los diseñadores hablaban, hacían gestos y modificaban representaciones gráficas o 3D. Los modelos crean un contexto objetivo en el que los diseñadores pueden realizar los movimientos de diseño[8]. Lo hacen modificando continuamente esas representaciones y realizando gestos y enacciones para comunicarse y explorar la dinámica de la interacción. Este proceso los ayuda a imaginarse a sí mismos como parte de los procesos de interacción entre personas y artefactos. Lo observado en estos talleres respalda el trabajo de Robertson[197] que describe cómo los diseñadores utilizan las enacciones para crear y participar en una representación del proceso o actividad basada en el tiempo en la que otros pueden participar (ver también el trabajo de van Dijk[52]).

Los bocetos de diferentes naturaleza (papel, hardware, experiencia) se pueden considerar como estados en un particular diagrama de estado; lo que falta en el diagrama son las transiciones. Para representar las transiciones entre estados, los diseñadores hacen uso de gestos y enacciones. De manera similar, cuando dramatizaron las expresiones y acciones de los usuarios, representaban transiciones dentro de y entre funciones, creando y experimentando estructura e interacción. Por ejemplo, la Figura 4.13 es la versión enactuada de la Figura 4.12, mediante el gesto completaron los estados necesarios para comprender la idea. Esto puede verse como una forma de creación de prototipos de experiencia[31]. El drama se convierte en un proceso de razonamiento colaborativo, firmemente anclado en una situación de uso imaginario. Una vez más, esto refleja la investigación de Tang[229], Robertson[197], Tuikka[235], van Dijk[52], entre otros. Los diseñadores de interacción corporizada deben aprender a reconocer e incluso articular estas enacciones como formas importantes de expresarse a medida que desarrollan diseños.

Estas enacciones fueron complementadas con idas y vueltas entre diferentes tipos de bocetos. En cada uno de ellos los atributos de interacción tuvieron una manifestación diferentes pero explícita. Las anotaciones en cada boceto, los videos-audios, etc. re-visitados luego de las pruebas funcionan también como trazas o huellas que suturan el proceso de creación. Al ser revisitadas recuerdan no sólo su contenido sino también el contexto en el que se generaron, por qué se tomaron esas decisiones, cómo era el flujo esperado, etc. tal como se mencioné más arriba.

Los bocetos como ideas de interacción enactuadas Todos los grupos mostraron que para los diseñadores el desafío de la concepción y creación de nuevas interfaces físicas con las que se pueda interactuar mediante gestos, movimientos corporales, manipulaciones, etc. demanda la generación de una gran cantidad de externalizaciones y representaciones para complementar la generación de ideas que puede ser soportada por el papel con la acción sobre el mundo real, usando el cuerpo (propio o actuando en grupo) y modelos físicos tridimensionales ("diseñar haciendo"[15]). El diseño de interacciones que busquen la sustitución o aumento sensorial adquiere una complejidad que no es posible imaginar sólo con el apoyo de representaciones visuales estáticas del tipo bocetos a mano alzada. Es evidente que los diseñadores necesitan valerse de herramientas que les permitan explorar y confrontar la interacción que buscan, casi 
como una puesta en escena que implica herramientas de diseño de gestos, performances casi coreográficas y bocetado interactivo (con o sin hardware electrónico).

Los diseñadores necesitan expresar la dinámica de la interacción. Para ello crean los aspectos dinámicos dentro de un estrecho acoplamiento de conversaciones, representaciones gráficas y representaciones gestuales. Los bocetos son importantes como herramientas para el pensamiento, pero son las representaciones y dramatizaciones las que hacen que los bocetos se comporten. Jugar el rol de un usuario y explorar la tecnología potencial con la intención de usarla, ayuda a los diseñadores a explorar el diseño y sus ideas de diseño, y también a generar nuevas ideas. Los creadores de Aplausos corporales y de Caricias remotas dramatizaron todo el tiempo la situación de uso que imaginaban (ver Figura 4.14).

Las enacciones ayudan a los diseñadores a enfocarse y moverse de manera imaginativa en el contexto objetivo donde se podría usar su solución de diseño. Como tales, los gestos sirven como un medio poderoso para evaluar colaborativamente el uso de su diseño y comprometerse con esa situación[235]. Pero los gestos no solo ayudan a los diseñadores a asumir el rol del usuario. También les ayudan a tomar el papel del artefacto en uso. Durante las observaciones, vimos por ejemplo en el grupo Empatheia que constantemente imaginaban y establecían lo que la IE debería estar haciendo, cómo debería comportarse para conseguir la apertura del usuario a otras posturas.

En el registro de los trabajos del grupo Sphaira los participantes realizan sus representaciones utilizando gestos que imitan las acciones de los usuarios en un recorrido de interacción, una especie de representación conducida por gestos. En el trabajo del grupo Caricias remotas asumieron el rol de dos usuarios y se imaginaron a sí mismos en diferentes situaciones de uso de la idea (al menos escenificaron tres casos: un pareja separada por un viaje temporal, familiares que viven lejos y amigos que se mudaban). Este juego de roles improvisado es una representación basada en escenarios, y se utiliza como una exploración de pensamiento en voz alta de un diseñador. Volviendo a las dimensiones de filtrado en la anatomía de los bocetos[152] vemos que los recorridos de interacción conducidos por gestos comenzaron desde la dimensión de interactividad y llevaron a los diseñadores a ver que había consecuencias principalmente para las dimensiones de forma y funcionalidad. Las enacciones en forma de juego de roles improvisado comienzan en la dimensión de la funcionalidd o concepto de diseño (en términos de necesidad y propósito) y propagan consecuencias principalmente para las funciones, la forma y la estructura.

El uso de recorridos de interacción conducidos por gestos y enacciones también facilita ver que hay consecuencias en las otras dimensiones del boceto, fuera de la interactividad. Un ejemplo de esto es cuando el grupo Sphaira durante las dramatizaciones grupales en los que bocetaban la experiencia de arrojar la esfera y para diseñar las reglas del juego descubrieron la importancia y necesidad de agregar más dimensiones al feedback háptico. 
Abordaje con un estilo tinkering fluido Todos los grupos emplearon un estilo de tinkering (una especie de "hágalo usted mismo" basado en la exploración de material existente) para construir modelos físicos e interactivos, con cualquier elemento a la mano o con sencillos circuitos sobre placas de prototipado, antes de intentar un modelo más refinado o con mayor fidelidad.

El ajuste de los atributos de interactividad fue realizado con procesos iterativos de re-codificación, compilado y subida del programa a Arduino, lo que claramente interrumpía el flujo cognitivo de los diseñadores. La posibilidad de cambiar el código de los programas que controlaban la captura de información mediante sensores y la respuesta de los actuadores facilitó que la interactividad estuviera en el centro del proceso de diseño. Sin embargo, tanto la carencia de alguna herramienta específicamente dirigida a soportar este ciclo como la falta de alguna forma compartida de definir la interactividad que se buscaba obligaron a numerosos ciclos de ajuste de esos programas. Este aspecto fue el más destacado por los diseñadores: la necesidad de disponer de herramientas que agilizaran esta dinámica de cambio y les facilitaran mantener el flujo de pensamiento sobre las ideas de la interacción buscada, en el sentido de flujo propuesto por Csikszentmihalyi[44].

Booth y sus colegas realizaron una serie de experimentos para determinar los principales problemas que usuarios finales encuentran durante las tareas de computación física. Sus conclusiones son de relevancia en este punto, en particular la comprobación de que la mayoría de los problemas ocurrieron durante la programación y casi todos los fracasos en terminar una tarea obedecieron a problemas de circuitos. Los participantes no pudieron darse cuenta que había una falla o error en el circuito y a menudo trataron de manera errónea de corregir el problema percibido con cambios en el código. El $80 \%$ de los fallos de circuitos se debieron a errores de cableado y falta de inclusión de algunos componentes electrónicos, pero los participantes tuvieron serias dificultades para localizar estos fallos[26]. De acuerdo con las estrategias de tinkering, refuncionalización de partes desguazadas, elaboración de circuitos ad hoc, etc. observadas en los talleres y las evidencias de Booth, es factible sugerir que los diseñadores se benefician con la disminución del umbral para la construcción con componentes electrónicos (por ejemplo, soporte para construir circuitos de manera correcta, herramientas de diagnóstico de error y correcciones apropiadas).

El balance entre calidad y cantidad de modelos o bocetos es particularmente difícil de manejar cuando el tiempo y las herramientas son limitadas. También cuando las condiciones de contexto obligan a una re-configuración del espacio de trabajo en cada sesión. Los participantes tienden a conformarse con los materiales disponibles, el acceso a las herramientas y la experiencia combinada de los miembros del grupo. 


\subsubsection{A modo de requerimientos}

En consecuencia, a modo de resumen y adoptando una postura tecnometodológica (ver el trabajo de Dourish y Button[58]) las observaciones nos habilitan a postular como requerimientos de las herramientas de soporte la necesidad de:

- Soportar de manera flexible el bocetado de la interacción, en el sentido de no imponer al diseñador un proceso predeterminado de generación del boceto.

- Facilitar la producción de bocetos en diferentes niveles de corporización. Es decir, soportar la generación de bocetos electrónicos bidimensionales como analogía de los gráficos realizados en papel (trazo libre, falta de estructura y ambigüedad), pero también permitir la realización de bocetos-maqueta y bocetos interactivos con hardware y software.

- Permitir una integración entre todas las formas del boceto que sea manejable por el diseñador. De alguna manera podrían ser consideradas diferentes "vistas" de una idea en concepción de modo que una anotación en alguna de ellas debería reflejarse en las otras.

- Facilitar la definición y el diseño de la interactividad mediante el uso de algún vocabulario de la interacción y su aplicación en el proceso de diseño.

- Mantener el umbral de acceso a la tecnología usada en la producción de bocetos, lo más bajo posible y orientado a diseñadores de interacción y no sólo a ingenieros o programadores

- Permitir el amojonamiento del proceso con huellas expresivas que sean re-visitables, sean estados intermedios de los bocetos o cualquier otro elemento ad hoc dejado por los diseñadores como señales de insights durante la ideación. 



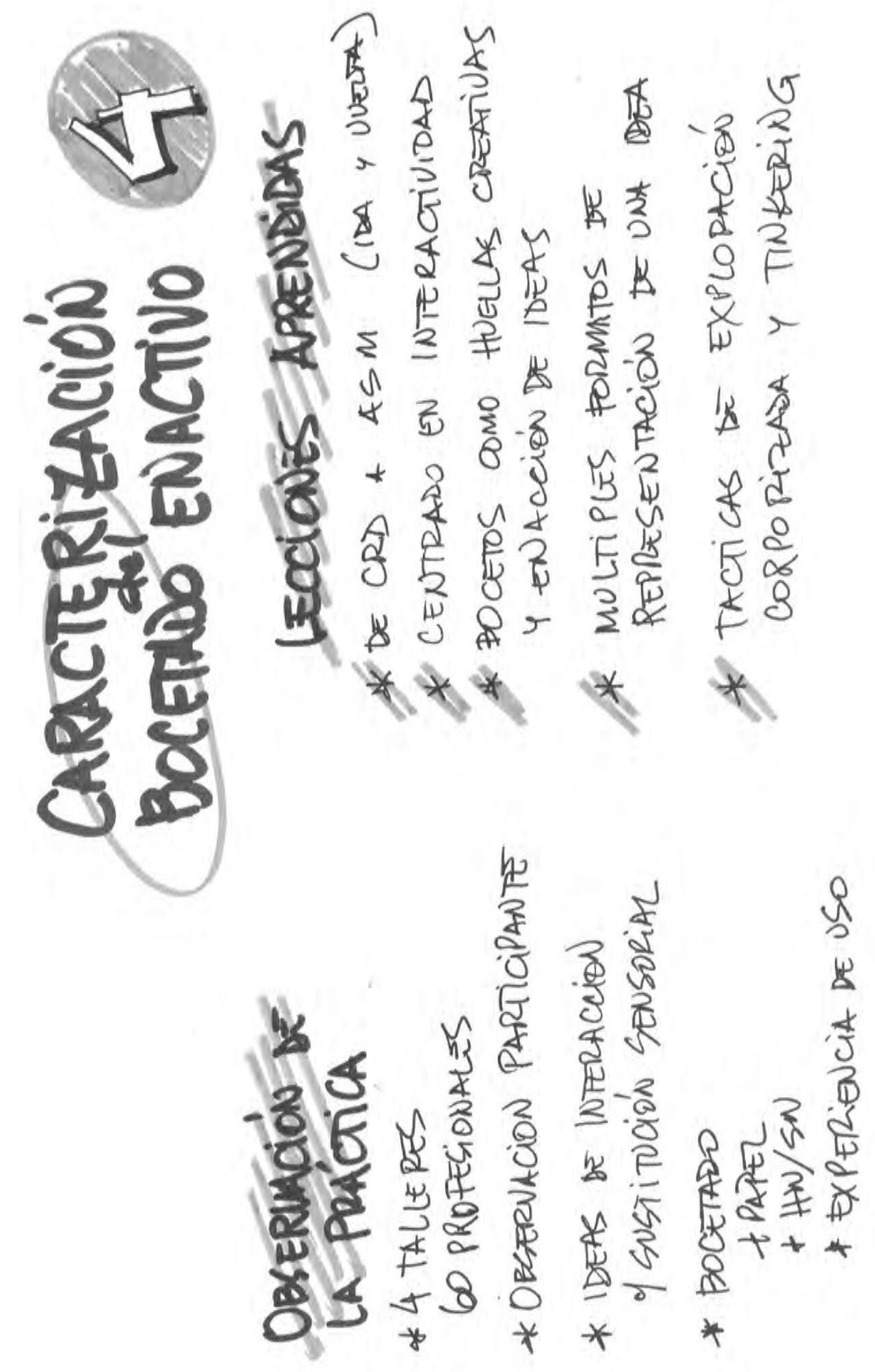





\section{Herramientas para el bocetado de interacciones enactivas}

Software is not a device with wich the user interacts; it is also the generator of a space in wihich the user lives

$$
\begin{aligned}
& \text { — Terry Winograd } \\
& \text { Bringing design to software[249] }
\end{aligned}
$$

En los capítulos anteriores abordamos la comprensión de las teorías de Cognición Corporizada y Enactiva aplicables al diseño de productos interactivos. Esto alimentó una serie de estudios etnometodológicos para conseguir una caracterización del diseño de interacciones enactivas y una elicitación incremental de requerimientos para las herramientas que puedan dar soporte a la práctica. A partir de los resultados de ambas actividades, triangulamos entonces diferentes acciones de diseño enfocadas en el desarrollo de herramientas que brinden soporte para los diseñadores.

Wobborck y Kientz ubican los toolkits en la investigación de HCI como contribuciones de tipo artefactual donde "el nuevo conocimiento está embebido en y manifestado por los artefactos y el material de soporte que los describen"[251]. La Figura 5.1 destaca las actividades y vinculaciones entre las diferentes metodologías que dan origen a las contribuciones que se presentan en este Capítulo.

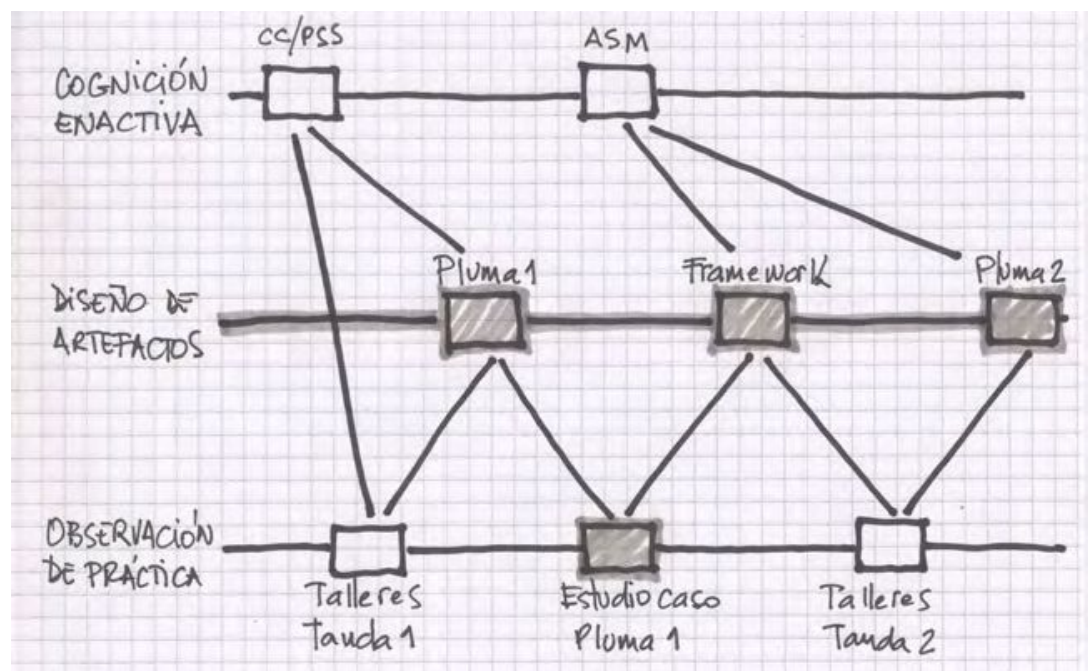

Fig. 5.1.: Ubicación de las contribuciones de este capítulo en la triangulación de métodos utilizada

La primera contribución es Pluma 1.0. Se trata de una pequeña aplicación que permite componer y configurar rápidamente bocetos interactivos con software y hardware empleando 
gestos manuales como input y actuación háptica e imágenes visuales como output. La mayor comprensión de las teorías y la práctica del diseño de interacciones, a partir de los estudios sobre Pluma 1.0 me permitieron formular un framework conceptual para organizar y relacionar los diferentes elementos y variables que entran en juego en el proceso del bocetado para la ideación de interacciones enactivas. Por una parte, el framework identifica y vincula las tres categorías de manifestaciones de bocetos que encontramos en la práctica observada y por otro las necesarias relaciones de trazabilidad entre los atributos de interactabilidad indicados en cada uno de esos niveles. Finalmente, presento Pluma 2.0, versión completamente reformulada que implementa varias de las ideas y requerimientos explorados en secciones precedentes. Pluma 2.0 facilita el bocetado de IEs conectando diferentes niveles de manifestaciones, baja el umbral para el bocetado interactivo con hardware y promueve un estilo de pensamiento en el diseño para la cognición corporizada basado en los estudios teóricos de la Cognición Corporizada Enactiva y las Observaciones de la Práctica por parte de los diseñadores.

\subsection{Pluma 1.0}

De acuerdo con las observaciones de la práctica reportadas en el Capítulo 4 y los reportes de trabajos relacionados en la literatura en el Capítulo 3 (por ejemplo, [172, 26, 132, 184] el bocetado interactivo con software y hardware puede considerarse una actividad de composición creativa en los términos propuestos por Shneiderman[215]. El diseñador genera o selecciona, modifica, interactúa y juega con artefactos tales como programas, diagramas, diseños, textos imágenes, componentes electrónicos, etc. en una actividad intensa que suele combinar además tinkering, desguace de artefactos usados para reutilizarlos o refuncionalizarlos. Este tipo de procesos de composición creativa difieren de los procesos rutinarios de producción sobre todo en que no pueden ser prescriptos. Las herramientas y representaciones que utilizan los diseñadores pueden afectar fuertemente el curso de sus acciones y procesos de pensamiento.

En el reporte del Workshop de la NSF liderado por Ben Shneiderman sobreHerramientas para el Soporte de la Creatividad se incluyeron doce principios para guiar el diseño y construcción de esas herramientas que enfatizan fundamentalmente la exploración fácil, la rápida experimentación y las combinaciones fortuitas que llevan a innovaciones[216]. De ese listado, hay seis que aplican directamente a mi trabajo y que utilizaré como guías conceptuales:

1. Soportar la exploración, permitiendo trabajar con diferentes versiones de una idea o diferentes ideas en paralelo.

2. Bajo umbral, techo alto y paredes amplias, que permitan el fácil acceso de novatos, que los expertos trabajen en proyectos de sofisticación creciente y que soporten un amplio rango de exploraciones.

3. Hacerlo tan simple como sea posible y quizá aún más simple.

4. Elegir las cajas negras cuidadosamente.

5. Iterar, iterar y entonces iterar nuevamente. El trabajo nunca está finalizado, siempre hay lugar para mejoras. 
6. Diseñar para diseñadores.

Además, de las toolkits en particular se espera que orienten al logro de las siguientes metas:

1. Reducir el tiempo y complejidad de autoría Los toolkits facilitan la autoría de nuevos sistemas interactivos mediante el encapsulamiento de conceptos para simplificar la expertise [182, 88]

2. Crear caminos de menor resistencia Los toolkits definen reglas o caminos para que los usuarios creen nuevas soluciones, llevándolos a soluciones correctas y evitando las erróneas[173]

3. Empoderar nuevas audiencias Como los toolkits reducen el esfuerzo para construir nuevas soluciones interactivas, pueden facilitar a otras audiencias la autoría de esas soluciones. Olsen discute de qué forma los constructores de interfaces abrieron el diseño de IU a diseñadores y artistas[182]

4. Integrar con prácticas e infraestructuras actuales Los toolkits pueden alinear sus ideas a infraestructuras o estándares existentes y de esta forma le agregan valor y facilitan su inclusión en investigación de HCI.

5. Facilitar la réplica y exploración creativa Los toolkits permiten replicar ideas que exploran un concepto, lo que de manera colectiva puede crear un nuevo conjunto de herramientas que trabajen juntas para escalar y crear "soluciones más grandes y poderosas"[182]

Con estos principios y metas, intentamos embeber y manifestar el conocimiento adquirido de los trabajos previos de estudio y observación en las siguientes herramientas de soporte al diseño de interacciones enactivas.

\subsubsection{Idea y objetivos}

La intención central fue explorar las posibilidades de integrar en herramientas para bocetar interacciones enactivas los atributos de interactabilidad[120,151] en una composición orientada al producto que se diseña, no solamente en la expresión abstracta de su interactividad (como hace Interactivity Sketcher[252], por ejemplo). Es decir que se pudieran componer bocetos simples en los que fuera factible reconocer las otras dimensiones de la anatomía de bocetos (forma, funcionalidad, materiales, etc.)

Pluma surgió como una primera aproximación de herramientas para soporte luego de la tanda inicial de talleres con observaciones etnometodológicas reportados en el Capítulo 4. Esta versión de Pluma está influida por la comprensión inicial del autor sobre la Cognición Corporizada en búsqueda de una visión diferente del congnitivismo estricto, aunque todavía muy vinculada al enfoque de Computación y Representación Distribuidas. Esto último queda claro en la descripción de la interactabilidad e interactivenes de un boceto en hardware con un punto de vista centrado en el sistema (al identificar los componentes como elementos de entrada y de salida más una relación parametrizada entre ambos). Pluma incluye algunos conceptos limitados de corporización, considerando las acciones del usuario como inputs y 
las respuestas del sistema como outputs (perspectiva del sistema) y favoreciendo un abordaje de la tangibilidad similar al propuesto por Ishii[237] donde los elementos tangibles son sólo contrapartidas físicas y tridimensionales de los datos y la información contenida en el software.

Para reducir el umbral necesario al especificar, implementar y probar bocetos de interacciones enactivas propuse una aplicación que permitiera a los diseñadores generar ideas de interacción con un proceso compositivo basado en selección de elementos predefinidos, estableciendo como interactabilidad un conjunto de relaciones y atributos parametrizados de su función de transferencia[79, 192], utilizando vocabularios y lenguajes como los Atributos de interactividad de Lim[151] o el Vocabulario de la interacción de Diefenbach[51].

La aplicación debía facilitar la exploración de alternativas de interactabilidad, simplificar tanto como sea posible la selección, combinación y parametrización de componentes y ocultar al diseñador toda la programación y atributos que pudieran ser autoconfigurables, manteniendo un abordaje visual del proceso de composición creativa.

El storyboard de la Figura 5.2 muestra el proceso de composición imaginado para Pluma. Supongamos el diseño de una aumentación del bastón para ciegos. Basándonos en las ideas de sustitución sensorial, deseamos aumentar un bastón para ciegos con la capacidad de extender el esquema corporal del portador más allá del extremo físico del bastón. Entonces buscamos agregarle la posibilidad de detectar obstáculos más allá de su extremo físico e informar al portador de esos escollos. Decidimos utilizar un sensor de distancia por ultrasonido y añadir el feedback mediante estímulo vibratorio, a menor distancia al obstáculo mayor estímulo. Para estimular utilizamos un pequeño motor de masa excéntrica que vinculamos a la muñeca del portador. Necesitamos una herramienta que nos permita bocetar rápidamente la vinculación entre estos dos componentes y establecer la curva de respuesta que esperamos.

\subsubsection{Diseño conceptual e implementación}

El bocetado con Pluma se entiende como un proceso de composición creativa[216, 193] basado en la selección y vinculación de elementos físicos de sensado y actuación, del modo que fue verificado en los talleres reportados en Capítulo 4. Un boceto entonces queda modelado como un conjunto de elementos de entrada y salida con las relaciones que definen su interactabilidad (vínculo entre un elemento de entrada y uno o más de salida y los parámetros de esas relaciones como una función de transferencia[79]).

Pluma está organizado sobre la base de dos módulos principales: uno permite seleccionar los elementos de sensado o respuesta y otro facilita la determinación de la interactabilidad del artefacto bocetado al definir la expresión del campo de operaciones (las acciones del usuario detectables por el sistema, como definen Janlert y Stolterman[120]. La aplicación facilita la "ejecución" del boceto y su modificación tantas veces como sea necesario sin requerir de la programación de Arduino u otro driver por parte del diseñador. 


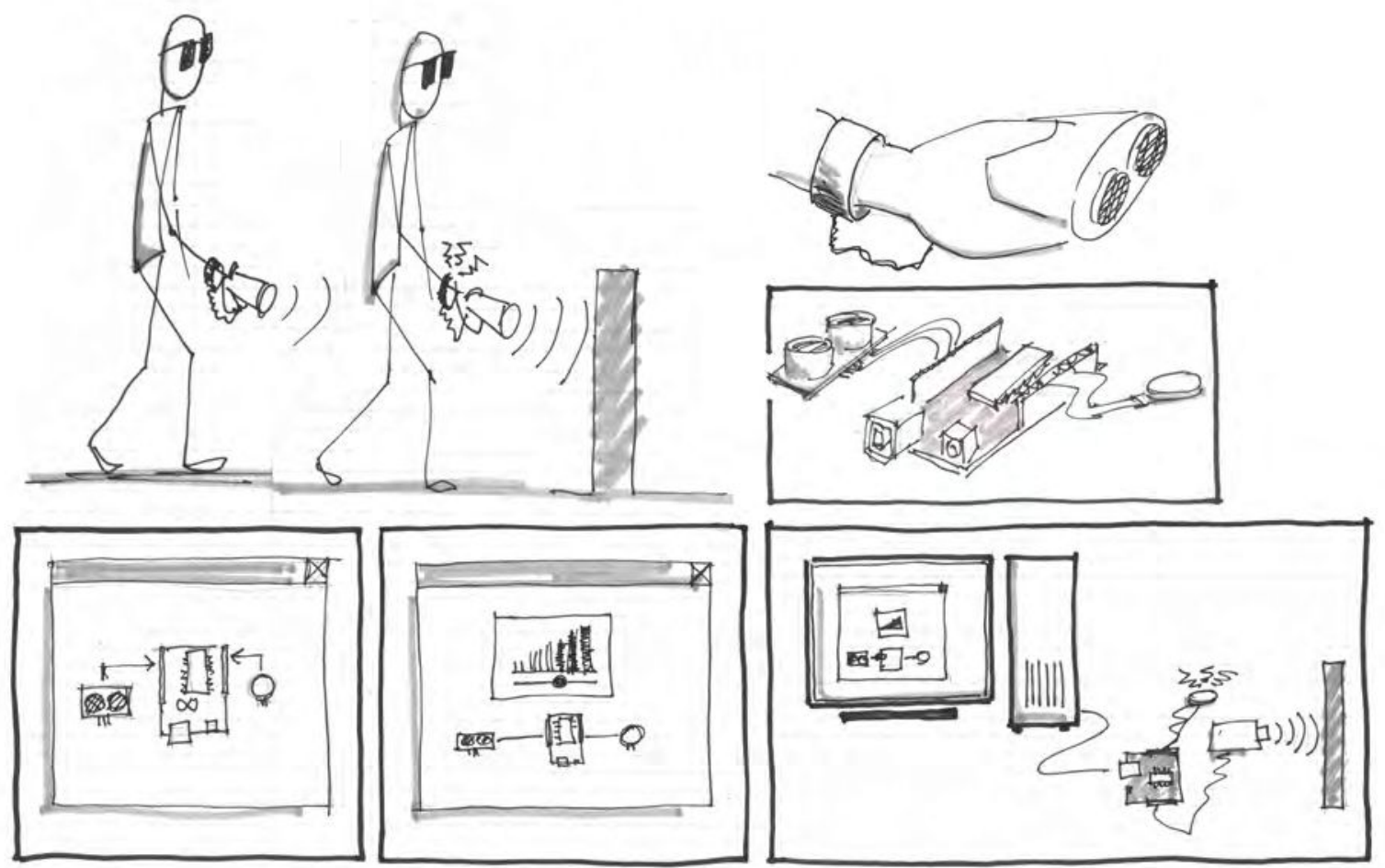

Fig. 5.2.: Storyboard con el proceso de composición imaginado para idear un bastón aumentado o enactivo para ciegos

El resto de los módulos implementan los siguientes bloques de funcionalidad (ver esquema simplificado en Figura 5.4):

- Catálogo de componentes de hardware Una biblioteca de drivers para manejar el conjunto de componentes que pueden ser conectados con Arduino para componer bocetos con Pluma. En principio hemos incluido la posibilidad de vincular a Arduino con motores vibradores, servomotores, pulsadores, sensor de distancia por ultrasonido y un minidisplay LCD.

- Catálogo de gestos Una biblioteca de definiciones de gestos manuales para emplear como inputs reconocibles por el dispositivo LeapMotion ${ }^{1}$.

- Entrenador de gestos Para evitar la restricción de los diseñadores a gestos preseteados, Pluma incluye una pequeña funcionalidad de entrenamiento para el reconocimiento de nuevos gestos manuales utilizando la API JavaScript de LeapMotion ${ }^{2}$ y la biblioteca LeapTrainer.js ${ }^{3}$. Es importante señalar que al momento de bocetar Pluma, LeapMotion disponía de funcionalidad limitada para el entrenamiento de nuevos gestos. Los gestos definidos en el entrenador son incorporados al Catálogo.

- Catálogo de imágenes Para simplificar la utilización de feedback visual a través del monitor de la misma computadora, Pluma incluye una biblioteca de imágenes y efectos que el diseñador puede extender. Por defecto hemos incorporado algunos componentes

\footnotetext{
${ }^{1}$ http://www. leapmotion.com/

${ }^{2}$ http://github.com/leapmotion/javascript/tree/master/v2

${ }^{3}$ http://github.com/roboleary/LeapTrainer.js/
} 


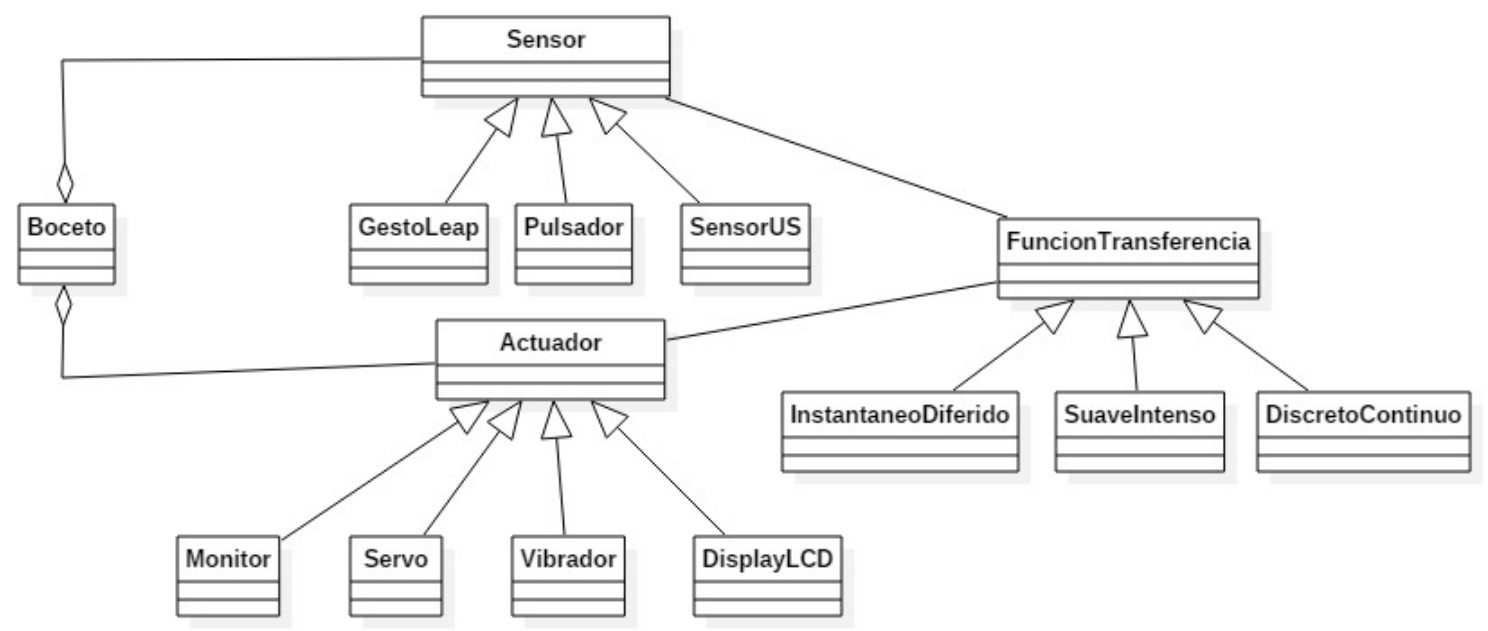

Fig. 5.3.: Modelo del boceto en Pluma

como la simulación de un carrusel de slides, el cambio de pantalla, apagado, encendido. En esta versión inicial, el diseñador puede extender el catálogo simplemente copiando los archivos que desea en la carpeta del servidor donde Pluma los busca.

- Definición de interactabilidad La definición de la interactabilidad buscada con el boceto de hardware es el corazón del uso de Pluma. Para plantearla, el diseñador debe vincular cada elemento de input definido con uno o más outputs utilizando el lenguaje de interacción (en esta primera versión de Pluma incorporé parte del vocabulario propuesto por Diefenbach[8], como se detalla más adelante).

- Sandbox de pruebas El diseñador puede analizar el comportamiento interactivo de su boceto con un sandbox de prueba. Cuando el diseñador prueba el boceto que ha creado, se procesan los inputs y outputs de acuerdo con las características definidas para cada uno y las propiedades de interactividad que les asoció. En poco tiempo el diseñador puede interactuar con sus bocetos y evaluar el tipo de experiencia que sus propuestas pueden proveer.

Los principios de Shneiderman mencionados en el inicio de esta sección sirvieron de guía en la formulación de estos módulos. El encapsulado de componentes de hardware y gestos nos permite cajanegrizar esta parte del trabajo de bocetado. Al mismo tiempo, con el foco en "diseñar para diseñadores", minimizando las prescripciones y potenciando la exploración, agregamos el entrenador de gestos y la posibilidad de extender el catálogo de imágenes. La secuencia de interacciones para componer bocetos entre elementos de hardware y el vocabulario de interacción es una forma de buscar simplificar el bocetado, bajar el umbral de acceso sin codificar. De todas maneras, este es un ejercicio inicial sobre el que habrá que iterar, iterar y volver a iterar para alcanzar buenas herramientas de soporte al bocetado de interacciones enactivas. 


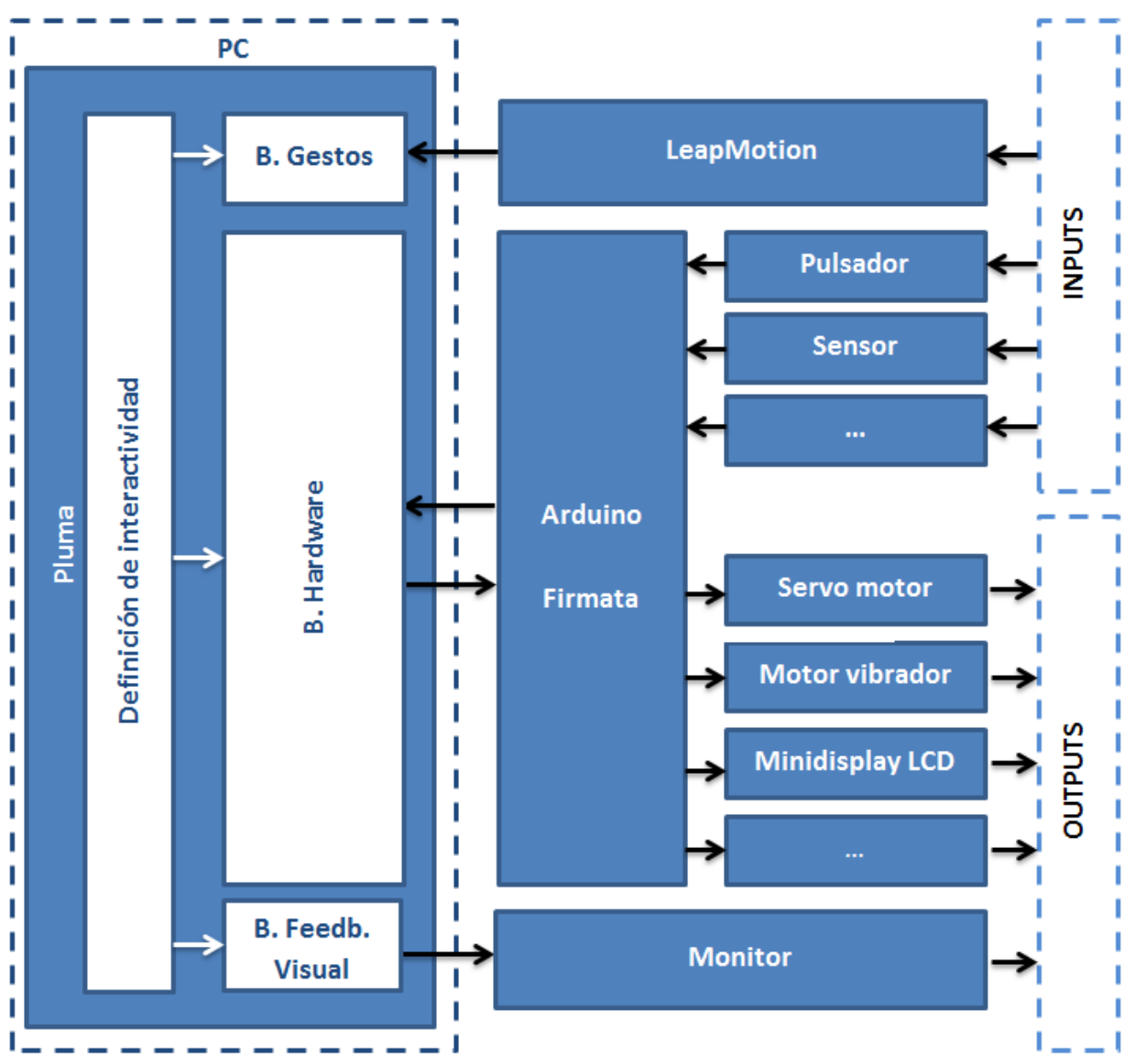

Fig. 5.4.: Esquema general de Pluma

En términos tecnológicos, Pluma está implementada con una pequeña arquitectura web basada en frameworks y bibliotecas disponibles y programación Javascript. Desde el lado de servidor se utilizó Node.js ${ }^{4}$ como plataforma y Backbone.js ${ }^{5}$ para simplificar la arquitectura MVC.

El servidor Node utiliza el framework Johnny-Five ${ }^{6}$ para administrar la comunicación con Arduino mediante el protocolo Firmata ${ }^{7}$. En el nivel de este ejercicio, esta comunicación resulta suficiente para enviar y recibir los datos necesarios y evita la modificación del firmware ejecutado en Arduino sin la necesidad de subir una nueva versión cada vez que se produzca algún cambio. Esta característica es un intento por mantener el umbral de acceso lo más bajo posible. De esta forma, el código que se ejecuta ante cada modificación de la composición se convierte en una caja negra cuyos detalles el diseñador no necesita conocer. Sólo compone los efectos de entrada y salida deseados.

\footnotetext{
${ }^{4}$ http://nodejs.org/es/

${ }^{5}$ http://backbonejs.org/

${ }^{6}$ http://johnny-five.io/

${ }^{7}$ Firmata es un protocolo de comunicaciones con microcontroladores desde un software hosteado en una computadora que utiliza mensajes en formato MIDI. La versión para Arduino y plataformas compatibles se encuentra en http://github.com/firmata/arduino
} 
El uso de templates de Jade ${ }^{8}$ simplifica una posible modularización y extensión. En los primeros bocetos de Pluma, tanto el servidor como el cliente se ejecutan en la misma máquina. Con excepción del LeapMotion (que se conecta con la máquina vía USB y provee una API a la que Pluma accede vía sockets) los demás componentes electrónicos para sensado o actuación se controlan mediante una placa Arduino UNO conectada por USB a la máquina (Figura 5.5). En la primera versión de Pluma las composiciones bocetadas no pueden ser persistidas.

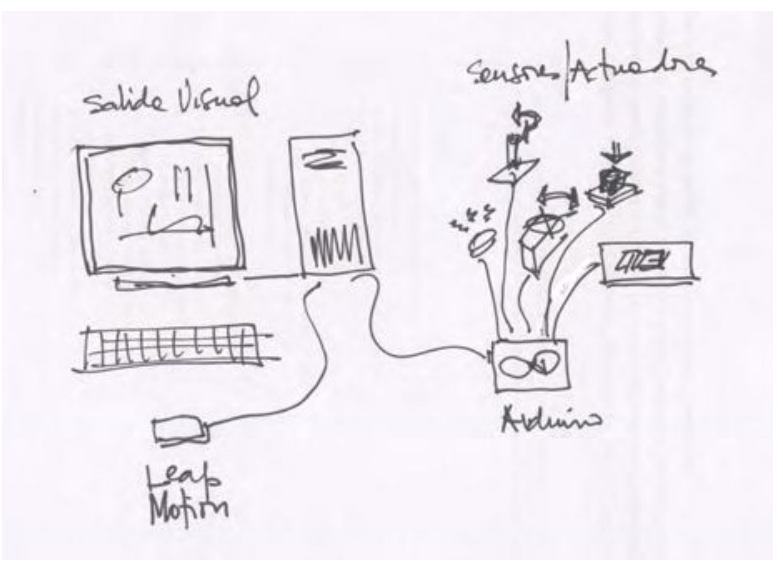

Fig. 5.5.: Esquema de conexiones en Pluma

\section{Forma de uso}

La definición de interactabilidad se realiza en dos pasos. Primero, el diseñador indica qué inputs y outputs se desea vincular. Luego, especifica qué valores tendrán los atributos de interacción disponibles para esa relación (el storyboard de la Figura 5.6 ejemplifica la secuencia). En el caso de utilizar gestos como inputs, el diseñador puede reutilizar alguno de los gestos previamente cargados en la Biblioteca o configurar uno nuevo. Para ello, utiliza el entrenador e incorpora el nuevo gesto a la Biblioteca. El entrenamiento consiste simplemente en realizar el gesto deseado y comprobar que el entrenador lo ha reconocido.

El Vocabulario de Interacción de Diefenbach[51] consta de once atributos especificados como rangos entre dos polos. Esta versión de Pluma incluye tres de ellos: instantáneo-diferido (definir con qué delay se genera la salida), suave-intenso (definir una salida en 3 niveles de intensidad), discreto-continuo (definir la salida en intervalos discretos o continua, por una duración determinada). Los tres atributos poseen valores por defecto, que pueden ser modificados en el bocetado, para generar una única función de transferencia integrada.

\subsubsection{Estudio de caso}

Para evaluar esta versión de Pluma realizamos un estudio de caso informal (en el sentido propuesto por Lazar[143]). El objetivo no es desarrollar un modelo general o construir un argumento riguroso, sino que tenemos interés en continuar la caracterización del bocetado de

\footnotetext{
${ }^{8}$ http://jade-lang.com/
} 

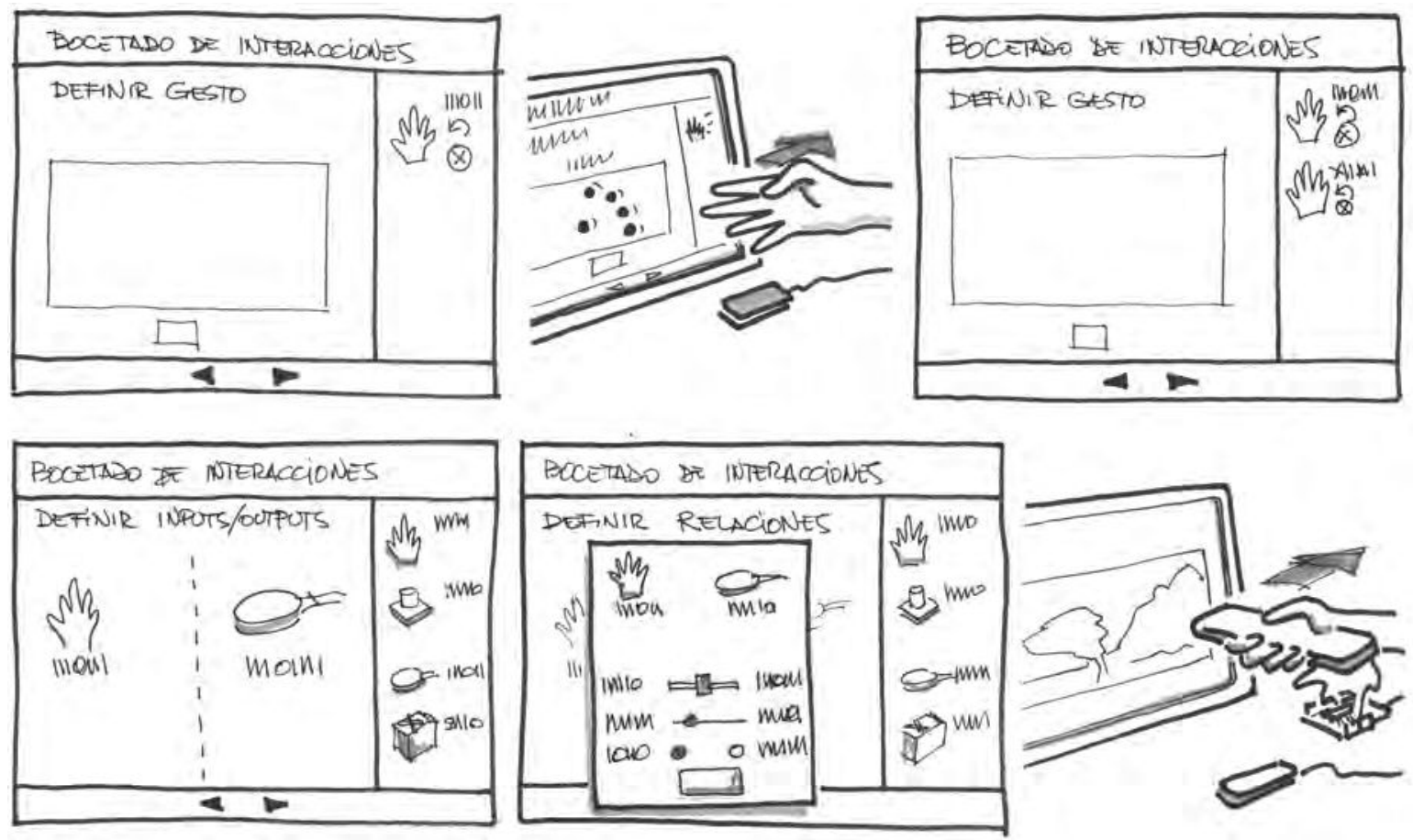

Fig. 5.6.: Pasos en el uso de Pluma. En la fila superior: apertura del entrenador de gestos, registro de un gesto y agregado a Biblioteca. Fila inferior: selección y agregado de inputs y outputs, vinculación y definición de interactabilidad, prueba con boceto hardware

IEs y explorar si las implementaciones en Pluma están en la línea correcta o debemos abordar otro camino. Como dice Lazar "Los investigadores de HCI utilizan con frecuencia los estudios de casos informales para describir el uso exitoso de una herramienta" (ver [143], pág.180). Un estudio de caso es informal en el sentido de que algunas de las pautas y procedimientos pueden ser relajados a favor de la conveniencia. Como no buscamos generalizaciones y reclamaciones amplias y de aplicación general, no necesita la planificación rigurosa o el mantenimiento de registros muy detallados para establecer cadenas de evidencia y protocolos de codificación para el análisis. Buscamos que algunos diseñadores utilicen Pluma en algún problema pertinente, por lo que organizamos una sesión informal para documentar la instancia de uso de la herramienta. Aún cuando los eventuales aspectos negativos serán de utilidad, ya que podremos identificar los errores en este nivel de propuesta de herramientas para mejorar las respuestas de la tesis a las preguntas de investigación originales.

De todos modos aún dentro de la informalidad del estudio, la selección de participantes ha seguido criterios de pertinencia lo mismo que la organización general de la sesión. El caso que se reportará a continuación está organizado a partir de los descubrimientos teóricos y de la observación de la práctica detallados en los capítulos precedentes. La unidad de análisis ha sido definida con cuidado, el procedimiento de recopilación de datos es un registro en video sobre el que se trabajó para el análisis que se presenta. Los informes de estudios de casos informales deben tener en cuenta las limitaciones enfrentadas. No pretendemos crear una impresión falsa sobre este estudio. Por eso reportaremos los resultados del análisis como "lecciones aprendidas" a partir de las observaciones del trabajo de los diseñadores involucrados. 
En todo momento hemos señalado el carácter exploratorio de esta tesis, mayores estudios que incluyan experimentos controlados deberán hacerse a partir de las propuestas de este trabajo.

\section{Metas}

Este estudio informal persigue metas de tipo exploratorias sobre la compatibilidad de Pluma con el proceso de ideación en diseño de interacciones. Vamos a concentrarnos en observar y analizar los siguientes aspectos de ese proceso:

- el uso de la composición creativa como forma de bocetado en hardware y software y su integración en el proceso de ideación general

- la utilidad de cajanegrizar la codificación del software para bajar el umbral de acceso

- la adecuación del vocabulario de interacción para definir interactabilidad

\section{Recolección de datos}

Como contexto de esta evaluación se utilizó un proyecto de diseño para Televisión Digital Argentina (TDA) que realizaba el Área de Transferencia de Centro de Investigación LIFIA de la Facultad de Informática por encargo del entonces Ministerio de Planificación Federal, Inversión Pública y Servicios del gobierno argentino. Entre otras tareas, el grupo tenía a cargo el desarrollo de software a embeber en una Set Top Box (STB) que incluía funcionalidades para configurar la recepción de señales, una guía de programación y un conjunto de aplicaciones interactivas basadas en el middleware Ginga ${ }^{9}$. Además el grupo estaba encargado de seleccionar de un amplio catálogo el control remoto que utilizarían los STB.

El autor organizó un taller de cuatro horas en el que participaron 5 integrantes del Area de Transferencia de Tecnología de LIFIA ( 3 asignados al proyecto TDA y otros 2 de diferentes proyectos de desarrollo, todos vinculados a tareas de diseño de Experiencias de Usuario). Los datos demográficos del grupo son: $\mathrm{M}=4, \mathrm{~F}=1$, edad promedio 29 años (desvío 2.4). La formación y experiencia previa de los participantes era: diseño en comunicación visual (2), diseño multimedial (1), diseño industrial (1), ingeniería electrónica (1).

La actividad se desarrolló en una oficina del grupo dedicado al proyecto de TDA que contaba con escritorios y PC para cada uno de los involucrados, pizarras en todas las paredes y un receptor de televisión conectado a un STB con la última versión del software en desarrollo (que incluía la sintonización de canales a través con la recepción de una antena de TDA). Se desplegó Pluma en cada una de las máquinas y se proveyó un controlador LeapMotion para cada instalación. Además se dispuso en el centro de la oficina una caja con distintos ejemplares de los componentes electrónicos conectables a Pluma (motores ERM, motores DC, servomotores, diplays LCD) más los elementos adecuados para su conectividad (tarjetas

\footnotetext{
${ }^{9}$ http://es.wikipedia.org/wiki/Ginga
} 
protoboard, cables con jumpers, diodos, transistores, resistores, etc.). También se dispusieron diferentes materiales para facilitar acciones tipotinkering y maquetado (cintas adhesivas, Post Its, cajas de diferentes tamaños, papeles de colores, marcadores, tijeras etc.).

La consigna inicial fue:

Generar ideas de interacción para que el control remoto del Set Top Box permita recorrer secuencialmente los canales sintonizados. Se espera una experiencia para el usuario final donde el desplazamiento entre canales basada en las flechas o con gestos de movimiento del control en una dirección o la contraria. Cuando el sistema sintoniza el siguiente canal y lo muestra en pantalla, el control remoto refuerza el cambio para el usuario con un feedback háptico. La información de haber alcanzado un extremo de la grilla también debe ser reforzada con un feedback háptico, distinguible del anterior. Para el bocetado interactivo a evaluar se deberá utilizar la herramienta Pluma que está desplegada en cada máquina.

El autor desempeñó un rol de observador y registró en audio y video toda la sesión para un análisis posterior (además de todo el material producido como gráficos, maquetas, bocetos de Pluma, etc.)

Al comienzo de la sesión de trabajo el autor expuso la consigna y brindó una una introducción de 30 minutos a la idea y funcionamiento de Pluma que incluyó el ejemplo de conexión y uso de cada uno de los componentes vinculables con la herramienta.

\section{Protocolo de análisis}

De acuerdo con Corbin y Strauss[41] el análisis cualitativo de datos consiste en tres etapas: primero es necesario obtener un conjunto de datos con información sobre el problema; segundo, indagar en cada componente para encontrar propiedades descriptivas y dimensiones relevantes; finalmente, usamos el conocimiento obtenido de estudiar cada componente individual para entender mejor el problema original y poder hacer inferencias. En consecuencia, nuestro protocolo de análisis incluye:

- Codificación abierta, identificar en el registro en audio-video los tramos que refieren a los aspectos de la ideación mencionados en el material revisado en Capítulos 2 (teorías de la cognición corporizada y enactiva) y 3 (teorías del diseño y bocetado).

- Desarrollo de conceptos y categorización, organizar esos tramos en conceptos básicos, vinculados con los aspectos mencionados entre las metas de este estudio y agruparlos en categorías que permitan el análisis

- Elaboración de inferencias, que permitan avanzar hacia una descripción y categorización del bocetado en la ideación de interacciones enactivas 


\section{Resultados}

Todos los diseñadores comenzaron con alguna maqueta rápida u objetos que convirtieron en prototipos on the fly. Un diseñador comenzó el trabajo construyendo una maqueta eligiendo entre los objetos disponibles una caja de dimensiones y proporciones similares a uno de los controles y adhiriéndole sólo unos recortes de papel para simular las teclas de acción que se solicitaban en la consigna, como se ve en la Figura 5.7. Este diseñador se paró a dos metros frente al TV sosteniendo la caja con su mano derecha y simuló un movimiento periódico hacia derecha y centro para "generar un cambio de canal". En ese momento, otro de los participantes tomó un marcador grueso (simulando que cumplía el rol del control), pero en lugar de hacer el gesto izquierda-centro-derecha, movía su mano hacia arriba y abajo.

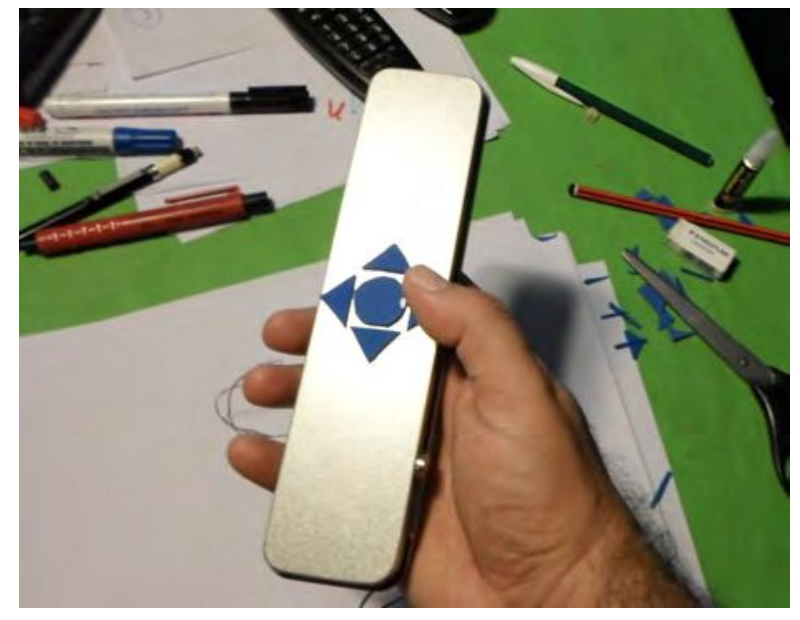

Fig. 5.7.: Caja adoptada como maqueta del control con el agregado de unos recortes de papel para simular las teclas de acción

En cualquiera de los dos casos, era obvio que necesitaban "corporizar" el gesto para explorar la idea que habían tenido. Ninguno de los dos había hecho hasta ese momento ningún dibujo. Para explorar implicancias de sus ideas, los diseñadores realizaron rápidos bocetos en papel e incluyeron anotaciones textuales e iconográficas para expresar las respuestas por parte del mando que contribuyeran a generar la experiencia de uso buscada. Ejemplos de esto se muestran en las Figuras 5.8 y 5.9. Esto coincide con la evidencia reportada por Hummels[108] donde los diseñadores hicieron una profusa utilización de flechas y anotaciones ad hoc así como del formato storyboard para indicar la secuencia de los efectos de interacción buscados.

Tras algunas modificaciones en los bocetos, los diseñadores conectaron un par de botones pulsadores y de motores vibradores con una placa Arduino y los adhirieron a una de las maquetas (ver Figura 5.10). También utilizaron un carrusel de imágenes como feedback visual para simular el cambio de canal.

Con Pluma conectaron todo para explorar la experiencia de interacción. En este paso, la participación del ingeniero electrónico fue fundamental para resolver las conexiones. Salvo el diseñador industrial, el resto de los participantes tenía muy poca experiencia en el manejo de hardware tipo Arduino. Intentaron buscar ayuda por internet, pero lo resolvieron más rápido 


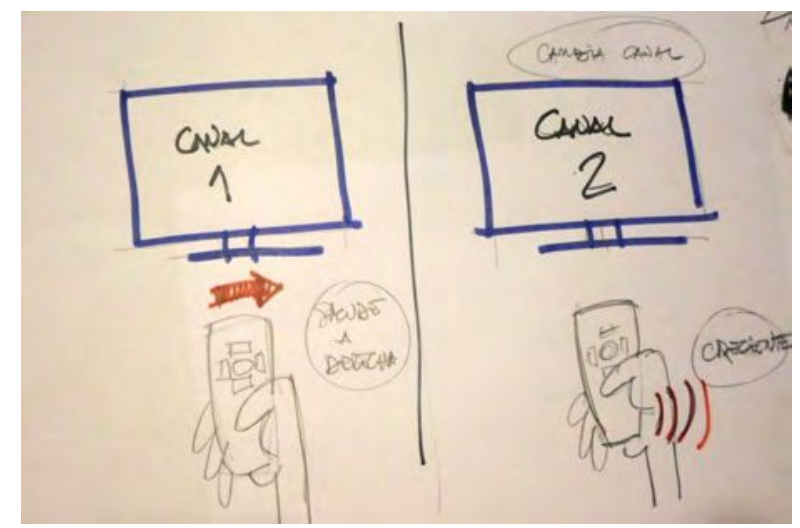

Fig. 5.8.: Para expresar interactabilidad pretendida, los diseñadores utilizaron anotaciones textuales ("sacude a derecha", "creciente") e iconográficas (ver flecha a la izquierda y signo de ondas en expansión a la derecha) en sus bocetos.

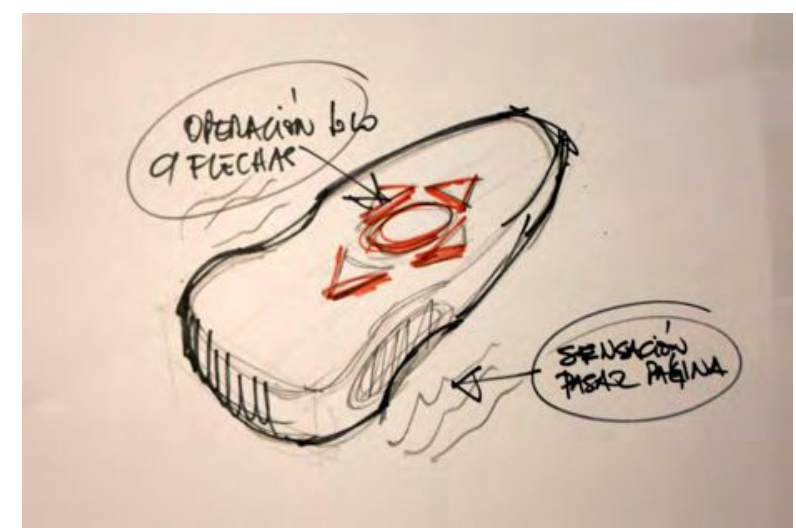

Fig. 5.9.: Uso de anotaciones, flechas y signos en bocetos

con la ayuda del ingeniero, que a partir de ese momento funcionó como el asesor técnico de los otros participantes (Figura 5.11).

Mediante la ejemplificación crearon dos gestos aéreos a identificar: mover a derecha y mover a izquierda. Los motores conectados a Arduino fueron identificados como actuadores para generar el output del sistema y los pulsadores como input. El bocetado del uso y reconocimiento de gestos claramente difiere mucho de las tecnologías posibles de implementación, lo que se quiere probar es la idea de que gesticulando con el control remoto en la mano "indicándole al TV" que mueva a derecha o arriba para "pasar" de canal y recibir la confirmación mediante el feedback visual reforzado con el feedback háptico es una experiencia "diseñable" y aceptable por usuarios.

Finalmente se establecieron las relaciones de pares: un pulsador-una acción de la aplicación de pantalla, un gesto-una acción de la aplicación, una acción de aplicación-un actuador (ver Figura 5.12). Para cada relación se establecieron los parámetros de la interactividad deseada (en la versión actual: discreto-continuo, suave-intenso e instantáneo-diferido). 


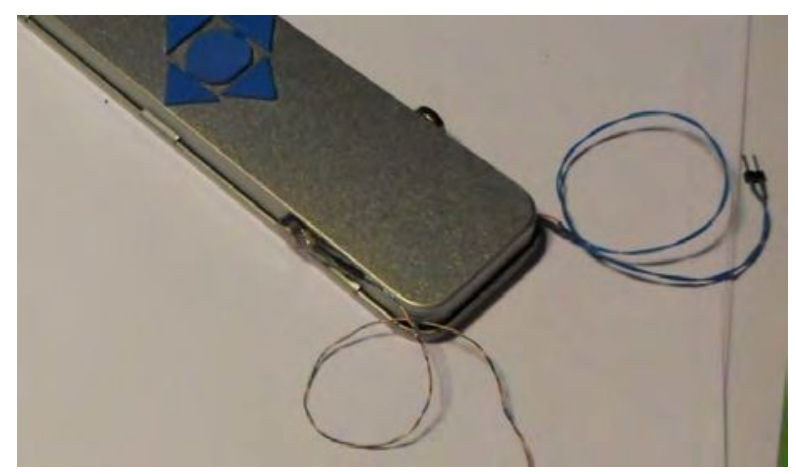

Fig. 5.10.: Agregado de motores tipo ERM a los lados de la maqueta para intentar generar el feedback vibro-táctil buscado

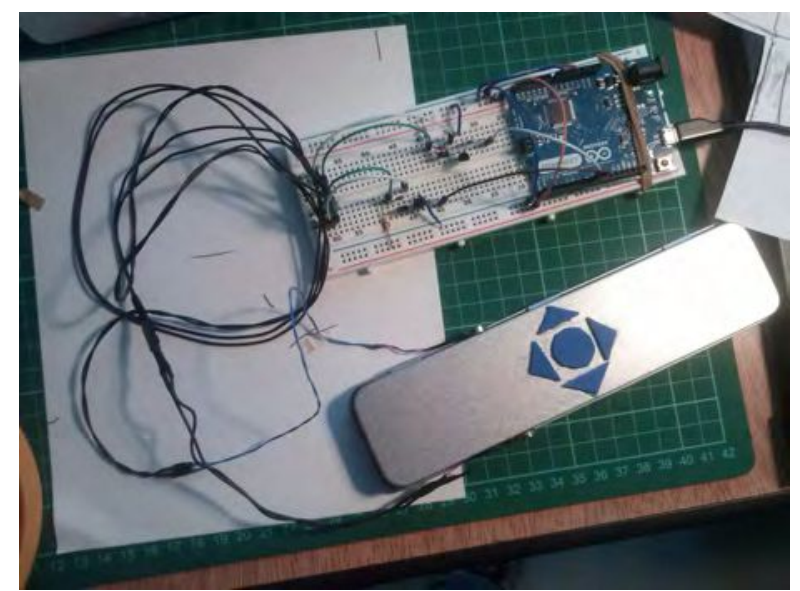

Fig. 5.11.: Boceto en hardware con las conexiones a los motores en la maqueta. Los circuitos para los motores debieron ser implementados por el ingeniero ante la falta de experiencia de los otros diseñadores. Aunque el esquema fue proporcionado y coincidía con otro que encontraron en internet, no se arriesgaron "a romper nada" (sic)

\section{Lecciones aprendidas}

De manera similar a los talleres reportados en el Capítulo 4, aquí también los diseñadores se enfocaron directamente en encontrar una buena interactividad y para eso filtraron todos sus bocetos con la interactabilidad que buscaban para el control. Sólo aparecieron algunos esbozos sobre forma en unos pocos bocetos en papel, fundamentalmente analizando formas de prensión y resolución de interactabilidad para ambidextros.

Fue interesante comprobar que los 4 participantes con formación y experiencia de diseño utilizaron bocetos 2D, storyboards y maquetas de cartón con numerosas gesticulaciones además del bocetado en hardware elaborado con Pluma. Es altamente probable que la falta de experiencia previa con hardware haya potenciado la necesidad de utilizar las herramientas familiares.

También aprendimos que la cajanegrización del código de software por sí sola no alcanza para bajar el umbral de acceso, es necesario incorporar en ese mecanismo de alguna forma también los circuitos y conexiones de componentes. La forma de trabajo sugerida por Pluma en términos 

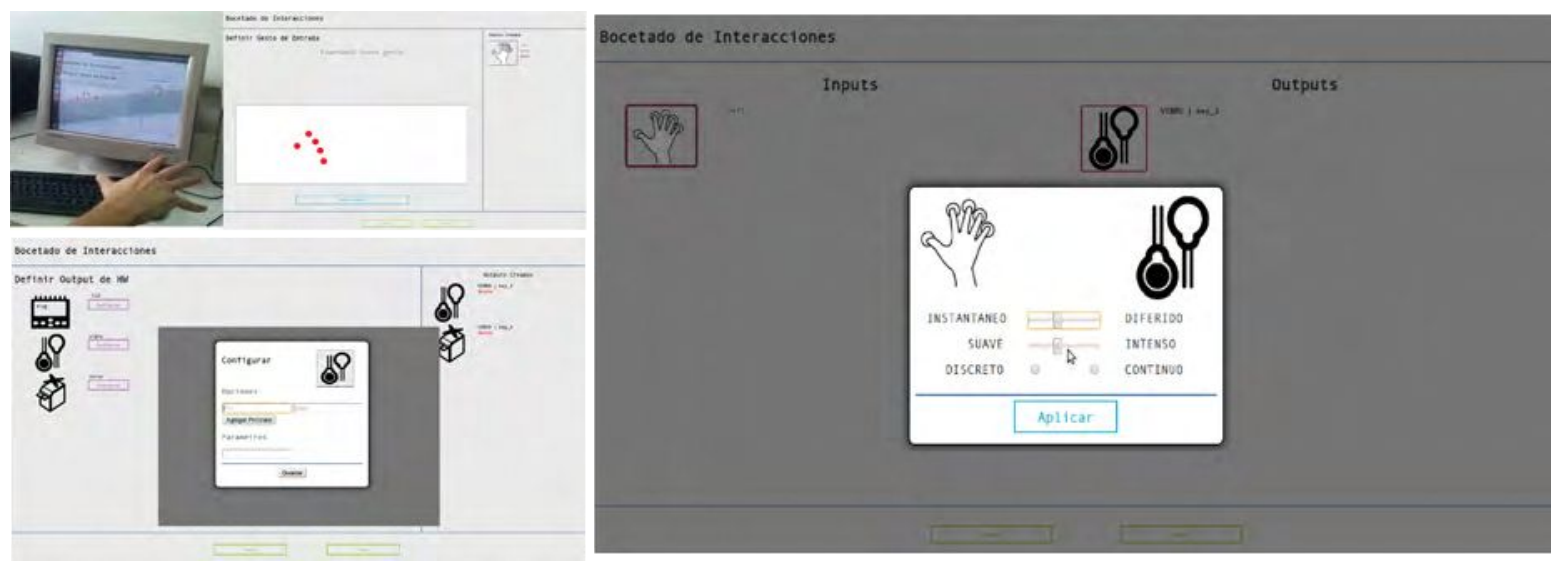

Fig. 5.12.: Definición de interactividad con Pluma. Definición de gestos como input (a la izquierda ejecución del gesto sobre Leap Motion, derecha reconocimiento y definición por Pluma). Agregado y configuración de un motor vibrador como output. Relación entre input y output y asignación de parámetros de interactividad

de composición creativa no pareció imponer restricciones especiales o fuera de la lógica propia de los diseñadores.

Uno de los temas que apareció en las evaluaciones de los bocetos por los diseñadores fue la importancia de conectar las representaciones y anotaciones en los diferentes tipos de bocetado. ¿Cómo vincular de manera efectiva una anotación "creciente" y signos de ondas dibujados en papel con el gesto de percibir una vibración incremental? ¿Cómo establecer que el gesto aéreo en un momento con expresiones verbales simultáneas son otra forma de expresar el parámetro de transferencia entre el gesto y el output vibratorio en Pluma? De todos modos, en el marco de las cuatro horas del taller, incluyendo el tiempo de exploración y búsquedas por internet para hallar circuitos apropiados cuando fue necesario, pudieron indagar y construir varios bocetos con hardware para explorar las interacciones imaginadas.

En las entrevistas posteriores al ejercicio, los diseñadores se manifestaron satisfechos sobre el uso de Pluma, tanto respecto del umbral de acceso que la plataforma les impone para bocetar como de las posibilidades de definición de elementos de la interacción. Sin embargo, solicitaron ampliar el vocabulario de interactabilidad disponible, tanto respecto de los componentes de entradas/salida soportados como de la parametrización de la funciones de transferencia. Uno de ellos sostuvo que "yo necesito poder establecer pasos más finos para distinguir entre dos opciones de vibración".

\subsection{Un marco para el bocetado de interacciones enactivas}

Hasta aquí hemos presentado una revisión de la literatura y estudios de observación que muestran el uso por parte de los diseñadores de múltiples formas de representación y modelización a la hora de generar ideas de interacción enactiva. Esos estudios alimentaron además 
el desarrollo de una pequeña herramienta de soporte y nuevas observaciones en un estudio informal de caso.

La actividad de dibujo en sus diversos formatos es la práctica por antonomasia durante la actividad de generar ideas de diseño[123, 65], sin embargo cuando se trata de interacciones corporizadas los diseñadores recurren a otras formas y modelos de representación. El boceto a mano alzada es muy poderoso para capturar y explorar rápidamente ideas de diseño, pero parece no ser del todo compatible con la ideación de interacciones tangibles o corporizadas, ya que el papel no puede expresar adecuadamente la dinámica ni la experiencia de las acciones. Surgen entonces otras opciones de modelización que pueden ser asimiladas a la práctica del bocetado, como el tinkering (una técnica en la que los diseñadores utilizan material sencillo y barato como elementos de oficina, bloques de espuma y objetos desguazados para crear rápidamente representaciones en físicas de sus ideas[122, 105]), el bocetado en hardware (donde se combinan maquetas 3D, software y hardware para dotar de interactabilidad a los modelos[100, 172]) y la puesta en escena de la propia experiencia de uso (los bocetos de experiencia de uso[31, 32]).

Esta combinación de modelos se produce en el marco de un flujo de ideas y acciones durante el cual las diferentes formas de presentación se crean, vinculan y retro-alimentan casi sin solución de continuidad, sin un orden predeterminado, sólo conducido por el propio proceso de indagación del diseñador.

Si es cierto, como sostiene la cognición corporizada y enactiva, que los objetos físicos son parte del proceso de pensamiento cada disposistivo con el que interactuamos se convierte en una oportunidad para el pensamiento, el control y la imaginación. Dejan de ser simples ayudas como las calculadoras (cosas que aceleran lo que, en principio, podemos hacer de otra manera). Nos permiten hacer cosas que no podemos hacer sin ellas, o al menos no sin un gran esfuerzo. Las implicaciones de incluir estas teorías que permiten que las cosas materiales sin vida sean componentes reales del proceso de pensamiento son de gran alcance. Señalan un futuro en el que un día, debido a la mejora digital y al buen diseño, será habitual pensar lo que hoy es inconcebible. Pero, sin diseñadores informados cognitivamente ni herramientas que soporten esa cognición, nunca llegaremos allí.

Presentamos ahora una organización posible de las prácticas del bocetado en este ámbito, tanto para que los propios diseñadores dispongan de marcos conceptuales para reflexionar en su actividad (estar preparados para la acción, en términos de Schön[208]) como para investigar y desarrollar herramientas que puedan brindar un soporte que respete y promueva la manera de diseño ala Janlert y Stolterman[121]. Este es el sentido del framework conceptual que presentamos a continuación ${ }^{10}$.

\footnotetext{
${ }^{10}$ Una versión previa fue presentada en [198]
} 


\subsection{1 ¿Para qué bocetar en la ideación?}

Existen al menos tres formas en que el bocetado adquiere sentido durante la ideación de interacciones corporizadas y enactivas. Por un lado, el uso de múltiples representaciones externas extiende el poder cognitivo del diseñador y le permite pensar lo que de otro modo es impensable. Además, los bocetos se convierten en andamios o trampolines que facilitan el flujo de un pensamiento al siguiente, aunque sean representaciones parciales e imperfectas y especialmente cuando es el propio diseñador quien enactúa la interacción. Finalmente, todas las producciones realizadas durante el bocetado amojonan el proceso con huellas creativas que permiten recorrer el camino en ambos sentidos y eventualmente elegir otros senderos de exploración desde algún punto anterior.

\section{Poner la idea en el mundo para pensarla mejor}

La utilización de bocetos y cualquier otra forma de modelización externa mejora el poder cognitivo del diseñador en diferentes maneras y contribuye a que pueda llegar a pensar aspectos del problema que de otra manera resultarían impensables, aspecto clave de la ideación en diseño según Kirsh[129]:

Reducen costos y mejoran la efectividad del pensamiento A través de la interacción es más fácil procesar de manera más eficiente y efectiva que trabajando solo dentro de la cabeza. La cognición interactiva mejora la eficiencia porque conduce a menos errores o a una mayor velocidad, lo que generalmente se traduce en enfrentar problemas más difíciles. También mejora la efectividad porque ayuda a calcular de manera más profunda, precisa y, a menudo, más amplia. Uno se beneficia de la restricción física y las sugerencias visuales que ayudan a la cognición $[40,130]$.

El pensamiento se puede compartir Cuando alguien externaliza una estructura se está comunicando con él mismo y hace posible que otros compartan con él un enfoque común, con beneficios para ambas partes.

Permiten reorganizar los componentes La reorganización de las piezas en el espacio físico hace posible examinar relaciones que antes eran distantes o visualmente complejas (por ejemplo, rotaciones y uniones). Al volver a ensamblar las piezas, la decisión es simplemente una cuestión de determinar si las piezas están bien acopladas. Esa es una pregunta que puede resolverse mediante ajustes físicos y visuales. El movimiento físico sustituye la computación mental. En lugar de imaginar transformaciones, las ejecutamos externamente.

Son persistentes e independientes del autor Los modelos son lógicamente y físicamente independientes de su autor y, por lo tanto, pueden manipularse independientemente de la noción previa de su autor sobre cómo interactuar con el modelo. Esto es vital para hablar con los clientes y otros diseñadores, mostrar el comportamiento, la funcionalidad y detectar efectos 
secundarios imprevistos. Además, a diferencia de una descripción o una representación mental, cualquier modelo físico real debe ser autoconsistente. No puede referirse a propiedades que no se pueden realizar simultáneamente. Si construimos e interactuamos con el modelo, probamos que es una idea factible. La inconsistencia es físicamente irrealizable. Todos los modelos físicos apoyan la interacción corporizada. Podemos moverlos de una manera que expone perspectivas y relaciones difíciles de ver. Cuando nuestra interacción se controla con precisión, o se interpreta como movimiento a lo largo de una línea de tiempo, podemos yuxtaponer instantáneas para comparaciones que simplemente serían imposibles de lo contrario. Sin esa reproducibilidad que brinda la persistencia, algunas de las ideas que formamos sobre la dinámica temporal de una interacción serían virtualmente impensables.

Dan acceso a un código natural Para ciertos tipos de pensamiento a veces preferimos una modalidad sensorial a otra, necesitamos que el medio de origen represente el contenido de una idea. Y esta es otra ventaja de externalizar porque para algunos problemas, la representación natural del contenido sólo existe fuera. Por ejemplo, son pocas las personas que pueden escuchar música en su cabeza de la misma forma en que suena fuera. Las imágenes mentales de los sonidos tienen diferentes propiedades que los sonidos reales. Para la mayoría de las personas para dar sentido a la música lo primero que hay que hacer es tocarla o escucharla. Algo similar ocurre con la dinámica de la interacción física.

Facilitan el descubrimiento de relaciones A pesar del valor de manipular un dispositivo, hay ocasiones en que una representación gráfica revela más que la propia interacción, casos en que una representación no natural puede ser más reveladora e intuitiva que la original. Esta es una ventaja clave del uso de múltiples representaciones. Un diseñador que se mueve desde una interacción enactuada hacia su bocetado gráfica y luego desde un diagrama hacia la enacción puede explorar elementos de la estructura que de otra manera son inaccesibles. Sin interactuar con múltiples representaciones, algunos descubrimientos simplemente estarían fuera de alcance.

Sirven como chequeo de realismo Al construir una estructura probamos que sus partes son mutuamente consistentes. Si podemos construirlo, entonces debe ser lógica y físicamente viable. Si podemos ejecutarlo, entonces las acciones de esas partes son consistentes, al menos parte del tiempo; y si podemos ejecutar la interacción requerida, entonces es consistente todo el tiempo. El mundo físico no miente.

\section{Usar andamios y trampolines para llegar más alto y más lejos}

Un boceto es el soporte externo o andamio que ayuda a tener en mente las imágenes mentales correctas. Para explicar cómo un modelo imperfecto de la interacción, que es lo un boceto literalmente es, puede comportarse como un apoyo físico es necesario entender la diferencia entre proyección, imaginación y percepción. La proyección es un proceso mental similar a unir una imagen mental a una estructura física. Cuando proyectamos sobre un objeto lo 
"aumentamos" intencionalmente. El objeto se convierte en un ancla de nuestra imagen mental. La proyección exitosa requiere el bloqueo espacial o temporal de la imagen proyectada en la estructura de anclaje (la imagen que se adjunta debe tener el tamaño correcto y estar conectada a una ubicación específica en la estructura externa). Cuando imaginamos un objeto, nuevamente estamos tratando con imágenes mentales, pero no las adjuntamos a nada en el mundo externo. La imaginación no tiene ancla física, y las imágenes imaginadas no necesitan tener un tamaño o ubicación específica. Por el contrario, cuando percibimos un objeto, no estamos imaginando o proyectando nada. Nuestra experiencia es de un objeto o escena externa que se supone que está realmente allí.

El boceto ayuda en la fase de proyección, al proveer un ancla física de la imaginación mental. Es mejor que simplemente simular mentalmente porque el acto de crear una estructura (un boceto, maqueta, cualquier tipo de representación) o hacer un movimiento (mediante gestos) provee un ancla física sobre la que se puede proyectar la interacción completa. Este ancla física se lleva parte del peso de la imaginación y ayuda a los diseñadores a pensar de manera más efectiva sobre los aspectos de la interacción que intentan revisar o mejorar.

Por otra parte, aunque los bocetos sean parciales o incompletos sirven igual porque lo que es importante es el flujo, no la precisión. El diseñador no busca la perfección en cada representación, sólo filtra algunos aspectos de su idea. Para eso puede ser más fácil trabajar con su cuerpo o un instrumento externo que pensar "fuera de línea", en su cabeza. Puede resultar extraño que practicar con algo intencionalmente incorrecto conduzca a una mejor evaluación de lo correcto. Pero funciona. ¿Por qué? Por una parte, porque tomar algo que es transitorio e interno (un pensamiento o idea) y convertirlo en algo persistente y externo le permite al diseñador volver repetidamente a él para interactuar de manera diferente a lo que se piensa[32]. Por otra, porque la actividad corporal funciona como una estructura externa que media entre el pensamiento y la acción. Aún cuando la interacción sea con un modelo que ofrece una versión parcial o imperfecta de la interactabilidad, el mover el cuerpo en el paso inicial es un trampolín que permite pensar en el siguiente paso con mayor claridad que simplemente imaginarlo con el "ojo de la mente"[128].

Un boceto ayuda a focalizar en algunos aspectos del diseño, por ejemplo concentrarse sólo en la interactabilidad del dispositivo o la interactividad conseguida. Con un boceto externo, el diseñador puede centrarse en las dimensiones de la idea una por una, revisando y evaluando aspectos de manera metódica que de otra manera serían fáciles de pasar por alto al simular mentalmente la interacción. Por otro lado, esta posibilidad de focalizar en las dimensiones de a una puede explicar por qué es conveniente que los bocetos sean parciales y limitados y no intenten reproducir el conjunto completo de dimensiones en juego. El cuerpo se mueve de manera diferente a la mente, obedece a un principio distinto de inercia (el dedo no se mueve a menos que haya intención de hacerlo, pero los pensamientos, incluso los ojos, son difíciles de controlar). Por lo tanto, una representación externa imparcial sobre la que se pueda gesticular es un recurso que se puede aprovechar para ayudar a gestionar la atención y resolver problemas complejos. 


\section{Dejar huellas para desandar y volver a andar el camino}

Como señalamos en el Capítulo 2, podemos aprovechar los conceptos de la estigmergia para analogar las movidas de un diseñador ejecutadas como acciones para cambiar el contexto como huellas que deja de su proceso creativo. Todas esas huellas son parte del mismo camino, tienen un rationale en los términos del propio diseñador que lleva de una a la siguiente. En el diseño de interacciones, el lenguaje de esa conexión es la interactabilidad que se persigue para el sistema o dispositivo que es objeto de diseño.

Cuando interactuamos con nuestro entorno por razones epistémicas dejamos señales en las que podamos apoyarnos para facilitar el pensamiento. Lo mismo hace un diseñador. Cuando trabaja un diseñador funciona como un "equipo de un integrante", para ser productivo, debe realizar tanto las movidas de creación como las de evaluación e integración (que en los equipos suelen estar divididas de acuerdo con la expertise de cada miembro). Para conseguirlo, tiene que aprovechar el espacio físico y el tiempo dejando marcas en ambos de manera que jueguen para su mismo equipo. Esas marcas en el espacio y a lo largo del tiempo permiten una trazabilidad del proceso. De acuerdo con el enfoque de acoplamiento sensorio motor, lo que se deja como huella (es decir el contenido de una nota, la imagen que se boceta, la estructura física de una maqueta o la combinación de sensores y actuadores en un boceto hardware) no representa literalmente su contenido. En realidad, su significado es el acto mismo de hacerla[84] y el artefacto es un elemento de andamiaje en la realización del acto [47]. El boceto es para el diseñador un soporte necesario para enactuar esa expresión. En otras palabras lo que importa no es sólo el contenido de la huella, sino el hecho de construirla y dejarla como hito, o dicho en términos de Dourish, el lugar donde está la acción [56].

En otras palabras, el uso de representaciones y modelizaciones externas en la interacción corporizada no es sólo una forma de hacer más eficiente el pensamiento o una base para construir nuevos pensamientos, también es una manera de jalonar el camino que lleva de una idea a la siguiente. Cada una de esas representaciones persistentes es la manera de dejar constancia de la idea, para sí mismo y para otros. Este jalonamiento luego servirá además, como las huellas en el bosque, para desandar el camino y volver a recorrerlo o iniciar un nuevo sendero a partir de algún punto anterior.

\subsubsection{Una forma de pensar la organización del bocetado}

Las múltiples formas de representación externa que ayudan a extender la cognición, moverse de una idea a la siguiente y dejar huellas de cada paso contribuyen al proceso de ideación de manera diferente. Además, como son parte de un mismo proceso creativo, existen vínculos y relaciones entre ellas. Es conveniente proveer alguna forma conducente de organización para ese conjunto de herramientas que los diseñadores ponen en juego.

En nuestro framework organizamos el proceso de ideación con bocetos en un esquema de dos dimensiones más una tercera que corresponde al desarrollo temporal del camino creativo: 
La corporización de interactabilidad Los diseñadores generan representaciones externas utilizando dos, tres o cuatro dimensiones: bocetos, diagramas, anotaciones en papel (2D); maquetas de estudio, a menudo de cartón y materiales de oficina, storyboards dibujados en papel o en formato digital, lo mismo que recorridos tipo sobrevuelo animado sobre renderizaciones computarizadas (3D, en espacio o tiempo) y estructuras espaciales con comportamiento que cambia dinámicamente gracias a la incorporación de hardware para sensar y actuar controlado por software o estructuras sin comportamiento que se utilizan en puestas en escena que modifican de manera dinámica su significado (conocidos como prototipos de la experiencia de uso, 4D).

La extensión y profundidad de la interactabilidad con representaciones que van desde una expresión estrecha y profunda de la interactabilidad (un aspecto particular con todas sus variaciones) hasta una amplia y superficial (un poco de toda la interactabilidad que se busca)

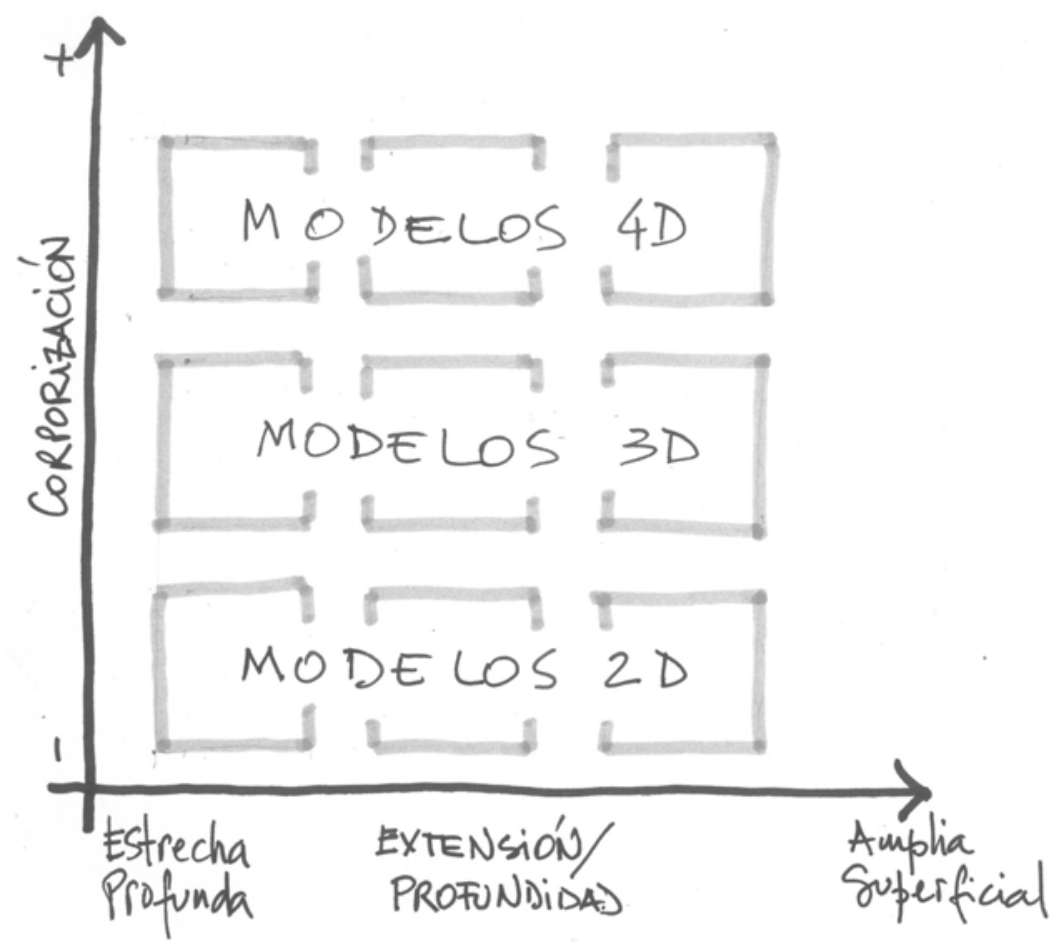

Fig. 5.13.: Modelo de bocetado de interacciones enactivas. Plano de corporización versus extensiónprofundidad de interactabilidad

La Figura 5.13 grafica el plano de las dimensiones de corporización y extensión-profundidad de la interactabilidad.

La ubicación temporal del boceto aunque es obvio que las representaciones se crean en distintos tiempos es necesario incluir esta temporalidad en la organización porque la secuencia que se produce de distintas externalizaciones es parte significativa del proceso de indagación del diseñador y, por otra parte, porque se podrán identificar trazas que vinculen una representación en un momento con otra de un momento posterior. 


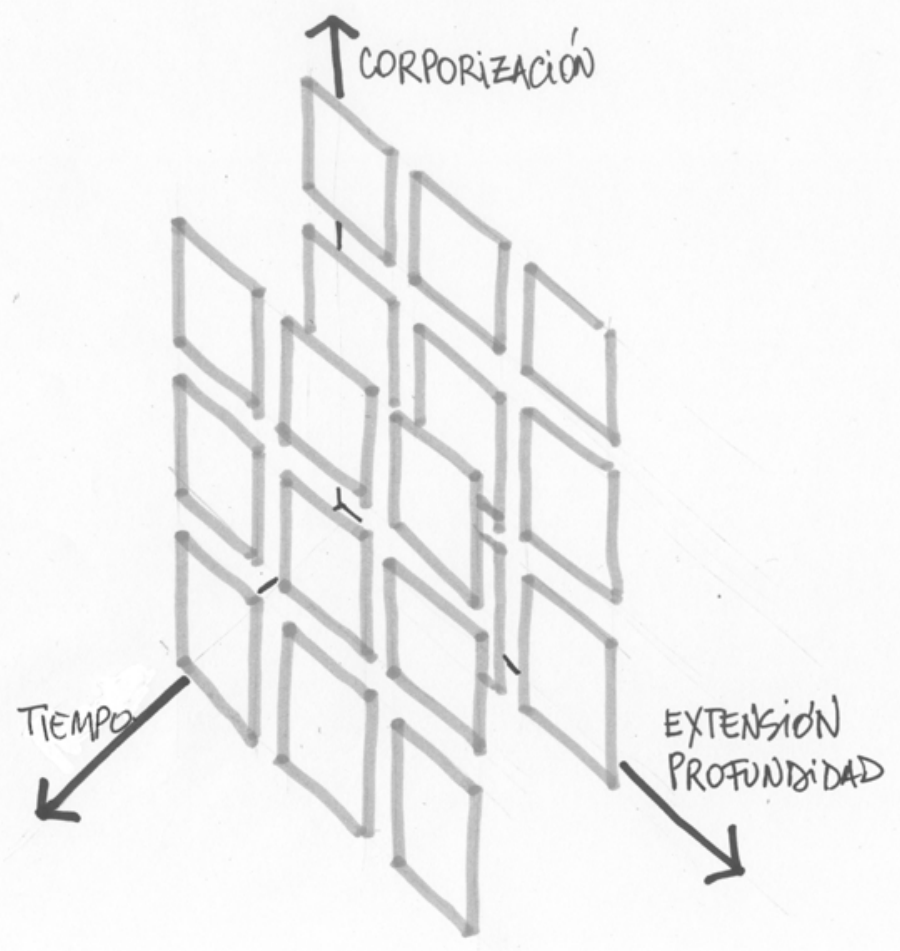

Fig. 5.14.: Modelo de bocetado de interacciones enactivas. Organización temporal del plano de corporización y extensión-profunidad

Tanto en la dimensión de la corporización como en el de la extensión-profundidad no es posible conocer de antemano el orden y formato de representación y modelado a utilizar por los diseñadores. Cada proceso, cada diseñador, cada problema es un universo en sí mismo en este aspecto, como bien pudimos observar en nuestros estudios (ver Capítulo 4). Aunque los modelos 2D brindan mayor nivel de abstracción y ambigüedad, el diseñador puede elegir comenzar realizando una maqueta (3D) o un boceto en hardware (4D), para luego explorar sus ideas en el papel y retornar más tarde a los bocetos tridimensionales. $\mathrm{O}$, comenzar con bocetos gráficos de ideas y tratar luego de aumentar la corporización de algunas pasrtes. Es necesario por lo tanto aceptar que el diseñador puede comenzar en cualquiera de los niveles y proveer mecanismos de traza que permitan relacionar la información entre los distintos niveles cuando se trate de diferentes vistas de una misma idea.

El hilo conductor que permite establecer conexión entre los diferentes niveles o vistas de una misma idea es la expresión de la interacción en acción (la interactividad, en términos de Janlert y Stolterman[120]) que se busca conseguir a través de la interactabilidad del artefacto o sistema en diseño (que es uno de los atributos a considerar en la dimensión de filtrado de la anatomía de prototipos[152]).

La interactabilidad buscada no puede expresarse de la misma manera en cada nivel. A medida que se asciende en la dimensión de corporización, adquiere cada vez mayor concreción. Así, en el bocetado 2D, puede expresarse simplemente con palabras, con flechas o signos, con una representación de secuencias temporales del tipo storyboard. Sin embargo, en un boceto en 
hardware habrá que decidir si la experiencia buscada se consigue con una respuesta que se produce de manera inmediata tras la acción del usuario o se difiere en el tiempo, si se produce de manera continua o periódica, etc. Las versiones corporizadas en alguna medida restringen el espacio de acción más que los bocetos enpapel, porque de una forma material incorporan restricciones específicas a través de las affordances (físicas o percibidas). Estos modelos fuerzan a una mayor precisión a la hora de posicionar objetos respecto de un boceto. Un cable puede ser vinculado con un conector específico, hay que decidirlo al momento de establecer esa conexión, no se puede simplemente "dejar para decidir después"[104]. En las representaciones gráficas, la interactabilidad e incluso la interactividad es a menudo expresada con flechas y signos que denotan algún tipo de movimiento o navegación[108, 110].

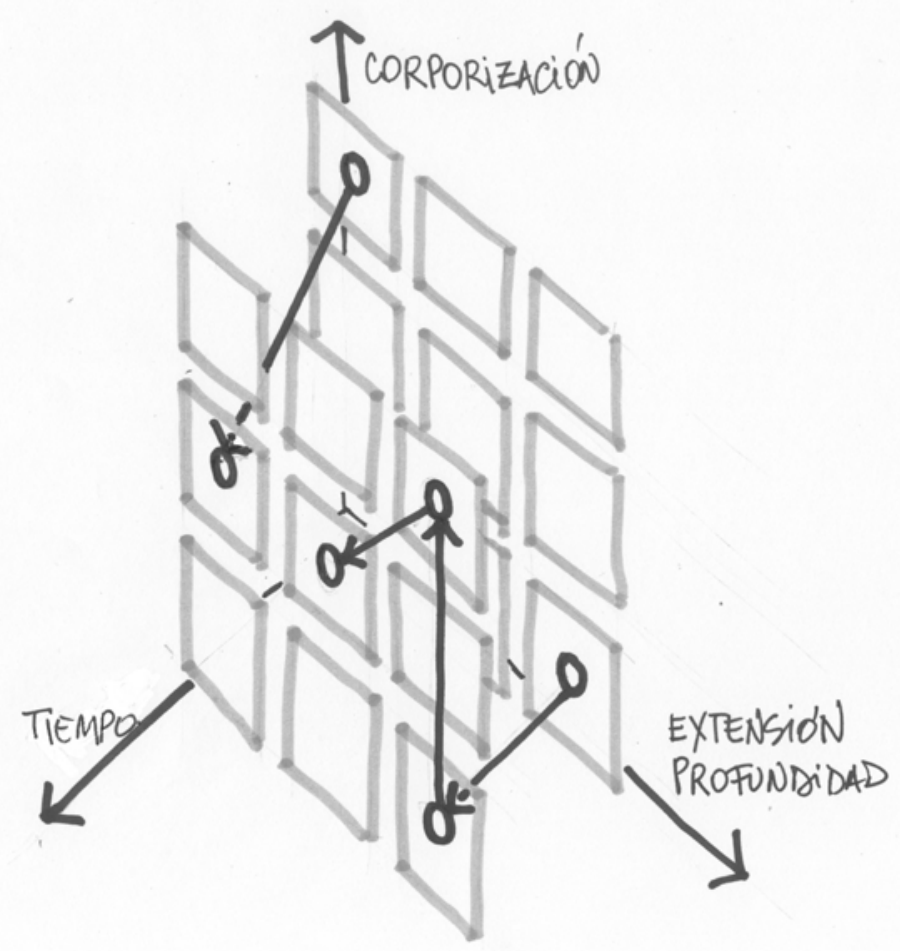

Fig. 5.15.: Modelo de bocetado de interacciones enactivas. Existe una trazabilidad entre las diferentes huellas creativas del proceso.

Por otra parte, es necesario asegurar mecanismos que permitan la trazabilidad de las ideas en las diferentes representaciones propuestas. Aquí entra en juego la interactabilidad descrita en término de sus atributos.

Varios lenguajes para expresar los atributos de la interactabilidad han sido definidos. Lim et al[152] definen un lenguaje para caracterizarla con siete elementos (concurrencia, continuidad, lo esperable, rango de movimiento, velocidad de movimiento, proximidad, velocidad de respuesta) a partir de los cuales poder describir lo que ellos llaman la "forma de la interactividad". Esto da soporte al diseñador para que piense en la naturaleza de la interacción a la vez que explora diferentes formas de llevarla a cabo. Diefenbach et al[51] proponen un lenguaje ampliado a partir de Lim. Contiene once atributos, definidos como rangos entre valores extremos: Lento- 
Rápido; Discreto-Continuo; Instantáneo-Diferido; Uniforme-Divergente; Constante-Inconstante; Mediado-Directo; Separación espacial-Proximidad espacial; Aproximado-Preciso; Suave- Intenso; Casual-Dirigido; Evidente-Oculto.

Además de señalar la idea de establecer alguna trazabilidad entre los diferentes bocetados, es importante considerar que el propio hecho de bocetar (ya sea en la generación de ideas como en su revisión/evaluación) es un acto de dejar huellas del proceso de pensamiento y armado de la idea. Por eso es que en la organización de las herramientas de soporte será importante tener en cuenta este hecho (por ejemplo como propone van Dijk[52]) con la utilización de herramientas para generar huellas del proceso creativo grupal.

\subsubsection{Resumen}

El framework que se propone organiza el bocetado para el diseño de interacciones enactivas en tres dimensiones: la corporización de la idea, la extensión y profundidad del filtrado y la secuenciación temporal de producción.

Esta forma de pensar la organización de la producción de externalizaciones puede servir como base para la definición de requerimientos de las herramientas que den soporte a la actividad. Para ello, las herramientas deberán combinar la posibilidad de integrar diferentes formas de externalización y además ser capaces de asegurar la trazabilidad de las características implícitas o emergentes en cada una de ellas hacia otras de distinto nivel de corporización y extensiónprofundidad. Si el diseñador realiza un boceto en el que busca generar una experiencia de uso que pueda caracterizarse como agradable y natural, es necesario que pueda ir refinando esas ideas con los atributos que una interacción de esas características, en representaciones que por su naturaleza son menos ambiguas o des-estructuradas. Para ello, el uso de lenguajes o vocabularios de interactividad pueden ofrecer la ayuda necesaria.

\subsection{Pluma 2.0}

Diseñar sistemas con interacción corporizada y enactiva no es fácil. Las tecnologías disponibles rara vez vienen equipadas con el hardware o software necesario. Incluso si el hardware de sensado está incorporado escribir un software para traducir información de sensado de bajo nivel en información enactiva es difícil: esta tarea a menudo requiere calibraciones desafiantes de la entrada de detección y cálculos matemáticos complejos para procesar datos del sensor, así como el desarrollo de una API reutilizable. Esto introduce un umbral alto para aquellos que deseen desarrollar sistemas de interacción enactiva. Como resultado, la mayoría no se molesta. De los pocos que lo hacen, pasan la mayor parte de su tiempo con detalles de implementación de bajo nivel para acceder y procesar la información sensada o el display de su función en lugar de refinar los conceptos de interacción y las técnicas de interés.

En consecuencia, además de promover una mayor comprensión por parte de los diseñadores de la cognición corporizadas y sus consecuencias para la práctica del diseño, también necesitamos 
que dispongan de las herramientas adecuadas que los empoderen, reduzcan la complejidad de autoría, faciliten la exploración creativa y se integren con las prácticas e infraestructuras actuales[182, 88, 173]. Para contribuir con este objetivo y mitigar los problemas anteriores, se presenta aquí una segunda versión de Pluma. Esta toolkit incluye herramientas para integrar un proceso de ideación de interacciones corporizadas y enactivas con composiciones creativas que utilizan elementos de hardware y software, bocetos en papel, maquetas adhoc, registros en video de bocetos de experiencia o de revisiones, en un proceso de soporte a la creación que responda a los desafíos y oportunidades desarrollados en los capítulos anteriores.

El resto del capítulo está estructurado de la siguiente manera: primero presento el diseño de la toolkit y utilizo un ejemplo Hola mundo para mostrar cómo permite a los diseñadores componer rápida y fácilmente interacciones corporizadas y enactivas entre personas, dispositivos y entorno. Luego describo los detalles técnicos de la implementación. Finalizo con descripción de ejercicios de bocetado que demuestran las posibilidades de ideación y composición creativa que soporta Pluma 2.0.

\subsubsection{Diseño}

A partir del relevamiento de estado del arte, los talleres realizados y la primera aproximación con Pluma, encontramos varios desafíos a ser abordados por un diseñador que intenta generar ideas de interacción enactiva. Por una parte, en el diseño específico de la interacción enactiva aparecen los desafíos planteados, por Bellotti[19]: cómo se accede al dispositivo, cuál es el campo de operaciones posibles, cuál es el campo de acciones y de esas cuáles son operaciones aceptables para el sistema, cómo saber qué es lo que el sistema está haciendo, cómo evitar errores. Por otra, aparecen también desafíos sobre el propio proceso de creación de ideas enactivas: cómo explorar la generación de ideas con diferentes tipos de bocetos, cómo vincular y establecer trazas entre esas diferentes expresiones, cómo debugear y probar una idea. Sobre las posibilidades creativas, cómo explorar las percepciones posibles de parte de un usuario, cómo evaluar si el efecto que se pretende es el que se consigue, etc.

Esta segunda versión de Pluma está diseñada como un Cuaderno de bocetos enactivos, donde el diseñador pueda desarrollar, incorporar, integrar y evaluar las diferentes manifestaciones del bocetado como quedaron planteadas en el Marco de la Sección anterior y la estrategia de composición creativa para la ideación (Figura 5.16). Pluma 2.0 presenta diferentes módulos que en su conjunto tratan de implementar esta metáfora de cuaderno: una biblioteca de componentes de sensado y actuación y otra de vocabularios de interactabilidad, que permiten componer bocetos en un Cuaderno Enactivo que no sólo permite agregar elementos y visualizar sus relaciones sino que en todo momento permite enactuar su funcionamiento.

\section{Cuaderno de bocetos enactivos}

El Cuaderno de bocetos enactivos es el corazón de Pluma 2.0. Cuando se inicia la aplicación, se presenta una pantalla con las opciones de trabajo alrededor de una superficie limpia que emula 


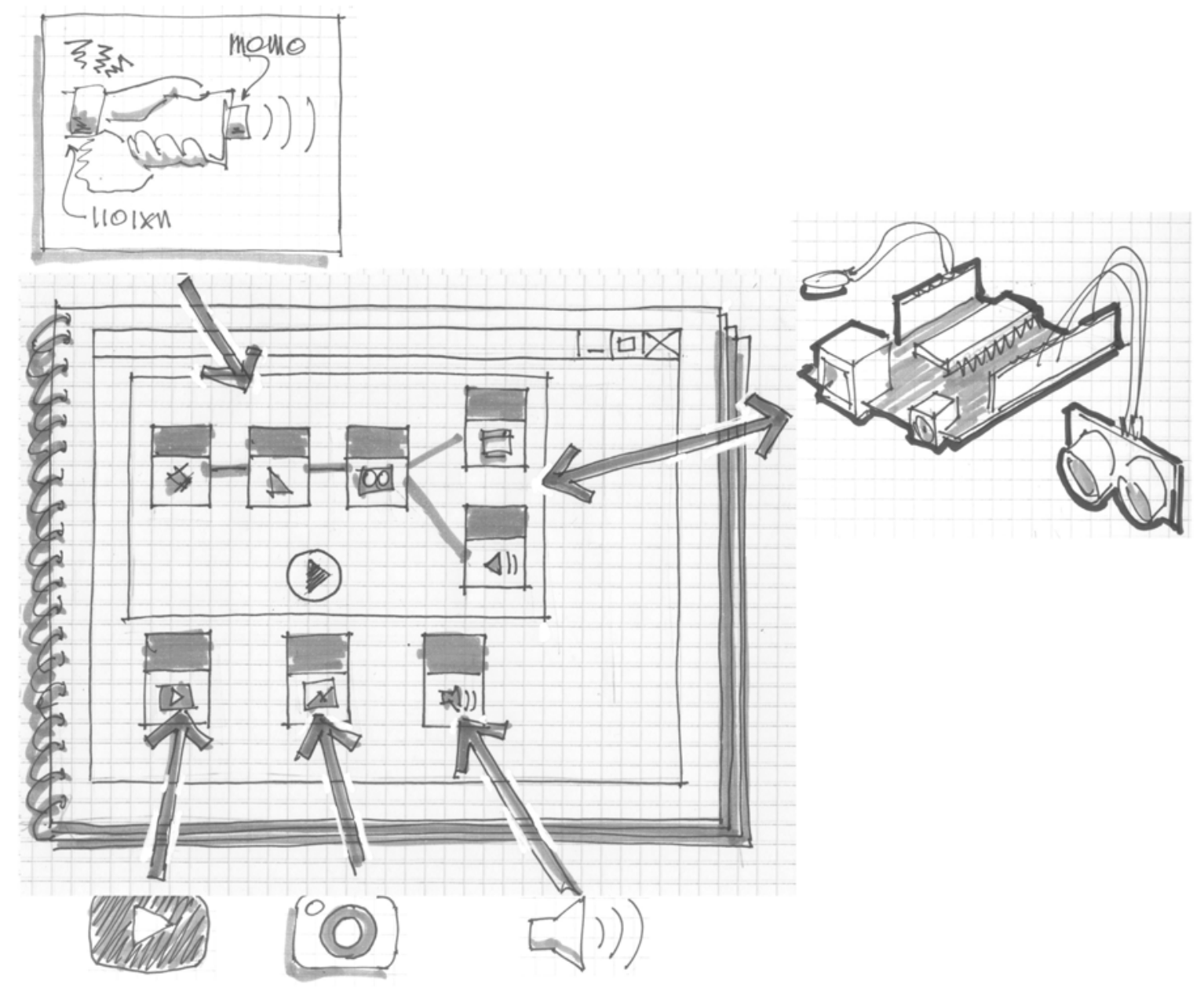

Fig. 5.16.: Metáfora del cuaderno enactivo de bocetos

la hoja en blanco al comenzar (ver Figura 5.17). La barra superior de la pantalla contienen los accesos para iniciar un boceto nuevo, abrir uno existente o guardarlo. Además está el acceso a la traza de huellas expresivas del boceto (más detalles sobre esto más adelante). A la izquierda una barra da acceso a los elementos para componer un boceto interactivo organizados en cinco bloques básicos, tres de ellos corresponden a un boceto interactivo (Percibir, Actuar, Interactuar) y otros dos a la inclusión en este Cuaderno de referencias a bocetos producidos fuera de él (Bocetos 2D y Maquetas).

Todos los componentes de un boceto o un conjunto de diferentes tipos de bocetos se ven en la hoja del cuaderno, que tiene dimensiones "ilimitadas" de manera que el proceso de ideación de un proyecto incluirá todos los bocetos y composiciones que se gestaron durante el proceso. En la implementación actual, el cuaderno asume que están conectados a la PC por puertos USB una placa Arduino con la versión Standard de Firmata y una shield Grove y un sensor Leap Motion. En la parte inferior de la barra de herramientas informa con indicadores las conexiones detectadas (en verde) o falta de ellas (en rojo). 


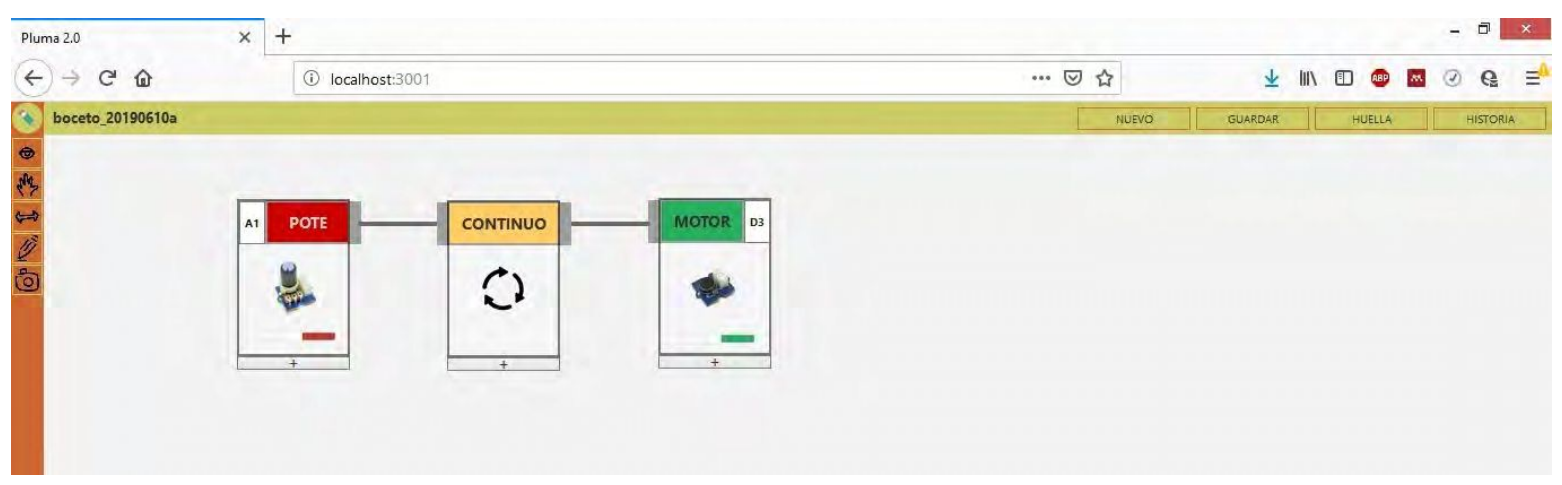

Fig. 5.17.: Base de cuaderno de bocetos

\section{Biblioteca de sketgets para actuar, percibir e interactuar}

Desde el Cuaderno de bocetos el diseñador tiene acceso a un conjunto de elementos para componer un boceto en software y hardware, que llamamos sketgets. El nombre surge de la contracción entre sketch y widget. Un sketget es un widget que compone un sketch o boceto y se caracteriza por modelar alguna capacidad de interactabilidad del boceto y relacionarse con otros sketgets.

Pluma cuenta con tres bibliotecas de sketgets para Actuar, Percibir e Interactuar. Las denominaciones están planteados con la perspectiva de usuario final de la interacción que se boceta, de modo que las operaciones de Acción corresponden a elementos que se transformarán en inputs de procesamiento, las de Percepción son los outputs del dispositivo y los elementos para Interactuar constituyen un vocabulario de interacción inspirado en el trabajo de Diefenbach[51]. En las Tablas 5.2, 5.1 y 5.3 se listan los sketgets incluidos en esta versión.

Los diferentes elementos permiten construir un modelo de bloques visuales para programar la composición y funcionamiento del boceto enactivo. En la mayoría de los casos sólo es necesario drag and drop y algunos clics de mouse. Si el diseñador desea modificar los atributos por defecto para los componentes puede hacerlo con el uso del teclado, abriendo la casilla de extensión del componentes (en la Figura 5.17 se incluye una composición mínima con un sketget de cada biblioteca). La utilización de imágenes de los componentes sobre los bloques tiene como objetivo proveer un mínimo andamiaje para facilitar la comprensión de la composición aunque no se haya construido físicamente aún, o para poder soportar una revisión de composición indistintamente entre el cuaderno y el modelo físico. La vinculación entre elementos se realiza arrastrando el conector de salida de un elemento sobre el conector de entrada del elemento de destino. En cada componente además es necesario indicar que está activo y a qué puerto está conectado (para los que van vinculados a Arduino). La Figura 5.17 incluye un modelo básico compuesto por un elemento de Acción (Pote) y uno de Percepción (MotorDC) vinculados por una Interacción Uniforme.

La composición está activa desde el mismo momento que se agrega un sketget, el acoplamiento sensorio motor entre la representación digital y el modelo de boceto hardware-software es in- 
mediato. El objetivo es que el diseñador utilice bocetos que son en sí mismos representaciones enactivas para la ideación de interacciones enactivas.

Por otra parte, embebemos en la toolkit la idea de huellas creativas en la persistencia de cada momento en que el diseñador incorpora o modifica un elemento a la composición. Con cada acción de diseño está dejando una huella en su proceso creativo. Por esta razón Pluma recuerda este momento y facilita luego la trazabilidad de la indagación.

\section{Importación en Cuaderno}

Para promover el uso de múltiples externalizaciones como huellas creativas en un mismo ciclo de ideación Pluma permite agregar al Cuaderno en cualquier momento un boceto en papel, una maqueta o un registro en video de un boceto de experiencia de uso. La opción de Importar facilita la posibilidad de agregar una imagen (escaneo o foto) o un archivo de video. En todos los casos, Pluma registra automáticamente el timestamp del agregado y solicita comentarios textuales. El boceto externo queda integrado en la hoja de bocetos actual.

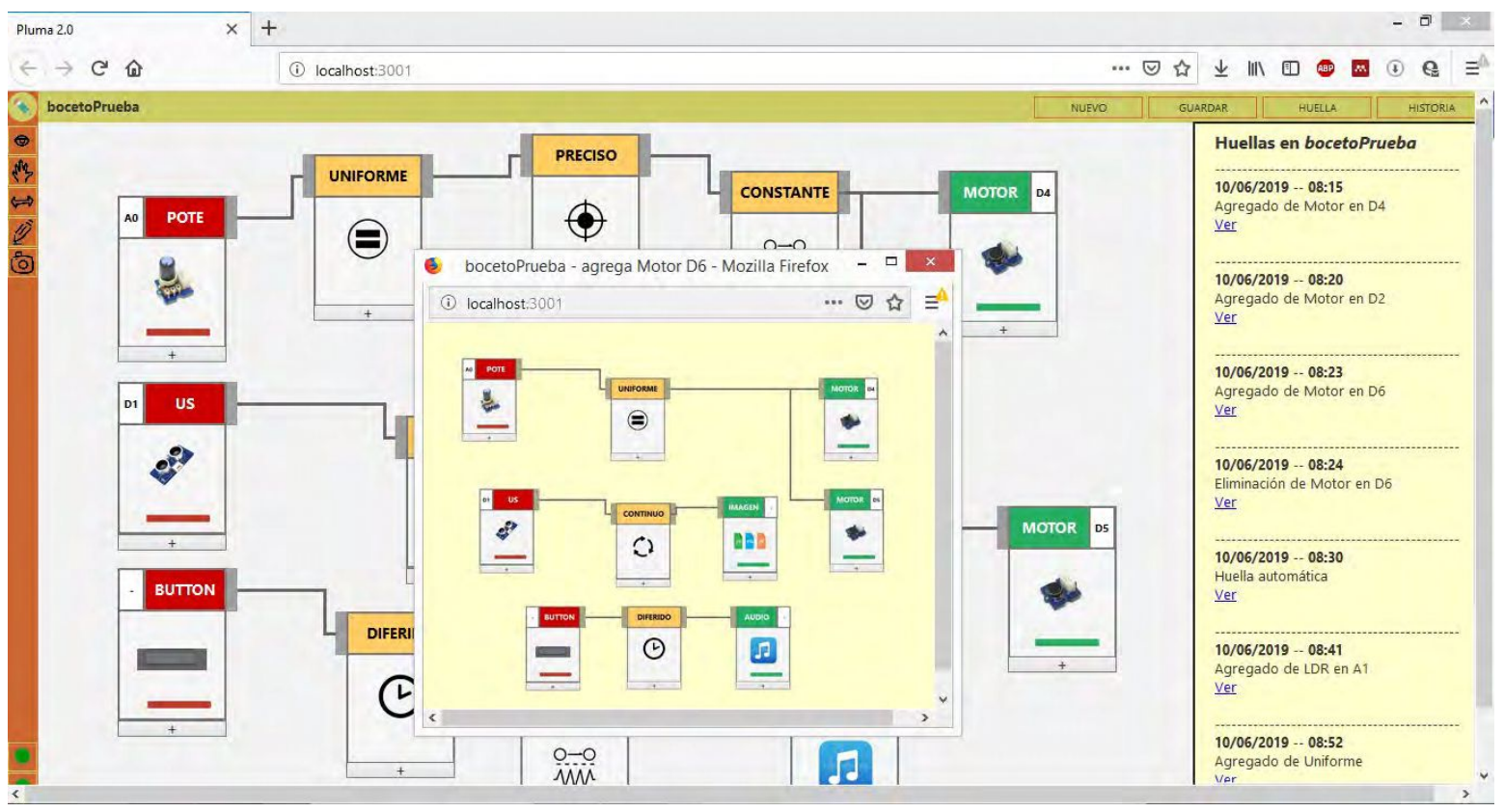

Fig. 5.18.: En el Cuaderno es posible consultar la historia de actividades del bocetado como registro de las huellas creativas. A la derecha de la pantalla se accede a la línea temporal de trabajo y con un clic en el link correspondiente se abre una nueva ventana que muestra el estado del boceto tras la acción seleccionada. El diseñador puede acumular en pantalla tantas vistas como desee para re-visitar la historia y eventualmente iniciar nuevas líneas de indagación

El timestamp permitirá luego reconstruir la historia del proceso de bocetado cuando el diseñador lo considere necesario y eventualmente abrir una nueva rama en el proceso de ideación. Los comentarios y vinculaciones visibles son parte del andamiaje cognitivo que Pluma ofrece al diseñador sobre el curso del bocetado como otras huellas expresivas en ese camino (ver Figura 5.18). 


\section{Escenario de uso}

Para explicar esta idea de cuaderno enactivo en funcionamiento utilizamos un escenario simple de exploración de una idea de interacción. El ejemplo es deliberadamente trivial, una especie de Hola mundo de Pluma 2.0. Aún así, tiene similitudes con sistemas más completos descriptos entre los trabajos relacionados (Capítulo 3) y con el tipo de exploraciones observadas en la práctica de diseñadores profesionales (Capítulo 4).

Se trata de una versión simplificada de la Linterna Enactiva propuesta por Froese[73] y que ya mencionamos en el Capítulo 4 (ver la Figura 4.2 en página 83). El escenario de diseño podría quedar definido de la siguiente manera:

El diseñador Agustín tiene que crear una idea de interacción para un dispositivo que permita a una persona con capacidades visuales limitadas recibir información sobre su entorno, en particular sobre las distancias a los obstáculos que pueden impedirle el paso. Se desea que la información de alguna manera sea entregada al usuario mediante un efecto vibrotáctil.

A continuación utilizamos un posible desarrollo del proceso de bocetado para ilustrar el uso de Pluma 2.0.

Agustín comienza con unos bocetos en papel, esbozando la idea de utilizar un dispositivo manual tipo linterna que la persona pueda apuntar hacia la zona de posibles obstáculos y recibir la información sobre la distancia directamente en su mano. Luego abre Pluma y agrega una imagen escaneada del boceto al cuaderno, con la opción de Importar imagen (Ver Figura 5.19). Además de registrar el nombre con el que Agustín decide identificar esta imagen, Pluma le permite agregar comentarios y automáticamente inserta el timestamp. La imagen escaneada se muestra en tamaño reducido en la hoja del cuaderno.

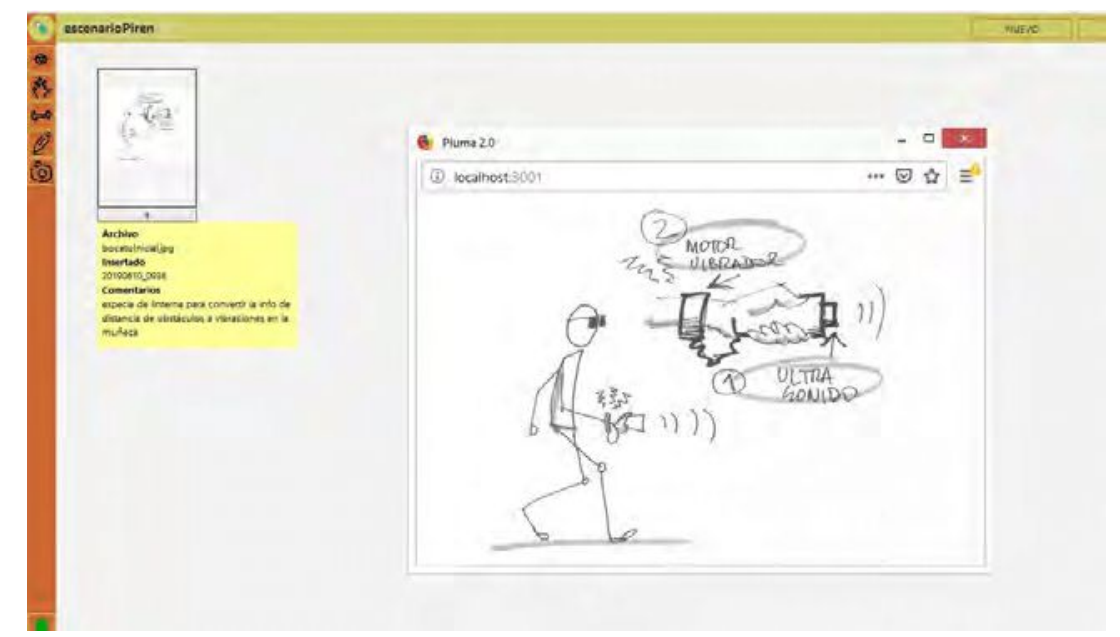

Fig. 5.19.: Escenario de uso: Agustín boceta sus ideas en papel y las incluye en Pluma. El boceto se agrega como imagen reducida con datos de huella y comentarios en el Cuaderno. Además puede visualizarse completo en ventana nueva 
Agustín decide elaborar un boceto interactivo y agrega como elemento de acción un Sensor de Distancia por Ultrasonido. Desde la biblioteca de componentes de Actuar, lo selecciona y arrastra a la hoja del cuaderno. Para la percepción, había imaginado un motor vibrador por lo que de la biblioteca correspondiente elige MotorDC. Para conseguir la interactabilidad que busca se imagina que va a mapear la distancia percibida por el sensor directamente a la intensidad de la vibración del motor. Entonces agrega un componente Uniforme (de la biblioteca Interactuar) y vincula su entrada con la salida del sensor y su salida con la entrada del Motor DC.

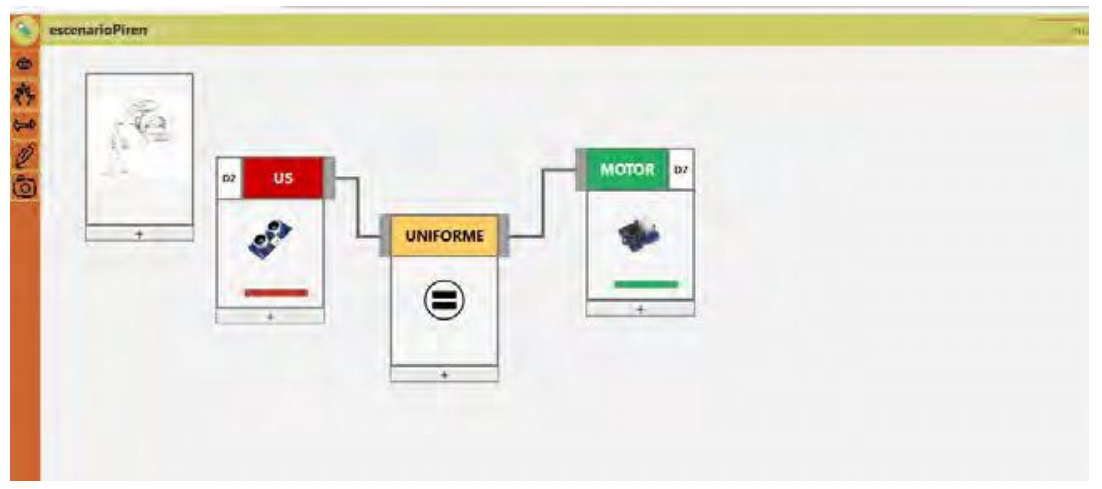

Fig. 5.20.: Escenario de uso: Agustín agrega tres sketgets a su boceto: un Sensor US (para actuar), un Motor (para percibir) y una Interacción Uniforme

Acto seguido, decide construir en hardware el boceto de Pluma. Con la placa Arduino con la shield Grove conectada al puerto USB, vincula un sensor US al puerto D2 y un motorDC al puerto D7. Pluma reconoce automáticamente que existen componentes conectados y refleja las acciones en los sketgets correspondientes. Agustín experimenta acercando y alejando su mano del sensor y verifica que el motor tiene cambios en la intensidad de su vibración.

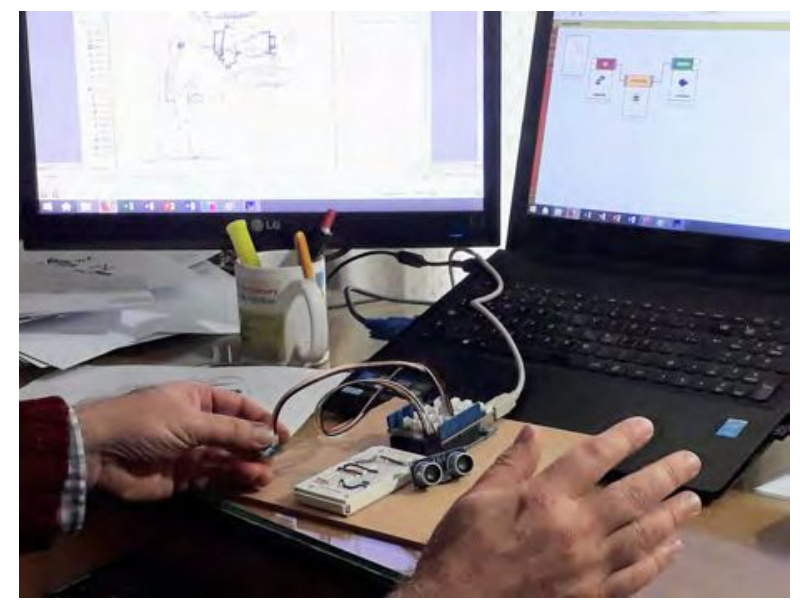

Fig. 5.21.: Escenario de uso: Agustín construye su boceto en hardware e interactúa con él provechando los proxies en Pluma

Entonces decide armar una maqueta para actuar la interacción. Toma una caja y le adhiere al frente el sensor US. Toma una cinta y la vincula por un extremo a la caja y por otro arma una especie de pulsera sobre la que adhiere el motorDC. Ahora prueba tomando la caja como 
una linterna y desplazándose la distancia que le permite el cable USB apuntando a obstáculos. Decide tomar un par de fotos de la maqueta y registrar con su smartphone un video de la actuación. Vuelve al entorno de Pluma y agrega las fotos de la maqueta y el video. En todos los casos, Pluma le pide comentarios y le agrega automáticamente el timestamp.

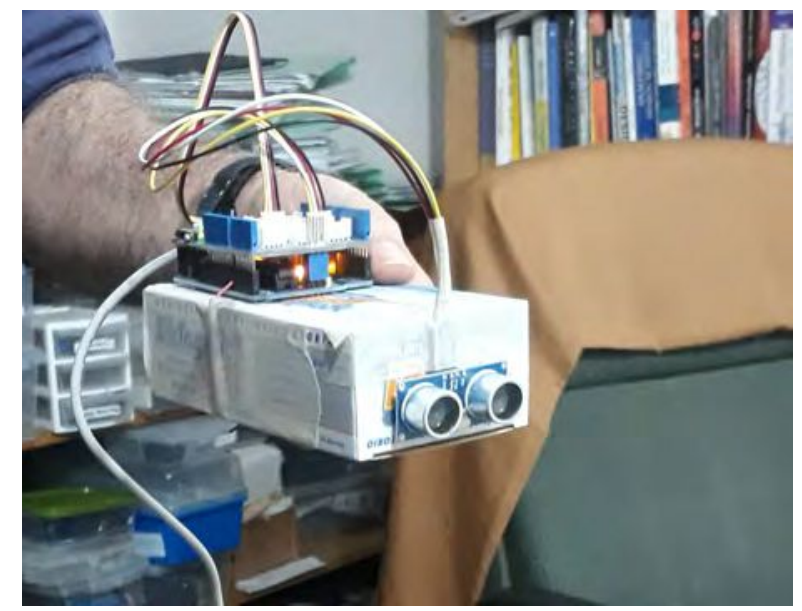

Fig. 5.22.: Escenario de uso: Agustín explora otras dimensiones del boceto (formas, tamaños) con una primera maqueta interactiva que puede integrar en Pluma con fotos o videos de uso

El ciclo puede repetirse y refinarse tantas veces como desee. El registro de huellas y la posibilidad de re-visitarlas facilita la iteración y avance incremental.

\subsubsection{Implementación}

La sección anterior describió Pluma 2.0 desde el punto de vista del diseñador de interacciones: cómo facilita la configuración de interactabilidad corporizada y enactiva y la exploración rápida de ideas. En esta sección vamos a presentar los detalles desde el punto de vista del desarrollador del kit de herramientas, alguien que desea comprender y tal vez extenderlo.

Modelo de objetos El modelo básico de Pluma 2.0 es la composición de una arquitectura que mediante Proxies puede entablar un diálogo con el mundo físico de los bocetos con hardware, maquetas, enacciones, dibujos en papel, etc. tal como se presenta en la Figura 5.23

En el universo de Pluma 2.0, el mundo es un cuaderno en el que se realizan bocetos. Un boceto es una agregación de Componentes, cada uno de los cuales es un Proxy del elemento correspondiente en el modelo construido con hardware en Arduino y Grove, con otros componentes de hardware vía USB, con bocetos dibujados en papel, fotos de pizarras, maquetas o enacciones de bocetos de UX registradas en audio y video. Cada elemento de interacción a su vez es un Mediador entre un elemento de Acción y uno de Percepción. Este Mediador a su vez puede estar Decorado por otros mediadores, de manera que una interactabilidad se completa con un conjunto de Mediadores que construyen sobre la interacción básica (Figura 5.24).

Cada sketget en el Boceto conserva dos atributos básicos para posibilitar la existencia de huellas expresivas. Por un lado mantiene el momento de su agregación al boceto. De manera 


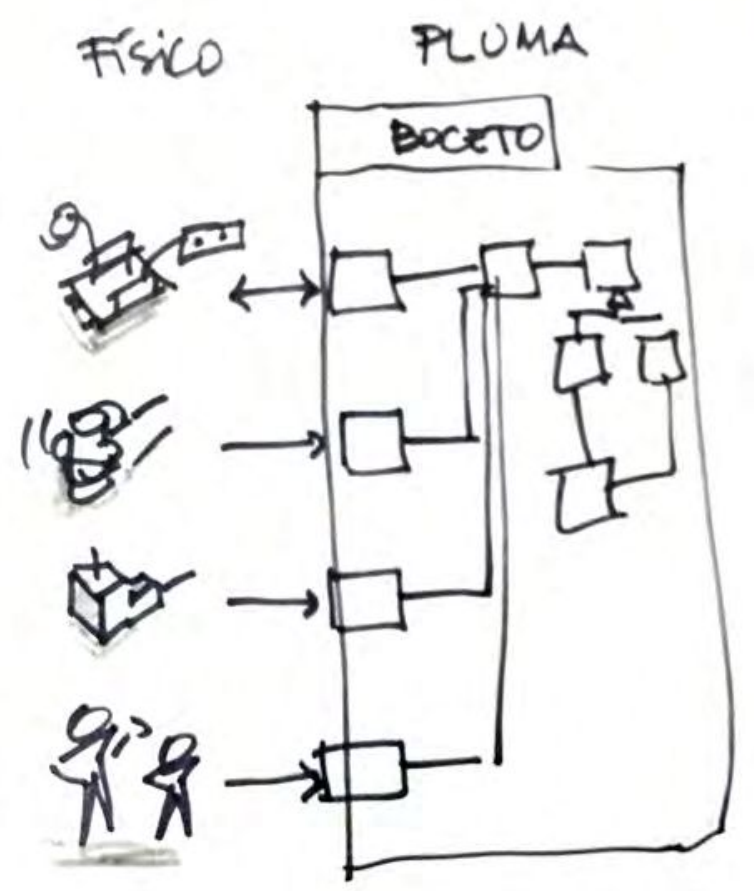

Fig. 5.23.: Modelo general de Pluma

que se pueda reconstruir qué otros objetos estaban presentes en el boceto cuando ese fue agregado. Por otra parte, un boceto tiene el registro de qué elementos están activos o han sido eliminados, para reconstruir el recorrido completo de una parte de esa historia y poder analizar el proceso.

Los proxies pueden actuar para establecer la relación tanto con el modelo de hardware como otros bocetos importados: bocetos dibujados e importados vía scanner, maquetas importadas como fotografías, videos de bocetos de experiencia de uso.

El modelo también incluye una huella entre el boceto y sus componentes y entre diferentes tipos de componente. En todos los casos el modelo genera automáticamente una huella implementada como una foto congelada del estado del boceto al momento. El diseñador puede generar de manera intencional una traza en cualquier momento, agregando algún tipo de comentario o descripción, que será asociada a ese momento. También se incluyen notas mentales que se asociarán aun componente concreto.

La Figura 5.25 presenta un diagrama de clases UML con el modelo descripto.

Implementación tecnológica La versión actual de la toolkit está implementada como aplicación web basada en los frameworks Node.js ${ }^{11}$ y Backbone-Marionette, para administrar el modelo de vistas en el cliente. El servidor web está construido sobre el framework Express y utiliza una combinación de HTML5, JavaScript y CSS para generar la interfaz de usuario y la plataforma Johnny-five para manejar los dispositivos basados en Arduino. Se utilizan

\footnotetext{
${ }^{11}$ Disponible online https://nodejs.org/es/ Accedido el 20/03/2019
} 


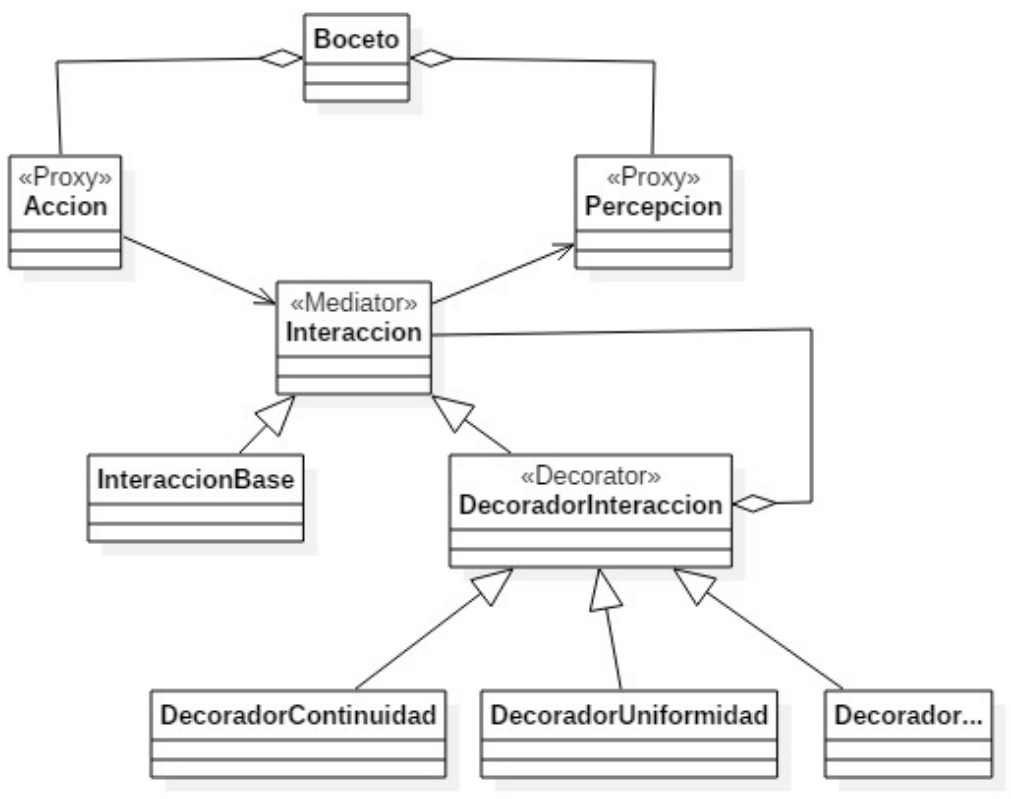

Fig. 5.24.: Relaciones entre los elementos de Accion y Percepción (proxies de los componentes de hardware) y los de Interacción (mediadores y decoradores)

sockets para la comunicación entre los dispositivos físicos de hardware conectados y el servidor. La arquitectura orientada a eventos y organizada como composición de parches está basada en el paquete NTK desarrollado en el Art Center College of Design en Pasadena[3]. Parte del código de Pluma 2.0 ha sido adaptado de la versión 1.1.9 de NTK (disponible en https://github.com/netlabtoolkit/ntk).

La implementación actual soporta la composición de bocetos sobre micro controladores basados en Arduino y la shield de Grove V2. La plataforma utiliza el protocolo Firmata para permitir comunicación I2C (inter integrated circuit).

La decisión de utilizar el sistema Grove ${ }^{12}$ como plataforma de conexión de componentes está basada en el objetivo de alcanzar la meta de bajar el umbral de acceso y evitar problemas con la construcción de circuitos de conexión de componentes[26]. Grove es un sistema modular basado en bloques para construir modelos con hardware que provee conectores estandarizados lo que facilita el armado y experimentación en el bocetado con hardware. El sistema Grove consta de una unidad base (shield, en la terminología de Arduino) y varios módulos con conectores estandarizados. Aunque el sistema Grove provee un cable adaptador de su conector estandarizado a los pines de Arduino, Pluma utiliza la shield base con los conectores estandarizados. La Figura 5.26 muestra el conjunto de conexiones posibles en una shield Grove estándar. La Figura 5.27 permite advertir la facilidad de incorporar componentes a un boceto con hardware utilizando Grove. Para controlar la intensidad lumínica de un Led mediante un Potenciómetro, en términos de hardware sólo hay que conectar directamente cada elemento en el puerto correspondiente (para lo cual la forma del conector es además una ayuda restrictiva

\footnotetext{
${ }^{12}$ http://wiki.seeedstudio.com/Grove_System/
} 


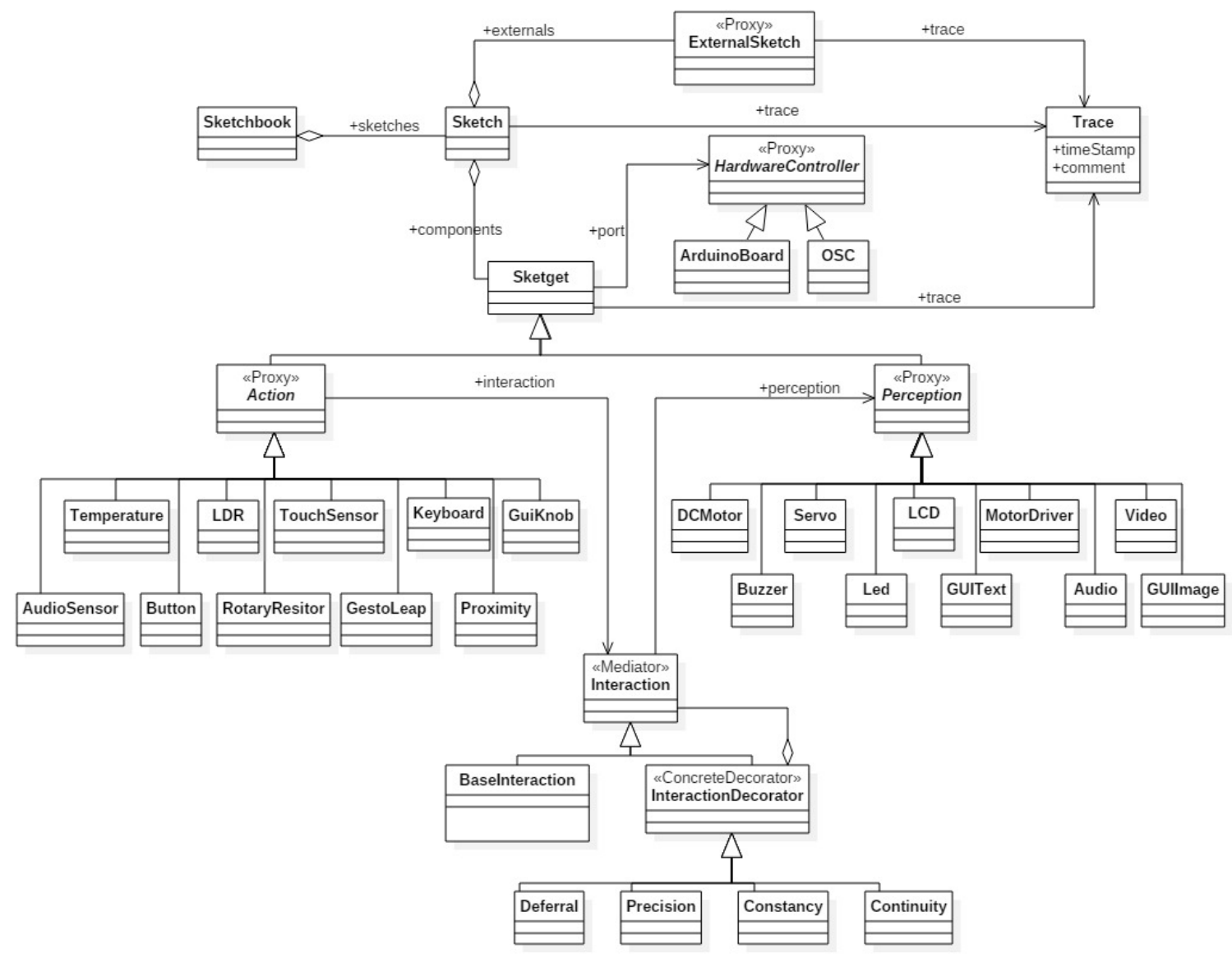

Fig. 5.25.: Diseño conceptual del cuaderno

importante, ver Figura 5.27a). Esto elimina la necesidad de construir circuitos específicos aunque sean mínimos, como se muestra en la Figura 5.27b, que ya fue reportado como uno de los problemas a la hora de bocetar en hardware[26].

El sistema permite extensiones como una shield para la placa Arduino Mega o extensores vía I2C. La versión actual de Pluma soporta la conexión de Arduino Uno más una shield Grove estándar, lo que cubre las necesidades de bocetado para todos los casos analizados en los estudios de la práctica. Sin embargo, la extensión a Arduino Mega o el uso de extensores I2C es posible y no representa grandes dificultades con la arquitectura actual (está incluido en los trabajos futuros de extensión de Pluma).

Los componentes para la actuación o sensado del usuario que se incluyen en esta versión de Pluma están listados en las Tablas 5.1,5.2 y 5.3. Se han incluido algunos módulos básicos de Grove, la capacidad de reconocimiento de gestos manuales de LeapMotion y elementos de interacción con una PC (teclado, audio y pantalla).

La utilización de gestos reconocibles mediante LeapMotion (un legacy de la versión 1.0 de Pluma) se implementa en esta versión con dos submódulos que incluyen un conjunto (extensible) de gestos predefinidos y un detector y grabador de gestos personalizados. La 


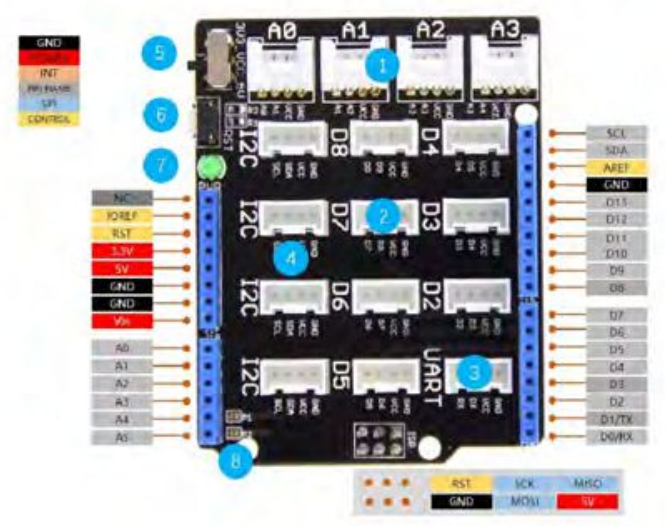

Fig. 5.26.: Shield Grove para Arduino Uno R3. 1.Cuatro puertos analógicos. 2.Siete puertos digitales. 3. Un puerto UART. 4. Cuatro puertos I2C. 5. Switch alimentación (3-5v). 6. Botón reset. 7. LED de Power on. 8. Pines para soldar si se usa con Seeduino V3, placa de SeeedStudio compatible con Arduino

conexión con LeapMotion utiliza la versión JavaScript de la biblioteca original del SDK. Pluma incorpora dos gestos precargados como opciones: Push-Pull (mover adelante y atrás con toda la mano) y Swipe (desplazar la mano lateralmente). Pluma incluye además un detector y grabador de gestos vía el plugin de Leapmotion ${ }^{13}$ que permite grabar, recortar y ejecutar un gesto generando los snippets de Javascript que Pluma utiliza para reconocerlos en la composición de un boceto.

\section{Posibilidades de extensión}

En esta versión de Pluma sólo se ha incorporado como mecanismo de extensión de la biblioteca de sketgets en Pluma el entrenador de gestos de LeapMotion. Sin embargo, también es posible agregar nuevos sketgets mediante la modificación de código Javascript subclasificando la clase Sketget y recompilando la plataforma, que reconocerá de manera automática el nuevo elemento y lo incluirá en las bibliotecas correspondientes.

\subsubsection{Evaluación}

La evaluación de una toolkit de soporte al diseño que refleje de manera adecuada la complejidad de la investigación que ha llevado a ella puede ser difícil ya que la utilización de métricas sencillas podrían sugerir un progreso simplista, no necesariamente significativo en términos de la propia lógica de la disciplina que se intenta soportar[182]. La famosa Madre de todas las demos de Douglas Engelbart ${ }^{14}$ estableció en qué medida la demostración de una nueva tecnología puede ser una forma simple y poderosa de comunicar, clarificar y ejemplificar nuevas ideas y conceptos. Recientemente, Ledo et al revisaron más de 60 artículos sobre toolkits significativos presentados en investigación en HCI y encontraron que la demostración sigue

\footnotetext{
${ }^{13}$ https://github.com/leapmotion/leapjs-playback/

${ }^{14}$ http://dougengelbart.org/content/view/209/448/
} 


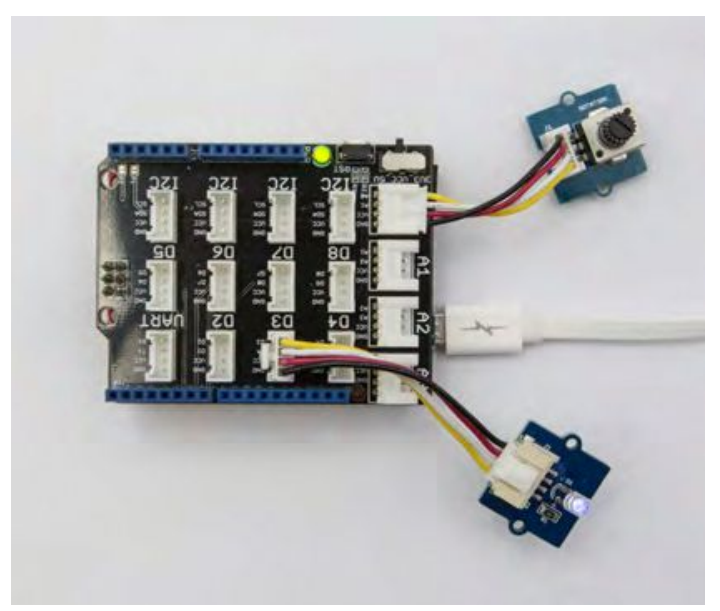

(a) Con Grove

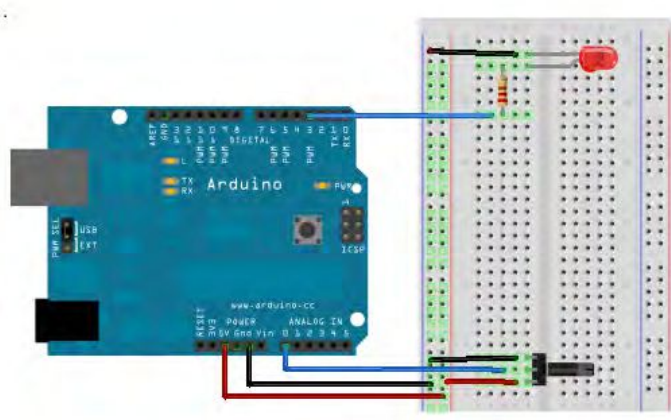

(b) Sin Grove

Fig. 5.27.: Comparación de las diferencias entre conectar un potenciómetro y un Led utilizando el kit Grove o utilizando una conexión directa entre protoboard y Arduino

siendo el método de evaluación más utilizado (66 casos sobre 68 analizados la utilizaron, 19 de ellos como único método)[144].

A continuación presento la evaluación de Pluma 2.0 como una demostración que explora el espacio de diseño accesible. Antes, una breve justificación sobre el uso de este método para evaluar toolkits en HCI.

\section{Acerca de las demostraciones}

Una demostración muestra lo que una toolkit puede soportar y cómo los usuarios pueden trabajar con ella. Una demostración es una prueba de existencia que muestra la factibilidad de usar y combinar sus componentes en ejemplos que exhiben los propósitos de la toolkit y los principios de diseño embebidos en ella. Las toolkits pueden considerarse un lenguaje para simplificar la creación de nuevos sistemas interactivos[88] y por lo tanto las demostraciones describen y muestran cómo facilitan los caminos de menor resistencia para la autoría.

En su forma más básica una demostración consiste de ejemplos que muestran su expresividad, exhibiendo el umbral de acceso, el techo de posibilidades o el espacio de diseño. La demostración que se describe más abajo se basa en esta última forma para incluir una exploración inicial de las posibilidades de diseño con ejemplos desde diferentes puntos en ese espacio[247]. Una exploración del espacio de diseño ejemplifica la amplitud de las aplicaciones admitidas por el kit de herramientas al encajarlo en un tema de investigación más amplio. Los espacios de diseño a menudo consisten en dimensiones con propiedades (variables categóricas o de espectro) a las que se pueden alinear los ejemplos. Un autor del kit de herramientas puede crear una colección de ejemplos que examinen diferentes puntos en el espacio de diseño. Por ejemplo, WatchConnect[106] describe un espacio de diseño de cómo el kit de herramientas 


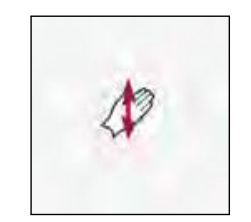

Gesto PushPull

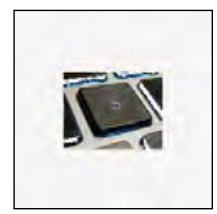

Keyboard

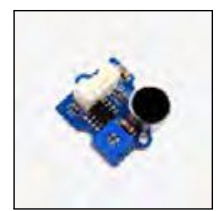

Audio sensor

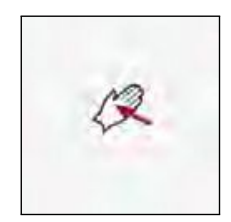

Gesto Swipe

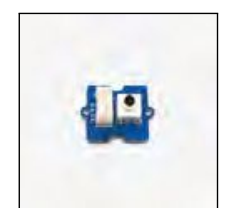

Physical Button

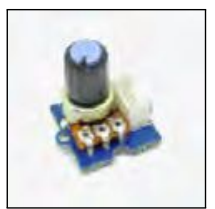

Rotary resitor

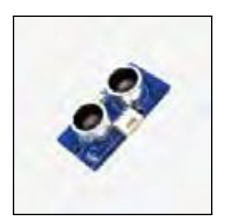

Proximity

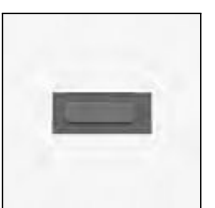

GUI Button

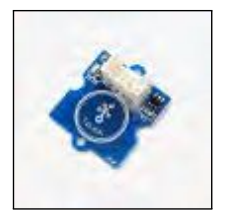

Touch sensor

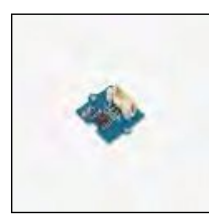

Temperature

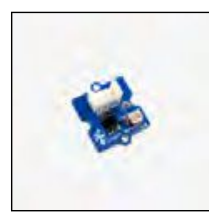

LDR

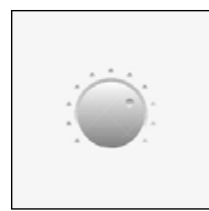

GUI Knob

Tab. 5.1.: Elementos de Acción para componer bocetos en Pluma 2.0

admite la interacción a través de un prototipo de reloj y una segunda pantalla. Una exploración del espacio de diseño es, por lo tanto, una forma sistemática de tratar de trazar posibles límites de diseño. Aunque a menudo es imposible explorar el espacio de diseño completo, los ejemplos demuestran la amplitud de los diseños habilitados por el kit de herramientas.

En el caso de Pluma, realizamos la exploración con una pequeña colección de tres ejemplos que replican casos presentados en la literatura. La recreación de aplicaciones, sistemas o técnicas de interacción anteriores sirve para mostrar cómo el kit de herramientas admite y encapsula ideas anteriores en un espacio de solución más amplio. Se intenta demostrar cómo las toolkits reducen la complejidad, el esfuerzo y el tiempo de desarrollo para recrear aplicaciones.

Si bien las demostraciones a menudo no se consideran una evaluación formal, muestran evidencia a través de la "investigación por diseño"[97] y son altamente efectivas para comunicar los principios, conceptos e ideas subyacentes del conjunto de herramientas. De hecho, el uso del kit de herramientas para crear bocetos puede llevar a refinamientos en el propio kit. Cuando se vinculan a los cinco objetivos de la investigación en toolkits (ver página 125), las demostraciones proporcionan la evidencia más completa y convincente para lograr los objetivos de diseño del nuevo conjunto de herramientas. La amplia adopción de la evaluación por demostración indica que los ejemplos pueden ser una medida de éxito para los conceptos e ideas subyacentes en la implementación de una toolkit específica[144]. 


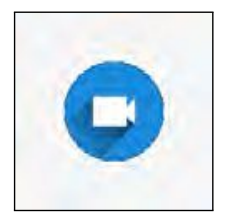

Video

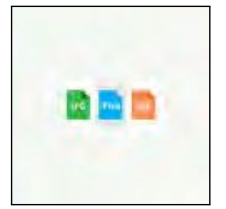

Image

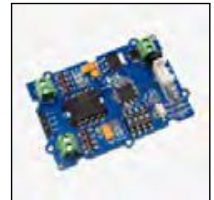

Motor Driver

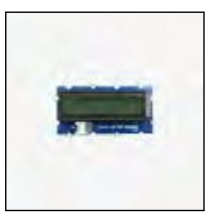

LCD

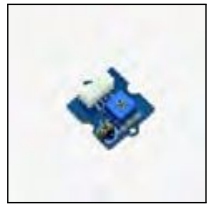

LED

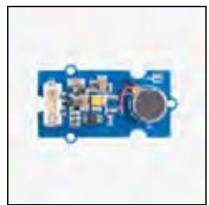

Motor DC

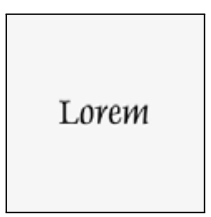

Text

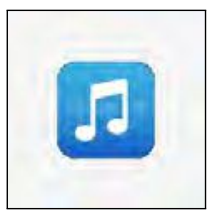

Audio

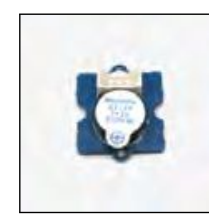

Buzzer

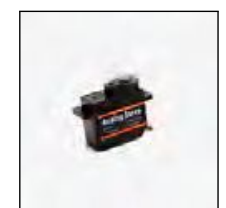

Servo

Tab. 5.2.: Elementos de Percepción para componer bocetos en Pluma 2.0

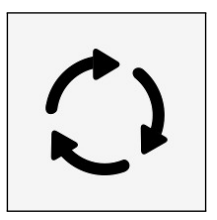

Continuidad

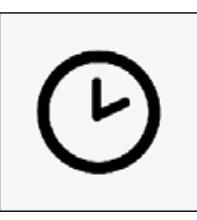

Diferimiento

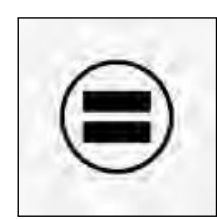

Uniformidad

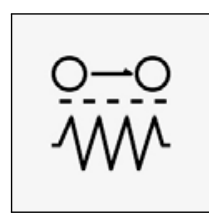

Constancia

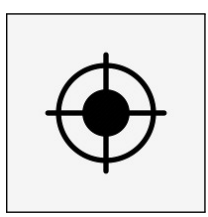

Precisión

Tab. 5.3.: Elementos de Interacción para componer bocetos en Pluma 2.0

\section{Demo de Pluma 2.0}

Presentamos ahora una demostración de Pluma 2.0 orientada a la exploración del espacio de diseño que permite acceder. En el bocetado de interacciones enactivas este espacio puede organizarse de acuerdo con las dimensiones incluidas en el framework de la sección anterior. La característica esencial a indagar en nuestro contexto es la interactabilidad de los sistemas o dispositivos, la cual se consigue trabajando sobre los campos de acción y operación (lo que el usuario puede hacer y aquello que el sistema es capaz de detectar). Por otra parte, el uso de múltiples formatos de externalización dejadas como huellas creativas a lo largo del proceso de indagación una de las características de la práctica de los diseñadores.

En consecuencia, disponemos de dos dimensiones para estructurar el espacio:

La definición de la interactabilidad Esta definición se genera en el cruce de Percepciones y Acciones por parte del usuario. En Pluma, este espacio se define por las siguientes variantes:

- Percepciones 
- Percibir actuaciones controladas por Arduino

- Percibir actuaciones desde la PC

- Actuaciones

- Actuar sobre elementos controlados por Arduino

- Actuar sobre los periféricos habituales de PC

- Actuar sobre el LeapMotion

La corporización de la interactabilidad En Pluma utilizamos lo definimos en el cruce de las dimensiones utilizadas para externalizar y la amplitud-profundidad considerada:

- Dimensiones de externalización

- Bocetado en 2 dimensiones

- Bocetado en 3 dimensiones

- Bocetado en 4 dimensiones

- Amplitud y profundidad de externalización

- Amplia y superficial

- Estrecha y profunda

Como estrategia para explorar este espacio, elegimos replicar tres ejemplos de la literatura sobre interacciones corporizadas y con acoplamiento sensorio motor. La Tabla 5.4 contiene un detalle de las dimensiones del espacio de diseño que cada uno de ellos permite explorar. Introduzco más abajo cada uno de los ejemplos y los artículos de los cuales fueron tomados.

\begin{tabular}{|c|c|c|c|c|c|c|c|c|c|c|}
\hline & \multicolumn{2}{|c|}{ Percibir } & \multicolumn{3}{|c|}{ Actuar } & \multicolumn{3}{|c|}{ Corporización } & \multicolumn{2}{|c|}{ Amp-Prof } \\
\hline & ARD & PC & ARD & PC & LM & $2 \mathrm{D}$ & 3D & 4D & AS & EP \\
\hline AudioPlayer & & $\mathrm{X}$ & $\mathrm{X}$ & & & $\mathrm{X}$ & $\mathrm{X}$ & & $\mathrm{X}$ & \\
\hline Feel Messenger & $\mathrm{X}$ & & & $\mathrm{X}$ & & $\mathrm{X}$ & & $\mathrm{X}$ & & $\mathrm{X}$ \\
\hline Mid-air browsing & & $\mathrm{X}$ & & & $\mathrm{X}$ & & $\mathrm{X}$ & $\mathrm{X}$ & $\mathrm{X}$ & \\
\hline
\end{tabular}

Tab. 5.4.: Tres aplicaciones de ejemplo para demostrar el uso del espacio de diseño con Pluma. Referencias: ARD: Arduino. LM: LeapMotion. Amp-Prof: Amplitud y Profundidad. AS: Amplia y superficial. EP: Estrecha y profunda

Las implementaciones que se describen a continuación utilizan sólo los componentes estándar de Pluma y no incluyen código o herramientas externas especializadas. El propósito de estos ejemplos es demostrar el tipo de ideas para un proceso de creación de interacciones corporizadas y enactivas que puede ser formuladas utilizando sólo los componentes básicos de la toolkit en el marco de una práctica de ideación como la caracterizada en capítulos anteriores.

Ejemplo 1. Audio player Se trata del diseño de interacción para un dispositivo que reproduzca una lista de audios y que pueda ser controlado por gestos (tanto para el recorrido de la lista o para el control del volumen). Este ejemplo fue presentado por Bill Buxton en Sketching User Experiences [32] (pág. 257) como parte de un taller coordinado por Caroline Hummels. En el 
ejemplo original (ver la Figura 5.28, tomada del libro mencionado) Buxton utilizó hardware Phidgets ${ }^{15}$ y software desarrollado con MAX/MSP y Jitter ${ }^{16}$.

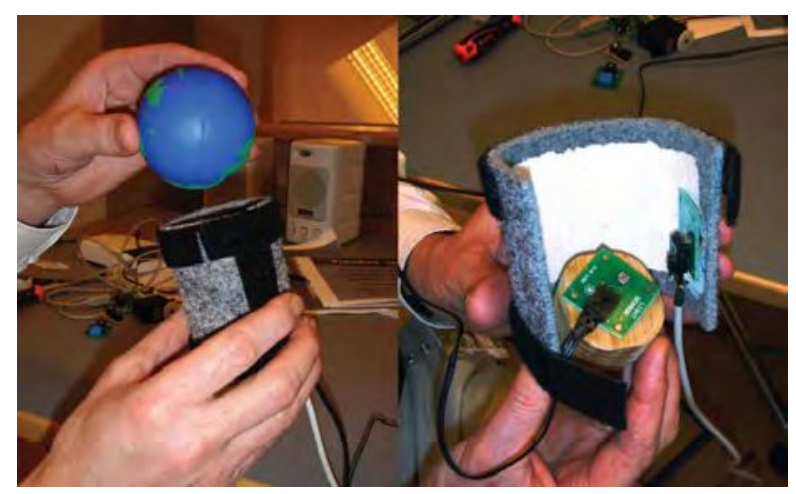

Fig. 5.28.: Boceto en hardware para un MP3 Player controlado por gestos (fotografía de Sketching User Experiences[32])

Con Pluma, un diseñador que desea comenzar con un boceto 2D puede integrarlo al Cuaderno y luego podría explorar mediante enacciones el uso de los gestos disponibles con LeapMotion (por ejemplo el gesto PushPull). Para ello genera una composición simple en el Cuaderno con tres sketgets: Gesto PushPull, Audio e Interacción Uniforme. Asocia la salida de la Interacción con el atributo Play/Stop del audio, de manera que la ejecución del gesto activa o detiene la reproducción. A este modelo es necesario agregar otro audio para explorar la idea de navegar una colección. Agrega un segundo sketget Audio y un gesto Swipe para ejecutarlo. Vincula el gesto con la misma Interacción. Ahora tiene dos gestos válidos, cada uno de ellos le permite enactuar las opciones requeridas.

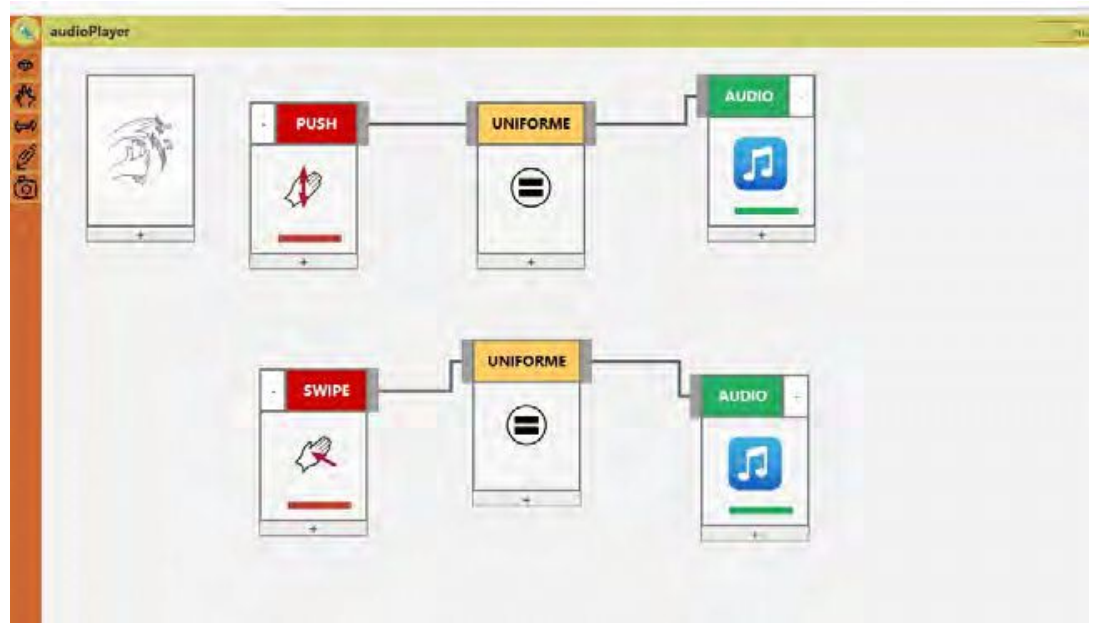

Fig. 5.29.: Demo Audio Player. Composición inicial en el Cuaderno con dos sketgets de gestos para activar dos audios. Incluye el boceto 2D inicial importado en el Cuaderno

Si desea explorar otras opciones, diferentes a la gesticulación aérea puede emplear, por ejemplo el esquema que empleó el grupo de Buxton. La actuación sobre la cantidad de luz que ingresa al dispositivo para regular el volumen y una reproducción automática con ese

\footnotetext{
${ }^{15}$ https : / /www phidgets . com/?tier=1\&catid=9\&pcid=7

${ }^{16}$ https://docs. cycling74. com/max7/
} 
gesto. Entonces quita del boceto Pluma el gesto PushPull y agrega un actuador de LDR. Con la interacción uniforme conecta tanto el atributo Play/Stop como el volumen y decide construir una maqueta 3D para explorar en conjunto con un boceto hardware. Puede completar la redefinición cambiando el gesto Swipe por un movimiento directamente de la maqueta para cambiar. Entonces cambia ese sketget por uno de actuación por Movimiento (acelerómetro) y reemplaza la conexión del gesto con la interacción Uniforme. Valida que se comporte como espera enactuando con su boceto hardware.

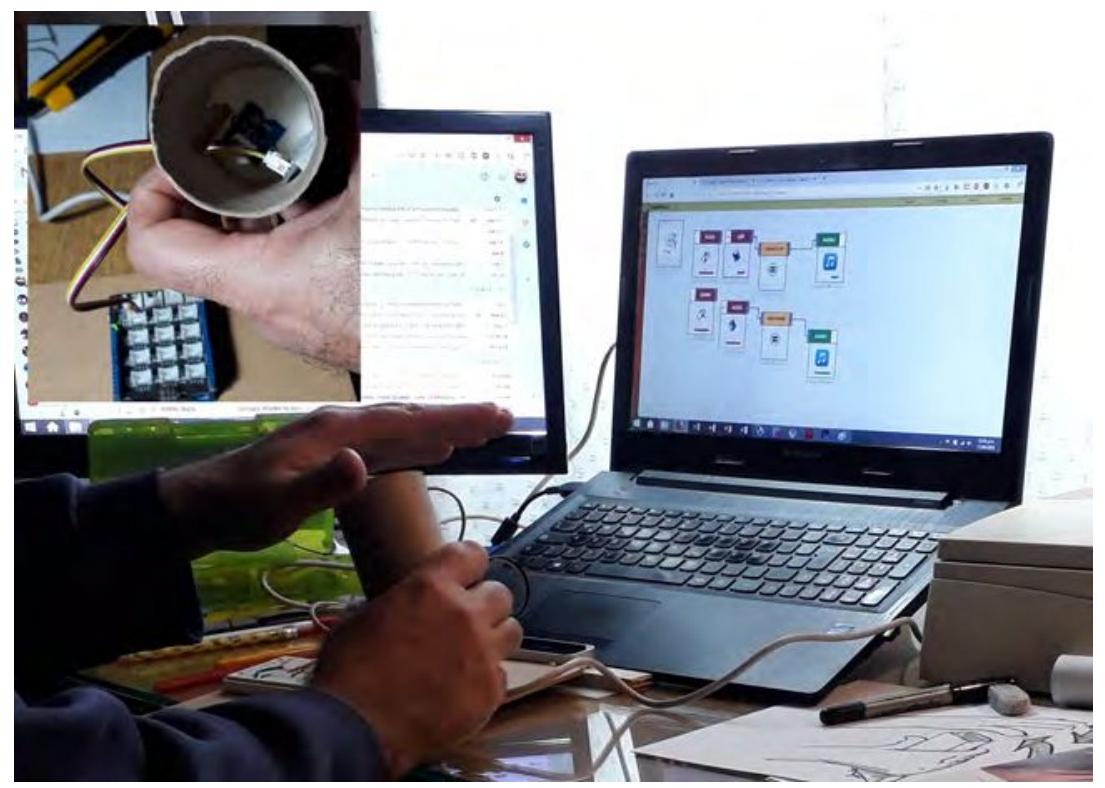

Fig. 5.30.: Demo Audio Player. Construcción y prueba de boceto con hardware. En el insert, el detalle del boceto con un sensor LDR y un acelerómetro incluido (para modificar la luz que ingresa simplemente se cubre parcial o totalmente la abertura con la mano). En la foto principal, el diseñador prueba su boceto hardware después de haber modificado la composición de sketgets en el Cuaderno de Pluma

Este relato, ilustrado por capturas de pantalla y fotos de los artefactos generados, muestra un proceso en el que un diseñador explora los espacios disponibles de Percepción con la PC y Acción con componentes controlados por Arduino con tanta facilidad como hacer drag and drop en pantalla. Puede integrar en su camino de indagación las huellas en formato de bocetos 2D y hardware, manteniendo una exploración de la interactabilidad que es al mismo tiempo amplia (todas las operaciones que se solicitan en el brief) y superficial (sin profundizar en refinar los valores de atributos por ejemplo).

Ejemplo 2. Feel Messenger El segundo ejemplo es el desarrollo de interacciones para un sistema de mensajería instantánea que permite a los usuarios compartir, expresar y comunicar patrones hápticos de manera estructurada. Está basado en el trabajo presentado por Ali Israr, Slyan Zhao y Oliver Schneider en Exploring embedded haptics for social networking and interactions [116]. En el artículo, los autores implementaron el sistema como una aplicación Android nativa para configurar los patrones de vibración y asociarlos con elementos de la interfaz de usuario que los disparan (la idea está planteada en la Figura 5.31, tomada del trabajo mencionado) 


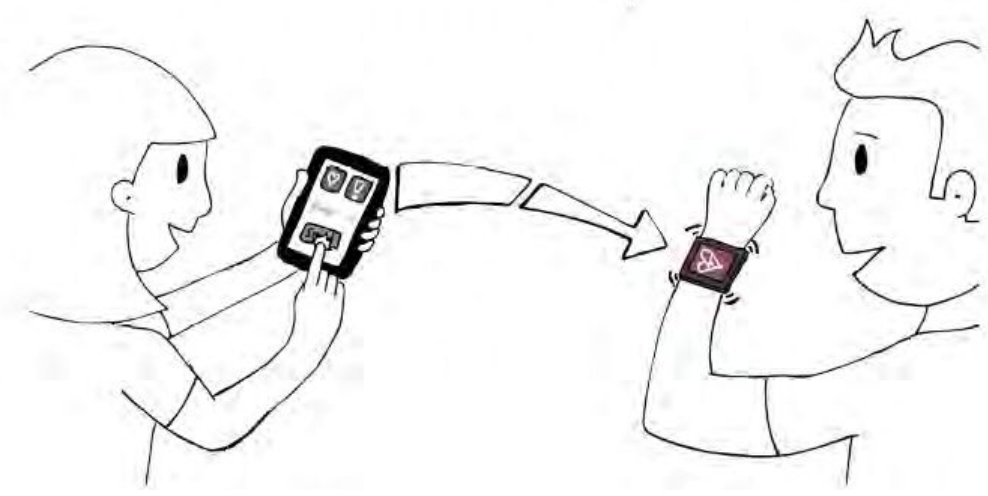

Fig. 5.31.: Storyboard del concepto de FeelMessenger, usuarios intercambiando mensajes hápticos expresivos con hardware embebido en dispositivos de consumo, tomado de [116]

Al igual que con Audio Player podemos introducir ese boceto en Pluma como el disparador inicial del proceso. El boceto enactivo puede estructurarse con una composición que combine la simulación de la pantalla del Smartphone en el monitor de la PC (agregando por ejemplo dos sketgets GUI Button) y un elemento de estimulación vibrotáctil (sketget Motor) conectado directamente sobre la muñeca del usuario.

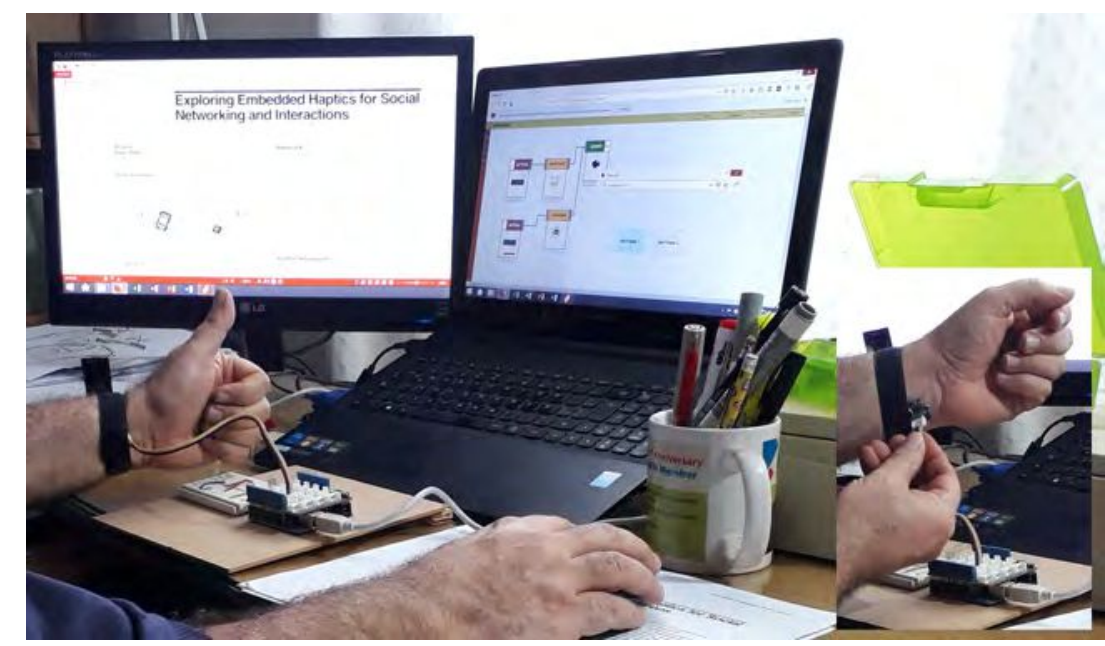

Fig. 5.32.: Demo Feel Messenger. Prueba de boceto enactivo. El boceto de la experiencia puede ser algo tan simple como combinar un par de botones GUI en una pantalla y un Motor DC colocado dentro de una muñequera (ver imagen interna)

El Cuaderno permite incorporar dos sketgets de GUIButton y dos elementos de Interacción para controlar diferentes patrones de estimulación. Las dos interacciones conectan sus salidas directamente al ingreso del sketget Motor. Una primera exploración simple, podría ser por ejemplo una interacción Constante, que genera un estímulo de frecuencia constante y breve, y una interacción Uniforme, en principio constante y sostenida. El diseñador puede enactuar las opciones con el boceto. Pluma le permite además especificar con más detalle para refinar la interactabilidad que desea. Entonces puede ajustar los parámetros de los sketgets de interacción tantas veces como desee hasta encontrar el efecto buscado. De esta manera estará explorando 
las posibilidades de definir en profundidad un sólo aspecto dela interactabilidad: los patrones hápticos a generar.

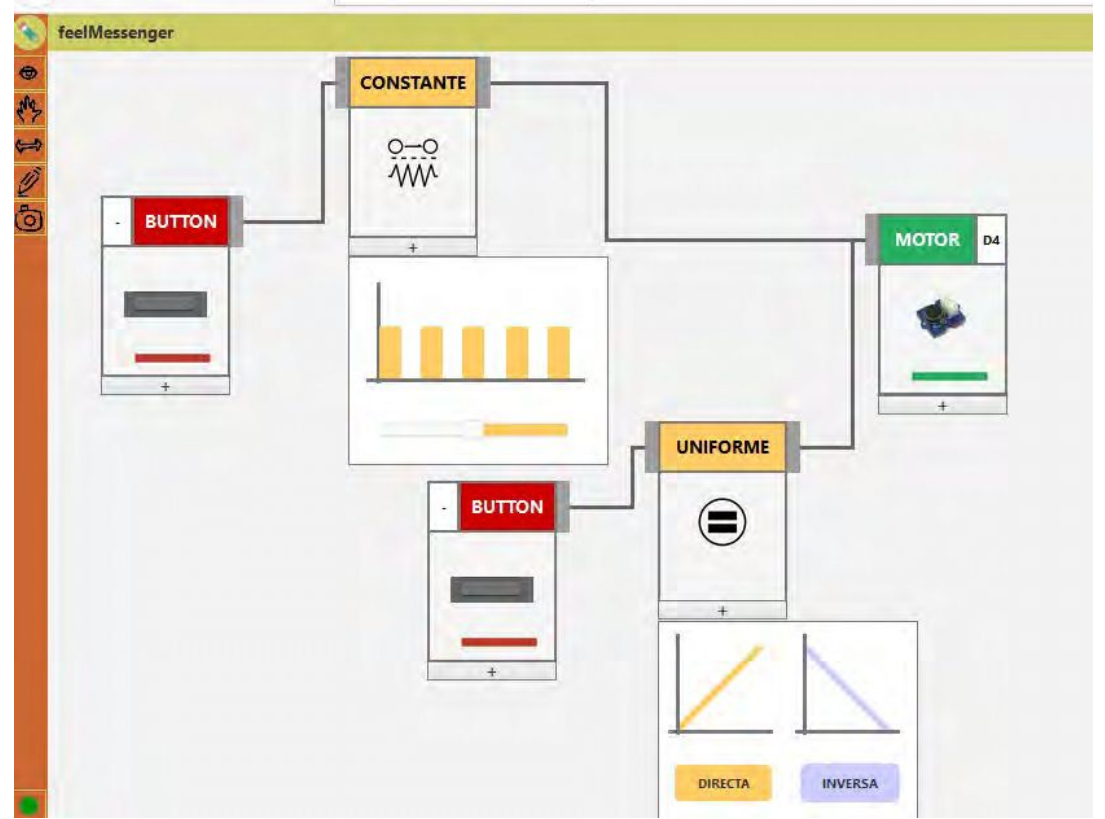

Fig. 5.33.: Demo Feel Messenter. Cada sketget de interacción permite al diseñador explorar una interactabilidad de manera más enfocada en algún parámetro. En el ejemplo, se está asignando un patrón semiconstante y otro con uniformidad directa

A diferencia del ejemplo del Audio Player, en este caso más que esbozar superficialmente toda la interactabilidad, aquí la exploración se focaliza en un refinamiento progresivo de la generación de patrones hápticos detallados (interactabilidad Estrecha y Profunda). Con sucesivas enacciones del mismo boceto de hardware que ha compuesto, mediante el control de su contraparte en el Cuaderno de Pluma, el diseñador puede avanzar de manera natural sobre el proceso de indagación: sólo tiene que cambiar los parámetros de los sketgets en pantalla para poder evaluar directamente sobre su boceto hardware si el efecto coincide con lo que imaginó.

Ejemplo 3. Mid-Air Browsing El tercer ejemplo está basado en el trabajo de Assam Boudjelthia y sus colegas de la Universidad de Oulu en Finandia: Enabling Mid-air Browser Interaction with Leap Motion[27] donde analizaron la utilización de una serie de gestos reconocibles con LeapMotion para navegar la web. Aquí extendemos su trabajo incorporando una dimensión más a la corporización de esa gestualidad con una retroalimentación sonora para confirmar el reconocimiento de la acción del usuario por parte del sistema.

La Figura 5.34 presenta los gestos explorados en el trabajo de Boudjelthia. Para este ejemplo vamos a utilizar solamente dos gestos. Uno de ellos ya está incluido en Pluma: el gesto Swipe que Boudjelthia utiliza para la navegación del historial. El otro, lo agregaremos con el entrenador de gestos: mover el índice en círculo para refrescar la página. Finalmente, utilizaremos los sketgets de Imagen para simular la presentación de una página web en pantalla. Cuando el sistema reconoce alguno de estos gestos, además de proveer la respuesta visual 
correspondiente, deberá generar un sonido breve con el objeto de reforzar la corporización multisensorial de la interacción para el usuario.
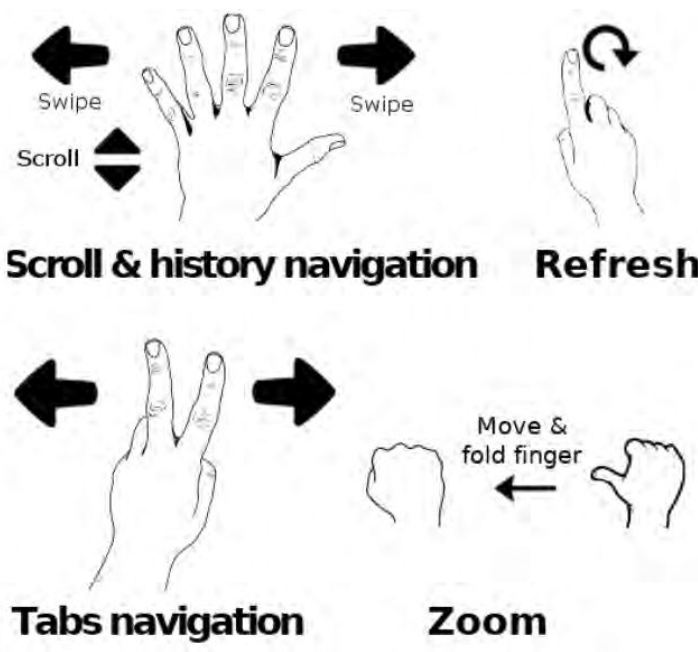

Fig. 5.34.: Gestos explorados en el ejemplo Mid-Air Browsing de Boudjelthia[27]

Para la introducción de un nuevo gesto, el diseñador activa el entrenador de gestos. Pluma solicita que se realice el gesto a grabar. Si puede grabarlo, solicita al diseñador que lo repita varias veces para confirmar que puede reconocerlo. Entonces el gesto puede incorporarse en la biblioteca asignándole un nombre. A partir de este momento ese gesto estará disponible para bocetos interactivos.

Con los dos gestos deseados ya disponibles, el diseñador puede incluir ambos sketgets en la hoja del Cuaderno. Agrega también dos sketgets de Imagen para simular dos páginas web entre las que se producirá la navegación y el audio que se utilizará como feedback sonoro. Finalmente agrega los sketgets de interacción y realiza las vinculaciones correspondientes.

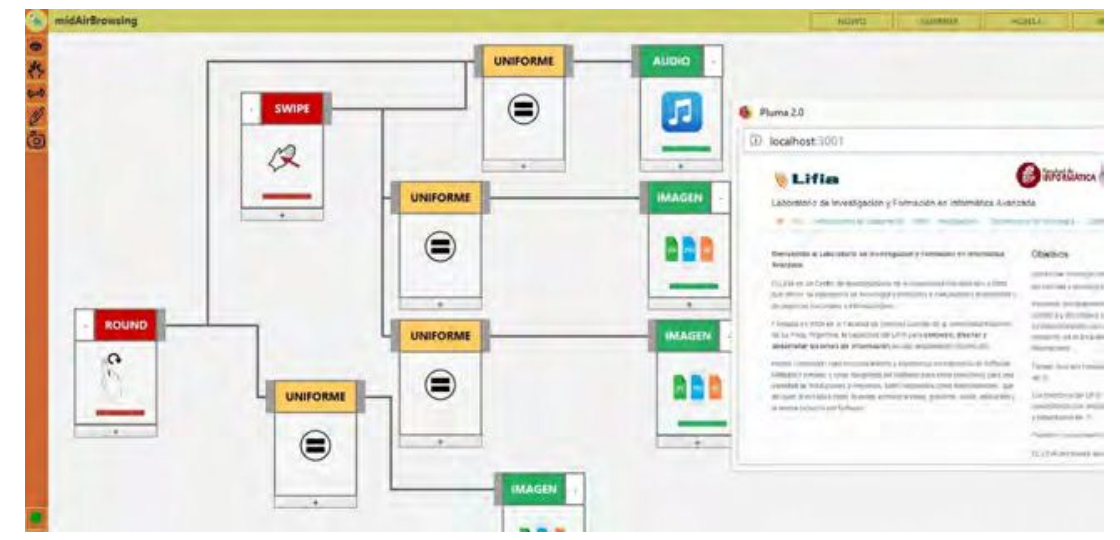

Fig. 5.35.: Demo Mid-Air Browsing. El sketget del nuevo gesto entrenado se incorpora como elemento de Acción en el boceto Pluma y se vincula tanto con la percepción de la imagen que simula el refresco como el audio que da feedback sonoro. La ventana que se muestra sobreimpresa simula la pantalla en la que se navegan las páginas con los gestos

Sólo queda testear la idea que se ha bocetado. Como el boceto está activo desde que se agrega cada uno de los sketgets, el diseñador sólo tiene que jugar con él para evaluar si la interactividad 
que se consigue es la que imaginó. También puede explorar el control de otros parámetros para el sonido (por ejemplo, volumen).

En este escenario, Pluma permite el bocetado de interacciones donde el cuerpo conecta percepciones y acciones sin tener que incluir una composición con hardware controlado por Arduino. Se mantiene una indagación superficial de la interactabilidad, facilitada por la posibilidad de extender parte de Pluma (en este caso la biblioteca de gestos) que libera al diseñador de tener que pensar sólo en los sketgets inicialmente disponibles.

\subsubsection{Discusión}

Con el ejemplo inicial de la Linterna Enactiva y los otros tres replicados de literatura mostramos de qué manera Pluma 2.0 contribuye al logro de algunos objetivos que nos planteamos para la toolkit al comienzo del capítulo (pág. 125).

Sobre todos hemos diseñado Pluma a partir de las prácticas que observamos en los diseñadores de interacciones corporizadas y enactivas: profesionales de la ideación que requieren herramientas flexibles para pensar, que les dejen seguir su propio curso de pensamiento, integrarse con las herramientas que están acostumbrados a utilizar y los ayuden a convertir cada movida de diseño en una huella creativa del proceso.

En particular, Pluma soporta la exploración de ideas y propuestas por parte del diseñador, permitiéndole trabajar con diferentes versiones de una misma idea, replicar su funcionamiento y re-visitar el camino de indagación que llevó a ellas tantas veces como el diseñador considere necesario.

Pluma baja el umbral al facilitar la modelización con unos pocos clics y drag and drop de proxies visuales que le permiten al diseñador disponer también de una guía sobre cómo construir su modelo en hardware. La adopción de un sistema como Grove con conexiones y componentes estandarizados es una decisión en ese sentido y que, al mismo tiempo, cajanegriza la elaboración de circuitos para cada componente electrónico, permitiendo que el diseñador pueda concentrarse en la idea de interactabilidad que busca perseguir.

Hemos detectado a su vez un espacio para mejoras necesarias. Por una parte, el avance de ideas en paralelo con bocetos de hardware requiere tantas versiones de la composición como variantes se quiera desarrollar. Será necesario mayor trabajo para facilitar la conexión simultánea de al menos dos o tres variantes en hardware de una idea. Además, hemos intentado mantener el espacio de diseño con paredes amplias y techos altos y facilitar además la extensión mediante sub-clasificación de elementos. Sin embargo, esta sub-clasificación requiere en este momento de la intervención en el código de Pluma. Este obstáculo deberá ser removido con mayor trabajo sobre la herramienta, como se menciona en el Capítulo de cierre de la tesis. 



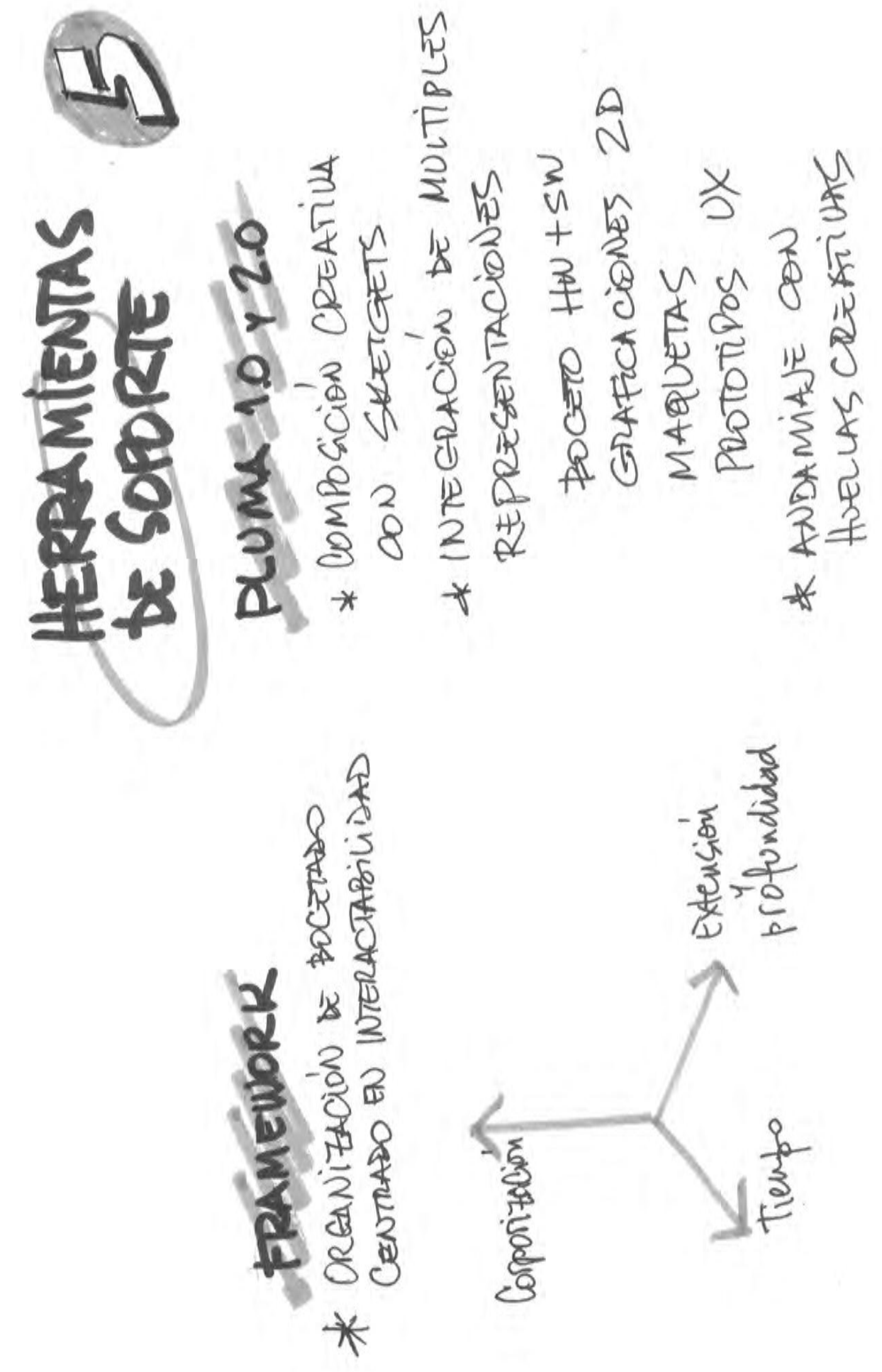





\section{Conclusiones}

This is a start. It is a rough sketch. The best that I can hope is that its timeliness will in some way compensate for its broad strokes. After all, isn't that what sketch is all about?

\footnotetext{
- Bill Buxton

Sketching user experiences[32]
}

La HCI está en una encrucijada. Hemos ingresado a un nuevo mundo de interfaces físicas, naturales y tangibles. Podemos interactuar con elementos digitales mediante gestos y movimientos corporales, manipulando objetos cotidianos e incluso entrenando la actividad cerebral para controlar las interfaces. Para comprender los principios de diseño de un mundo así y contribuir a su construcción, es necesario que nos familiaricemos con las prácticas de los diseñadores, los desarrollos en curso de la cognición corporizada y establezcamos relaciones más cercanas a su agenda de investigación.

En ese escenario, esta tesis se constituyó en la intersección de tres temas de interés para HCI: la práctica del diseño de sistemas interactivos, con énfasis en los mecanismos de creación de interacciones que combinan un pie en lo digital y uno en lo físico, las teorías de la cognición corporizada y enactiva sobre la manera del usuario de dar sentido a su experiencia en el mundo real y las prácticas de bocetado, como actividades centrales para los procesos de ideación en diseño.

\subsection{Preguntas, respuestas, contribuciones}

Con ese cruce como marco, con el objetivo de caracterizar la Cognición Corporizada Enactiva para el bocetado y la generación de ideas en el diseño de interacciones y soportar la práctica con herramientas computacionales nos planteamos las siguientes preguntas de investigación:

\section{PI1. ¿Cuáles son las características de los sistemas interactivos que se apoyan en la Cognición} Corporizada y Enactiva?

- PI 1.1 ¿De qué manera la Cognición Corporizada y Enactiva provee información al diseño sobre la forma en que los sistemas interactivos se conectan con las prácticas corporizadas de la gente y situadas en el mundo real?

- PI 1.2 ¿Cuáles son las características de los sistemas interactivos digitales que facilitan una interacción Corporizada y Enactiva entre las personas y esos sistemas? 


\section{PI 2. ¿Cómo podemos diseñar sistemas interactivos que se apoyen en la Cognición Corporiza- da y Enactiva?}

- PI 2.1. ¿Qué características de la Cognición Corporizada y Enactiva son relevantes en el proceso de diseño de los sistemas interactivos?

- PI 2.2. ¿Qué características debe poseer el bocetado para dar soporte a la generación y evaluación de ideas para interacciones enactivas?

Los tres campos involucrados (diseño de sistemas interactivos; cognición corporizada y enactiva; bocetado) tienen tradiciones, métodos y principios diferentes por lo que he seguido la aproximación triangular que proponen Mackay y Fayard[156]. A lo largo de los cuatro capítulos precedentes he intentado responder a las preguntas de investigación con un abordaje de perspectivas múltiples: a) una perspectiva teórica, en la cual estudiamos y utilizamos las teorías y modelos para comprender la Cognición Corporizada y Enactiva y dar forma su relación con el diseño de sistemas interactivos, b) una perspectiva de observación en la que estudiamos y observamos la práctica de los diseñadores cuando idean dispositivos y sistemas para interactuar en y con el mundo y c) una perspectiva de diseño en la que trasladamos el análisis de los datos de las observaciones y teorías construcción de herramientas para soportar el bocetado en el diseño de interacciones enactivas, lo que a su vez alimentó nuevos estudios de observación y análisis teórico.

En los Capítulos 2 y 3 abordé las respuestas a la PI 1.En el primero presenté una introducción a los conceptos básicos de la Cognición Corporizada y Enactiva y las tres variantes en que puede organizarse, con consecuencias particulares para el diseño en cada una de ellas: la perspectiva de representación y computación distribuidas, la perspectiva de la práctica socialmente situada y la perspectiva de acoplamiento sensorio motor. La primera es la más cercana al cognitivismo y, quizá por esa razón, la más fácilmente comprendida en la comunidad informática. Ha demostrado ser un conjunto de principios útil y relevante para los diseñadores de interacción. Sin embargo, para entender la cognición corporizada en diseño es imprescindible comprender el aspecto sensorio motor de la cognición (de qué manera la percepción surge a partir del acoplamiento en tiempo real entre la percepción y la acción) y la situación social de la cognición (cómo se coordina socialmente la cognición entre las personas). El acoplamiento sensorio motor y la situación en el entorno (físico y social) están integrados en una actividad corporizada unificada que las personas refuerzan con huellas expresivas en el ambiente. Estas huellas son, por un lado el resultado de las acciones anteriores y, por otro, guían las acciones futuras. Al mismo tiempo, las huellas expresivas también son artefactos sociales, creados en y para un contexto social. Funcionan para coordinar el posicionamiento social de las personas en el espacio físico.

El diseño orientado a la cognición corporizada genera sistemas interactivos que transforman nuestras formas de percibir, nuestras posibilidades de actuar, nuestras formas de interactuar socialmente con los demás y nos ayuda a crear huellas expresivas sostenibles en el entorno. Una consecuencia directa de esta visión para el diseño de sistemas digitales es que la"función" de un artefacto ya no se puede predefinir antes de que uno comience a diseñar la"interfaz": en 
el diseño de cognición corporizada, las interacciones concretas entre el usuario y el sistema producen, o enactúan el significado que el sistema tiene para el usuario. Esto significa que uno tiene que diseñar el comportamiento interactivo y el"para qué sirve el sistema" al mismo tiempo, sin distinción a priori entre el aspecto digital y el aspecto físico.

Luego realicé una revisión del conocimiento sobre la ideación en diseño de interacciones, los roles que el bocetado cumple en ese proceso (como herramienta central del pensamiento de diseño) y una revisión de las herramientas que se han propuesto para darle soporte, en particular para el diseño de sistemas interactivos corporizados.

El diseño de la interacción es una práctica que merece entidad propia en el proceso de creación y desarrollo de sistemas digitales. Es compleja entre otras cosas por el manejo de incertidumbre, pero no es un arte negro. Tiene sus propias reglas y lógicas que involucran un camino esencialmente iterativo de enmarcado, propuesta, evaluación y re-encuadre de problemas. En esa práctica el bocetado es esencial. Los diseñadores utilizan múltiples externalizaciones de sus ideas y propuestas que los ayudan a pensarlas, compartirlas o ponerlas a resguardo para el futuro. Todas las ideas se enfocan alrededor de la interactividad, entendida como la interacción-en-acción y definida a partir del espacio de interactabilidad (las acciones del usuario que el sistema es capaz de detectar).

Se han propuesto numerosas herramientas para dar soporte a esta práctica, desde frameworks conceptuales hasta toolkits para construir bocetos interactivos con hardware y software. Algunas, centradas en la corporización física de las ideas. Otras, en los atributos de la interactabilidad o en las cualidades de la experiencia final del usuario. Sin embargo, no todas se avienen a contribuir a la lógica y racionalidad propia del diseñador, sin enfrentarla o encorsetarla. Los estudios sobre diseñadores revelan que éstos necesitan estar preparados para la acción de diseñar, pero no deben ser guiados de una manera prescriptiva en esa acción, a riesgo de obturar las posibilidades reales de que su tarea contribuya a una mejor interacción para el usuario final. En ese relevamiento, encontramos espacio para mejorar el soporte de la práctica con dos elementos centrales: ampliar el hábitat de diseño (bajar el piso, subir el techo y ampliar las paredes) e integrar las múltiples representaciones como mojones de un mismo camino creativo.

Los Capítulos 4 y 5 presentan los aportes de esta tesis para responder a la PI 2. En el primero, una caracterización del bocetado de interacciones enactivas basada en estudios de observación etnometodológica durante unos talleres con profesionales del diseño. En el segundo, un framework para organizar conceptualmente el bocetado de interacciones enactivas y dos versiones de unas herramientas para incluir en esa actividad la composición de bocetos con software y hardware e integrarlos con otras externalizaciones.

Las observaciones permitieron echar luz tanto sobre la forma en que los diseñadores utilizaron las ideas de cognición corporizada y enactiva para fundamentar sus procesos de diseño como sobre los requerimientos a satisfacer por las herramientas que se propongan brindarles un soporte adecuado a esos procesos. Encontramos que en oportunidades los diseñadores mantienen 
sesgos hacia un enfoque representacional y luego vuelven al cuerpo, poniéndolo en el centro de la idea. Por otra parte en todos los procesos encontramos el uso de huellas expresivas que permiten jalonar el camino creativo y volver rápidamente a la situación que envolvía a uno de esos mojones (lo que otorga una especie de trazabilidad al proceso).

El proceso de ideación de interacciones enactivas se caracteriza por un recorrido de idas y vueltas entre la posición representacional (casi cognitivista) al enfoque más radical del acoplamiento sensorio motor. Con el avance del bocetado la corporización deja de estar representada digitalmente para ser su propio modelo. Ese camino se ve jalonado por un espacio compartido de huellas que perduran en los bocetos, las anotaciones en papel o pizarra, las configuraciones del espacio de trabajo, las maquetas, etc. Ese camino de migas de pan no es lineal, como en cualquier exploración tiene curvas y contracurvas, pero puede ser recorrido en el sentido opuesto para abrir nuevas bifurcaciones. Por otra parte, no se trata de simples huellas dejadas por el mero hecho de actuar, son huellas creativas, expresiones intencionadas, actos en los que el diseñador expresa no sólo el contenido de una idea sino que construye un andamio que le sirve para enactuar esa expresión. Es decir, la conexión entre esos andamios y el acoplamiento sensorio motor del proceso se da justo mismo donde está la acción.

Respecto de las herramientas utilizadas por los diseñadores hemos encontrado cuatro aspectos fundamentales: la elección de la interactividad como dimensión del filtrado en cada uno de los bocetos (tanto dibujos y esquemas gráficos como elementos tridimensionales físicos e interactivos), la presentación de los atributos de interacción en todos los tipos de modelos y actuaciones empleadas, el uso de bocetos como interacciones "actuadas" muchas veces conducidas por gestos y el abordaje del estilo tinkering con la necesidad de mantener la creación de los bocetos alineada con el flujo cognitivo de los diseñadores.

Colocar el foco en la interactividad, interacción-en-acción, implica además una postura de exploración y creación en la acción, porque es la propia interactividad la que genera el significado y ayuda a consolidar la idea de la interfaz. El producto surge como una encarnación o corporización de la interactividad que se busca, en un ida y vuelta constante de definiciones sobre la extensión de campos de acción y operación. Los diseñadores registraron los atributos de interacción en cada modelo que construyeron. Lo hicieron de manera explícita, pero utilizando recursos diferentes en cada forma de representación (flechas o símbolos en los dibujos, post-its en las maquetas, comentarios en software). En el contexto de acción del aquí y el ahora, los diseñadores hablaban, hacían gestos y modificaban sus externalizaciones. Esas enacciones, con idas y vueltas entre los diferentes bocetos, construían en los hechos el camino de creación de la idea. Cada representación reforzaba su carácter de huella que podía ser compartida, re-visitada y analizada gracias a su persistencia. Todos los diseñadores emplearon un estilo de tinkering (una especie de"hágalo usted mismo" basado en la exploración de material existente) para construir modelos físicos e interactivos, con cualquier elemento a la mano o con sencillos circuitos sobre placas de prototipado, antes de intentar un modelo más refinado o con mayor fidelidad. En este proceso, el ajuste de los atributos de interacción implica procesos iterativos de re-codificación y compilación de software, con interrupciones en el flujo cognitivo de los 
diseñadores. La carencia de herramientas que agilicen el ciclo o que bajen el umbral en la conexión de componentes es una limitación a este abordaje.

Otra de las contribuciones es un framework que se propone para dar estructura y organización conceptual al bocetado de interacciones enactivas. Por una parte, clarifica las tres funciones que el bocetado parece adquirir en este proceso de ideación: mejorar la capacidad cognitiva del diseñador, establecer andamios y trampolines para garantizar el flujo de pensamientos y dejar huellas para recorrer el camino ida y vuelta tantas veces como iteraciones hagan falta. Por otro lado, organiza la producción de externalizaciones en tres dimensiones: la corporización de la idea, la extensión y profundidad del filtrado y la secuencia temporal de producción.

La caracterización obtenida en las observaciones se tradujo en un listado de requerimientos que embebimos en dos versiones de una herramienta para el bocetado con un abordaje de composición creativa. Soportar de manera flexible el bocetado de la interacción, en el sentido de no imponer al diseñador un proceso predeterminado de generación del boceto. Facilitar la producción de bocetos en diferentes niveles de corporización. Es decir, soportar la generación de bocetos electrónicos bidimensionales como analogía de los gráficos realizados en papel (trazo libre, falta de estructura y ambigüedad), pero también permitir la realización de bocetos-maqueta y bocetos interactivos con hardware y software. Permitir una integración entre todas las formas del boceto que sea manejable por el diseñador. De alguna manera podrían ser consideradas diferentes "vistas" de una idea en concepción de modo que una anotación en alguna de ellas debería reflejarse en las otras. Facilitar la definición y el diseño de la interactividad mediante el uso de algún vocabulario de la interacción y su aplicación en el proceso de diseño. Mantener el umbral de acceso a la tecnología usada en la producción de bocetos, lo más bajo posible y orientado a diseñadores de interacción y no sólo a ingenieros o programadores. Permitir el amojonamiento del proceso con huellas expresivas que sean re-visitables, sean estados intermedios de los bocetos o cualquier otro elemento ad hoc dejado por los diseñadores como señales de insights durante la ideación. La validación inicial de estas herramientas se ha presentado por estudios informales de casos y demostración del espacio de diseño alcanzable.

\section{Contribuciones}

Las respuestas esbozadas en los párrafos anteriores han sido embebidas en tres tipos de contribuciones principales (de acuerdo con la clasificación de Wobbrock para la investigación en HCI[251]):

1. Una contribución conceptual: un framework que estructura y organiza el bocetado en la generación de ideas de interacción corporizada y enactiva. Reconoce las dimensiones en las que se puede externalizar la propuesta de diseño (2, 3 y 4D), la importancia de utilizar y vincular múltiples formas de modelización, la utilización de la interactabilidad como dimensión privilegiada del filtrado con su comprobación de interactividad efectivamente 
alcanzada además de la necesidad de constituir todas esas representaciones como huellas expresivas que jalonan el camino creativo en la ideación.

2. Una contribución artefactual: dos versiones de una herramienta para bocetar interacciones corporizadas y enactivas utilizando un abordaje de composición creativa que incluya hardware y software, integre múltiples representaciones y permita el amojonamiento del proceso. Las herramientas se plantearon como objetivos reducir los tiempos y complejidad de autoría (bajar el umbral de acceso), integrar con las prácticas e infraestructuras actuales de los diseñadores y facilitar la réplica y exploración creativa de acuerdo con la lógica del diseñador.

3. Una contribución empírica: estudios de observación con base etnometodológicos para caracterizar la práctica de ideación en el diseño para la interacción corporizada y enactiva, que muestran la centralidad del bocetado iterativo, con múltiples formatos de externalización y enfocado en los atributos de interactabilidad y el chequeo constante de la interactividad.

\subsection{Trabajos futuros}

Para dar continuidad y profundidad a este trabajo, considero importante extender la serie de observaciones de la práctica del bocetado, incorporando la utilización de herramientas específicas como Pluma y otros abordajes de diseño por fuera de la sustitución sensorial. En particular resulta de interés incorporar mayores observaciones sobre los aspectos vinculados con el contexto social de la enacción, tanto durante la ideación como en el uso de productos interactivos. Tanto estudios de observaciones etnometodológica como el presentado en esta tesis como estudios de casos controlados podrán aportar mayor información sobre la práctica y contribuir a extender y profundizar el framework presentado.

Por otra parte, respecto de Pluma será necesario actualizar su arquitectura tecnológica, aumentar y complejizar formatos de creación y re-visitado de huellas expresivas (por ejemplo, incorporar registros en video de sesión de trabajo en primera persona con marcado automático de huellas o construir automáticamente grafos con la historia de las líneas de indagación abordadas en el boceto) y realizar experimentos controlados de validación. Para extender la satisfacción de los requerimientos planteados deberán realizarse también trabajos para facilitar la conexión simultánea de al menos dos o tres variantes de una idea y bajar el umbral de acceso a la extensión de Pluma, incluyendo el kit completo de componentes del sistema Grove y evitando la necesidad de modificación de código.

La realización de estudios de casos controlados aportará mayor información sobre el alcance de la validez de Pluma como herramienta de soporte al bocetado de interacciones enactivas. 


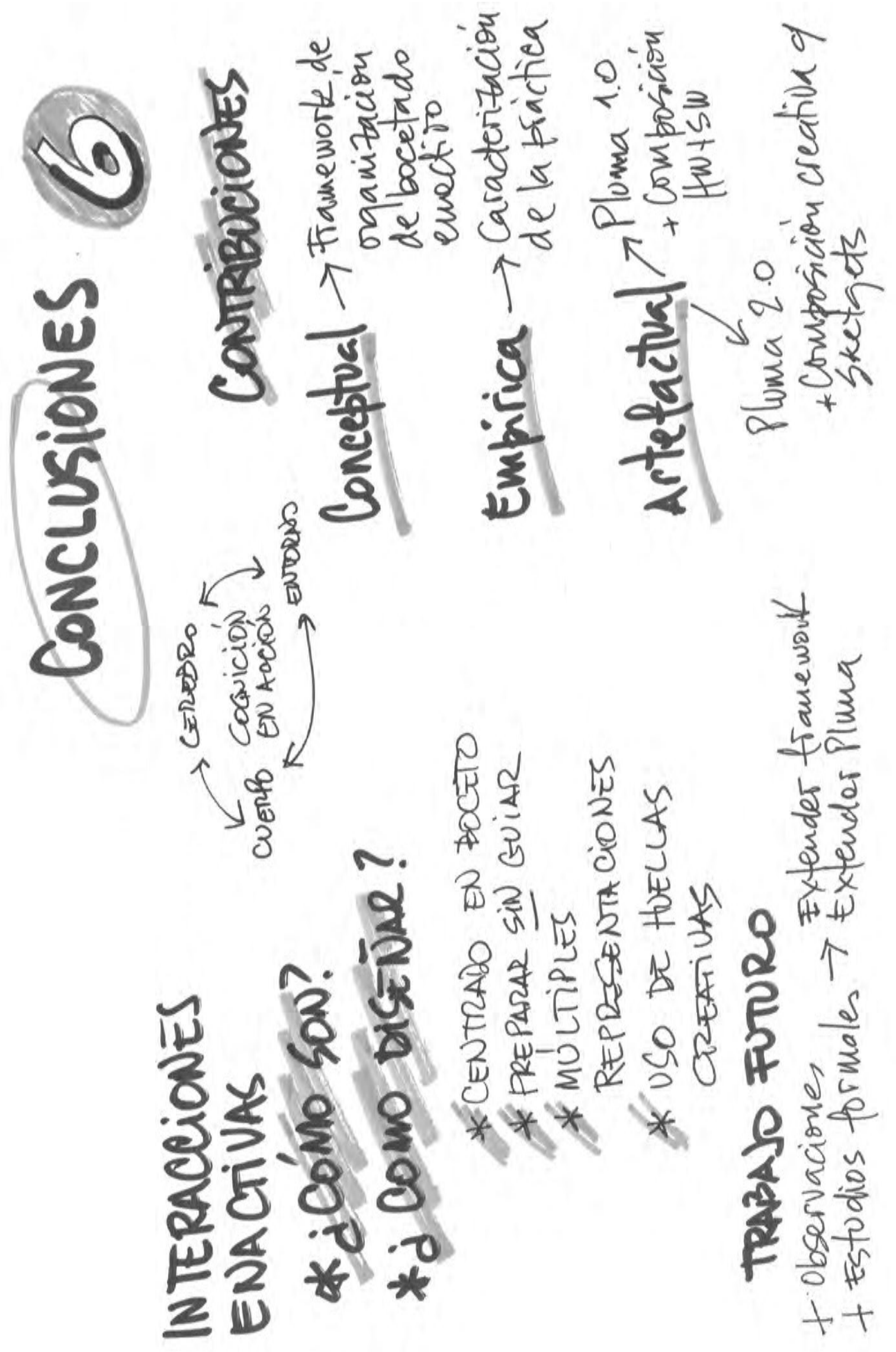





\section{Bibliografía}

[1]P. Agre e I. Horswill. „Lifeworld Analysis“. En: J. Artif. Intell. Res. 6 (abr. de 1997), págs. 111-145 (vid. pág. 22).

[2]Christopher Alexander, Sara Ishikawa, Murray Silverstein y col. A pattern language: towns, buildings, construction. Oxford University Press, 1977, pág. 1171 (vid. pág. 44).

[3]Phillip van Allen. NTK. NETLabTK: tools for tangible design. 2003 (vid. pág. 155).

[4]R Anderson. „Representations and requirements: the value of ethnography in system design“. En: Hum. Comput. Interact. 9 (1994), págs. 151-182 (vid. pág. 11).

[5]Leonardo Angelini, Elena Mugellini, Nadine Couture y Omar Abou Khaled. „Designing the Interaction with the Internet of Tangible Things“. En: Proc. Twelfth Int. Conf. Tangible, Embed. Embodied Interact. - TEI '18. New York, New York, USA: ACM Press, 2018, págs. 299-306 (vid. págs. 56, 70).

[6]Bruce Archer. „The nature of research“. En: CoDesign 2.11 (1995), págs. 6-13 (vid. págs. 10, 11).

[7]Newton Armstrong. „An Enactive Approach to Digital Musical Instrument Design“. Tesis doct. Princeton University, 2006, pág. 181 (vid. pág. 24).

[8]Henrik Artman, Robert Ramberg, Hillevi Sundholm y Teresa Cerratto-Pargman. „Action Context and Target Context Representations: A Case Study on Collaborative Design Learning“. En: Proc. th 2005 Conf. Comput. Support Collab. Learn. Learn. 2005 Next 10 Years! CSCL '05. International Society of the Learning Sciences, 2005, págs. 1-7 (vid. pág. 116).

[9]Malika Auvray y Erik Myin. „Perception with compensatory devices: from sensory substitution to sensorimotor extension.“ En: Cogn. Sci. 33.6 (ago. de 2009), págs. 1036-58 (vid. pág. 80).

[10]Edward Baafi y Amon Millner. „A toolkit for tinkering with tangibles and connecting communities“. En: TEI '11. New York, New York, USA: ACM Press, 2011, pág. 349 (vid. págs. 56, 73).

[11]Christopher Baber. Cognition and tool use: forms of engagement in human and animal use of tools. Taylor \& Francis, 2003, pág. 172 (vid. pág. 47).

[12]P Bach-y-Rita, C C Collins, F A Saunders, B White y L Scadden. „Vision substitution by tactile image projection.“ En: Nature 221.5184 (1969), págs. 963-964 (vid. págs. 34, 80).

[13]Paul Bach-y-Rita, Mitchell E. Tyler y Kurt A. Kaczmarek. „Seeing with the Brain“. En:Int. J. Hum. Comput. Interact. 15.2 (abr. de 2003), págs. 285-295 (vid. pág. 80).

[14]Rafael Ballagas, Meredith Ringel, Maureen Stone y Jan Borchers. „iStuff: a physical user interface toolkit for ubiquitous computing environments". En: Proc. SIGCHI Conf. Hum. factors Comput. Syst. Vol. 16. CHI ’03 5. New York, NY, USA: ACM, 2003, págs. 537-544 (vid. págs. 56, 68). 
[15]D H Ballard, M M Hayhoe, P K Pook y R P Rao. „Deictic codes for the embodiment of cognition.“ En: Behav. Brain Sci. 20.4 (dic. de 1997), 723-42, discussion 743-67 (vid. pág. 21).

[16] Gregory Bateson. Pasos hacia una ecología de la mente. Lohlé-Lumen, 1985 (vid. pág. 3).

[17]Benjamin. Bederson y Ben. Shneiderman. The craft of information visualization: readings and reflections. Morgan Kaufmann, 2003, pág. 410 (vid. pág. 7).

[18]Randall D. Beer. „Dynamical systems and embedded cognition“. En: Cambridge Handb. Artif. Intell. Ed. por Keith Frankish y William M. Ramsey. Cambridge: Cambridge University Press, 2014, págs. 128-148 (vid. pág. 24).

[19]Victoria Bellotti, Maribeth Back, W Keith Edwards y col. „Making sense of sensing systems: five questions for designers and researchers". En: Proc. SIGCHI Conf. Hum. factors Comput. Syst. Chang. our world, Chang. ourselves. Vol. 1. CHI '02 1. New York, NY, USA: ACM, 2002, págs. 415-422 (vid. págs. 55-57, 60, 147).

[20]Andrea Bellucci, Ignacio Aedo y Paloma Díaz. „ECCE Toolkit: Prototyping Sensor-Based Interaction“. En: Sensors 17.3 (feb. de 2017), pág. 438 (vid. págs. 56, 70).

[21] Steve Benford, Holger Schnadelbach, Boriana Koleva y col. Sensible, sensable and desirable : a framework for designing physical interfaces. Inf. téc. 2003 (vid. págs. 56, 57, 61).

[22] Eric Berne. Juegos en que Participamos. Mexico: Editorial Diana, 1986, págs. 1-90 (vid. pág. 110).

[23]Yogi Berra y Dave Kaplan. You can observe a lot by watching : what I've learned about teamwork from the Yankees and life. John Wiley \& Sons, Inc, 2008, pág. 232 (vid. pág. 79).

[24]Olav W. Bertelsen, Susanne Bødker, Eva Eriksson, Eve Hoggan y Jo Vermeulen. „Beyond generalization: research for the very particular“. En: Interactions (2018), págs. 34-38 (vid. pág. 8).

[25]W Bijker. Of bicycles, bakelites and bulbs: toward a theory of sociotechnical change. Cambridge, MA: MIT Press, 1995 (vid. pág. 4).

[26] Tracey Booth, Simone Stumpf, Jon Bird y Sara Jones. „Crossed Wires“. En: Proc. 2016 CHI Conf. Hum. Factors Comput. Syst. - CHI '16 (2016), págs. 3485-3497 (vid. págs. 118, 124, 155, 156).

[27]Assam Boudjelthia, Sofeem Nasim, Janne Eskola y col. „Enabling Mid-air Browser Interaction with Leap Motion“. En: Proc. 2018 ACM Int. Jt. Conf. 2018 Int. Symp. Pervasive Ubiquitous Comput. Wearable Comput. UbiComp '18. New York, NY, USA: ACM, 2018, págs. 335-338 (vid. págs. 165, 166).

[28]L. Brayda, C. Campus y M. Gori. „What you touch is what you get: Self-assessing a minimalist tactile sensory substitution device“. En: IEEE World Haptics Conf. 2013 (abr. de 2013), págs. 491-496 (vid. pág. 90).

[29] Frederick P. Brooks. The design of design. Essays from a computer scientist. Addison-Wesley, 2010 (vid. págs. 42, 45).

[30]Rodney Brooks. „Intelligence without representation“. En: Artif. Intell. 47 (1991) (vid. págs. 4, 23).

[31]Marion Buchenau, Jane Fulton J.F. Suri, I.S. Francisco y Jane Fulton J.F. Suri. „Experience Prototyping“. En: Conf. Des. Interact. Syst. Process. Pract. methods, Tech. DIS '00 October (2000). Ed. por D Boyarski y W A Kellogg, págs. 424-433 (vid. págs. 53, 116, 138).

[32]Bill Buxton. Sketching user experiences: getting the design right and the right design. Morgan Kaufmann, 2007, pág. 445 (vid. págs. 1, 42, 45, 46, 49, 51, 138, 141, 161, 162, 171). 
[33]Filipe Calegario, Marcelo M. Wanderley, Stephane Huot, Giordano Cabral y Geber Ramalho. „A Method and Toolkit for Digital Musical Instruments: Generating Ideas and Prototypes“. En: IEEE Multimed. 24.1 (ene. de 2017), págs. 63-71 (vid. pág. 56).

[34]Stuart K. Card, Allen. Newell, Thomas P. Moran y Allen. Newell. The psychology of human-computer interaction. Hillsdale, NJ, USA: Lawrence Erlbaum Associates, 1986, pág. 469 (vid. págs. 4, 17, 19).

[35]John M. Carroll, ed. HCI Models, Theories, and Frameworks. Morgan Kaufmann, 2003 (vid. págs. 6, 43).

[36]John M. Carroll. „Human-Computer Interaction: Psychology as a Science of Design“. En: Annu. Rev. Psychol. 48.1 (feb. de 1997), págs. 61-83 (vid. pág. 17).

[37]Stephen J Ceci y Antonio Roazzi. „The effects of context on cognition: Postcards from Brazil.“ En: Mind Context Interact. Perspect. Hum. Intell. New York, NY, US: Cambridge University Press, 1994, págs. 74-101 (vid. pág. 22).

[38]William J Clancey. Situated Cognition: On Human Knowledge and Computer Representations. 1997 (vid. págs. 12, 19, 22, 23).

[39]Andy Clark. Being there. Putting brain, body and world together again. The MIT Press, 1997 (vid. págs. 3, 19, 21, 22, 24, 28, 37).

[40]Andy Clark. Supersizing the mind. Embodiment, Action and Cognitive Extension. Oxford University Press, 2008 (vid. págs. 18, 139).

[41]Juliet Corbin y Anselm Strauss. Basics of qualitative research: techniques and procedures for developing grounded theory. fourth. Los Angeles, CA: Sage Publications, 2017 (vid. pág. 133).

[42],Introduction to the Special Issue of \&Ldquo;The Turn to The Wild\&Rdquo;" en: ACM TOCHI 20.3 (2013). Ed. por Andy Crabtree, Alan Chamberlain, Rebecca E Grinter y col., 13:1-13:4 (vid. pág. 47).

[43]Nigel Cross. Designerly Ways of Knowing. Vol. 3. 4. Springer, 2006, pág. 114 (vid. págs. 11, 44, 53).

[44]Mihaly Csikszentmihalyi. Flow: the psychology of optimal experience. Harper \& Row, 1990, pág. 303 (vid. págs. 25, 118).

[45]Peter Dalsgaard. „Instruments of inquiry: Understanding the nature and role of tools in design“. En: Int. J. Des. 11.1 (2017), págs. 21-33 (vid. págs. 45, 50).

[46]Antonio Damasio. „Fundamental feelings.“ En: Nature 413.6858 (2001), pág. 781 (vid. pág. 19).

[47]Hanne De Jaegher y Ezequiel A Di Paolo. „Participatory sense-making: An enactive approach to social cognition“. En: Phenomenol. Cogn. Sci. 6.4 (2007), págs. 485-507 (vid. págs. 114, 142).

[48]John Dewey. How we think. Dover Publications, 1997, pág. 224 (vid. pág. 3).

[49]Anind K Dey. „Understanding and Using Context“. En: Pers. Ubiquitous Comput. 5.1 (2001), págs. 4-7 (vid. pág. 17).

[50]Ezequiel Di Paolo, Marieke Rohde y Hanne De Jaegher. „Horizons for the enactive mind: values, social interaction and play“. En: Enaction. Ed. por J Stewart, O Gapenne y E Di Paolo. The MIT Press, 2010, págs. 33-87 (vid. pág. 28). 
[51]Sarah Diefenbach, Eva Lenz y Marc Hassenzahl. „An interaction vocabulary. Describing the how of interaction." En: CHI '13 Ext. Abstr. Hum. Factors Comput. Syst. - CHI EA '13. Paris: ACM Press, abr. de 2013, pág. 607 (vid. págs. 56, 58, 60, 67, 126, 130, 145, 149).

[52]Jelle van Dijk. „Creating Traces, Sharing Insight: Explorations in Embodied Cognition Design“. Tesis doct. 2013, pág. 269 (vid. págs. 20, 114, 116, 146).

[53]Alan Dix y Layda Gongora. „Externalisation and design“. En: 2nd Conf. Creat. Innov. Des. DESIRE'11 (oct. de 2011), págs. 31-42 (vid. pág. 43).

[54]Tom Djajadiningrat, Stephan Wensveen, Joep Frens y Kees Overbeeke. „Tangible Products: Redressing the Balance Between Appearance and Action“. En: Pers. Ubiquitous Comput. 8.5 (2004), págs. 294-309 (vid. págs. 56, 65, 66).

[55]Paul Dourish. „<Implication_for_Design.pdf>“. En: (2006) (vid. págs. 11, 28).

[56]Paul Dourish. Where the action is. The foundations of embodied interaction. MIT Press, 2004 (vid. págs. $1,4,18,22,23,30,32,36,114,142$ ).

[57]Paul Dourish y Genevieve Bell. Divining a digital future. Mess and mythology in ubiquitous computing. Vol. 41. 1. The MIT Press, 2011, pág. 264 (vid. pág. 3).

[58]Paul Dourish y Graham Button. „On "technomethodology": foundational relationships between ethnomethodology and system design“. En: Hum. Comput. Interact. 13.4 (1998), págs. 1-28 (vid. págs. 10, 11, 81, 119).

[59] Steven P. Dow, Alana Glassco, Jonathan Kass y col. „Parallel prototyping leads to better design results, more divergence, and increased self-efficacy“. En: ACM TOCHI 17.4 (dic. de 2010), págs. 1-24 (vid. pág. 50).

[60]Steven Dow, Julie Fortuna, Dan Schwartz y col. „Prototyping Dynamics: Sharing Multiple Designs Improves Exploration, Group Rapport, and Results“. En: Proc. SIGCHI Conf. Hum. Factors Comput. Syst. CHI '11. New York, NY, USA: ACM, 2011, págs. 2807-2816 (vid. pág. 6).

[61]Hubert L. Dreyfus. „Intelligence without representation: Merleau-ponty's critique of mental representation“. En: Phenomenol. Cogn. Sci. 1.4 (2002), págs. 367-383 (vid. pág. 37).

[62] Hubert L. Dreyfus. What computers can't do. A critique of artificial reason. Harper \& Row, 1972 (vid. pág. 18).

[63]Augusto Esteves, Saskia Bakker, Alissa N. Antle y col. „The ATB Framework“. En: Proc. Ninth Int. Conf. Tangible, Embed. Embodied Interact. - TEI '14. New York, New York, USA: ACM Press, 2015, págs. $13-20$ (vid. págs. $56,65,66$ ).

[64]Daniel Fallman. „Design-Oriented Human-Computer Interaction“. En: Proc. Int. Conf. Hum. Factors Comput. Syst. MAY 2003 (2003), págs. 225-232 (vid. págs. 43, 60).

[65]Daniel Fallman. „The Interaction Design Research Triangle of Design Practice, Design Studies, and Design Exploration“. En: Des. Issues 24.3 (jul. de 2008), págs. 4-18 (vid. pág. 138).

[66]Eugene S. Ferguson. Engineering and the mind's eye. Cambridge, MA: MIT Press, 1992 (vid. pág. 52).

[67]Ylva Fernaeus, Jakob Tholander y Martin Jonsson. „Towards a New set of Ideals : Consequences of the Practice Turn in Tangible Interaction“. En: Proc. Second Int. Conf. Tangible Embed. Interact. TEI08. ACM Press, 2008, págs. 223-230 (vid. pág. 31).

[68]Kenneth P Fishkin. „A Taxonomy for and Analysis of Tangible Interfaces“. En: Pers. Ubiquitous Comput. 8.5 (2004), págs. 347-358 (vid. págs. 56, 57). 
[69]George W. Fitzmaurice y William Buxton. „An empirical evaluation of graspable user interfaces“. En: Proc. SIGCHI Conf. Hum. factors Comput. Syst. - CHI '97. 1. New York, New York, USA: ACM Press, mar. de 1997, págs. 43-50 (vid. pág. 28).

[70]Jerry Fodor. The modularity of mind. Cambridge MA: The MIT Press, 1983 (vid. pág. 18).

[71]Jonas Forsslund y Ioanna Ioannou. „Tangible Sketching of Interactive Haptic Materials“. En: TEI 2012. Vol. 1. 212. New York, New York, USA: ACM Press, 2012, págs. 111-114 (vid. pág. 56).

[72]Tom Froese y Shaun Gallagher. „Getting interaction theory (IT) together: Integrating developmental, phenomenological, enactive, and dynamical approaches to social interaction“. En: Interact. Stud. 13.3 (2012), págs. 436-468 (vid. pág. 79).

[73]Tom Froese, Marek McGann, William Bigge, Adam Spiers y Anil K. Seth. „The Enactive Torch: A New Tool for the Science of Perception“. En: IEEE Trans. Haptics 5.4 (2012), págs. 365-375 (vid. págs. 80, 82, 83, 88, 151).

[74]H. Garfinkel. Studies in ethnomethodology. Cambridge, UK: Polity Press, 1967 (vid. pág. 11).

[75]Henrik Gedenryd. „How Designers Work. Making Sense of Authentic Cognitive Activities“. Tesis doct. Lund University, 1998, pág. 233 (vid. págs. 43, 49).

[76]Clifford Geertz. The interpretation of cultures. New York: Basic Books, 1973 (vid. págs. 10, 11, 83).

[77]James J Gibson. La percepcion Del Mundo Visual. Buenos Aires: Ediciones Infinito, 1974 (vid. pág. 26).

[78]James Jerome Gibson. The Ecological Approach to Visual Perception. 1986 (vid. págs. 4, 19, 30).

[79]Bernd Girod, Rudolf Rebenstein y Alexander Stenger. Signals and systems. 2nd. Wiley, 2001 (vid. pág. 126).

[80]Vinod Goel. Sketches of thought. Vol. 18. 1. MIT Press, 1997 (vid. pág. 43).

[81]Kristian Gohlke, Michael Hlatky y Bram de Jong. „Physical Construction Toys for Rapid Sketching of Tangible User Interfaces“. En: TEI '14. New York, New York, USA: ACM Press, 2015, págs. 643-648 (vid. pág. 56).

[82]Gabriela Goldschmidt. „The dialectics of sketching“. En: Creat. Res. J. 4.2 (ene. de 1991), págs. 123-143 (vid. págs. 1, 52).

[83]Charles Goodwin. „Action and embodiment within situated human interaction“. En: J. Pragmat. 32 (2000) (vid. pág. 10).

[84]Charles Goodwin. „The semiotic body in its environment“. En: Discourses body January 2003 (2003), págs. 19-42 (vid. págs. 114, 142).

[85]Saul Greenberg y Michael Boyle. „Customizable Physical Interfaces for Interacting with Conventional Applications". En: Proc. 15th Annu. ACM Symp. User Interface Softw. Technol. UIST '02. New York, NY, USA: ACM, 2002, págs. 31-40 (vid. pág. 69).

[86]Saul Greenberg, Sheelagh Carpendale, Nicolai Marquardt y Bill Buxton. Sketching user experiences. The workbook. Morgan Kaufmann, 2012, pág. 262 (vid. pág. 12).

[87]Saul Greenberg y Chester Fitchett. „Phidgets: Easy Development of Physical Interfaces Through Physical Widgets“. En: Proc. 14th Annu. ACM Symp. User Interface Softw. Technol. UIST '01. New York, NY, USA: ACM, 2001, págs. 209-218 (vid. pág. 68).

[88]Saul Greenberg y Saul. „Toolkits and interface creativity“. En: Multimed. Tools Appl. 32.2 (ene. de 2007), págs. 139-159 (vid. págs. 55, 125, 147, 158). 
[89]Jayavardhana Gubbi, Rajkumar Buyya, Slaven Marusic y Marimuthu Palaniswami. „Internet of Things (IoT): A vision, architectural elements, and future directions“. En: Futur. Gener. Comput. Syst. 29.7 (sep. de 2013), págs. 1645-1660 (vid. pág. 17).

[90]Rosana Guber. La etnografía. Método, campo y reflexividad. Buenos Aires: Siglo XXI Editores, 2011 (vid. pág. 83).

[91]Edward T. Hall. La dimensión oculta. México: Siglo XXI Editores, 2003 (vid. pág. 82).

[92]Lars Hallnäs y Johan Redström. „From use to presence: on the expressions and aesthetics of everyday computational things“. En: ACM TOCHI 9.2 (jun. de 2002), págs. 106-124 (vid. pág. 4).

[93]Björn Hartmann, Scott Doorley y Scott R. Klemmer. „Hacking, mashing, gluing: Understanding opportunistic design“. En: IEEE Pervasive Comput. (2008) (vid. págs. 6, 115).

[94]Björn Hartmann, Scott R Klemmer, Michael Bernstein y col. „Reflective physical prototyping through integrated design, test, and analysis“. En: Proc. 19th Annu. ACM Symp. User interface Softw. Technol. Vol. 40. UIST '06 3. New York, NY, USA: ACM, 2006, págs. 299-308 (vid. págs. 56, $60,61)$.

[95]Marc Hassenzahl. Experience Design: Technology for All the Right Reasons. Vol. 3. 1. 2010, págs. 1-95 (vid. pág. 48).

[96]Martin Heidegger. Being and time. Reprint ed. Harper Perennial Modern Cassics, 2008 (vid. págs. 3, $4,25)$.

[97]Alan R Hevner, Salvatore T March, Jinsoo Park y Sudha Ram. „Design Science in Information Systems Research“. En: MIS Q. 28.1 (2004), págs. 75-105 (vid. pág. 159).

[98]Thomas Hewett, Ronald Baecker, Stuart Card y col. ACM SIGCHI Curricula for Human-Computer Interaction. 1992 (vid. pág. 6).

[99]James Hollan, Edwin Hutchins y David Kirsh. „Distributed cognition: toward a new foundation for human-computer interaction research“. En: ACM TOCHI 7.2 (jun. de 2000), págs. 174-196 (vid. págs. 21, 37).

[100]Lars Erik Holmquist y Lars Erik. „Sketching in hardware“. En: Interactions 13.1 (ene. de 2006), págs. 47-60 (vid. págs. 68,138 ).

[101]Lars Erik Holmquist, Johan Redström y Peter Ljungstrand. „Token-Based Acces to Digital Information“. En: Proc. 1st Int. Symp. Handheld Ubiquitous Comput. HUC '99. London, UK, UK: Springer-Verlag, 1999, págs. 234-245 (vid. págs. 56, 58, 59).

[102] Karen Holtzblatt, Jessamyn Burns Wendell y Shelley Wood. Rapid Contextual Design. A how to guide to key techniques for user centered design. San Francisco, USA: Morgan Kaufmann, 2005 (vid. pág. 83).

[103]Kasper Hornbæk y Antti Oulasvirta. „What Is Interaction Design?“ En: CHI 2017. 2017 (vid. pág. 47).

[104]Eva Hornecker. „Sketches, Drawings, Diagrams, Physical Models, Prototypes, and Gesture as Representational Forms“. En: Phys. 2007. 2007 (vid. pág. 145).

[105]Eva Hornecker y Jacob Buur. „Getting a grip on tangible interaction: a framework on physical space and social interaction“. En: Proc. SIGCHI Conf. Hum. Factors Comput. Syst. Vol. 1. CHI '06 12. New York, NY, USA: ACM, 2006, págs. 437-446 (vid. págs. 4, 18, 28, 56, 66, 138). 
[106]Steven Houben y Nicolai Marquardt. „WatchConnect: A toolkit for prototyping smartwatch-centric cross-device applications“. En: Conf. Hum. Factors Comput. Syst. - Proc. Vol. 2015-April. 2015, págs. 1247-1256 (vid. págs. 56, 70, 71, 158).

[107]Elise van den Hoven y Berry Eggen. „Tangible Computing in Everyday Life: Extending Current Frameworks for Tangible User Interfaces with Personal Objects“. En: Ambient Intell. Ed. por Panos Markopoulos, Berry Eggen, Emile Aarts y James L Crowley. Berlin, Heidelberg: Springer Berlin Heidelberg, 2004, págs. 230-242 (vid. pág. 57).

[108]Caroline Hummels. „Gestural design tools: prototypes, experiments and scenarios“. Tesis doct. Technical University of Delft, 2000 (vid. págs. 53, 134, 145).

[109]Caroline Hummels y Jelle van Dijk. „Seven Principles to Design for Embodied Sensemaking“. En: Proc. Ninth Int. Conf. Tangible, Embed. Embodied Interact. - TEI '14 figure 1 (2015), págs. 21-28 (vid. págs. 20, 56-58).

[110]Caroline Hummels, Kees C. J. Overbeeke y Sietske Klooster. „Move to get moved: a search for methods, tools and knowledge to design for expressive and rich movement-based interaction". En: Pers. Ubiquitous Comput. 11.8 (nov. de 2006), págs. 677-690 (vid. pág. 145).

[111]Susan Hurley. „Perception and action: Alternative views“. En: Synthese 129.129 (2001), págs. 3-40 (vid. pág. 35).

[112]Edwin Hutchins. Cognition in the Wild. Vol. 19. 1. MIT Press, 1995. Cap. 9, pág. 381 (vid. págs. 3, 19, 21, 23, 37).

[113]Hiroshi Ishii. „Tangible bits“. En: Proc. 2nd Int. Conf. Tangible Embed. Interact. - TEI '08. New York, New York, USA: ACM Press, 2008, pág. xv (vid. págs. 28, 30, 32).

[114]Hiroshi Ishii y Brygg Ullmer. „Tangible bits“. En: Proc. SIGCHI Conf. Hum. factors Comput. Syst. CHI '97. New York, New York, USA: ACM Press, 1997, págs. 234-241 (vid. págs. 29, 30).

[115]ISO/IEC. 13407 Human-centred design processes for interactive systems. 1999 (vid. pág. 11).

[116]Ali Israr, Siyan Zhao y Oliver Schneider. „Exploring Embedded Haptics for Social Networking and Interactions“. En: Ext. Abstr. ACM CHI'15 Conf. Hum. Factors Comput. Syst. Vol. 2. 2015, págs. 1899-1904 (vid. págs. 163, 164).

[117]Robert J K Jacob, Audrey Girouard, Michael S Horn y Jamie Zigelbaum. „Reality-Based Interaction : A Framework for Post-WIMP Interfaces“. En: CHI 2008. Florence, Italy, 2008, págs. 201-210 (vid. pág. 47).

[118]Lars Erik Janlert y Erik Stolterman. „The Meaning of Interactivity—Some Proposals for Definitions and Measures“. En: Human-Computer Interact. 32.3 (2017), págs. 103-138 (vid. pág. 60).

[119]Lars-Erik Janlert y Erik Stolterman. „Faceless Interaction-A Conceptual Examination of the Notion of Interface: Past, Present, and Future“. En: Human-Computer Interact. 30.6 (2015), págs. 507-539 (vid. pág. 36).

[120]Lars-Erik Janlert y Erik Stolterman. „The Meaning of Interactivity-Some Proposals for Definitions and Measures“. En: Human-Computer Interact. 0024.September (2016) (vid. págs. 48, 49, 115, $125,126,144)$.

[121]Lars-Erik Janlert y Erik Stolterman. Things That Keep Us Busy: The Elements of Interaction. The MIT Press, 2017 (vid. pág. 138). 
[122]Mads Vedel Jensen, Jacob Buur y Tom Djajadiningrat. „Designing the user actions in tangible interaction“. En: Proc. 4th Decenn. Conf. Crit. Comput. between sense Sensib. - CC '05 (2005), pág. 9 (vid. pág. 138).

[123]J. Christopher (John Christopher) Jones. Design methods: seeds of human futures. Wiley-Interscience, 1970, pág. 407 (vid. págs. 42, 43, 138).

[124]Sergi Jordà, G. Geiger, M. Alonso y M. Kaltenbrunner. „The reacTable Exploring the Synergy between Live Music Performance and Tabletop Tangible Interfaces“. En: Conf. tangible Embed. Interact. (2007) (vid. pág. 31).

[125]Victor Kaptelinin y Bonnie A. Nardi. Acting with technology activity theory and interaction design. The MIT Press, 2006 (vid. pág. 47).

[126]J Karat. Taking software design seriously: practical techniques for Human Computer Interaction Design. San Diego: Academic Press, 1991 (vid. pág. 3).

[127]Majeed Kazemitabaar, Jason McPeak, Alexander Jiao y col. „MakerWear“. En: Proc. 2017 CHI Conf. Hum. Factors Comput. Syst. - CHI '17 (2017), págs. 133-145 (vid. págs. 56, 70, 73).

[128]David Kirsh. „Embodied cognition and the magical future of interaction design“. En:ACM TOCHI 20.1 (2013), 3:1-3:30 (vid. págs. 1, 17, 27, 54, 141).

[129]David Kirsh. „Thinking with external representations“. En: AI Soc. 25.4 (2010), págs. 441-454 (vid. págs. 37, 139).

[130]David Kirsh y Paul Maglio. „On Distinguishing Epistemic from Pragmatic Action“. En: Cogn. Sci. 18.4 (1994), págs. 513-549 (vid. págs. 21, 54, 139).

[131]Scott R Klemmer, Björn Hartmann y Leila Takayama. „How bodies matter“. En: Proc. 6th ACM Conf. Des. Interact. Syst. DIS 06. ACM Press, 2006, pág. 140 (vid. págs. 4, 32).

[132]Shigeru Kobayshi. „Re-inventions and Improvements on Toolkits and Workshops“. En: Sketching 2011. 2011, págs. 1-73 (vid. pág. 124).

[133]Jon Kolko. Thoughts on Interaction Design. 2nd. Morgan Kaufmann, 2011, pág. 128 (vid. pág. 46).

[134]Werner A. König, Roman Rädle y Harald Reiterer. „Interactive design of multimodal user interfaces“. En: J. Multimodal User Interfaces 3.3 (abr. de 2010), págs. 197-213 (vid. págs. 56, 62, $63)$.

[135]Michinari Kono, Yoshio Ishiguro, Takashi Miyaki y Jun Rekimoto. „Design and Study of a MultiChannel Electrical Muscle Stimulation Toolkit for Human Augmentation“. En:Proc. 9th Augment. Hum. Int. Conf. - AH '18. New York, New York, USA: ACM Press, 2018, págs. 1-8 (vid. pág. 56).

[136]Ilpo Koskinen, John Zimmerman, Thomas Binder, Johan Redström y Stephan Wensveen. Constructive Design Research. 2012, págs. 1-13 (vid. pág. 11).

[137]Klaus. Krippendorff. The semantic turn : a new foundation for design. CRC/Taylor \& Francis, 2006, pág. 349 (vid. págs. 45, 47).

[138]Thomas Kubitza, Albrecht Schmidt, Norman Pohl y col. „Tools and methods for creating interactive artifacts". En: Proc. 8th Int. Conf. Tangible, Embed. Embodied Interact. - TEI '14. New York, New York, USA: ACM Press, 2013, págs. 385-388 (vid. pág. 56).

[139]James A Landay. „SILK: sketching interfaces like krazy“. En: Conf. Companion Hum. Factors Comput. Syst. CHI '96. New York, NY, USA: ACM, 1996, págs. 398-399 (vid. pág. 64). 
[140]Paul Laseau. Graphic thinking for architects \& designers. Third. John Wiley \& Sons Ltd., 2001 (vid. pág. 51).

[141]Bryan Lawson. How designers think: the design process demystified. 3rd. Vol. 3rd revise. 3. Elsevier, 2006, pág. 321 (vid. págs. 41, 44).

[142]Bryan Lawson. How designers think. Fourth edition. 2005 (vid. pág. 1).

[143]Jonathan Lazar, Jinjuan Heidi Feng y Harry Hochheiser. Research methods in Human-Computer Interaction. Second. Cambridge, MA, USA: Morgan Kaufmann Publishers, 2017 (vid. págs. 130, 131).

[144]David Ledo, Steven Houben, Jo Vermeulen y col. „Evaluation Strategies for HCI Toolkit Research“. En: Proc. 2018 CHI Conf. Hum. Factors Comput. Syst. - CHI '18 (2018), págs. 1-17 (vid. págs. 55, $158,159)$.

[145]Charles Lenay, Olivier Gapenne, Sylvain Hanneton, Catherine Marque y Christelle Genouëlle. „Chapter 16. Sensory substitution“. En: 2003, págs. 275-292 (vid. págs. 80, 81).

[146]Eva Lenz, Sarah Diefenbach y Marc Hassenzahl. „Exploring Relationships between Interaction Attributes and Experience“. En: DPPI 2013. ACM, 2013, págs. 126-135 (vid. págs. 56, 66-68).

[147]Kurt Lewin. Field theory in social science. Harper \& Bros, 1951 (vid. pág. 11).

[148]Makayla Lewis, Miriam Sturdee y Nicolai Marquardt. „Applied Sketching in HCI: Hands-on Course of Sketching Techniques“. En: Ext. Abstr. 2018 CHI Conf. Hum. Factors Comput. Syst. CHI EA '18. New York, NY, USA: ACM, 2018, C08:1-C08:4 (vid. pág. 12).

[149]Makayla Lewis, Miriam Sturdee, Nicolai Marquardt y Thuong Hoang. „SketCHI: Hands-on Special Interest Group on Sketchin in HCI“. En: Ext. Abstr. - CHI '18. April. 2018, págs. 1-4 (vid. pág. 12).

[150]Ted G Lewis. „Cognitive stigmergy: A study of emergence in small-group social networks“. En: Cogn. Syst. Res. 38 (2012), págs. 4-13 (vid. pág. 113).

[151]Youn-kyung Lim, Sang-Su Lee y Kwang-young Lee. „Interactivity attributes“. En: CHI 2009. New York, New York, USA: ACM Press, abr. de 2009, pág. 105 (vid. págs. 56, 58-60, 63, 125, 126).

[152]Youn-Kyung Lim, Erik Stolterman y Josh Tenenberg. „The anatomy of prototypes“. En: ACM TOCHI 15.2 (jul. de 2008), págs. 1-27 (vid. págs. 56, 58, 59, 63, 84, 115, 117, 144, 145).

[153]Jonas Löwgren y Erik Stolterman. Thoughtful Interaction Design: A Design Perspective on Information Technology. MIT Press, 2004, xiii, 198 p. (Vid. págs. 3, 43-46).

[154]Remko van der Lugt. „How sketching can affect the idea generation process in design group meetings“. En: Des. Stud. 26.2 (mar. de 2005), págs. 101-122 (vid. pág. 53).

[155]Kent Lyons, David H. Nguyen, Shigeyuki Seki y col. „BitWear“. En: Proc. Adjun. Publ. 26th Annu. ACM Symp. User interface Softw. Technol. - UIST '13 Adjun. New York, New York, USA: ACM Press, 2013, págs. 73-74 (vid. pág. 56).

[156]W Mackay y A Fayard. „HCI, Natural Science and Design: A Framework for Triangulation Across Disciplines“. En: DIS’ 97 Amsterdam (1997), págs. 223-233 (vid. págs. 1, 8, 9, 172).

[157]S. Mann. „Wearable computing: a first step toward personal imaging“. En: Computer (Long. Beach. Calif). 30.2 (1997), págs. 25-32 (vid. pág. 17).

[158]Nicolai Marquardt. „Proxemic interactions in ubiquitous computing ecologies“. Tesis doct. Calgary, 2013 (vid. pág. 12). 
[159]Nicolai Marquardt y Saul Greenberg. „Distributed Physical Interfaces With Shared Phidgets“. En: Proc. 1st Int. Conf. Tangible Embed. Interact. - TEI 'O7 (2007), págs. 13-20 (vid. pág. 56).

[160]Nicolai Marquardt y Saul Greenberg. „Sketching User Experiences“. En: Proc. 33rd Annu. ACM Conf. Ext. Abstr. Hum. Factors Comput. Syst. - CHI EA '15. New York, New York, USA: ACM Press, 2015, págs. 2479-2480 (vid. pág. 12).

[161]Nikolas Martelaro, Wendy Ju y Mark Horowitz. „The Interaction Engine“. En: Desigh Think. Res. Undersanding Innov. Ed. por Larry Leifer, Hasso Plattner y Christoph Meinel. Springer International Publishing, 2018, págs. 147-169 (vid. págs. 56, 73, 74).

[162]Jonatan Martínez, Arturo S. García, Miguel Oliver, José P. Molina y Pascual González. „VITAKI: A Vibrotactile Prototyping Toolkit for Virtual Reality and Video Games“. En: Int. J. Hum. Comput. Interact. 30.11 (nov. de 2014), págs. 855-871 (vid. págs. 56, 70, 72).

[163]Humberto R. Maturana y Francisco J. Varela. The tree of knowledge : the biological roots of human understanding. Shambhala, 1992, pág. 269 (vid. págs. 27, 28).

[164]Ali Mazalek, Elise van den Hoven y Elise Den hoven. „Framing tangible interaction frameworks“. En: Artif. Intell. Eng. Des. Anal. Manuf. 23.3 (jun. de 2009), págs. 225-235 (vid. pág. 56).

[165]John McCarthy y Peter Wright. Technology as experience. The MIT Press, 2007, pág. 224 (vid. pág. 4).

[166]Robert McKim. Experiences in visual thinking. Cengeage Learning, 1980 (vid. pág. 5).

[167]Anita Meier, Denys J C Matthies, Bodo Urban y Reto Wettach. „Exploring Vibrotactile Feedback on the Body and Foot for the Purpose of Pedestrian Navigation". En: Proc. 2Nd Int. Work. Sensor-based Act. Recognit. Interact. iWOAR '15. New York, NY, USA: ACM, 2015, 11:1-11:11 (vid. pág. 113).

[168]Christoph Meinel y Larry Leifer. Design Thinking Research - Building Innovators. 2015, págs. xiii-xxi. arXiv: arXiv:1011.1669v3 (vid. pág. 42).

[169]Christoph Meinel y Larry Leifer. Design thinking. Understand. Improve. Apply. Springer, 2011. arXiv: arXiv: 1011.1669v3 (vid. pág. 42).

[170]Maurice Merleau-Ponty. Fenomenología De la Percepción. 1945, pág. 474 (vid. págs. 3, 18).

[171]Bill Moggridge. Designing interactions. The MIT Press, 2009, pág. 792 (vid. págs. 45, 46, 53).

[172]Camille Moussette y Fabricio Dore. „Sketching in Hardware and Building Interaction Design : tools, toolkits and an attitude for Interaction Designers“. En: Proc. Des. Res. Soc. IxD. Montreal, Canada: Design Research Society, Canada, 2010 (vid. págs. 124, 138).

[173]Brad Myers, Scott E. Hudson, Randy Pausch y Randy Pausch. „Past, present, and future of user interface software tools“. En: ACM TOCHI 7.1 (mar. de 2000), págs. 3-28 (vid. págs. 125, 147).

[174]Alan Newell y Herbert Simon. Human problem solving. Englewood Cliffs: Prentice Hall, 1972 (vid. págs. 17, 18).

[175]Mark W. Newman y James A. Landay. „Sitemaps, storyboards, and specifications“. En:Proc. Conf. Des. Interact. Syst. Process. Pract. methods, Tech. - DIS '00. New York, New York, USA: ACM Press, 2000, págs. 263-274 (vid. pág. 64).

[176]D.N. Norman. The design of everyday things. 1988 (vid. págs. 20, 27).

[177]Donald A. Norman. Emotional design. Vol. 2004. January. 2004, págs. 1-1 (vid. pág. 43).

[178]Donald A. Norman. The invisible computer : why good products can fail, the personal computer is so complex, and information appliances are the solution. MIT Press, 1998, pág. 302 (vid. pág. 47). 
[179]Donald A. Norman y Stephen W. Draper. User centered system design: new perspectives on humancomputer interaction. L. Erlbaum Associates, 1986, pág. 526 (vid. pág. 11).

[180]Scott D. Novich y David M. Eagleman. „Using space and time to encode vibrotactile information: toward an estimate of the skin's achievable throughput“. En: Exp. Brain Res. 233.10 (2015), págs. 2777-2788 (vid. págs. 33, 112).

[181]Zeljko Obrenovic y Jean-Bernard Martens. „Sketching interactive systems with sketchify“. En: ACM TOCHI 18.1 (abr. de 2011), págs. 1-38 (vid. págs. 56, 62-64).

[182]Dan R. Olsen Jr. „Evaluating user interface systems research“. En: 20th Annu. ACM Symp. User interface Softw. Technol. (2007), págs. 251-258 (vid. págs. 125, 147, 157).

[183]Kees C.J. Overbeeke y Stephan S.A.G. Wensveen. „From perception to experience, from affordances to irresistibles“. En: Proc. 2003 Int. Conf. Des. pleasurable Prod. interfaces - DPPI '03. New York, New York, USA: ACM Press, 2003, pág. 92 (vid. pág. 36).

[184]Dan Overholt. „A System for Sketching in Hardware : Do-It-Yourself Interfaces for Sound and Music Computing“. 2012 (vid. pág. 124).

[185]Nenad Pavel. The Industrial Designer's Guide to Sketching. 2005 (vid. pág. 1).

[186]Daniela Petrelli, Nick Dulake, Mark Marshall y col. „Prototyping Tangibles: Exploring Form and Interaction Daniela“. En: Proc. 8th Int. Conf. Tangible, Embed. Embodied Interact. - TEI '14. New York, New York, USA: ACM Press, 2013, págs. 41-48 (vid. págs. 56, 65).

[187]Hasso Plattner, Christoph Meinel y Larry Leifer. Design thinking research: Making design thinking foundational. 2015. arXiv: arXiv:1011.1669v3 (vid. pág. 42).

[188]Hasso Plattner, Christoph Meinel y Larry Leifer. Design thinking research. Studying co-creation in practice. Springer, 2012. arXiv: 1002.2080 (vid. pág. 42).

[189]Mary C. Potter y Barbara Faulconer. „Time to understand pictures and words“. En: Nature 253.5491 (feb. de 1975) (vid. pág. 53).

[190]Jennifer Preece, Yvonne Rogers y Hellen Sharp. Interaction design. 4th edition. Wiley, 2015 (vid. pág. 6).

[191]A T Purcell y J S Gero. „Drawings and the design process“. En: Des. Stud. 19.4 (1998), págs. 389-430 (vid. pág. 52).

[192]Philip Quinn, Andy Cockburn, Géry Casiez, Nicolas Roussel y Carl Gutwin. „Exposing and Understanding Scrolling Transfer Functions“. En: Proc. 25th Annu. ACM Symp. User Interface Softw. Technol. UIST '12. New York, NY, USA: ACM, 2012, págs. 341-350 (vid. pág. 126).

[193]M. Resnick, B. Myers, K. Nakakoji y col. Design principles for tools to support creative thinking. Inf. téc. Washington, DC, USA: National Science Foundation, 2005, págs. 1-16 (vid. pág. 126).

[194]Román Reyes. Diccionario crítico de ciencias sociales. México: Editorial Plaza y Valdez, 2009 (vid. pág. 87).

[195]H.W.J. Rittel y M.M. Webber. „Dilemnas in a general theory of planning“. En: Policy Sci. 4.December (1973), págs. 155-169 (vid. pág. 43).

[196]Dan Roam. The Back of the Napkin. Expanded edition. 2009 (vid. pág. 12).

[197]Toni Robertson. „Cooperative Work and Lived Cognition: A Taxonomy of Embodied Actions“. En: Proc. Fifth Conf. Eur. Conf. Comput. Coop. Work. ECSCW'97. Norwell, MA, USA: Kluwer Academic Publishers, 1997, págs. 205-220 (vid. págs. 53, 116). 
[198]Andrés Rodríguez, Pascual González y Gustavo Rossi. „Marco de Trabajo para el Bocetado de Interacciones Enactivas“. En: Rev. Colomb. Comput. 16.1 (2015), págs. $48-74$ (vid. pág. 138).

[199]Andrés Rodriguez, Pascual González, Gustavo Rossi y col. „Enactive Sketches for Designing Enactive Interactions“. En: Proc. Lat. Am. Conf. Hum. Comput. Interact. CLIHC '15. New York, NY, USA: ACM, nov. de 2015, 15:1-15:4 (vid. pág. 10).

[200]Yvonne Rogers. HCI Theory: Classical, Modern, and Contemporary. Morgan \& Claypool Publishers, 2012, págs. 1-129 (vid. págs. 3, 7).

[201]Yvonne Rogers. „New theoretical approaches for human-computer interaction“. En: Annu. Rev. Inf. Sci. Technol. 38.1 (sep. de 2005), págs. 87-143 (vid. págs. 43, 46, 113).

[202]Yvonne Rogers y Henk Muller. „A framework for designing sensor-based interactions to promote exploration and reflection in play“. En: Int. J. Hum. Comput. Stud. 64.1 (2006), págs. 1-14 (vid. págs. 55-57, 66, 67).

[203]Mike Rohde. The Sketchnote Handbook: the illustrated guide to visual note taking. Peachpit Press, 2013 (vid. pág. 12).

[204]Iris van Rooij, Raoul M. Bongers y F.G. Haselager. „A non-representational approach to imagined action“. En: Cogn. Sci. 26.3 (mayo de 2002), págs. 345-375 (vid. pág. 10).

[205]Joel Sadler, Kevin Durfee, Lauren Shluzas y Paulo Blikstein. „Bloctopus“. En: Proc. Ninth Int. Conf. Tangible, Embed. Embodied Interact. - TEI '14. New York, New York, USA: ACM Press, 2015, págs. 347-354 (vid. págs. 56, 74, 75).

[206]Carlos Sainz Martinez y Faustina Hwang. „TESSA“. En: Proc. 33rd Annu. ACM Conf. Ext. Abstr. Hum. Factors Comput. Syst. - CHI EA '15. New York, New York, USA: ACM Press, 2015, págs. 259-262 (vid. págs. 56, 70, 71).

[207]Markus Lorenz Schilling, Ron Wakkary y William Odom. „Focus Framework“. En: TEI '18. New York, New York, USA: ACM Press, 2018, págs. 684-693 (vid. pág. 56).

[208]Donald A Schön. The Reflective Practitioner: How Professionals Think in Action. Basic Books, 1983. Cap. 374 (vid. págs. 11, 42, 44, 45, 47, 138).

[209]Donald A. Schon. „Designing as reflective conversation with the materials of a design situation“. En: Knowledge-Based Syst. 5.1 (mar. de 1992), págs. 3-14 (vid. págs. 3, 43, 54).

[210]Donald A. Schon y Glenn Wiggins. „Kinds of seeing and their functions in designing“. En: Des. Stud. 13.2 (abr. de 1992), págs. 135-156 (vid. pág. 52).

[211]Douglas. Schuler y Aki. Namioka. Participatory design : principles and practices. L. Erlbaum Associates, 1993, pág. 319 (vid. pág. 31).

[212] Stephen Scrivener y S M Clark. „Sketching in collaborative design“. En: Interact. with virtual Environ. Ed. por L MacDonald y J Vince. Chichester UK: Wiley, 1994 (vid. pág. 53).

[213]Orit Shaer, Nancy Leland, EduardoH. Calvillo-Gamez y RobertJ.K. Jacob. „The TAC paradigm: specifying tangible user interfaces“. En: Pers. Ubiquitous Comput. 8.5 (jul. de 2004) (vid. págs. 56, $62)$.

[214]Ehud Sharlin, Benjamin Watson, Yoshifumi Kitamura, Fumio Kishino y Yuichi Itoh. „On Tangible User Interfaces, Humans and Spatiality“. En: Pers. Ubiquitous Comput. 8.5 (2004), págs. 338-346 (vid. págs. 56, 64, 65).

[215]Ben Shneiderman. Leonardo's laptop. Human needs and the new computing technologies. The MIT Press, 2002 (vid. pág. 124). 
[216]Ben Shneiderman, Gerhard Fischer, Mary Czerwinski y col. „Creativity Support Tools: Report From a U.S. National Science Foundation Sponsored Workshop“. En: Int. J. Hum. Comput. Interact. 20.2 (mayo de 2006), págs. 61-77 (vid. págs. 124, 126).

[217]Herbert Simon. The sciences of the artificial. The MIT Press, 1969 (vid. págs. 18, 42).

[218]Michael Smyth, Ingi Helgason, Frank Kresin y col. „Maker Movements, Do-It-Yourself Cultures and Participatory Design: Implications for HCI Research Background and Questions". En: Chi Ea '18. 2018, págs. 1-7 (vid. pág. 68).

[219]Jelle Stienstra, C.J. Overbeeke y Stephan Wensveen. „Embodying Complexity Through Movement Sonification : Case Study on Empowering the Speed-skater". En: Proc. 9th ACM SIGCHI Ital. Chapter Int. Conf. Comput. Interact. Facing Complex. (2011), págs. 39-44 (vid. págs. 33, 34, 36).

[220]Thomas a. Stoffregen, Benoît G. Bardy y Bruno Mantel. „Affordances in the design of enactive systems“. En: Virtual Real. 10.1 (abr. de 2006), págs. 4-10 (vid. pág. 26).

[221]Erik Stolterman. „The 'transfer of rationality': Acceptability, adaptability and transparency of methods“. En: Proc. Second Eur. Conf. Inf. Syst. \{ECIS\} 1994, Nijenrode Univ. Netherlands, 1994. Ed. por Walter Baets. Nijenrode University Press, 1994, págs. 533-542 (vid. págs. 46, 113).

[222]Erik Stolterman. „The Nature of Design Practice and Implications for Interaction Design Research“. En: Int. J. Des. 2.1 (2008), págs. 55-65 (vid. págs. 44, 46).

[223]Lucy Suchman. Human-machine reconfigurations. Plans and situated Actions, 2nd edition. Cambridge University Press, 2007 (vid. págs. 3, 5, 19, 22, 23, 114).

[224]Lucy Suchman. Plans and Situated Actions. Cambridge University Press, 1987. Cap. IV, pág. 224 (vid. págs. 4, 22).

[225]Workshop Summaries, Makayla Lewis, Miriam Sturdee y col. „SketchingDIS : Hand-drawn sketching in HCI“. En: DIS '17. 2017, págs. 356-359 (vid. pág. 12).

[226]Masaki Suwa y Barbara Tversky. „What architects see in their sketches“. En: Conf. companion Hum. factors Comput. Syst. common Gr. - CHI '96. New York, New York, USA: ACM Press, 1996, págs. 191-192 (vid. pág. 43).

[227]Dag Svanaes. Understanding Interactivity. Steps to a phenomenology of human-computer interaction. 2000, págs. 1-294 (vid. pág. 60).

[228]John Sweller. „Cognitive load theory, learning difficulty, and instructional design“. En: Learn. Instr. 4.4 (ene. de 1994), págs. 295-312 (vid. pág. 20).

[229]J.C. Tang. „Toward an understanding of the use of shared workspaces by design teams“. Tesis doct. Stanford University, 1989 (vid. págs. 53, 116).

[230]Toshiharu Taura y Yukari Nagai. Design creativity 2010. Ed. por Toshiharu Taura y Yukari Nagai. Springer, 2010 (vid. pág. 1).

[231]Esther Thelen, Gregor Schoner, Christian Scheier y Linda B Smith. „The Dynamics of Embodiment: A Field Theory of Infant“. En: Behav. Brain Sci. 24 (2001), págs. 1-86 (vid. pág. 18).

[232]Esther Thelen y Linda B. Smith. A dynamic systems approach to the development of cognition and action. MIT Press, 1994, pág. 376 (vid. págs. 4, 24).

[233]Guy Theraulaz y Eric Bonabeau. „A brief history of stigmergy“. En: Artif. Life (1999) (vid. pág. 114).

[234]Steve Torrance. „In search of the enactive: Introduction to special issue on enactive experience“. En: Phenomenol. Cogn. Sci. 4.4 (2005), págs. 357-368 (vid. pág. 28). 
[235]Tuomo Tuikka y Kari Kuutti. „Thinking Together in Concept Design for Future Products - Emergent Features for Computer Support“. En: Proc. 4th Int. Conf. Cogn. Technol. Instruments Mind. CT '01. London, UK, UK: Springer-Verlag, 2001, págs. 40-54 (vid. págs. 116, 117).

[236]Jakob von Uexkull. Andanzas por los mundos circundantes de los animales y los hombres. Buenos Aires: Editorial Cactus, 2016 (vid. págs. 28, 82).

[237]B Ullmer e H Ishii. „Emerging frameworks for tangible user interfaces“. En: IBM Syst. J. 39.3-4 (2000). Ed. por John M Carroll, págs. 915-931 (vid. págs. 28, 56-58, 62, 126).

[238]Brygg Ullmer e Hiroshi Ishii. „The metaDESK“. En: Proc. 10th Annu. ACM Symp. User interface Softw. Technol. - UIST '97 (1997), págs. 223-232 (vid. pág. 29).

[239]F J Varela, E Thompson y E Rosch. The embodied mind. Vol. 6. 3. MIT Press, 1991, págs. 151-172 (vid. págs. 3, 27).

[240]Bill Verplank. Interaction Design Sketchbook. Inf. téc. July 2009. Media Computing Group. RTWH Aachen University, 2003, págs. 1-20 (vid. pág. 2).

[241]Yon Visell. „Tactile sensory substitution: Models for enaction in HCI“. En: Interact. Comput. 21.1-2 (ene. de 2009), págs. 38-53 (vid. págs. 80-82).

[242]Karel Vredenburg, Ji-Ye Mao, Paul W. Smith y Tom Carey. „A survey of user-centered design practice“. En: Proc. SIGCHI Conf. Hum. factors Comput. Syst. Chang. our world, Chang. ourselves CHI '02. New York, New York, USA: ACM Press, 2002, pág. 471 (vid. pág. 17).

[243]Lev S Vygotsky. Thought and language. Cambridge MA: The MIT Press, 1956 (vid. pág. 21).

[244]Mark Weiser y Mark. „The computer for the 21st century“. En: ACM SIGMOBILE Mob. Comput. Commun. Rev. 3.3 (jul. de 1999), págs. 3-11 (vid. págs. 3, 17).

[245]S A G Wensveen, J P Djajadiningrat y C J Overbeeke. „Interaction Frogger: A Design Framework to Couple Action and Function Through Feedback and Feedforward“. En: Proc. 5th Conf. Des. Interact. Syst. Process. Pract. Methods, Tech. DIS '04. New York, NY, USA: ACM, 2004, págs. 177-184 (vid. págs. 56, 65, 66).

[246]S.A.G. Wensveen. „Design research: generating knowledge through doing“. En: SIDER 08. Sonderborg, Denmark: Mads Clausen Institute, Univ. of Southern Denmark, 2008, págs. 10 -10 (vid. pág. 10).

[247]Mikael Wiberg y Erik Stolterman. „What makes a prototype novel?" En: Proc. 8th Nord. Conf. Human-Computer Interact. Fun, Fast, Found. - Nord. '14 October 2015 (2014), págs. 531-540 (vid. pág. 158).

[248]T Winograd. „From Computing Machinery to Interaction Design“. En: Beyond Calc. Next Fifty Years Comput. Ed. por Peter Denning y Robert Metcalfe. Amsterdam: Springer, 1997, págs. 149-162 (vid. pág. 7).

[249]Terry Winograd, John Bennett, Laura De Young y Bradley Hartfield. Bringing design to software. New York: Addison Wesley, 1996 (vid. págs. 3, 42, 46, 123).

[250]Terry Winograd y Fernando Flores. Understanding computers and cognition a new foundation for design. Addison-Wesley, 1987. Cap. 5 (vid. pág. 4).

[251]Jacob O Wobbrock y Julie A Kientz. „Research Contributions in Human-computer Interaction“. En: interactions 23.3 (2016), págs. 38-44 (vid. págs. 13, 123, 175).

[252]Jong-bum Woo, Da-jung Kim, Jaesung Jo y Youn-kyung Lim. „Interactivity Sketcher: Crafting and Experiencing Interactivity Qualities“. En: CHI 2011 (2011), págs. 1429-1434 (vid. pág. 125). 
[253]Jong-bum Woo, Da-jung Kim, Suin Kim, Jaesung Jo y Youn-kyung Lim. „Interactivity sketcher“. En: CHI 2011. New York, New York, USA: ACM Press, mayo de 2011, pág. 1429 (vid. págs. 56, $62,63,65)$.

[254]John Zimmerman, Jodi Forlizzi y Shelley Evenson. „Research Through Design as a Method for Interaction Design Research in HCI design research in HCI“. En: Proc. SIGCHI Conf. Hum. factors Comput. Syst. 2007, págs. 493-502 (vid. págs. 11, 46). 



\section{Índice de figuras}

1.1 Bocetos de Bill Verplank para un proyecto de "Haptic pager" [240] . . . . . . . . . 2

1.2 Iteración básica de diseño según McKim, tomado de [166] . . . . . . . . . . 5

1.3 Contexto de la investigación de acuerdo con el Computing Coding System de ACM 6

1.4 HCI crea y examina la interacción de la gente con artefactos creados artificialmente, moviéndose entre la teoría y la observación empírica. Las cajas representan la interacción con los artefactos creados artificialmente. Adaptada del trabajo de Mackay y Fayard[156] . . . . . . . . . . . . . . . . . . . . . 9

1.5 Implementación de la triangulación de métodos en este proyecto $\ldots \ldots$. . . . . 10

$2.1 \quad$ El modelo del Procesamiento Humano de Información de [34] . . . . . . . . . . . 19

2.2 Esquema de Cognición Corporizada, adaptado de Hummels[109] . . . . . . . . . 20

2.3 Evolución del flujo de interacciones enactivas . . . . . . . . . . . . 25

2.4 El modelo cognitivista de interacción . . . . . . . . . . . . . . . . 25

2.5 Modelo enactivo de interacción . . . . . . . . . . . . . . . . . . . 25

2.6 Las affordances no son propiedades del objeto, sino relaciones percibidas en el contexto. El mismo curso de agua puede parecer "cruzable" o no dependiendo del contexto y la situación . . . . . . . . . . . . . . . . . . 26

2.7 Sistema transBOARD con sus "hipertarjetas" de Ullmer y Ishii[238 $\ldots \ldots$. . . . . . 29

2.8 Passive Lens en MetaDesk . . . . . . . . . . . . . . . . . . . . . . . . . . 29

2.9 Active Lens en MetaDesk . . . . . . . . . . . . . . . . . . . . . . . . . . . . . 29

2.10 Reactable . . . . . . . . . . . . . . . . . . . 31

2.11 Esquema de ASE (Augmented Skating Experience) de Stienstra[219] . . . . . . . 33

2.12 Componentes de ASE de Stienstra[219] . . . . . . . . . . . . . . . . . 34

2.13 Chaleco para transducir sonido a feedback vibrotáctil de Novich y Eagleman . . . 35

3.1 Modelo de investigación iterativa a la manera del diseño adaptada de Dalsgaard[45] 45

3.2 Ejemplos de bocetos durante el diseño de interacciones para un dispositivo con feedback vibrotáctil. A la izquierda y centro estudios sobre posibles circuitos y conexiones, a la derecha esbozo de guante con ubicación de sensores y actuadores (de los talleres reportados en el Capítulo 4) f . . . . . . . . . . . . . . 50

3.3 El doble embudo de diseño: elaboración (búsqueda de ideas y posibilidades, divergencia) y reducción (evaluación y toma de decisiones, convergencia). El primero es dominado fundamentalmente por el bocetado (barato y rápido) mientras los prototipos (más elaborados y caros) son la base para la toma de decisiones basada en pruebas. Adaptado de Buxton[32] y Laseau[140] . . . . . . . . . . . . . . . . 51 
3.4 Modelo de interacción de interfaces tangibles MCRpd -Model Control Representation (physical and digital)- propuesto por Ullmer e Ishii y basado en el MVC de Smalltalk-80. Tomado de [237] . . . . . . . . . . . . . . . . 58

3.5 Soporte del pensamiento de diseño en d.tools[94] . . . . . . . . . . . . . . . . . . 61

3.6 d.tools en modo análisis. La ejecución del statechart y el video se sincronizan y marcan para facilitar el análisis . . . . . . . . . . . . . . . . . 62

3.7 Pipeline en Squidy. El pipeline recibe datos de posición, botón e inercia del puntero laser, aplica un filtro Kalman, un filtro para reconocer cambio y otro para mejora de la selección y finalmente emula un mouse standar y envía datos via TUIO a las aplicaciones registradas. En la parte inferior de la pantalla presenta la base disponible de inputs, filtros y outputs. Tomado del trabajo de König[134] . . . . .

3.8 Boceto a mano alzada en Sketchify que contiene tres regiones activas para capturar los eventos del mouse y simular interacción. Tomado de [181] . . . . . . . . . . . 64

3.9 Interactivity sketcher. A la izquierda hardware que integra el toolkit, a la derecha layout de la aplicación IA para configurar la interactividad. Adaptado de [253] . . 65

3.10 El marco Interaction Frogger de Wensveen. Esquema de las posibilidades de acoplamiento entre la información funcional y las acciones del usuario. En términos de los autores: la información inherente y aumentada se puede usar como "saltos de rana" cuando el acoplamiento directo no se puede usar. Tomada de [245] . . . 66

3.11 Comparación de perfiles de interacción de tres objetos (lámpara, marco de fotos y caja para un anillo de compromiso) con el vocabulario de Lenz, tomada de [146]

3.12 Una consola construida con varios inputs y outputs utilizados para ajustar el control del volumen utilizando Phidgets. Tomado de [85] . . . . . . . . . . . 69

3.13 Componentes de input en iStuff, de https://hci.stanford.edu/research/istuff/ . . 69

3.14 Captura de pantalla de la interfaz ECCE para defnir entidades interactivas conectadas a la placa Tinkerkit. El usuario hace drag\&drop del sensor o actuador desde la paleta al puerto deseado. Tomado de $[20] \ldots \ldots$. . . . . . . . 70

3.15 Programación por demostración en ECCE. El usuario interactúa con el sensor para completar las reglas de activación. Tomado de [20] . . . . . . . . . . . . 70

3.16 TESSA. Izquierda, configuración como guante y como cinturón. Derecha, GUI para configurar. Tomado de [206] . . . . . . . . . . . . . . . . . . . 71

3.17 Izquierda: concepto de WatchConnect: a) prototipo de smartwatch con sensores, b) capa de hardware extensible, c) plataforma de desarrollo en PC, d) interacciones entre dispositivos con e) superficies interactivas. Derecha: arquitectura general del software . . . . . . . . . . . . . . . . . . . 72

3.18 Codificación de la señal Morse de la letra d con la interfaz gráfica de Vitaki. Tomado de [162] . . . . . . . . . . . . . . . . . . . 72

3.19 Representación visual o en formato texto del código. Tomado de [10] . . . . . . . 73

3.20 Base de Modkit para la composición visual de los bocetos con Arduino más sensores y actuadores. Tomado de $[10] \ldots \ldots$. . . . . . . . . . . . 73 
3.21 Arquitectura conceptual del Motor de interaccioens, que facilita las interacciones físicas y digitales entre personas, la nube y los dispositivos. Como se advierte en la figura está centrado en una computadora de tarjeta única, un microcontrolador, software abierto y conexión a servicios de la nube. Los autores lo han implementado utilizando Arduino como microcontrolador de sensroes y actuadores y desde Raspebrry Pi hasta ODROID XU-3 de ocho cores como computadora central. Tomado de $[161] \ldots \ldots \ldots \ldots \ldots$. . . . . . . . . . . . . . 74

3.22 Ejemplo de un prototipo de controlador para un DJ construido con Bloctopus.

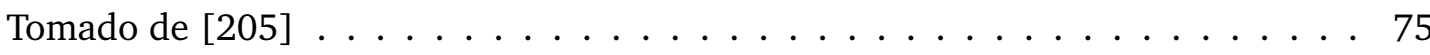

4.1 A la izquierda la versión original de TVSS por Bach-y-Rita con un array de 20x20 pines vibrotáctiles aplicados en la zona lumbar para representar la imagen capturada por la cámara. A derecha una versión posterior con un array de pines en el abdomen y la cámara montada en la cabeza, de [241] . . . . . . . . . . . . . 81

4.2 Enactive Torch de Froese $[73] \ldots \ldots \ldots \ldots$. . . . . . . . . . . 83

4.3 Un sector del aula taller utilizada . . . . . . . . . . . . . . . . 86

4.4 Abuelino: los aspectos visuales del títere se estructuraron de manera oportunista a partir de la forma del sensor de ultrasonido . . . . . . . . . . . . . . 89

4.5 Algunos pasos en el bocetado de Abuelino: bocetado del cuerpo a partir de retazos disponibles de telas, construcción de la curva de interactividad mediante secuencias de programación, descarga a placa, ejecución y corrección, pruebas con usuarios y boceto final . . . . . . . . . . . . . . . . . . 90

4.6 Atrapa pesadillas: maqueta inicial, bocetos en papel, pruebas funcionales, boceto

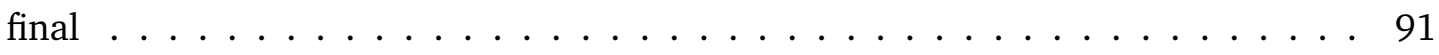

4.7 Mouse háptico: primeros bocetos interactivos, pruebas funcionales con usuario y boceto final . . . . . . . . . . . . . . . . . . . 91

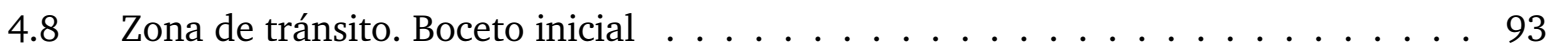

4.9 Zona de tránsito. Ultimo boceto de dispositivo vestible . . . . . . . . . . . . . 93

4.10 Zona de tránsito. Elaboración de cinturón en pecho . . . . . . . . . . . . . 93

4.11 Zona de tránsito, propuesta de instalación . . . . . . . . . . . . . . . . 94

4.12 Aplausos corporales, boceto papel . . . . . . . . . . . . . . . . . 94

4.13 Aplausos corporales, prueba de boceto de actuador . . . . . . . . . . . . . 95

4.14 Aplausos corporales, prueba en boceto de experiencia . . . . . . . . . . . . . 95

4.15 Tocar el alma. Boceto a mano alzada de la posible estructura de interfaz . . . . . 96

4.16 Tocar el alma. Boceto de circuito utilizando lenguaje de esquemas electrónicos y anotaciones de materiales . . . . . . . . . . . . . . . . 97

4.17 Tocar el alma. Boceto en prueba de usuario durante la demo final . . . . . . . . 97

4.18 Sphaira. Boceto inicial de plano ecuatorial con posible fijación de motores vibradores 98

4.19 Sphaira. Versión de boceto con motores y electrónica fijada con precintos previa al cierre y demo. . . . . . . . . . . . . . . . . . . . . 99

4.20 Proyecto Color por Calor. Idea general de sensado en guante y actuado en chaleco 100 
4.21 Proyecto Color por Calor. Ideas para el circuito de sensado y actuación dibujadas como esquemático . . . . . . . . . . . . . . . . . . . . . 101

4.22 Proyecto zapatillas para ciegos. Boceto de ubicación de actuadores . . . . . . . . 102

4.23 Proyecto zapatillas para ciegos. Sensor de color, primer boceto (izquierda) y refinamiento de prototipo con carcasa impresa en 3D y componentes soldados (derecha) . . . . . . . . . . . . . . . . . . . . . 103

4.24 Proyecto zapatillas para ciegos. Boceto de zapatilla utilizado en la demo final . . 104

4.25 Letras en los dedos. Boceto en papel con los bloques de software y las conexiones requeridas . . . . . . . . . . . . . . . . . . . . 105

4.26 Letras en los dedos. Bocetos en papel con ideas del guante, componentes y cableado105

4.27 Letras en los dedos. Bocetos en hardware del guante. Nótese la aproximación rápidad de fijar una protoboard al guante con precintos y utilizar cableado con jumpers simples para las conexiones . . . . . . . . . . . . . . . . 106

4.28 Letras en los dedos. Segundo boceto en hardware, incorporando el módulo Bluetooth y el Arduino Nano, con el boceto de aplicación Android para recibir el input mediante texto escrito . . . . . . . . . . . . . . . . . 107

$4.294 .7 \mathrm{k}$ Luz háptica. Bocetos en harware . . . . . . . . . . . . . . . . . . . . . 108

$4.304 .7 \mathrm{k}$ Luz háptica. Prueba con usuario . . . . . . . . . . . . . . . . . . . . 108

4.31 Empatheia vibratio. Visualización que inspiró al grupo sobre los twits de las tribus a favor (verde) y en contra (rojo) de la legalización del aborto. Tomado de https://elgatoylacaja.com.ar/pensar_con_otros/capitulo-7 . . . . . . . . . . 109

4.32 Empatheia. El proceso incluyó diversas actividades de tinkering y desguace, en este caso de un controlador de juegos para extraer los motores vibradores . . . 110

4.33 Empatheia. Bocetado de componentes vestibles. Izquierda: vincha para "movilizar pensamientos"; derecha: cinturón pectoral para "abrir el corazón al diálogo" . . . 110

4.34 Caricias remotas. Bocetado de ideas para el dispositivo de actuación y sensado . . 111

4.35 Caricias remotas. Prueba de experiencia . . . . . . . . . . . . . . 111

5.1 Ubicación de las contribuciones de este capítulo en la triangulación de métodos utilizada . . . . . . . . . . . . . . . . . . . . . . . . . 123

5.2 Storyboard con el proceso de composición imaginado para idear un bastón aumentado o enactivo para ciegos . . . . . . . . . . . . . . . . . 127

5.3 Modelo del boceto en Pluma . . . . . . . . . . . . . . . . . . . . . . . . . 128

5.4 Esquema general de Pluma . . . . . . . . . . . . . . . . . . . . . . . . . 129

5.5 Esquema de conexiones en Pluma . . . . . . . . . . . . . . . . . . . 130

5.6 Pasos en el uso de Pluma. En la fila superior: apertura del entrenador de gestos, registro de un gesto y agregado a Biblioteca. Fila inferior: selección y agregado de inputs y outputs, vinculación y definición de interactabilidad, prueba con boceto hardware . . . . . . . . . . . . . . . . . . . . 131

5.7 Caja adoptada como maqueta del control con el agregado de unos recortes de papel para simular las teclas de acción . . . . . . . . . . . . . . . . 134 
5.8 Para expresar interactabilidad pretendida, los diseñadores utilizaron anotaciones textuales ("sacude a derecha", "creciente") e iconográficas (ver flecha a la izquierda y signo de ondas en expansión a la derecha) en sus bocetos. . . . . . . . . . . . 135

5.9 Uso de anotaciones, flechas y signos en bocetos . . . . . . . . . . . . . . . 135

5.10 Agregado de motores tipo ERM a los lados de la maqueta para intentar generar el feedback vibro-táctil buscado . . . . . . . . . . . . . . . . . . . . 136

5.11 Boceto en hardware con las conexiones a los motores en la maqueta. Los circuitos para los motores debieron ser implementados por el ingeniero ante la falta de experiencia de los otros diseñadores. Aunque el esquema fue proporcionado y coincidía con otro que encontraron en internet, no se arriesgaron "a romper nada"

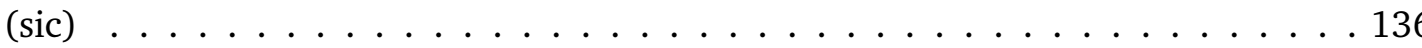

5.12 Definición de interactividad con Pluma. Definición de gestos como input (a la izquierda ejecución del gesto sobre Leap Motion, derecha reconocimiento y definición por Pluma). Agregado y configuración de un motor vibrador como output. Relación entre input y output y asignación de parámetros de interactividad . . . . 137

5.13 Modelo de bocetado de interacciones enactivas. Plano de corporización versus extensión-profundidad de interactabilidad . . . . . . . . . . . . . . . . . . . 143

5.14 Modelo de bocetado de interacciones enactivas. Organización temporal del plano de corporización y extensión-profunidad ． . . . . . . . . . . . . . . . . . . . 144

5.15 Modelo de bocetado de interacciones enactivas. Existe una trazabilidad entre las diferentes huellas creativas del proceso. . . . . . . . . . . . . . . . . . . 145

5.16 Metáfora del cuaderno enactivo de bocetos . . . . . . . . . . . . . . . . . . 148

5.17 Base de cuaderno de bocetos . . . . . . . . . . . . . . . . . . . . . . 149

5.18 En el Cuaderno es posible consultar la historia de actividades del bocetado como registro de las huellas creativas. A la derecha de la pantalla se accede a la línea temporal de trabajo y con un clic en el link correspondiente se abre una nueva ventana que muestra el estado del boceto tras la acción seleccionada. El diseñador puede acumular en pantalla tantas vistas como desee para re-visitar la historia y eventualmente iniciar nuevas líneas de indagación . . . . . . . . . . . . . . . . 150

5.19 Escenario de uso: Agustín boceta sus ideas en papel y las incluye en Pluma. El boceto se agrega como imagen reducida con datos de huella y comentarios en el Cuaderno. Además puede visualizarse completo en ventana nueva . . . . . . . . . 151

5.20 Escenario de uso: Agustín agrega tres sketgets a su boceto: un Sensor US (para actuar), un Motor (para percibir) y una Interacción Uniforme . . . . . . . . . . 152

5.21 Escenario de uso: Agustín construye su boceto en hardware e interactúa con él provechando los proxies en Pluma . . . . . . . . . . . . . . . . . . 152

5.22 Escenario de uso: Agustín explora otras dimensiones del boceto (formas, tamaños) con una primera maqueta interactiva que puede integrar en Pluma con fotos o videos de uso . . . . . . . . . . . . . . . . . . . . . . . . . 153

5.23 Modelo general de Pluma . . . . . . . . . . . . . . . . . . . 154

5.24 Relaciones entre los elementos de Accion y Percepción (proxies de los componentes de hardware) y los de Interacción (mediadores y decoradores) . . . . . . . . . . 155 
5.25 Diseño conceptual del cuaderno . . . . . . . . . . . . . . . . . . . . . 156

5.26 Shield Grove para Arduino Uno R3. 1.Cuatro puertos analógicos. 2.Siete puertos digitales. 3. Un puerto UART. 4. Cuatro puertos I2C. 5. Switch alimentación (3-5v). 6. Botón reset. 7. LED de Power on. 8. Pines para soldar si se usa con Seeduino V3, placa de SeeedStudio compatible con Arduino . . . . . . . . . . . . . . 157

5.27 Comparación de las diferencias entre conectar un potenciómetro y un Led utilizando el kit Grove o utilizando una conexión directa entre protoboard y Arduino 158

5.28 Boceto en hardware para un MP3 Player controlado por gestos (fotografía de Sketching User Experiences[32]) . . . . . . . . . . . . . . . . . . . . . 162

5.29 Demo Audio Player. Composición inicial en el Cuaderno con dos sketgets de gestos para activar dos audios. Incluye el boceto 2D inicial importado en el Cuaderno . . 162

5.30 Demo Audio Player. Construcción y prueba de boceto con hardware. En el insert, el detalle del boceto con un sensor LDR y un acelerómetro incluido (para modificar la luz que ingresa simplemente se cubre parcial o totalmente la abertura con la mano). En la foto principal, el diseñador prueba su boceto hardware después de haber modificado la composición de sketgets en el Cuaderno de Pluma . . . . . . 163

5.31 Storyboard del concepto de FeelMessenger, usuarios intercambiando mensajes hápticos expresivos con hardware embebido en dispositivos de consumo, tomado de $[116] \ldots \ldots$. . . . . . . . . . . . . . . . . . . . . . . 164

5.32 Demo Feel Messenger. Prueba de boceto enactivo. El boceto de la experiencia puede ser algo tan simple como combinar un par de botones GUI en una pantalla y un Motor DC colocado dentro de una muñequera (ver imagen interna) . . . . . 164

5.33 Demo Feel Messenter. Cada sketget de interacción permite al diseñador explorar una interactabilidad de manera más enfocada en algún parámetro. En el ejemplo, se está asignando un patrón semiconstante y otro con uniformidad directa . . . . . 165

5.34 Gestos explorados en el ejemplo Mid-Air Browsing de Boudjelthia[27] . . . . . 166

5.35 Demo Mid-Air Browsing. El sketget del nuevo gesto entrenado se incorpora como elemento de Acción en el boceto Pluma y se vincula tanto con la percepción de la imagen que simula el refresco como el audio que da feedback sonoro. La ventana que se muestra sobreimpresa simula la pantalla en la que se navegan las páginas con los gestos . . . . . . . . . . . . . . . . . . . . 166 


\section{Índice de tablas}

3.1 Mapa de organización de los trabajos revisados f . . . . . . . . . . 56

3.2 Dimensiones de filtrado de bocetos y prototipos, adaptado de Anatomía de Prototipos de $\operatorname{Lim}[152] \ldots \ldots \ldots$. . . . . . . . . . . . . . . . . . 58

3.3 Dimensiones de manifestación de bocetos y prototipos, adaptado de Anatomía de Prototipos de $\operatorname{Lim}[152] \ldots \ldots$. . . . . . . . . . . . . . . . 59

4.1 Distribución por background en cada instancia . . . . . . . . . . . . . 87

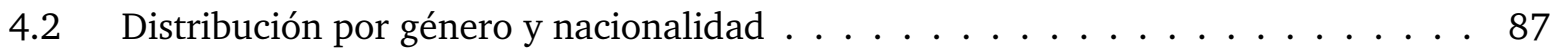

4.3 Ideas de interacción enactivas generadas en los Talleres . . . . . . . . . . . 88

5.1 Elementos de Acción para componer bocetos en Pluma 2.0 . . . . . . . . . . . 159

5.2 Elementos de Percepción para componer bocetos en Pluma 2.0 . . . . . . . . . . 160

5.3 Elementos de Interacción para componer bocetos en Pluma 2.0 . . . . . . . . . 160

5.4 Tres aplicaciones de ejemplo para demostrar el uso del espacio de diseño con Pluma. Referencias: ARD: Arduino. LM: LeapMotion. Amp-Prof: Amplitud y Profundidad. AS: Amplia y superficial. EP: Estrecha y profunda . . . . . . . . . . . . 161 



\section{Talleres de observación}

\section{Taller T-1}

Fechas de realización $\quad 5,12,19$ y 26 de mayo de 2015

Lugar de realización Aulas Taller y Laboratorio, Sede Centro Cultural Borges, Universidad Nacional de Tres de Febrero

Consigna Generar ideas para una Interfaz Enactiva (IE) basada en la sustitución-aumento sensorial para proveer al usuario percepción visual a través del tacto.

La IE debe ser vestible. Se puede utilizar cualquier tecnología de software y hardware. Se pueden generar todas las ideas que se quiera, pero al final será entregada una sola idea por grupo. La idea a presentar deberá ser entregada en forma de bocetos o prototipos que puedan demostrar el funcionamiento buscado.

La presentación consistirá en una demo en la que intervendrán los otros participantes de la clase como usuarios.

El trabajo se desarrollará en forma colaborativa en grupos de 3 a 4 personas durante 4 clases en el ámbito del Aula Taller.

\section{Proyectos desarrollados}

- Abuelino

- Atrapa pesadillas

- Mouse háptico

Link a registro completo https://tinyurl.com/y2rdswgj

\section{Taller T-2}

Fechas de realización $\quad 3,10,17$ y 24 de mayo de 2016

Lugar de realización Aulas Taller y Laboratorio, Sede Centro Cultural Borges, Universidad Nacional de Tres de Febrero 
Consigna Generar ideas para una Interfaz Enactiva (IE) basada en la sustitución-aumento sensorial para proveer al usuario percepción visual a través del tacto.

La IE debe ser vestible. Se puede utilizar cualquier tecnología de software y hardware. Se pueden generar todas las ideas que se quiera, pero al final será entregada una sola idea por grupo. La idea a presentar deberá ser entregada en forma de bocetos o prototipos que puedan demostrar el funcionamiento buscado.

La presentación consistirá en una demo en la que intervendrán los otros participantes de la clase como usuarios.

El trabajo se desarrollará en forma colaborativa en grupos de 3 a 4 personas durante 4 clases en el ámbito del Aula Taller.

\section{Proyectos desarrollados}

- Zona de tránsito

- Aplausos corporales

- Tocar el alma

Link a registro completo https://tinyurl.com/y2rdswgj

\section{Taller T-3}

Fechas de realización 9, 16, 23 y 30 de mayo de 2017

Lugar de realización Aulas Taller y Laboratorio, Sede Centro Cultural Borges, Universidad Nacional de Tres de Febrero

Consigna Generar ideas para una Interfaz Enactiva (IE) basada en la sustitución-aumento sensorial para proveer al usuario percepción visual a través del tacto.

La IE debe ser vestible. Se puede utilizar cualquier tecnología de software y hardware. Se pueden generar todas las ideas que se quiera, pero al final será entregada una sola idea por grupo. La idea a presentar deberá ser entregada en forma de bocetos o prototipos que puedan demostrar el funcionamiento buscado.

La presentación consistirá en una demo en la que intervendrán los otros participantes de la clase como usuarios.

El trabajo se desarrollará en forma colaborativa en grupos de 3 a 4 personas durante 4 clases en el ámbito del Aula Taller. 


\section{Proyectos desarrollados}

- Spahira

- Color por calor

Link a registro completo https://tinyurl.com/y2rdswgj

\section{Taller T-4}

Fechas de realización $\quad 8,15,22$ y 29 de mayo de 2018

Lugar de realización Aulas Taller y Laboratorio, Sede Centro Cultural Borges, Universidad Nacional de Tres de Febrero

Consigna Generar ideas para una Interfaz Enactiva (IE) basada en la sustitución-aumento sensorial para proveer al usuario percepción visual a través del tacto.

La IE debe ser vestible. Se puede utilizar cualquier tecnología de software y hardware. Se pueden generar todas las ideas que se quiera, pero al final será entregada una sola idea por grupo. La idea a presentar deberá ser entregada en forma de bocetos o prototipos que puedan demostrar el funcionamiento buscado.

La presentación consistirá en una demo en la que intervendrán los otros participantes de la clase como usuarios.

El trabajo se desarrollará en forma colaborativa en grupos de 3 a 4 personas durante 4 clases en el ámbito del Aula Taller.

\section{Proyectos desarrollados}

- Zapatillas para ciegos

- Letras en los dedos

- 4.7k luz háptica

- Empatheia vibratio

- Caricias remotas

Link a registro completo https://tinyurl.com/y2rdswgj 



\section{Colofón}

Esta tesis fue editada con $\mathrm{AT}_{\mathrm{E}} \mathrm{X} 2 \varepsilon$. Utiliza el estilo Clean Thesis desarrollado por Ricardo Langner. El diseño del estilo Clean Thesis está inspirado en los documentos de usuarios de Apple Inc.

Estilo Clean Thesis disponible en http://cleanthesis.der-ric.de/. 